\title{
The Social Context of Smoking: Measuring Social Capital among College Students
}

Traci Dawn Jarrett

West Virginia University

Follow this and additional works at: https://researchrepository.wvu.edu/etd

\section{Recommended Citation}

Jarrett, Traci Dawn, "The Social Context of Smoking: Measuring Social Capital among College Students" (2012). Graduate Theses, Dissertations, and Problem Reports. 3557.

https://researchrepository.wvu.edu/etd/3557

This Dissertation is protected by copyright and/or related rights. It has been brought to you by the The Research Repository @ WVU with permission from the rights-holder(s). You are free to use this Dissertation in any way that is permitted by the copyright and related rights legislation that applies to your use. For other uses you must obtain permission from the rights-holder(s) directly, unless additional rights are indicated by a Creative Commons license in the record and/ or on the work itself. This Dissertation has been accepted for inclusion in WVU Graduate Theses, Dissertations, and Problem Reports collection by an authorized administrator of The Research Repository @ WVU.

For more information, please contact researchrepository@mail.wvu.edu. 
The Social Context of Smoking: Measuring Social Capital among College Students

Traci Dawn Jarrett

Dissertation submitted to the

School of Medicine

at West Virginia University

in partial fulfillment of the requirements for the degree of

Doctor of Philosophy

in

Public Health Sciences

Kimberly Horn, EdD

Steve Branstetter, PhD

Lesley Cottrell, PhD

Geri Dino, PhD

Cindy Tworek, PhD

Department of Community Medicine

Morgantown, West Virginia

2012

Keywords: Social Capital, College Student Health, Tobacco Use, Measurement, Qualitative Data Analysis, Survey Research 


\section{ABSTRACT \\ The Social Context of Smoking: Measuring Social Capital among College Students Traci Dawn Jarrett}

Social capital is an ecological theory that explains access to resources as a result of social relationships between individuals and communities. The appeal of social capital across scientific disciplines, including public health, lies in its ability to account for multiple individual and ecological factors in relation to health outcomes, economic and social disparity, and social empowerment as a result of social connections. However, scientists do not agree on the most appropriate indicators of social capital, and a panel of experts tasked with developing a methodological approach to measure social capital indicate that measurement should be context specific. Currently, there are no instruments available for researchers to measure the impact of social capital on health behaviors that is unique to college campuses. The primary goal of this project is to develop an instrument to measure social capital in college students which can then be used to assess the relationship between social capital and health behaviors in college students, such as cigarette use. The objectives of the dissertation include 1) to investigate the relationship between campus environment and individual behaviors using data from a large national college health survey; 2) to conduct a qualitative assessment to examine social capital in college students to ascertain differences between campus and hometown social capital; and 3) to develop an instrument to measure social capital specific to college students. We chose to focus on cigarette use in the first study because college students are at risk for cigarette smoking initiation and current occasional smokers are at risk of progression to heavy or daily smoking. The environment is recognized to have an influence on smoking initiation and maintenance, but the interaction between individual smoking behaviors and the college environment is largely unknown. We expect that the development of a college student social capital instrument will serve to increase understanding of the inter-relations between campus environment and individual characteristics and eventually be able to as relate them to smoking behaviors in college students. Such understanding can inform college campus-level smoking prevention and cessation interventions in order to achieve better and more efficient outcomes. 


\section{DEDICATION}

For Marilyn and Arilyn. 


\section{ACKOWLEDGEMENTS}

First, I would like to extend my deepest love and gratitude to my family, my partner, Shane, who supported me through the dissertation process and more, my father, Steve Jarrett who allowed me to spend weeks parked at his kitchen table studying for comprehensive exams, my daughter, Arilyn and mother, Marilyn who both served as my inspiration and drive. Also, I want to thank my extended family, the Travelsteads and Whitts. Their encouragement and guidance shaped my life path and I am eternally grateful.

I would also like to express my deepest gratitude to my mentor, Dr. Kimberly Horn, who over the course of my education, has provided guidance and wisdom beyond expectation. Dr. Horn's support and encouragement allowed me to pursue opportunities, develop a love and respect for research and practice, pushed me to challenge myself, and taught me the value of caring about the communities in which we are privileged to touch with our academic endeavors. Thank you.

The work presented here would not be possible without the additional expertise and guidance by my committee members- Dr. Steve Branstetter, Dr. Lesley Cottrell, Dr. Geri Dino, Dr. Cindy Tworek, and Dr. Carol Harris. I know the road was a long one, thank you all for hanging in there. Your incredible combination of skills and consistently solid encouragement and support are a continuing inspiration to me.

For my colleagues, Penelope Baughman, Ekta Choudhary, Danielle Davidov, John Blosnich, and Lova Jaros, I want to extend a special appreciation for the process of growing together in this public health research (ad)venture. You are all amazing professional colleagues and people, and I am glad that I had the honor and privilege of working with and learning from all of you. Special thanks to Danielle for spending hours as my secondary coder.

To the faculty and staff of the Department of Community Medicine, thank you all for the opportunity to be involved in the development and growth of an amazing doctoral program. It was extraordinary experience that would not be possible without the tremendous support, the open doors, and the collaborative spirit of such a talented group of people. Dr. Keith Zullig and Dr. Robert Pack deserve additional thanks for their role in making the doctoral program a reality.

Thank you to the social capital experts who generously reviewed my survey, Drs. Geri Dino, Michael Hendryx, Michaela Colombo, Nathan Martin, Richard Warnecke, Richard Carpiano, Nicole Ellison, Michael Oakes, Peter Levine, Neil Carlson, and Erin Cassese. Dr. Cassese, thank you for the pep talks when I needed them most.

Finally, this work would not have been possible without the generous financial support of the National Institute for Drug Abuse (R36DA029301-01A1). 


\title{
TABLE OF CONTENTS
}

\begin{abstract}
...................................................................................................................
DEDICATION...........................................................................................................ii

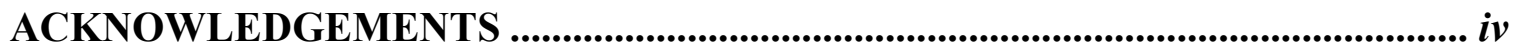

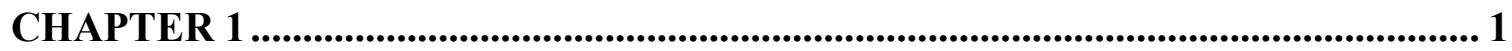

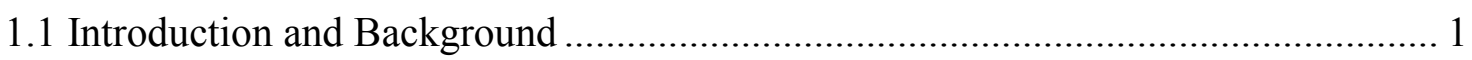

1.1.1 The Evolution of Social Capital Theory ……………....................................... 3

1.1.2 Measuring Social Capital........................................................................... 12

1.2 Social Capital and College Students..................................................................... 16

1.3 College Students and Cigarette Use ................................................................... 19

1.4 The Purpose of the Current Research ....................................................................... 23
\end{abstract}

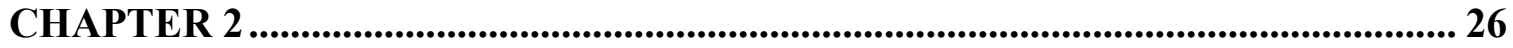

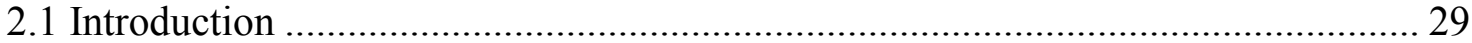

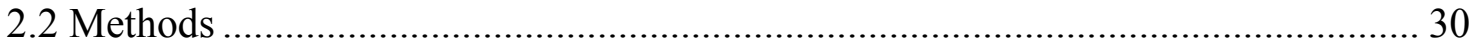

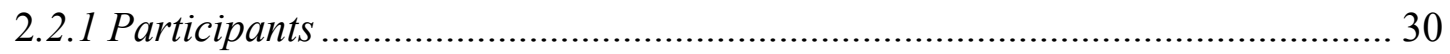

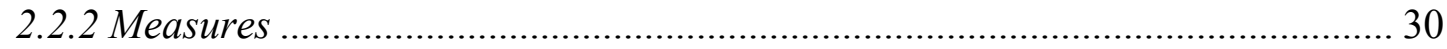

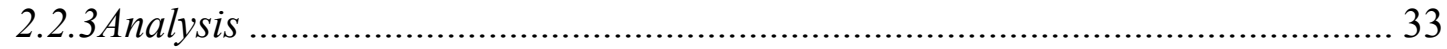

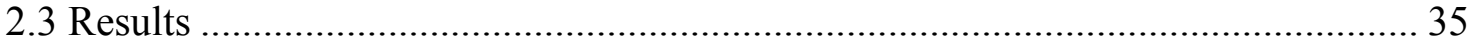

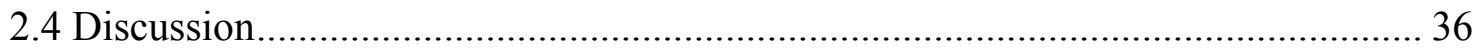

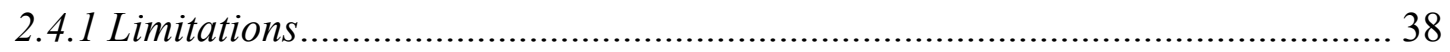

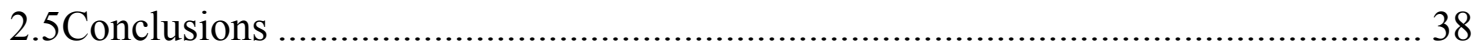

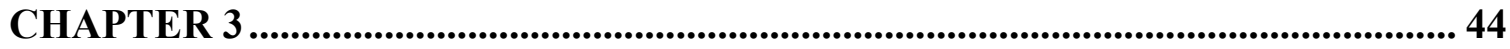

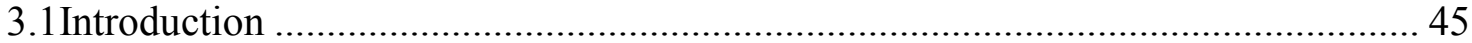

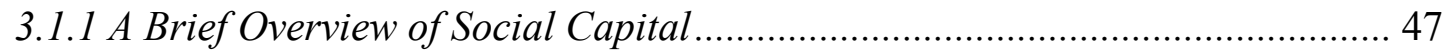

3.1.2 The College Community ............................................................................... 49

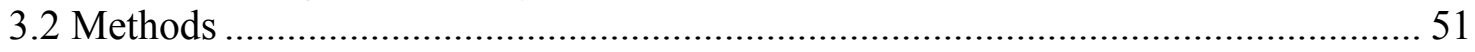

3.2.1 Focus Group Procedures ………………………..................................... 51

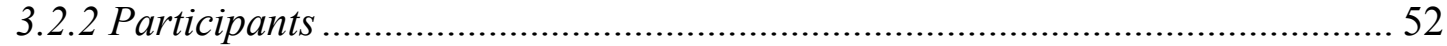

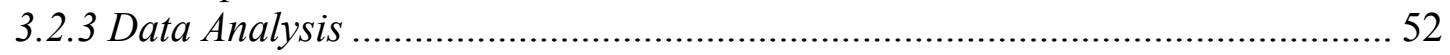

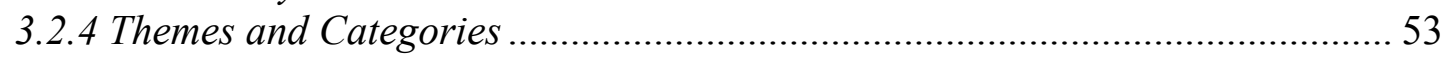

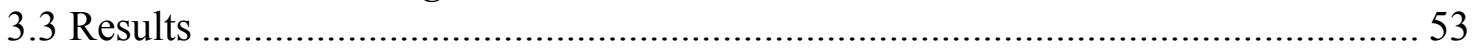

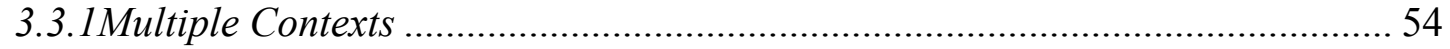

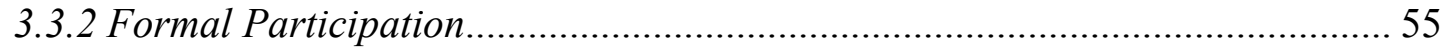

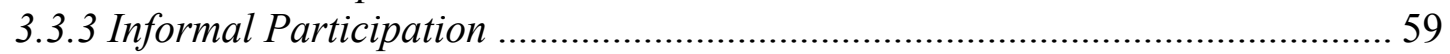

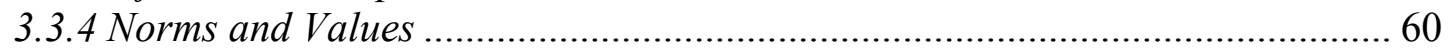

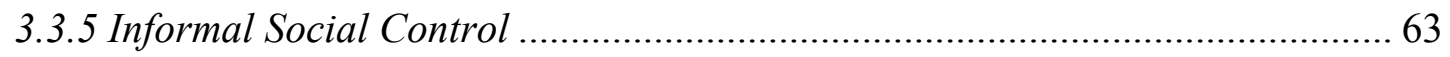

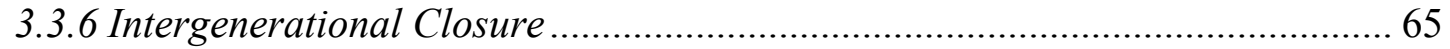

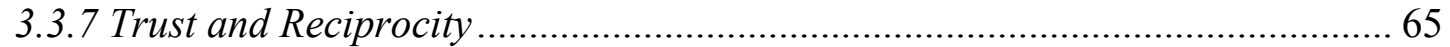

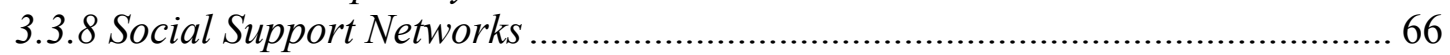

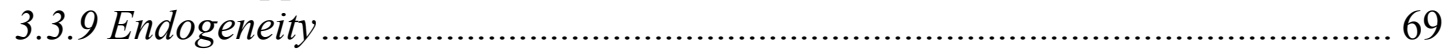

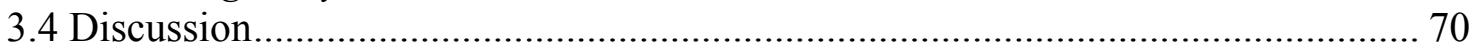




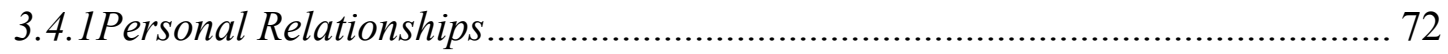

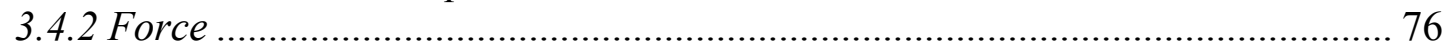

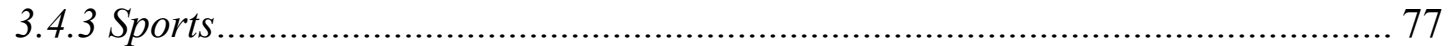

3.4.4 Social Networking on the Internet- The Paradox of Facebook ……………...... 78

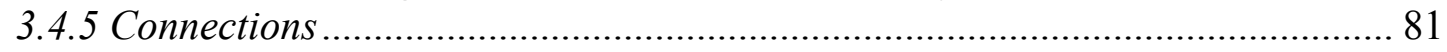

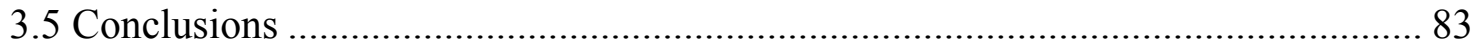

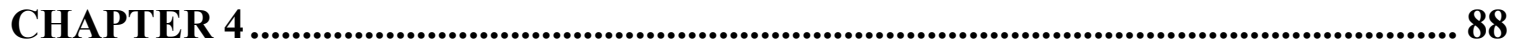

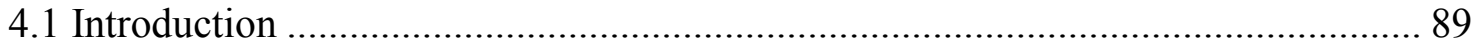

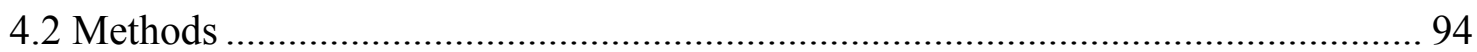

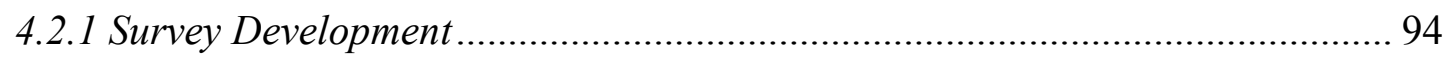

4.2.2 Survey Instrument .................................................................................... 94

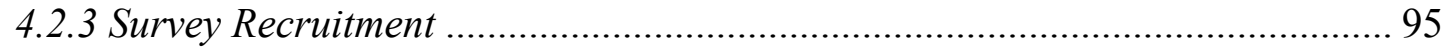

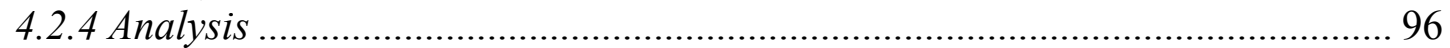

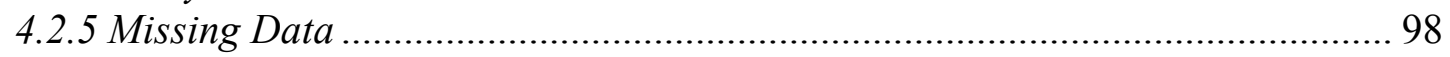

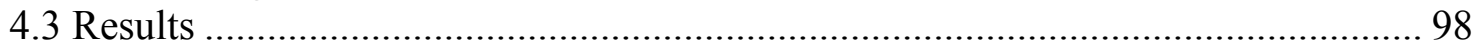

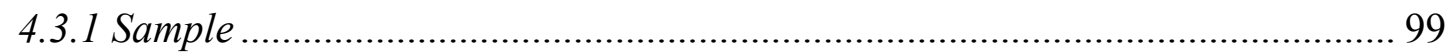

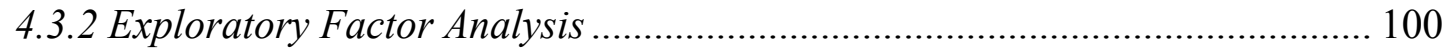

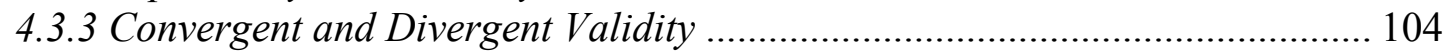

4.3.4 Confirmatory and Hierarchical Factor Analysis .......................................... 105

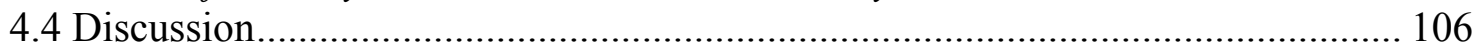

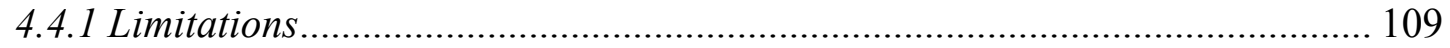

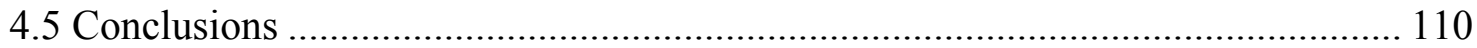

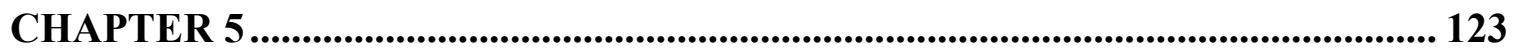

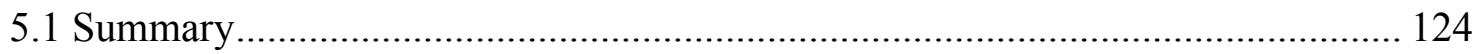

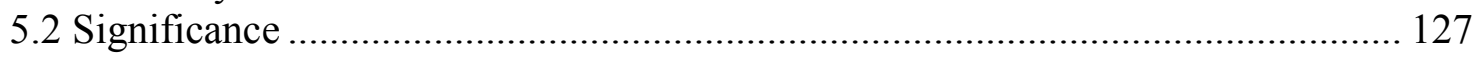

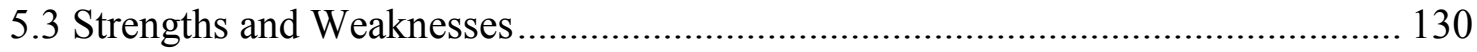

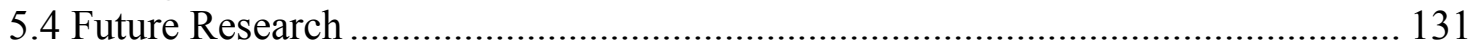

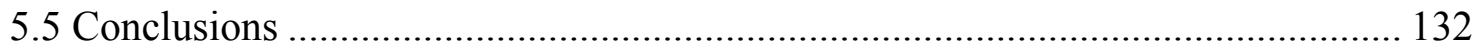

APPENDIX A: GAPS IN THE LITERATURE................................................... 133

APPENDIX B: QUALITATIVE CODEBOOK....................................................... 135

APPENDIX C: COLLEGE STUDENT SOCIAL CAPITAL SURVEY .................. 153

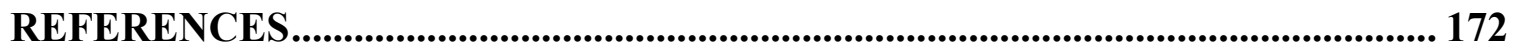


Chapter 1 


\section{Chapter 1}

\subsection{Introduction and Background}

Social capital is a multidisciplinary theoretical concept that accounts for both structural and cognitive social processes involved in the development of formal and informal social connections, and utilization of the resources available as a result of those connections. ${ }^{1-3}$ Social capital gained popularity in recent decades across social science fields including sociology, political science, public policy, economics, organizational and institutional behavior, and public health. It is an attractive theory due to its broad application to explain human, group, community, organization, and governmental behavior. However, criticism of the operationalization and measurement of social capital limits its application as a framework for individual or social change.

Applicable to public health research, there is consistent evidence that social contextual influences are associated with individual health risk behaviors including increased cigarette use, crime, adolescent pregnancy, obesity, heart disease, and general self-rated health. ${ }^{1,2,4-19}$ These health risk indicators are responsible for billions of direct and indirect health care costs, ${ }^{20-22}$ potentially lower quality of life, and are both preventable and mutable. Social context is also related to reduction in educational outcomes such as low academic achievement in adolescents. ${ }^{23-26}$ Educational attainment, in turn, is linked to better health outcomes across the lifespan. ${ }^{27}$ Although social capital research spans nations and neighborhoods, a gap exists in our knowledge of social capital formation and maintenance in relation to college students. College students are in a unique position of straddling prolonged adolescence and emerging adulthood in which social capital may develop independent of parents, yet ties to families and hometown 
neighborhoods persist. Traditionally, social capital research on adolescents utilizes measures of social capital based on parents responses, ${ }^{28-31}$ without acknowledging the potential of adolescents' own social agency. ${ }^{25}$ Unfortunately, most research using a social capital framework among college students also employs parental measures. In order to best optimize social capital theory in public health research, it is important to develop valid and reliable measures relative to the population of interest. ${ }^{25}$

\subsubsection{The Evolution of Social Capital Theory}

The groundwork for social capital was introduced by classical sociologist, Emile Durkheim in 1893. In The Division of Labor in Society, he identifies industrialization as a point of divergent specialization and increasing social complexity that created a moral imperative (as opposed to a necessity of survival) to act collectively. "Two consciousnesses exist within us; the one that comprises only states that are personal to each one of us, characteristics of us as individuals, whilst the other comprises states that are common to the whole society... Now, although distinct, these two consciousnesses are linked to each other, since in the end they constitute only one entity, for both have one and the same organic basis (page 61)." In fact, it was this divergence of skills and trades that helped induce greater interdependence of individuals and groups with one another, or organic solidarity. Robert Alun Jones explains, "In other words, we seek in others what we lack in ourselves, and associations are formed wherever there is such a true exchange of services. ${ }^{, 33}$ According to Durkheim, increased physical population density, the formation of towns and cities, and more efficient infrastructure for greater speed of communication and transmission are responsible for increased social morality/solidarity. He states, the pre-institutionalization agricultural segmentation of individuals must disappear, "social segments must lose their individuality, [so] that the partitions dividing them become 
more permeable. In short, there occurs between them, a coalescence that renders the social substance free to enter upon new combinations (page 200)." ${ }^{, 32}$ This transition from individuals acting collectively as a matter of law and survival to one of collective symbiosis and moral law unofficially binding societies based on exchange of goods and services, is a forerunner to the constructs of trust and reciprocity pervasive as the hallmark of modern social capital theory. Even in this earliest interpretation of social processes, Jones points out that, "Durkheim faced one of the most formidable obstacles to his science of ethics; The fact that, as a 'completely moral phenomenon,' social solidarity did not lend itself to exact observation or measurement."33

In 1897, Durkheim published Suicide, easily the most oft-cited early work for evidence of social capital in the literature, and an attempt to scientifically quantify the mechanics of social influences on human behavior. ${ }^{34}$ In the book, Durkheim presents data on suicide rates by gender, religious affiliation, country of origin, educational level, family structure, and social conflict (specifically wartime versus peacetime) to argue that suicide is "not wholly an individual act," but one of complicated social processes. ${ }^{34}$ Although not without flaws, this distinction between purely individual behavior and the juxtaposition of individual attributes and social influences as the motivating factors for human actions is important as the foundation for any discussion of the processes involved in both individual and collective decision making.

A second precursor to social capital research, economist and organizational theorist, Mancur Olson, published The Logic of Collective Action: Public Goods and the Theory of Groups in $1965 .^{35}$ In this essential look at motivations for collective action among groups, Olson discusses the composition, functionality, and processes involved in group membership. He actively debunks the idea that access to collective goods and resources with less effort than is required by an individual, and shared interests, is the sole motivation of group membership 
regardless of the size of the group (small or large). He posits that small groups require less formalization, more active participation and engagement by members, and fewer external inducements to participate compared to large groups. In addition, the collective goods attained by the group will be more dispersed among members of large groups than among small groups. These contrasts illustrate that the motivation for group membership are not solely for the accumulation of public goods and resources, but there are also "social incentives for grouporiented action...for social status and social acceptance are individual, non-collective goods (page 61)."35 This highlights the dual nature of group membership, greater ease of access to collective resources while necessarily subverting individual goals for group goals, and cognitive rewards in the form of social acceptance.

Modern concepts of social capital emerged in education and sociology literature. The term "social capital" is itself attributed to a State Supervisor of Rural Schools in West Virginia, Lyda J. Hanifan. Putnam describes a 1916 paper by Hanifan (to explain the importance of community involvement in schools) and social capital as:

"those tangible substances [that] count for most in the daily lives of people: namely good will, fellowship, sympathy, and social intercourse among the individuals and families who make up a social unit. ... The individual is helpless socially, if left to himself. If he comes into contact with his neighbor, and they with other neighbors, there will be an accumulation of social capital, which may immediately satisfy his social needs and which may bear a social potentiality sufficient to the substantial improvement of living conditions in the whole community. The community as a whole will benefit by the cooperation of all its parts, while the individual will find in his associations the advantages of the help, the sympathy, and the fellowship of his neighbors." (Putnam, page 19). ${ }^{36}$

In the 1980's two contrasting conceptualizations of social capital emerged. In 1986, Pierre Bourdieu, a French sociologist, differentiated between economic, cultural, and social 
capital in his work, The Forms of Capital. Bourdieu's conceptualization of social capital focused on the formation and reproduction of access to resources through social structures inherent in group membership. Bourdieu's instrumental view defines social capital as, "the aggregate of the actual or potential resources which are linked to possession of a durable network of more or less institutionalized relationships of mutual acquaintance and recognition- or in other words, to membership in a group- which provides each of its members with the backing of collectivelyowned capital, a credential which entitles them to credit, in the various senses of the word (page 51). ${ }^{37}$ Although social capital can be produced and reproduced, it requires an investment of time that may have no immediate value or reciprocal outcomes. ${ }^{37,38}$ The position of the agents or individuals within the social structure (gender, race, occupation, education, etc.) mediates the access to institutional resources of social capital via symbolic power structures. ${ }^{25,37-39}$ While economic and cultural capital can be assessed independently for individuals or groups, social capital, by its very nature is dependent on social exchanges and thus is a function of the connectedness of the individual or group (including the size and quality of the social networks). In Bourdieu's framework, existing social structures and policies as a major determinant of social capital has important implications for public health research, in that it accounts for both group mechanisms and existing environmental infrastructure by which power and inequality (a major determinant of health disparities) is reproduced. ${ }^{39}$

In contrast to Bourdieu's instrumental approach to social capital, James Coleman, a sociologist and education researcher, published a functional conceptualization of social capital in $1988 .^{38,40}$ In Social Capital in the Creation of Human Capital, James Coleman combines sociological (individual behavior is guided by shared norms, rules, and obligations) and economic (individual behavior is guided by self-interest, independent goals, and maximum 
utility) theory to derive a conceptualization of social capital as a functional mechanism in which relations between individuals (generating trust and normative behavior) generate collective capital. ${ }^{24,41}$ He states, "social capital...comes about through changes in the relations among persons that facilitate action (page S100). ${ }^{24} \mathrm{He}$ identifies the mechanisms of social relations that allow for the creation of social structures through which social capital is created including obligations and expectations (norms of reciprocity), social trust, availability of information as a result of social relations, and norms and effective sanctions (to facilitate or constrain actions). In addition, the social structures themselves allow for the creation and maintenance of social capital. Specifically, he applied the concept of intergenerational closure in families to describe how norms are developed and reproduced horizontally through social relationships between and among parents of children, and vertically through relationships with generations of family members. This closure allows for collective sanctioning (informal social control) should standards and norms of behavior and values not be met. He also spoke to the purposeful formation of complex associations and voluntary organizations to meet individual needs. Coleman's conceptualization of social capital focuses on the intentional building of relationships in order to maximize individual opportunities. ${ }^{41}$ Coleman's exploration of social capital concentrated in the field of educational research, which is discussed in detail in the following sections.

Finally, the work of Robert Putnam, a political scientist, is often cited as bringing the concept of social capital to mainstream attention. ${ }^{42}$ His first work in the paradigm, Making Democracy Work: Civic Traditions in Modern Italy, was published in 1993 and highlighted the importance of civic engagement to develop social trust and cooperation, which led to greater economic development and democratically functioning governmental bodies. ${ }^{41,43,44}$ This was 
illustrated through a presentation of the horizontal voluntary participation of individuals in groups in northern Italy and contrasted with vertical relationships in southern Italy in which social power was concentrated in the hands of a few, corruption was extensive, and governments were weaker and ineffective. ${ }^{41,42,44,45}$ In an analysis of Putnam's work, Boix and Posner conclude, "If we want to predict the capacity for social cooperation in a given community, Putnam's analysis suggests, we need simply to count up the number of horizontal civic associations it contains. The higher number of such groups, the greater the capacity of community members to overcome self-defeating opportunism and collaborate for mutual benefit (page 2). ${ }^{.42}$ In fact, this is precisely the evidence Putnam presents in Bowling Alone: The Collapse and Revival of American Community (2000). Putnam outlines the historical decline of membership in civic organizations, voter participation, religious organizations, and other formal and informal opportunities for socialization and community engagement to support his hypothesis that social capital is declining in American society. ${ }^{36} \mathrm{He}$ suggests that technological advancements, pressures of time and money, the ability to more easily relocate to new neighborhoods and employment scenarios, the loosening of family bonds (via divorce or distance), and generational succession (or the gradual weakening of the value of community participation across generations) all advance the state of decline of social bonds, and social capital. These structural elements contribute to increased isolation and less interdependence on others. (Interestingly, Putnam attributes the decline of social capital in modern societies to essentially the same underlying causes as those identified by Durkheim that gave rise to social interconnection, and the foundation of social capital originally - mobility and technology). He suggests this rapid decline negatively affects effective governance, health, child welfare and education, neighborhood safety, and economic prosperity. Similar to Coleman's 
conceptualization, Putnam's social capital speaks to the generation of trust and norms of reciprocity as a result of participation in social organizations. However, Putnam suggests that social capital operates primarily on a community level, although benefits may be shared among individuals. He also indicated that social capital is simultaneously a cause and an effect of civic engagement. ${ }^{36,41}$

Common themes emerge, across social science theories related to social capital. Social capital is derived from social relationships (products), as opposed to the social associations themselves (agents). ${ }^{46}$ First, there are collective and individual benefits from participation in organizations and groups, including access to resources and psychological benefits. However, participation must be voluntary (as opposed to compulsory) and equal. ${ }^{47,48}$ Second, social capital is dependent upon trust (either interpersonal or generalized) among those who engage in social relationships. Third, norms of reciprocity are a condition of social capital. The term "capital" implies an exchange of goods and services. Reciprocity may include information, instrumental exchanges (favors), time, access to resources, and emotional or psychological support, among others. Norms of reciprocity apply to the shared understanding (as a function of internalized normative social behavior) that investment in voluntary associations, either interpersonal or group, will result in a return on the investment. Although these concepts are central to each theory of social capital, the structural mechanisms by which each is achieved differs.

The appeal of social capital as an indicator of community health in public health research over the last 15 years is substantial. It accounts for structural elements such as education, racial discrimination, income inequality, and access to services, and for cognitive aspects such as trust/reciprocity and norms that not only play a role in many health education behavior change 
theories, but contribute to social and health disparities among populations and communities. ${ }^{27,49-}$ ${ }^{54}$ Findings from public health research using social capital found that low levels of social capital are linked to poor self-reported health status; firearm violence; increased mortality from coronary heart disease, malignant neoplasms, and infant mortality; reduction in exercise, consumption of fruits and vegetables, and diffusion of health information across communities; increased demand for cigarettes; greater non-specific psychological distress; and higher rates of obesity and physical inactivity. ${ }^{2,5-8,10,12,15,55-57}$ However, measurement of social capital was not uniform across studies, most used secondary data analysis that did not include direct measures of social capital constructs, there is no agreement on the most appropriate level of measurement (individual or community/nation), or the most relevant conceptual framework. ${ }^{13,14,55,57-60}$

These issues are not confined to public health research. Each conceptualization of social capital is not without flaws and criticisms. Importantly, social capital is criticized as being too broad; it attempts to explain too many social phenomenon, from income inequalities, power distribution and reproduction in government, educational outcomes, public health outcomes, to community empowerment. ${ }^{61}$ Should such expansive definitions and potential applications of social capital hold true, increasing social capital in neighborhoods and communities would necessarily improve the outcomes for those communities, evening out the most peaked social disparities. This is fundamentally incorrect. In this broad spectrum of social capital, the responsibility of correcting social disparities may be placed solely and squarely on the shoulders of the individuals within communities to expand and diversify their social networks so that the keys to health, happiness and prosperity are theirs for the taking. Specifically, as Pearce states, “...it has been used to depoliticize issues of social and economic development (page 127)."61 This hints at a "blame the victim" mentality. ${ }^{61}$ Indeed, social capital is often conceptualized as a 
wholly positive product, when in fact, it can produce negative outcomes. It can lead to exclusion of outsiders in group associations, ${ }^{36,38,62}$ excess claims on group members, downward leveling norms in which group association is based solely on feelings of mutual discrimination and adversity, and restrictions on individual freedoms (if informal and formal social control is strong such as in a small community). ${ }^{32,38}$ In fact, it is often these potential iatrogenic effects (discrimination and inequality), that are associated with poor health outcomes. ${ }^{63}$

Such diffuse conceptualizations of social capital lead to a critical and pervasive issue in regards to its research and practical application potential- the issue of operationalization and measurement. A score of social science and public health research across fields apply concepts similar to social capital (community engagement, collective action, social support, empowerment, capacity, cohesion, connectedness, community competence, and conscientization). ${ }^{41,46,61}$ Some researchers indicate that this "repackaging" of familiar sociological, economic, and public health concepts muddies the potential for social capital as a research framework. ${ }^{61}$ However, not all researchers consider the challenge of integrating fields and concepts as completely negative. As stated by Paldam and Svendsen, "We do concur with the old saying that smoke is an indicator- and the family of social capital-like concepts is a field with a lot of smoke (page 1)." ${ }^{48}$ One thing is certain, historically, social capital indicators lack clear definition. ${ }^{41,46}$ Two other major measurement debates are central to the practical application of social capital in social science research. First, conceptualization and measurement of social capital are often tautological. ${ }^{41,46}$ What is an outcome of social capital for one researcher may be an indicator of social capital for another. ${ }^{41,64}$ Second, at what level (individual, community, nation) is the most appropriate to operationalize social capital. ${ }^{3,13,36,41 \text {, }}$ 48, 58, 62, 64-66 Even in the face of measurement issues, social capital has merit. In 1996, The World 
Bank commissioned a group of social capital scientists to investigate current studies of social capital and to, "contribute to the development of indicators for monitoring social capital and methodologies for measuring its impact on development. ${ }^{67}$ This goal was one of three in The World Bank's ambitious Social Capital Initiative. The results, along with those of independent researchers, are summarized in section 1.1.2.

\subsubsection{Measuring Social Capital}

Studies of social capital are fraught with measurement flaws, however, each methodological approach that is tested and validated incrementally refines our global understanding of how social capital should be operationalized. ${ }^{3,68}$ As a relatively modern theoretical concept, this is a completely appropriate scientific process. However, as social capital research advances, several points must be addressed. First, social capital research must be theoretically sound. ${ }^{68}$ Although there are differences in the theoretical approaches discussed above, a set of central dimensions of social capital consistently emerge. These dimensions include groups and networks, trust and solidarity, collective action and cooperation (reciprocity), information and communication, social cohesion and inclusion, and empowerment and collective action. ${ }^{62}$ Unfortunately, most research on social capital are based on studies utilizing secondary data analysis, using a set of indicators not specifically designed to measure social capital. ${ }^{64}$ Often, these studies rely on unidimensional measures ${ }^{64}$ However, social capital, regardless of theoretical framework, is a multidimensional concept. ${ }^{68}$

Fundamentally, social capital operates in two ways, cognitively and structurally, and each

must be accounted for in research. ${ }^{1-3,39}$ Cognitive social capital includes shared norms and values, interpersonal trust, attitudes, and beliefs. ${ }^{3,39,68}$ Structural social capital includes infrastructure of social relationships that facilitate information sharing, collective action through 
established roles, social networks and other social structures supplemented by rules, procedures, and precedents. ${ }^{1-3,39}$ As described by Grootaert and Bastalar, these levels may or may not intersect, "Cooperation between neighbors can be based on a personal cognitive bond that may not be reflected in a formal structural arrangement. Similarly, the existence of a community association does not necessarily testify to strong personal connections among its members, either because participation in its activities is not voluntary or because its existence has outlasted the external factor that led to its creation (page 5)."3

Second, what is the appropriate unit of measurement to capture social capital and its outcomes? Arguments abound as to whether social capital is essentially an individual, community, or societal property. ${ }^{3,39,64,68}$ In fact, social capital can be examined using all three units of analysis depending on the context in which social capital is investigated. ${ }^{3,48,68,69}$ Grootaert suggests that a single indicator or method to assess social capital is "unlikely." In fact, the contextual nature of social capital requires mixed method approaches that account for the unit of analysis, level of operation (cognitive and structural), geographic location, and the characteristics of the individuals or societies in which it is being studied. ${ }^{3,68}$ Qualitative methods provide vital in depth contextual and experiential information while quantitative methods, such as surveys, allow for generalizable conclusions. $3,62,70$

Similar to Brofenbrenner's work on environmental and family contexts related to child development (mesosystems, exosystems and chronosystems), ${ }^{23}$ and applied sociology, Social Capital Initiative researchers identify three interrelated levels in which social capital operates. ${ }^{3}$ In the micro-level context, individuals and families act as procurers of social capital in the manner and complexity in which they personally engage in their communities. ${ }^{3}$ Examples of micro-level social capital indicators may include interpersonal trust, informal and formal 
participation in group activities, norms of reciprocity, and information sharing. These most closely reflect the conceptualizations of social capital presented by Putnam and Coleman. The meso-level context includes the structure of relationships among groups and communities that allows for access to and allocation of resources (this includes both horizontal and vertical relationships). ${ }^{3}$ Social capital indictors at the meso-level may include informal social control, intergenerational closure, horizontal and vertical network connections, volunteerism and philanthropy, generalized trust and social cohesion, information sharing, empowerment, and collective action (or meso-level reciprocity). These also align with Putnam and Coleman, but begin to hint at the structural allocation of resources as described by Bourdieu. Finally, the macro-level considers the political and social structural environment (e.g. income distribution, laws and policies, formal institutions, institutionalized discrimination) that enable norms and culture to develop (horizontal- reproduction of values and norms and vertical- reproduction of institutional control and power). ${ }^{3}$ Macro-level indicators include institutional trust, collective action and empowerment, institutionalized social cohesion and inclusion, the distribution of power (Is power primarily horizontal, or does it represent a vertical hierarchy in which most social power is in the hands of a few? How are those in power selected and who influences their decision making?), and formalized laws and policies that guide or prevent access to resources. Bourdieu's conceptualization of social capital most closely aligns with this level. See Table 1.1 for dimensions. 
Table 1.1: Social Capital Dimensions

\begin{tabular}{|c|c|}
\hline Dimension & Description \\
\hline $\begin{array}{l}\text { Micro-level Cognitive Dimensions } \\
\text { Informal Participation }\end{array}$ & $\begin{array}{l}\text { Informal participation includes both planned and unplanned } \\
\text { activities that have no formal protocol such as parties, family } \\
\text { get togethers, talking with friends and neighbors, peer study } \\
\text { groups, etc. Such activities strengthen social bonds, reinforce } \\
\text { norms, and create social cohesion. }\end{array}$ \\
\hline \multirow[t]{2}{*}{ Trust and Reciprocity } & $\begin{array}{l}\text { Trust and reciprocity refer to the belief that neighbors can be } \\
\text { trusted and that they can be relied on to provide instrumental } \\
\text { resources if needed. Trust and reciprocity often include } \\
\text { measures of feelings of safety and crime. } 39,66,71\end{array}$ \\
\hline & $\begin{array}{l}\text { Norms and values refer to a set of community norms that } \\
\text { reflect a shared meaning of behaviors. } 5,16,18,19,24,66,72\end{array}$ \\
\hline \multirow[t]{2}{*}{$\begin{array}{l}\text { Micro- and Meso-level Structural } \\
\text { Dimensions } \\
\quad \text { Formal Participation }\end{array}$} & $\begin{array}{l}\text { Putnam described three facets of formal participation: civic } \\
\text { (participation in organized clubs or groups), political (active } \\
\text { engagement in local and national political processes like } \\
\text { voting), and religious (active participation in spiritual } \\
\text { activities). These formal groups allow for social networks with } \\
\text { access to and mobilization of various informational, } \\
\text { educational, and financial resources. They also permit access } \\
\text { to both bonding (if groups are homogenous) and bridging } \\
\text { social capital (see below). } 5,19,39,71,73,74\end{array}$ \\
\hline & $\begin{array}{l}\text { Volunteerism and philanthropy tap into citizens' willingness } \\
\text { to give back to the community. }\end{array}$ \\
\hline $\begin{array}{l}\text { Meso-level Structural Dimensions } \\
\text { Informal Social Control }\end{array}$ & $\begin{array}{l}\text { Informal social control refers to the extent to which neighbors } \\
\text { work collectively to maintain social order. Applied by } \\
\text { Sampson and Raudenbush to the measure neighborhood } \\
\text { delinquency of children, it included the extent to which } \\
\text { neighbors disciplined children, called parents when children } \\
\text { misbehaved, and reported delinquent behaviors. } 39,66,75\end{array}$ \\
\hline Intergenerational Closure & $\begin{array}{l}\text { Intergenerational closure refers to relationships between } \\
\text { individuals and adults and mentors who are not their parents, } \\
\text { through which norms are internalized. }{ }^{33,66,73}\end{array}$ \\
\hline $\begin{array}{l}\text { Macro-level Structural Dimensions } \\
\text { Concentrated Disadvantage } \\
\text { Concentrated Affluence } \\
\text { Stability }\end{array}$ & $\begin{array}{l}\text { Macro-level structures refer to the pre-existing conditions in } \\
\text { communities, such as poverty, community connectedness } \\
\text { through home ownership, and density of college educated } \\
\text { individuals. Macro-level structures have the potential to be } \\
\text { reflexive in regards to social capital if residents are able to } \\
\text { harness their social capital and are empowered to make } \\
\text { changes. }{ }^{4,5,19,39,66,71,74}\end{array}$ \\
\hline
\end{tabular}

As stated above, it is not always prudent or appropriate to measure social capital using every level of analysis. In addition, the structural nature and subsequent manifestations of social capital vary by context. In order to best examine social capital among a specific population, 
preliminary understanding of the population and its infrastructure is necessary. One population of particular interest is college students. They straddle adolescence, in which parents' social capital may have facilitated access to resources and social networks, and adulthood in which they may increasingly become independent agents of social capital. However, little is known about this process, or what specific dimensions of social capital are salient in this transitional time of life. College is also a time of uptake in multiple risk behaviors, such as tobacco and cigarette use, which may influence lifelong health decisions and have long-term health and economic consequences. $^{76,77}$

\subsection{Social Capital and College Students}

College students experience multiple social contexts. ${ }^{78}$ When they enter college, college students bring the experiences of hometown family and peer networks, high school, organizations and religious institutions, and community social networks. They have an understanding of local services and have varying levels of engagement in their family, school, or community. When emerging adults enter college, they must renegotiate these relationships while simultaneously developing new social networks, memberships in student and local activities, learn how to access and use services, and adapt to new campus community norms. ${ }^{79-82}$ This does not mean that students will fully adopt one context, home or school, over the other, but that they must assimilate, navigate and incorporate facets of each into their own identity and behavior. ${ }^{78}$ Which of these relationships is most important in the development of a shifting identity for students? How do these relationships shape identity and behavior?

Before we can answer these questions, it is essential to identify cognitive and structural indicators of social capital in this population and determine the appropriate unit of analysis 
using a mixed methods approach, including a comprehensive literature review, qualitative and quantitative data collection. Integrating into campus communities may be a very different experience than patterns of social engagement in general communities. In addition to social engagement through associations in residence halls, classes, and social organizations (which implies shared interests), students also network through internet social networking sites such as Facebook, Pinterest, and Twitter. ${ }^{83-86}$ Adolescent outcomes have been related to both parental and adolescent social capital networks. ${ }^{87}$ As emerging adults transition to college, it stands to reason that the parental network would become less prominent and students would develop and strengthen their own individual, non-familial network ties to the community. Peer network formation, individual participation in community activities, and autonomous participation in civic and political processes as students take on more adult responsibilities expose students to individuals and peers that may be different from them. However, due to the transitory nature of college, it is likely that both play a role in student outcomes.

In a review of the literature, high levels of social capital (defined as family support and structures, and size of hometown residence) were associated with school enrollment and attendance, and academic performance. ${ }^{28,29,31}$ However, these studies relied solely on measures of parental social capital. In two studies that assessed social capital based on measures from college students themselves, social capital (defined as participation in voluntary organizations) is protective against college binge drinking and negative consequences associated with heavy alcohol consumption among college students. ${ }^{88,89} \mathrm{~A}$ third study of social capital among college students that utilized students' measures [family resources and structures, and social networks including campus ties (relationships with college staff), dorm ties, and university ties], found that those with greater social capital were more likely to report aspirations for high status 
professional careers post-graduation than those with low scores of social capital. ${ }^{90}$ Although these studies provide a building block to understand the underlying functional and structural mechanisms of social capital in the college population, they do not provide a clear picture. In fact, it is unclear as to whether or not the measures employed provide adequate assessment of the underlying dimensions of social capital at work in students' lives.

College is also often a time of exploration and experimentation with risky behaviors including cigarette smoking initiation or intensification, alcohol use, unprotected sex, mental health concerns, as well as academic pressures. ${ }^{77,91}$ Other than the two studies concerning alcohol use discussed above, no studies to date have investigated if associations between social capital and health risk behaviors in college students exist. Studies using parental and community structural measures to investigate links between social capital and adolescent outcomes found that low measures of social capital were associated with increased risk behaviors in adolescents: including risky sexual behaviors, higher teen pregnancy rates, crime and juvenile delinquency, neglectful parenting, domestic violence, poor psychological adjustment, and poor academic performance. ${ }^{4,13,14,16-19,24,66,72-74,87}$ As described in the introduction, low levels of social capital are related to myriad poor health outcomes in adults, yet suffer from poorly defined indicators and reliance on secondary data analysis in which social capital was not a primary focus, often making results unclear. ${ }^{2,5,7,15,55,56}$ However, a study of adults in Los Angeles by Carpiano and Link (based on Bourdieu's conceptualization of social capital) found that smoking and binge drinking were positively associated with a reciprocity/social support dimension of social capital. ${ }^{92}$ Because these are two primary risk behaviors adopted by college students, which can have lifelong health consequences, it is increasingly important to understand if there is an association between college student social capital and health, and if so, is that association 
protective or iatrogenic. Studies in which a full range of latent constructs underlying social capital are utilized are regrettably sparse, and an instrument to specifically measure dimensions social capital does not exist for college students. An analysis of gaps in social capital literature pertaining to college students and adults is presented in Appendix A.

Using a mixed methods approach, the goal of this study is twofold. The first goal is to explore the relationship between social capital and smoking behaviors among college students to uncover if there is a "whiff of smoke" to indicate that social capital is at work in this population. The second goal is to develop a valid and reliable College Student Social Capital Survey that (although is not the primary outcome of this study) can be utilized to examine the relationship between social capital and health.

\subsection{College Students and Cigarette Use}

Why initially focus on cigarette use as an outcome in the first goal of the study? Cigarette smoking is among the most harmful health behaviors adopted by individuals. Smoking accounts for over 440,000 deaths annually and costs upwards of $\$ 157$ billion in health-care related expenses. ${ }^{20}$ It is linked to myriad negative health outcomes including heart attack and stroke, multiple cancers, chronic obstructive lung disease, and reduced reproductive outcomes. ${ }^{93}$ Tobacco use remains a Healthy People 2010 leading health indicator and the most preventable behavioral risk factor for disease and death in the United States. ${ }^{94,95}$ Fifty-three percent of current smokers became daily smokers before the age of 18 , and are likely to continue smoking through adulthood. ${ }^{95,96}$ Cigarette smoking peaks between the ages of $18-24,{ }^{97}$ and $28 \%$ of current college smokers started smoking regularly in college. ${ }^{98,99}$ 
Emerging adults represent the fastest growing cigarette users in the population. ${ }^{100}$ Although smoking prevalence is greater among emerging adults who do not enter or complete college, prevalence among college students is concerning. Estimates of lifetime smoking prevalence among college students ranges from 34\%-75\%. ${ }^{98,99,101}$ Prevalence of current smoking in college students ranges from 19\%-29\% based on the Centers for Disease Control and Prevention definition of current smoking as one cigarette in the preceding thirty days. ${ }^{99,101,102}$ While some national studies have examined behavioral correlates of smoking in college, most studies of behavioral and psychosocial factors associated with smoking in college have used small convenience samples. ${ }^{103}$ These studies also lack measures that incorporate the social context of college student life in the analysis. ${ }^{104}$

College student smokers represent a distinct category of smoker that does not reflect either adolescents or adults in attitudes or practice of smoking behaviors, ${ }^{105-107}$ that may be due in part to their shift in context. While many non-college bound emerging adults continue to live at home or near home, college students transition to a completely new context. College students are generally between the ages of 18-24, which is a time of significant risk for smoking uptake, but is also a time of substantial developmental and life changes. Generally associated with a change in residence, ${ }^{108}$ greater autonomy over decisions, and interpersonal relations, ${ }^{108}$ emerging adulthood is a time of transition both of context and individual identity. ${ }^{78,91,109,110}$ In addition, access to cigarettes, (because the young adult is legally able to purchase tobacco), fewer parental restrictions, interpersonal relationships, and greater access to smoking cessation services all may influence smoking behaviors during this time.

Similar to teens, current college student smokers in one study thought it would be easy to quit and generally did not seek assistance to do so. ${ }^{107}$ Many college smokers deny personal risk 
and perceive risks differently depending on self-classification as a smoker or non-smoker (also similar to teens). ${ }^{105,111}$ It is unclear from previous research if researcher assigned categories of smoking status are congruent with self-perceived smoking status of college smokers, what factors influence quit attempts, what type of intervention delivery method is most appropriate for this population, or if multiple delivery methods are warranted depending on the characteristics of the participants, how institutional and personal expectations of smoking in college impact individual behaviors, how smoking history impacts smoking behaviors in college, how opportunities to engage in university sponsored activities may impact smoking behaviors, and the context within which social smokers move toward the early stages of nicotine addiction. ${ }^{103}$, 107, 112, 113 Finally, studies on college student smoking lack a theoretical framework or have limited theoretical considerations to perceived personal risk and individual behavior modifications. ${ }^{103,105}$

Studies that examine cigarette use within the framework of social capital are limited. Two studies investigated the relationship between social capital (defined here as formal and informal social participation and trust). One study found that lower rates of social capital are associated with daily smoking, but that high social participation and low trust were associated with increased levels of occasional smoking. ${ }^{11}$ The second study found that the proportion of daily smokers in a neighborhood was affected by factors unrelated to social capital. ${ }^{12}$ A third study of rural adolescents found that low income youth who lived in communities with greater measures of social capital (social cohesion, social control, and relationships with adults) were less likely to smoke cigarettes and have lower BMI than those in similar financial circumstances in low social capital communities. ${ }^{114}$ Studies that used individual-level measures of social capital or variables related to social capital related to smoking are summarized in Table 1.2. 
Table 1.2: Individual-Level Social Capital Measures Related to Smoking

\begin{tabular}{|c|c|c|c|}
\hline Measure & $\begin{array}{l}\text { Matching Social } \\
\text { Capital Dimension }\end{array}$ & Population & Source \\
\hline Participation in athletics & Participation- formal & College students & Emmons, Schorling ${ }^{112,115}$ \\
\hline Religion & Participation- formal & $\begin{array}{l}\text { High school and college } \\
\text { students, Swedish } \\
\text { adults, }{ }^{*} \text { NHIS* }\end{array}$ & $\begin{array}{l}\text { Emmons, Choi, } \\
\text { Lindstrom, Brown } 111,112 \text {, }\end{array}$ \\
\hline Leisure activities & Participation- informal & $\begin{array}{l}\text { College students and } \\
\text { Swedish adults* }\end{array}$ & Emmons, Lindstrom ${ }^{11,112}$ \\
\hline "Productive" activities & Participation- formal & $\begin{array}{l}\text { College students and } \\
\text { Swedish adults* }\end{array}$ & Emmons, Lindstrom ${ }^{11,112}$ \\
\hline $\begin{array}{l}\text { Fraternity or Sorority } \\
\text { member }\end{array}$ & Participation- formal & College students & Schorling, Weschler ${ }^{99,115}$ \\
\hline Neighborhood organizations & Participation- formal & $\begin{array}{l}\text { Los Angeles } \\
\text { Neighborhoods, * NCIS and } \\
\text { County Business Patterns* }\end{array}$ & Capriano, Brown ${ }^{1,92}$ \\
\hline $\begin{array}{l}\text { Region of country school is } \\
\text { located }\end{array}$ & Macro-level & College students & Weschler $^{99}$ \\
\hline Public vs. Private school & Macro-level & College students & Weschler $^{99}$ \\
\hline Setting (rural/urban) & Macro-level & College students & Weschler, Evans ${ }^{99,114}$ \\
\hline Size of School Enrollment & Macro-level & College students & Weschler $^{99}$ \\
\hline $\begin{array}{l}\text { Peer and family smoking } \\
\text { context }\end{array}$ & Norms & College students & Wetter, Choi ${ }^{116,117}$ \\
\hline Smoking normative beliefs & Norms & $\begin{array}{l}\text { College students, US adult } \\
\text { cohort, US adult smokers }\end{array}$ & $\begin{array}{l}\text { Choi, Honjo, van den } \\
\text { Putte }^{116,118,119}\end{array}$ \\
\hline Social networks & Participation- informal & $\begin{array}{l}\text { College students, } \\
\text { Framingham Heart Study } \\
\text { cohort and networks }\end{array}$ & $\begin{array}{l}\text { Choi, Christakis, Carpiano } \\
92,116,120\end{array}$ \\
\hline Social support & Social support & $\begin{array}{l}\text { Los Angeles } \\
\text { Neighborhoods* }\end{array}$ & Carpiano $^{92}$ \\
\hline Trust/Social cohesion & Trust and reciprocity & $\begin{array}{l}\text { Swedish adults, }{ }^{*} \text { Los } \\
\text { Angeles Neighborhoods, }{ }^{*} \\
\text { NHIS, Rural youth in NY* }\end{array}$ & $\begin{array}{l}\text { Lindstrom, Carpiano, } \\
\text { Brown, Evans 1,11,92,114 }\end{array}$ \\
\hline Informal social control & Informal social control & $\begin{array}{l}\text { Los Angeles } \\
\text { Neighborhoods* } \\
\text { Rural youth in NY* }\end{array}$ & Carpiano, Evans ${ }^{92,114}$ \\
\hline Intergenerational closure & $\begin{array}{l}\text { Intergenerational } \\
\text { closure }\end{array}$ & Rural youth in $\mathrm{NY}^{*}$ & Evans $^{114}$ \\
\hline
\end{tabular}

* investigated as "social capital”

More knowledge and a systematic theory driven approach are needed to understand how social capital factors influence individual smoking. ${ }^{121}$ Wilcox outlines a number of potential 
dynamic confounders that may affect youth smoking. For instance, can distal conditions at the community level such as policies and norms moderate the effects of proximal conditions, such as peer and family smoking in youth? She also questions whether there is a time lagged effect in which neighborhood differences in policies and norms in youth may impact smoking in early adulthood. ${ }^{121}$ These questions create a complex picture of how environment, both proximal and distal (in both time and space) may influence smoking status in college. ${ }^{121}$

There is a need to understand how the college campus social context (social capital) contributes to smoking. Comprehensive qualitative and quantitative studies that capture multiple contexts within which young people move are key to understanding the "meanings that young people attach to the complex set of smoking-relevant messages they receive (p.154).."122 As community-level smoking interventions grow, understanding how social capital interplays with individual smoking behaviors is critical to developing effective interventions. ${ }^{122}$ An integrated approach to understanding social capital and its influence on community and individual risk allows for planning of comprehensive community-level interventions.

\subsection{The Purpose of the Current Research}

There are gaps in our knowledge of how emerging adults form and maintain social capital, as well as how to best measure the dimensions of social capital in this population (and others). Before we can begin to understand the effects of social capital in this population, a theoretically sound, valid and reliable way to measure it must be developed. Based on known strengths and weaknesses of social capital studies across academic paradigms, theory-driven techniques, identified issues in the operationalization and measurement of social capital 
dimensions, and results of a mixed method approach, this study will utilize a multi-prong approach to address the goals of the research.

The study described in Chapter 2 uses secondary data analysis to conduct a multi-level investigation of the influence of social capital at an individual (micro) and community (meso) level on cigarette use among college students. Data from the National College Health Assessment (Fall 2005-Spring 2006) were analyzed using hierarchical linear modeling to explore the relationship between measures identified as the hallmarks of social capital (interpersonal and generalized trust and voluntary association), and cigarette use among college students on 144 campuses nationwide. The results of this study supplement prior research on the associations between social capital and risk behavior (binge drinking) among college students. It also allows for the exploration of both the magnitude and direction of potential associations between college students' health risk behaviors (cigarette use) and social capital at campus and individual levels. Although the findings in Chapter 2 provide evidence of social capital at work among college students, it maintains measurement shortcomings identified in previous research (secondary data analysis using indicators not specifically designed to measure social capital, and utilizing a relatively unidimensional understanding of social capital). However, as described above, scientific research is incremental, and the findings presented in Chapter 2 are a foundation upon which we can build an understanding of social capital in this population. It also allows for a baseline from which to develop a qualitative study to explore the dimensions of social capital among college students and to develop a survey to test the validity and reliability of indicators of social capital specific to college students. These findings are discussed in Chapters 3 and 4.

In summary, although research on social capital is extensive with a long and complicated history across many scientific fields, there remain flaws in its operationalization and 
measurement. If we endeavor to garner the positive potential of social capital to influence individual, community and national public health outcomes, we must first understand how to best develop a set of indicators to measure it within the context in which we are interested. In the United States, college is a time of great change, risk taking, identity exploration, and the development of interpersonal relationships that potentially have far-reaching implications for health. ${ }^{77,109,110}$ The understanding of the operation of social capital could help guide public health focused campus policies, community norms, and intervention strategies for in this population. The combined results of the three independent studies, and the overall dissertation study will serve to advance our understanding of social capital in the context of college campuses. 


\section{Chapter 2}




\section{Chapter 2}

\section{Campus Social Capital as a Determinant for Smoking among College Students}

\subsection{Introduction}

Reducing tobacco-related deaths and illness remains one of the nation's top health priorities. ${ }^{93,95}$ In the United States, tobacco use is linked to one in five deaths annually, and costs over $\$ 193$ billion in health care expenditures and lost productivity each year. ${ }^{20}$ Cigarette smoking is linked to multiple cancer, respiratory, and cardiovascular diseases, yet smoking remains the most preventable cause of morbidity and mortality in the United States. ${ }^{93}$ Cigarette smoking prevention and cessation efforts made important gains to reduce the prevalence in smoking in the United States, however, each day, approximately 1,100 persons younger than 18 years of age become daily smokers. ${ }^{123}$ Emerging adults aged 18-24 have the second largest uptake in cigarette use $97,117,124$ and trends indicate that smoking among emerging adults is on the rise. ${ }^{100,102}$

Although non-college emerging adults have a greater prevalence of cigarette use (ranging from $35-42 \%)$ than emerging adults who attend college overall (23-31\% prevalence $)^{100}$, college students who reported daily smoking increased at a greater rate over a decade (1990-1999) than non-college enrolled emerging adults. ${ }^{102}$ Twenty-eight percent of current college smokers start smoking regularly when they were in college, and many students who begin smoking socially progress to heavy daily smoking. ${ }^{98,99,117,125}$ A study by Stockdale and colleagues comparing adolescent versus college cigarette use initiation showed that both groups experienced prosmoking social influences and attitudes, but college initiators who were "able to fend off smoking influences before coming to college, but then succumbed to them upon entering 
college" (p.320). ${ }^{106}$ A qualitative study by Thompson also found that social influences, particularly peer smoking and the college environment, contributed to college student smoking. ${ }^{107}$ It is unclear what characteristics of campus environments contribute to smoking behaviors in college students. However, studies that examine the influence of campus factors on smoking behaviors in a college-aged population are limited. Aggregate patterns and trends of smoking behaviors point to a contextual influence beyond individual and proximal social networks. ${ }^{99}$ A series of articles on smoking behaviors in youth and adolescence called for inclusion of environmental variables to understanding cigarette use. ${ }^{121,122,126}$ Environmental influence is recognized to have a role in smoking uptake and maintenance, although that role is largely unknown.

The closed campus community and the indoctrination of students into the culture, traditions, and norms unique to the campus create a social interconnectedness. Often, this sense of collective identity, whether it revolves around sporting events, academic achievement, or social activities evolves and allows for a sense of reciprocity and shared values and norms. ${ }^{89}$ Social capital affords a theoretical framework to examine both individual (micro) and campus (meso) level factors in order to better understand how the unique campus environment may influence individual smoking behaviors.

Social capital is used in multiple social science fields (sociology, economics, education, political science, and public health). At the micro or individual level, social capital is used broadly to describe the cognitive and structural elements of social relationships through mutual obligation, trust, norms, and voluntary participation in civic and social organizations. 5, 24, 36, 37, 39, ${ }^{88,89}$ However, social capital is a function of both individual and community level factors. ${ }^{56,58,65}$ Aggregate levels of trust and participation in voluntary associations are consistently important 
structural measures of social capital at the meso-level. ${ }^{56,58,65,88,89}$ Participation in voluntary associations bring people together with shared interests who can then mobilize resources and develop trust both at the individual and institutional levels. ${ }^{46}$ Volunteerism is an indicator of individual's willingness to contribute to collective good, a sense of mutual obligation and reciprocity that is central to social capital theory. ${ }^{36,56,88,89}$

In the present study, we used a multilevel design to investigate the relationship, including direction and magnitude, between indicators of social capital at the individual and campus levels (campus level trust and volunteerism), and individual smoking behavior. In addition, we examined the relationship between campus characteristics and individual smoking behaviors in order to identify campus characteristics associated with increased smoking at the individual level. We hypothesize that individual level social capital will be negatively associated with individual smoking behavior. We further hypothesize that campus level trust and participation in volunteerism will be negatively associated with individual smoking behaviors.

\subsection{Methods}

The National College Health Assessment (NCHA) is a college student health survey covering a range of health risk behaviors, social norms, and disease prevalence. NCHA aligns with Healthy Campus 2010 Objectives (ACHA) and specifically address behaviors relevant to college students. ${ }^{127}$ The survey was tested for analysis of rare events, construct validity, measurement validity, and item reliability by comparing item responses for NCHA (1998-2000) with the 1995 CDC National College Behavior Risk Survey, the 1999 College Alcohol Survey, and the 2000 US Department of Justice: The National College Women Sexual Victimization Study. ${ }^{128}$ Schools paid the American College Health Association (ACHA) to use the survey and 
were responsible for the administration of the survey on their campus (securing Institutional Review Board approval, sampling, and administration). Schools that used a simple random sampling method (individuals or classrooms) were included in a national database. Schools completed a demographic information form that included information on college enrollment, region of the country, size of city within which the college is located, Carnegie Designation (an indicator of competitiveness), and if the school is public or private. In the academic year of 2005-2006 (data collected Fall 2005 and Spring 2006), 85,475 college students completed the survey. Sample sizes ranged from 28-2,762 across 144 unique institutions. The national database is available from the ACHA.

\section{$\underline{2.2 .1 \text { Participants }}$}

Inclusion criteria for this study included complete data on the individual and campus level variables of interest. Respondents must also be between the ages of 18-24 with a known grade point average. Information on response rate for schools overall was not available from the ACHA. Across individual level variables, missing data was less than $2 \%$; cases were deleted listwise in the analysis. There were 79,868 respondents who had complete data on all individual and campus-level independent and dependent variables of interest and comprised our analytic sample.

\section{$\underline{\text { 2.2.2 Measures }}$}

Smoking Outcome. The dependent variable measured individual differences in current cigarette smoking among college students. The smoking outcome was measured using a single item from the National College Health Assessment. The item asked "On how many days in the past 30 days did you use cigarettes?" Response items were coded from 1-8 in which 1= "never used," 
$2=$ "have used, but not in last 30 days," $3=$ " $1-2$ days," $4=$ " $3-5$ days," $5=$ " $6-9$ days," 6= "10-19 days," 7= "20-29 days," and 8= "all 30 days".

Micro-level Individual Social Capital Index Score. We operationalized social capital at the individual level as a composite score on available measures of standard dimensions of social capital including mutual obligation (volunteerism), trust (believability of campus services/resources for health information), norms (difference between perceived smoking behavior and actual campus smoking prevalence), and participation in organizations (fraternity/sorority participation). In addition, we included a proxy measure for social support in the form of living situation (on campus or off campus) and relationship status (in a committed relationship or single).

A social capital index was created specifically for this study by the researchers, and included measures of social capital constructs drawn from available survey items, based on social capital indices created in other studies. ${ }^{16}$ The social capital index score (SCIS) was the sum of scores on measures of social capital constructs available in the survey rescaled as continuous measures from $0-1$ in order to give equal weight to each including: volunteerism, trust, participation, shared norms, and social support. The SCIS ranged from 0-6, with $0=$ "low social capital" and 6= "high social capital" (see Table 2.1).

Volunteerism was measured based on a question about the number of hours respondents volunteered per week. Trust was created using a composite score on six variables measuring trust in campus services (Table 2.1). Respondents were asked to rate the believability of campus sources of health information (campus newspaper articles, health center medical staff, health educators, resident assistants/advisors, campus peer educators, and faculty/coursework). The 
items were combined to form a composite score ranging from 1-18 ( $\alpha=.67)$, and then re-scaled to $0-1(0=$ low trust and $1=$ high trust $)$. Formal participation in activities included a measure of participation in a social fraternity or sorority. Shared norms and values were based on respondents' perception that past 30-day prevalence of cigarette use at their school was higher than the reported prevalence on campus. Social support measures were not available in the survey. Therefore, we used two variables as proxies for social support: ${ }^{103,115}$ living situation, or living on-campus versus off-campus; and relationship status, based on respondent report of being in a current romantic relationship or no relationship (Table 2.1). People who are single are more likely to smoke cigarettes than their married counterparts. ${ }^{1,9,129}$

Micro-Level Individual Covariates. Demographic, psychosocial, and co-occurring risks shown to be associated with smoking outcomes among college students in the literature were controlled for in the analysis (Table 2.1). Demographic variables included age, sex, and race/ethnicity. Racial categories were dummy coded into mutually exclusive categories that included White (non-Hispanic), African American/Black (non-Hispanic), Hispanic or Latino/Latina, Asian or Pacific Islander, American Indian or Alaska/Hawaiian Native, Multi-race, or Other race. Multirace included any respondent who indicated more than one race; whereas, 'Other race' included only respondents who indicated the response option of "other." Although generally coded as ethnicity, Hispanic was included as a racial category in this survey and was coded as such for the final analysis. Lifetime depression was included as a psychosocial indicator. Co-occurring risks included binge drinking in the past 2 weeks, drug use in the past 30 days, and grade point average. Binge drinking was measured by the question "how many times (in the last two weeks), if any, have you had five or more alcoholic drinks at a sitting." Grade point average was coded as $4=\mathrm{A}$ to $1=\mathrm{D} / \mathrm{F}$. 
Meso-Level Campus Social Capital. Meso-level campus social capital was operationalized as campus trust and volunteerism based on consistent findings in the literature to support these as community measures of social capital..$^{3,5,7,36,41,56,64,68}$ Campus trust was operationalized as the aggregate mean score by campus on the composite trust variable. Volunteerism was a measure of the mean score students on each campus dedicated to volunteer activities per week.

Meso-Level Campus Characteristics. Campus characteristics were controlled for in the analysis (see Table 2.2), including categorical level campus enrollment, size of the city where the campuses were located, and region of the country. Size of the city included urban (reference category), suburban, other urban (small city), rural, and other. Region of the country included Northeast (reference category), Midwest, South, West and Other. A competitiveness index was created in which combined scores on Carnegie designation, aggregate grade point average, and whether the school was private (versus public).

\section{$\underline{2.2 .3 \text { Analysis }}$}

Initial analysis included diagnostics for missing data, outliers, homoskedasticity, multicollinearity, and distributional form of the independent and dependent variables and residuals. Univariate statistics including means and frequencies of each variable were conducted. In order to address the study objective, we conducted a hierarchical linear model (HLM) using HLM $6.06^{130}$ in which the individual level variables were included as level 1 and the campus level variables were level 2. HLM does not assume independence of observations, and allows for grouping at level 2 (here, campuses) which may impact the observations. ${ }^{131}$

First, an interclass correlation assessed the variance in the dependent variable accounted for by including the campus-level variables in the model by running an unconstrained model. In 
Level 1 of the model, grade point average and the social capital index score were group centered because there is no true zero point. In Level 2 of the model, the campus level measures of trust, volunteerism, and competitiveness were grand mean centered. Then, a random coefficients model was specified as shown below to account for social capital at the individual and campus level controlling for demographic confounders, and known behavioral covariates. A random coefficients model allows for intercepts and slopes in the regression model to vary by campus.

Level 1: $\quad \mathrm{Y}_{i j}=\beta_{0 j}+\beta_{1 j}($ Social Capital Index $)+\beta_{2 j}($ age $)+\beta_{3 j}($ sex $)+\beta_{4 j}($ GPA $)+\beta_{5 j}($ Depression $)+\beta_{6 j-} \beta_{11}$ ${ }^{132}+\beta_{12 j}$ (other drug use $)+\beta_{13 j}$ (binge drinking) $+\mathrm{r}_{i j}$

Where, $\mathrm{Y}_{i j}$ is the smoking outcome of student $i$ in school $j$ $\beta_{0}$ is the intercept $\beta_{l j}$ is the slope for the Social Capital index and $\beta_{2 j}$ to $\beta_{13 j}$ are the slopes for the covariates $\mathrm{r}_{i j}$ is the random error term in which $\sim \mathrm{N}\left(0, \sigma^{2}\right)$

Level 2: $\quad \beta_{00}=\gamma_{o o}+\gamma_{01}($ Campus Trust $)+\gamma_{02}$ (Campus Volunteerism $)+\gamma_{03}$ (Competitiveness $)+$ $\gamma_{04}($ Population $)+\gamma_{05}-\gamma_{08}($ Urbanicity $)+\gamma_{09^{-}} \gamma_{013}$ (Region) $+u_{\mathrm{ij}}$ $\beta_{01}=\gamma_{10}+, u_{1 \mathrm{j}} \ldots$

Where, $\gamma_{o o}$ is the average smoking behaviors across the population of campuses

$\gamma_{01}-\gamma_{02}$ are the average slopes across schools for social capital variables

$\gamma_{03}-\gamma_{013}$ are the average slopes across schools for campus characteristics

$u_{0 \mathrm{j}}$ is the unique increment to the intercept associated with school $\mathrm{j}$

$u_{1 \mathrm{j}}$ is the unique increment to the slope associated with school $\mathrm{j}$ and the variance components are

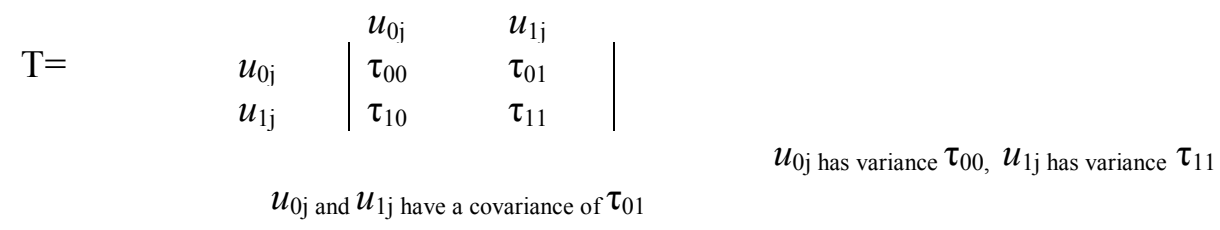

All HLM models were analyzed using full maximum likelihood (FML) estimation for two reasons. The use of FML allows for comparison of model fit by comparing the deviance in 
the null model compared to the full model. ${ }^{133}$ Second, the initial regression diagnostics for the individual level model alone indicated that there was heteroskedasticity in the variance of the residuals. The fixed effects coefficient robust standard errors were also used in order to correct for the level 1 heteroskedasticity. The full model was compared to both the null model (without any covariates at either level 1 or level 2) and a model with all of the covariates included except social capital. Although the individual level variables are controlled in the model, we report only the campus level results.

\subsection{Results}

Univariate results for the individual-level variables are presented in Table 3. Most of the 79,868 participants were female $(64.9 \%)$, white $(75.6 \%)$, and had an average age of 20.24 years $(\mathrm{SD}=1.633)$. Over all 144 campuses, $55.0 \%$ of student respondents lived in on-campus housing or in a fraternity/sorority house, $9.7 \%$ reported fraternity or sorority membership, and $41.2 \%$ currently being in a romantic relationship. Over all campuses, $17.6 \%$ of students reported current cigarette use (use in the past 30 days), 17.0\% reported using at least one of the following drugs in the past 30 days: marijuana, cocaine, or amphetamines. Student respondents also reported an average of 2.08 (on a scale of $1=$ none to $10=10$ or more) occasions on which they drank five or more alcoholic beverages in a sitting. The combined average score on the social capital index across all campuses was $2.23(\mathrm{SD}=.922)$.

Of the 144 campuses, most were public institutions (61.1\%) and four year schools (95.8\%). The distribution of schools represented across the United States was $22.9 \%$ from the northeast, $25.7 \%$ from the Midwest, $20.1 \%$ from the south, $27.8 \%$ from the West, and 3.5\% from other locations. Most schools were located in an urban area with a population between 100,000- 
$1,000,000(31.9 \%)$, followed by rural locales $(31.2 \%)$, suburban $(18.8 \%)$, urban inner city (13.2\%), and others (4.9\%). Most were designated as a doctoral research extensive institution (34.0\%) or a Masters Level I and II (30.6\%) by the Carnegie Designation classification system (see Table 2.3).

The intraclass correlation for the unrestricted model was 0.03 , therefore $3 \%$ of the variance in average days of cigarette use is between campuses. The results of the full hierarchical linear model are presented in Table 2.4. The results show a statistically significant negative relationship between the social capital construct of campus level volunteerism $(\beta=-.059, \mathrm{SE}=$ $.036, p<.05)$ and the intercept, average days of reported use of cigarettes, controlling for other campus variables and individual level factors. Campus characteristics including region being in the West (compared to the Northeast) showed a negative association with average days of cigarette use $(\beta=-0.082, \mathrm{SE}=.039, p<.05)$ when controlling for other individual and campus factors. Size of campus city including suburban, other urban (small city), rural and other (compared to urban locations) also showed negative associations $(\beta=-147, \mathrm{SE}=.045, p<.05, \beta=-$ $0.120, \mathrm{SE}=.035, p<.05, \beta=-0.170, \mathrm{SE}=.043, p<.05, \beta=-0.0124, \mathrm{SE}=.049, p<.05$ respectively) with average days of cigarette use when controlling for other factors. The adjusted model showed improved explained variance over the unrestricted null model $\left(\chi^{2}=12883.64, p<.000\right)$ and over the model that did not include campus level social capital measures $\left(\chi^{2}=8.008, p<.05\right)$.

\subsection{Discussion}

Results of this study show that a measure of campus level of social capital, volunteerism, is related to decreased individual level cigarette use in college students. Other studies of social capital and college student risk behaviors, specifically, binge drinking, showed social capital 
measured as volunteerism on both an individual and campus level to be protective in preventing college binge drinking and negative consequences associated with heavy alcohol consumption among college students. ${ }^{88,89}$ This is consistent with cigarette use in this study. In other public health literature, aggregated participation in voluntary associations and community trust was associated with lower state-level mortality and community firearm violence. ${ }^{6,7}$ Lindstrom and Janzon found that in Sweden, lower levels of institutional (or vertical) trust was associated with higher rates of daily smoking. ${ }^{10}$ Contrary to previous studies, campus level measures of institutional trust were not significant in this study. This may be related to the measure itself. The measure of institutional trust we used measured aggregated believability of campus resources for health information. This is an incomplete measure of vertical or institutional trust.

Location of the campus within an urban environment (compared to other localities) and in the West region (compared to the Northeast) were also significant. Campuses in the West were found to have lower rates of smoking than in other areas of the country. This is consistent with other studies. National surveillance data show that western states have the lowest prevalence of cigarette smoking ${ }^{134}$ and a study among college students that accounted for region of the country in which the school was located was also found to be associated with less cigarette use. ${ }^{99}$ This may be due, in part to strict clean indoor air protection acts enacted in these states. Specifically, California has among the longest enforced policies and the strictest restrictions on smoking in public places. $^{135}$

However, this study does not support findings related to campus characteristics in other studies. Other campus characteristics including enrollment, school type, and competitiveness at the campus level were not found to be significant in predicting the change in intercept of average days smoking in college students. A study by Weschler showed that on a campus level, 
increased rates in smoking occurred at less competitive schools, schools in the Northeast and South, and at public schools. ${ }^{99}$ However, Weschler's study did not use a multilevel analysis, which may account for the differing findings.

\subsubsection{Limitations}

There are inherent limitations in studies on community influence on health and other risk behaviors. There is the possibility of endogeniety, which refers to the free choice by which individuals chose their campus environment. This is a particular concern when studying the effects of environment in a college population as the decision to attend a particular college can be influenced by a number of factors, financial, family, and reputation (both academic and social). A second concern is simultaneity, which asks, does the community context create the behavior or do the individual behaviors create the context? Finally, a concern with any secondary data analysis is the potential for omitted variables and variables not specifically created to measure social capital. Although we used measures of social capital consistent with other studies, ${ }^{88,89}$ future studies should include indicators of social capital validated in this population (such as measures of institutional/vertical trust).

\subsection{Conclusions}

Results of this study provide evidence that social capital at the individual and campus levels are associated with current smoking outcomes. Specifically, high rates of social capital (volunteerism) at the campus level are associated with lower measures of cigarette use among college students. Enhanced understanding of what regions of the country at highest risk for individual smoking, and school factors associated with increased risk of individual smoking can help college administrators plan for campus level smoking interventions, including promoting 
volunteerism on campus. Although we controlled for age in this study, additional research on the associations between volunteerism and cigarette use by year in school, part-time versus full-time students, and international student status may provide further insight into the nature of the relationship. Future research should focus on understanding the macro-level influence of state and local level smoking bans and meso-level institutional smoking policies on college student smoking, In addition, finer distinctions between daily or heavy smokers and social smokers may enhance our understanding of the influence of social capital on smoking uptake and increases among college students. Social connections, particularly with other smokers, may exert significant influence on smoking behaviors. Comprehensive understanding of smoking patterns and social capital in the context of formal and informal interactions between students would inform how engagement in college campus communities and adoption of campus norms interact with individual characteristics to influence smoking patterns among students. This understanding would lead to improved campus community intervention campaigns to curtail smoking in college, including translational implications, from research to practice, that engage parents, alumni, and university administrations in creating opportunities for students to participate in campus-sanctioned activities that may curb tobacco use. Finally, studies that operationalize social capital using multidimensional indicators in manner relevant to the college student context must be undertaken in order to accurately discuss the influence on emerging adults. 
Table 2.1: Individual Level Variable Descriptions

NCHA Item

Coding

Outcome Variable- Smoking Outcome

On how many days in the past thirty days

did you use cigarettes?

$1=$ "never"

$2=$ "have used, but not in past 30 days"

$3=$ " $1-2$ days"

$4=$ "3-5 days"

$5=$ " $6-9$ days"

$6=$ "10-19 days"

$7=$ " $20-29$ days"

$8=$ "all 30 days"

\begin{tabular}{|c|c|}
\hline \multicolumn{2}{|l|}{ Individual Level Social Capital Index Variables* } \\
\hline $\begin{array}{l}\text { Volunteerism: "How many hours per week } \\
\text { do you volunteer? }\end{array}$ & $\begin{array}{l}1=" 0 \text { hours" } \\
2=" 1-9 \text { hours" } \\
3=\text { " } 10-19 \text { hours" } \\
4=\text { " } 20-29 \text { hours" } \\
5=\text { " } 30-39 \text { hours" } \\
6=\text { "40 hours" } \\
7=\text { "more than } 40 \text { hours" }\end{array}$ \\
\hline $\begin{array}{l}\text { Trust: Composite score for six items } \\
\text { "Record the believability of each source of } \\
\text { health information: }\end{array}$ & $\begin{array}{l}1=\text { "unbelievable" } \\
2=\text { "neither believable nor unbelievable" } \\
3=\text { "believable" }\end{array}$ \\
\hline $\begin{array}{l}\text { campus newspaper articles } \\
\text { health center medical staff } \\
\text { health educators } \\
\text { resident assistants/advisors } \\
\text { campus peer educators } \\
\text { faculty/coursework" }\end{array}$ & $\begin{array}{l}\text { Score on each combined for a composite score ranging from } 1-18 \text { where } 1 \text { is the } \\
\text { least trust in campus resources and } 18 \text { is the most trust in campus health resources }\end{array}$ \\
\hline $\begin{array}{l}\text { Formal Participation: "Are you a member } \\
\text { of a social fraternity or sorority? }\end{array}$ & $\begin{array}{l}1=\text { "yes" } \\
0=\text { "no" }\end{array}$ \\
\hline $\begin{array}{l}\text { Shared Norms and Values: "Within the last } \\
30 \text { days, what percent of students at your } \\
\text { school used cigarettes?" }\end{array}$ & $\begin{array}{l}\text { Created a dummy variable in which when the answer to this item was compared } \\
\text { to actual percentage of student who reported cigarette use in the past } 30 \text { days: } \\
1=\text { perceived less cigarette use than reported } \\
0=\text { perceived more cigarette use than reported }\end{array}$ \\
\hline Social Support: "What is your current relationship status?" & $\begin{array}{l}1=\text { in a current committed relationship } \\
0=\text { not in a current committed relationship }\end{array}$ \\
\hline "Where do you currently live?" & $\begin{array}{l}1=\text { in an on-campus facility or fraternity/sorority house } \\
0=\text { lives off-campus }\end{array}$ \\
\hline Combined Social Capital Index Score & $\begin{array}{l}\text { Each SCIS variable was rescaled to } 0-1 \text {, giving equal weight to each measure, } \\
\text { then combined to form a composite score } \\
1=\text { low social capital } \\
6=\text { high social capital }\end{array}$ \\
\hline \multicolumn{2}{|l|}{ Individual Level Covariates } \\
\hline $\begin{array}{l}\text { Psychosocial: "Have you ever been diagnosed with } \\
\text { depression?" }\end{array}$ & $\begin{array}{l}1=\text { "yes" } \\
0=\text { "no" }\end{array}$ \\
\hline $\begin{array}{l}\text { Co-occurring risks: } \\
\text { Grade point average* "What is your approximate } \\
\text { cumulative grade point average?" }\end{array}$ & $\begin{array}{l}4=" A " \\
3=" B " \\
2=" C " \\
1=" D / F "\end{array}$ \\
\hline $\begin{array}{l}\text { Binge Drinking "Think back over the last two weeks. } \\
\text { How many times, if any, have you had two or more } \\
\text { alcoholic drinks at a sitting?" }\end{array}$ & $1="$ none" to $10=" 9$ or more times" \\
\hline $\begin{array}{l}\text { Drug Use "How many days in the past thirty days did you } \\
\text { use:" marijuana, cocaine, or amphetamines?" }\end{array}$ & $\begin{array}{l}1=\text { "never" } \\
2=\text { " have used, but not in past } 30 \text { days" } \\
3=\text { " } 1-2 \text { days" } \\
4=" 3-5 \text { days" } \\
5=\text { = } 6-9 \text { days" } \\
6=" 10-19 \text { days" } \\
7=\text { " } 20-29 \text { days" } \\
8=\text { "all } 30 \text { days" }\end{array}$ \\
\hline
\end{tabular}


Table 2.2: Campus Level Predictor Descriptions

NCHA Item

Coding

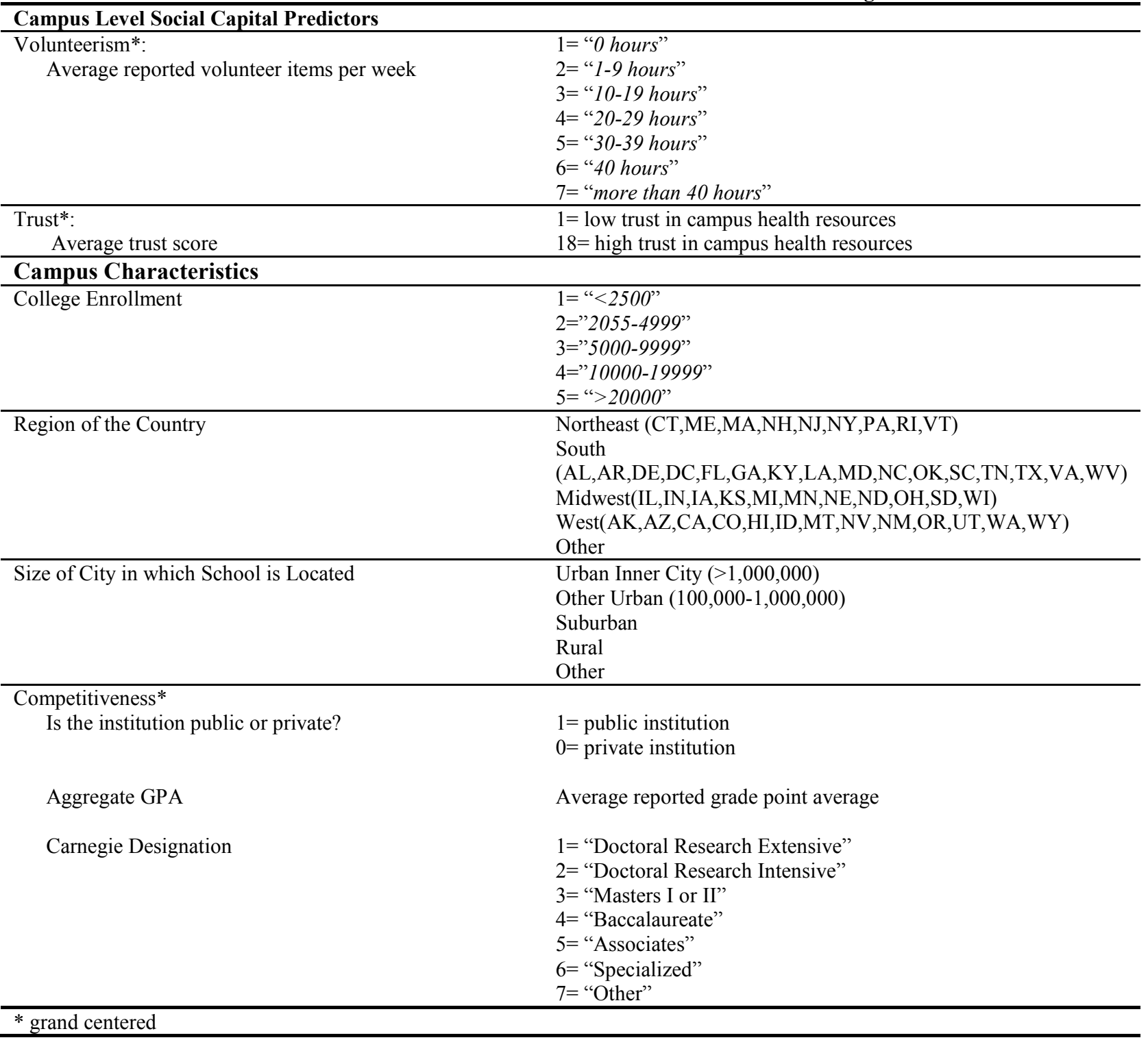


Table 2.3: Sample Characteristics

\begin{tabular}{|c|c|}
\hline Demographic Characteristics & $\mathbf{N}(\%)$ \\
\hline $\begin{array}{l}\text { Sex } \\
\text { Female } \\
\text { Male }\end{array}$ & $\begin{array}{l}54,647(64.9 \%) \\
29,589(35.1 \%) \\
\end{array}$ \\
\hline $\begin{array}{l}\text { Race } \\
\text { White (including Middle Eastern) } \\
\text { Black } \\
\text { Hispanic or Latino } \\
\text { Asian or Pacific Islander } \\
\text { American Indian or Alaskan Native } \\
\text { Other race } \\
\text { Multiracial }\end{array}$ & $\begin{array}{l}63,687(75.6 \%) \\
3550(4.2 \%) \\
3931(4.7 \%) \\
7536(8.9 \%) \\
323(0.38 \%) \\
1960(2.3 \%) \\
3280(3.9 \%) \\
\end{array}$ \\
\hline $\begin{array}{l}\text { Living Situation } \\
\text { In on-campus housing or a fraternity/sorority house } \\
\text { Off-campus housing }\end{array}$ & $\begin{array}{l}46,855(55 \%) \\
38,292(45 \%)\end{array}$ \\
\hline $\begin{array}{l}\text { Relationship status } \\
\text { Married/domestic partnership, engaged, or in a committed } \\
\text { dating relationship } \\
\text { Single, divorced, separated, or widowed } \\
\end{array}$ & $\begin{array}{l}35,235(41.4 \%) \\
49,940(58.6 \%)\end{array}$ \\
\hline $\begin{array}{l}\text { Fraternity or Sorority Membership } \\
\text { Member } \\
\text { Not a member }\end{array}$ & $\begin{array}{l}8190(9.7 \%) \\
76,677(90.3 \%)\end{array}$ \\
\hline $\begin{array}{l}\text { Past } 30 \text { day drug use (marijuana, cocaine, amphetamines) } \\
\text { Used in past } 30 \text { days } \\
\text { No use in past } 30 \text { days }\end{array}$ & $\begin{array}{l}14,519(17.0 \%) \\
70,891(83.0 \%)\end{array}$ \\
\hline $\begin{array}{l}\text { Depression } \\
\text { Ever diagnosed } \\
\text { Not diagnosed }\end{array}$ & $\begin{array}{l}11,335(13.4 \%) \\
73,323(85.8 \%)\end{array}$ \\
\hline Covariates Mean for all Campuses & Mean (SD) \\
\hline Age & $20.24(1.633)$ \\
\hline Trust & $15.417(2.08)$ \\
\hline Volunteerism & $1.44(.643)$ \\
\hline Grade Point Average & $3.249(.681)$ \\
\hline Binge Drinking Occasions Past Two Weeks & $2.08(1.796)$ \\
\hline Social Capital Index & $2.23(.922)$ \\
\hline Campus-Level Characteristics & $\mathbf{N}(\%)$ \\
\hline $\begin{array}{l}\text { College enrollment } \\
<2500 \\
2055-4999 \\
5000-9999 \\
10000-19999 \\
>20000 \\
\end{array}$ & $\begin{array}{l}23(16.0 \%) \\
18(12.5 \%) \\
31(21.5 \%) \\
42(29.2 \%) \\
30(20.8 \%)\end{array}$ \\
\hline $\begin{array}{l}\text { Region of the United States } \\
\text { Northeast } \\
\text { Midwest } \\
\text { South } \\
\text { West } \\
\text { Other } \\
\end{array}$ & $\begin{array}{l}33(22.9 \%) \\
37(25.7 \%) \\
29(20.1 \%) \\
40(27.8 \%) \\
5(3.5 \%) \\
\end{array}$ \\
\hline $\begin{array}{l}\text { Size of school location } \\
\text { Urban Inner City } \\
\text { Small City } \\
\text { Suburban } \\
\text { Rural } \\
\text { Other } \\
\end{array}$ & $\begin{array}{l}19(13.2 \%) \\
46(31.9 \%) \\
27(18.8 \%) \\
45(312 \%) \\
7(4.9 \%)\end{array}$ \\
\hline $\begin{array}{l}\text { Carnegie Designation } \\
\text { Doctoral Research Extensive } \\
\text { Doctoral Research Intensive } \\
\text { Masters I or II } \\
\text { Baccalaureate } \\
\text { Associates } \\
\text { Specialized } \\
\text { Other }\end{array}$ & $\begin{array}{l}49(34.0 \%) \\
16(11.1 \%) \\
44(30.6 \%) \\
24(16.7 \%) \\
6(4.2 \%) \\
1(0.7 \%) \\
4(2.8 \%)\end{array}$ \\
\hline
\end{tabular}


Table 2.4: Individual and Campus Level Random Intercept Regression Model for Smoking Behavior in College Students, Social Capital, Neighborhood Structures, and Individual Covariates

\begin{tabular}{|c|c|c|c|c|c|}
\hline Fixed Effects & $\begin{array}{c}\text { Coefficient } \\
\text { (Robust SE) }\end{array}$ & $t$ & $d f$ & \multicolumn{2}{|c|}{$p$} \\
\hline Smoking Behavior (Intercept) & $0.442(.185)$ & 2.384 & 130 & \multicolumn{2}{|c|}{$.019^{*}$} \\
\hline \multicolumn{6}{|l|}{ Campus Social Capital Measures } \\
\hline Effect of Campus Trust $\mathrm{a}^{\mathrm{a}}$ & $-0.059(.037)$ & -1.602 & 130 & \multicolumn{2}{|c|}{.111} \\
\hline Effect of Campus Volunteerism $^{\mathrm{a}}$ & $-0.326(.132)$ & -2.473 & 130 & \multicolumn{2}{|c|}{$.015^{*}$} \\
\hline \multicolumn{6}{|l|}{ Campus Characteristics } \\
\hline \multicolumn{6}{|l|}{ Effect of Location } \\
\hline Northeast & reference & & & & \\
\hline Midwest & $-0.052(.037)$ & -1.416 & 130 & \multicolumn{2}{|c|}{159} \\
\hline West & $-0.082(.039)$ & -2.131 & 130 & \multicolumn{2}{|c|}{$.035^{*}$} \\
\hline South & $0.029(.035)$ & 0.816 & 130 & \multicolumn{2}{|c|}{.416} \\
\hline Other & $-0.170(.094)$ & -1.800 & 130 & \multicolumn{2}{|c|}{.074} \\
\hline \multicolumn{6}{|l|}{ Effect of Urbanicity } \\
\hline Urban (Inner City) & reference & & & \multirow{2}{*}{\multicolumn{2}{|c|}{$001 * *$}} \\
\hline Other Urban (Small City) & $-0.120(.035)$ & -3.475 & 130 & & \\
\hline Suburban & $-0.147(.045)$ & -3.300 & 130 & \multicolumn{2}{|c|}{$\begin{array}{l}.001 * * \\
.002 * *\end{array}$} \\
\hline Rural & $-0.170(.043)$ & -3.972 & 130 & \multicolumn{2}{|c|}{$.000 * * *$} \\
\hline Other & $-0.120(.049)$ & -2.526 & 130 & \multicolumn{2}{|c|}{$.013 *$} \\
\hline Effect of Competitiveness $^{\mathrm{a}}$ & $-0.014(.013)$ & -1.101 & 130 & \multicolumn{2}{|c|}{.273} \\
\hline Effect of School Type (4 year vs. 2 year) & $-0.218(.153)$ & -1.422 & 130 & \multicolumn{2}{|c|}{.157} \\
\hline Enrollment of school & $-0.003(.013)$ & -0.248 & 130 & \multicolumn{2}{|c|}{.804} \\
\hline $\begin{array}{l}\text { Random Effects } \\
\end{array}$ & $\begin{array}{c}\text { Standard } \\
\text { Deviation } \\
\end{array}$ & $\begin{array}{c}\text { Variance } \\
\text { Component }\end{array}$ & $d f$ & $\begin{array}{c}\text { Chi- } \\
\text { square }^{\ddagger}\end{array}$ & $p$ \\
\hline Intercept (Level 1) & .674 & .455 & 69 & 145.8 & $0.000^{* * *}$ \\
\hline SC Index & .070 & .005 & 82 & 149.6 & $0.000^{* * * *}$ \\
\hline Age & .040 & .002 & 82 & 163.5 & $0.000^{* * *}$ \\
\hline Sex & .130 & .017 & 82 & 144.2 & $0.000^{* * *}$ \\
\hline Race & $\mathrm{N} / \mathrm{S}$ & $\mathrm{N} / \mathrm{S}$ & $\mathrm{N} / \mathrm{S}$ & $\mathrm{N} / \mathrm{S}$ & $\mathrm{N} / \mathrm{S}$ \\
\hline Grade Point Average & .096 & .009 & 82 & 183.7 & $0.000^{* * * *}$ \\
\hline Depression & .219 & .048 & 82 & 167.5 & $0.000^{* * * *}$ \\
\hline Binge Drinking past 2 weeks & .095 & .009 & 82 & 167.5 & $0.000^{* * *}$ \\
\hline Level 1 & 1.59899 & 2.55677 & & & \\
\hline Note: Individual covariates described in the & $\begin{array}{l}\text { in Parentheses are } \\
\text { reported fort units th } \\
{ }^{a} \text { Grand Mean Cen } \\
5,{ }^{* *} \text { Significant at }<. \\
r \text { were controlled for } \\
\text { ace, binge drinking, }\end{array}$ & $\begin{array}{l}\text { ist Standard Erro } \\
\text { ad sufficient data } \\
\text { d } \\
\text { *** Significant at }< \\
\text { the full model, but } \\
\text { g use, and depres. }\end{array}$ & nalysis & he table. & lual social \\
\hline
\end{tabular}


Chapter 3 


\section{Chapter 3}

Who you know: Developing and Maintaining Social Capital among Emerging Adults in College

\subsection{Introduction}

Social capital is an increasingly popular theory applied broadly in social science including sociology, political science, economics, education, and public health to explain social and health disparities. However, it is often criticized as being conceptually and operationally flawed. Even within each field, the central constructs and understanding of social capital and its function as it relates to both individuals and society incorporate multiple paradigms, and the operationalization of the constructs differ.

Among public health researchers, there are disagreements as to how to best assess social capital as it relates to health outcomes. Public health studies indicate a negative relationship between social capital and poor self-rated health status, violence, obesity, mortality related to coronary heart disease and malignant neoplasms, infant mortality, and demand for cigarettes. ${ }^{2,5-8,}$ $10,12,15,55-57$ Yet, researchers diverge in regards to the appropriate unit of analysis (individual versus community) to measure social capital, whether it is an indicator, mediator, or outcome of social conditions, and what constructs best measure social capital. ${ }^{5,7,8,55,57-60,65,136}$ Social capital is an appealing theoretical framework for public health scientists because it can account for meso- and macro-level social conditions in communities (such as income inequality, racial discrimination, and educational factors, among others) and simultaneously account for individual (micro) level factors associated with health behaviors. However, across public health literature, there is no consensus as to a theoretical conceptualization of social capital and the indicators that best capture its multiple dimensions. ${ }^{57}$ 
A group of scientists from The World Bank tasked with investigating the most appropriate measures of social capital concluded that studies of social capital need to be context specific and to employ a mixed methods (qualitative and quantitative) approach in order to best understand social capital in a given community. ${ }^{62,68}$ A population of college students/emerging adults is an interesting microcosm of community in which to study social capital development. Described in detail below, college is a unique time in an individual's life in which they become more autonomous, develop identities and social networks separate from their parents, and are privy to a plethora of resources and support provided by their educational institution. In addition, college is a time of significant health risk behaviors. ${ }^{91}$ This makes college a key context within which to examine the operationalization of social capital constructs in order to broaden our understanding in public health research.

Generally, social capital constructs span formal (religiosity, volunteerism, political participation, and club/organization membership) and informal participation, shared norms and values, informal social control, intergenerational closure, and trust and reciprocity depending on the paradigm of origin. Because the structural mechanism by which social capital is formed relies on social relationship, we also explored social support networks. These constructs account for both cognitive (shared norms and values, interpersonal trust, attitudes, and beliefs) ${ }^{3,39,68}$ and structural (infrastructure of social relationships that facilitate information sharing, collective action through established roles, social networks and other social structures supplemented by rules, procedures, and precedents) $)^{3,39,64,68}$ functions of social capital. Social capital concepts are not new, and were introduced by sociologists over a century ago, ${ }^{32,34}$ but became popularized in the late 1980 's, primarily in the fields of education and economics. ${ }^{24,36,37,44}$ Over the course of 20 years, empirical studies of social capital are fraught with poor measurement, arbitrary 
selection of variables to measure social capital constructs, and inconsistencies across disciplines. ${ }^{3,25,40,41,46,61,68}$ Proponents of social capital theory are often criticized for overreaching science primarily because of ambiguous and vague operationalization of constructs. $^{25,38,61}$

Although many studies of social capital originated in the educational field, there are few studies that examine social capital at a postsecondary level. ${ }^{63,90}$ Most studies of social capital in emerging adults (aged 18-24) and children focus on access to parental social capital. ${ }^{25,28-30}$ At a secondary education level, the focus is often on the access to family resources and educational attainment for adolescents and adult social capital as it relates to child outcomes, including

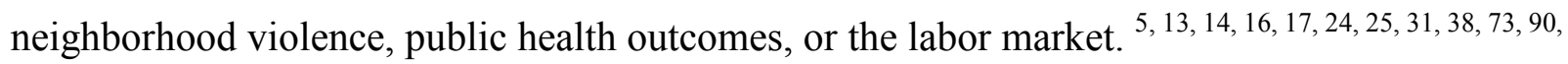
${ }^{92,137}$ In a review of social capital in secondary educational literature by Dika and Siggh, there were statistically significant findings showing a moderate relationship between educational attainment and social capital, an association between educational achievement and social capital, and a positive association between social capital and psychosocial factors. ${ }^{25}$ However, they conclude that many of the educational studies are methodologically flawed due to poor conceptualization and measurement.

\subsubsection{A Brief Overview of Social Capital}

Although the idea of origins of social capital are not new, and can be traced to the forefathers of sociology, such as Emile Durkheim, modern views of social capital stem from James Coleman's work on children's academic achievement as it relates to access to social capital through family structures and networks, ${ }^{24,73}$ and Robert Putnam's work in understanding social capital as a function of community structures and the ability of a community to mobilize 
resources based on collective identity and mutual advantage. ${ }^{36}$ Bourdieu's work in sociology and subsequent interpretation of his work by Richard Carpiano in social capital as it relates to public health and health outcomes frame social capital in the greater social context of institutionalized neighborhood or community structures within which individuals must navigate and operate in order to develop and maintain social capital, such as socioeconomic status, ethnic composition, and social and economic inequality or disparity with adjacent neighborhoods. ${ }^{39,138}$ However, central to Bourdieu and Carpiano's theoretical framework, these neighborhood structures are antecedents to the development of social networks and relationships in which individuals can access resources. Carpiano goes one step further and separates the concept of social cohesion from that of social capital. ${ }^{39}$ In his definition of social cohesion, patterns of social interaction such as network formation, social ties, familiarity, and mutual trust, act to mediate between structural antecedents and social capital but are necessary before social capital can exist. Carpiano's concept of social cohesion incorporates the cognitive functions of social capital, while the delineated social capital (in line with Bourdieu's conceptualization) refers to the structural elements. ${ }^{37,39}$ Portes and Pearce emphasize that social capital is not always a positive influence on individuals or neighborhoods (including issues of exclusivity, downward leveling norms, and restrictions on individual freedoms) and studies that use social capital theory must be critically examined. ${ }^{38,61}$ There is little agreement on how the macro/meso/micro aspects of social capital converge or how to best define them in order to capture the complex and diffuse underlying mechanisms of social capital and the social interactions inherent in its development and maintenance.

Coleman's work on social capital as it related to academic achievement in school children emphasized family ties and intergenerational closure. ${ }^{24}$ The family structure, whether 
the mother worked away from home, religious school affiliation, informal social control (how much parents monitored other children's behavior) and intergenerational closure (adults outside of the immediate family to which youth were connected) were significant constructs in Coleman's work. ${ }^{24}$ Putnam emphasized community engagement as the hallmark of social capital and the decline of engagement as a forewarning to the collapse of traditional western society. ${ }^{36}$ Central to his understanding of social capital included civic engagement in the political process, participation in voluntary and philanthropic organizations, participation in informal social activities, and participation in formal clubs or groups. Carpiano stressed social cohesion, the individual's attachment and connectedness to the community including social support, trust and reciprocity, and shared norms and values. ${ }^{39}$

\subsubsection{The College Community}

College is a transitional time of development during which emerging adults juggle shifting identities, are challenged by new life roles and experiences, and renegotiate roles with parents, family, and high school friends..$^{91,109,110}$ Maintenance of parental ties from home are shown to support positive outcomes in college including better adaptation to the new environment. ${ }^{79}$ Continuation of hometown peer relationships, however, seems to be important to early adjustment to college life, but may hinder attachment and adjustment to the new environment if new attachments are not formed in college. ${ }^{81}$ The role of social capital in this transition, and its contextual basis (hometown or campus) is unclear in this population.

College campuses are often closed communities with their own resources, traditions, norms, and identity that revolve around attendance. Formal and informal activities, living quarters with or in close proximity to other students, sporting events, institutional traditions and 
stories, and shared academic goals often lead to a sense of collective identity which allows norms of reciprocity and shared values to develop. ${ }^{89}$ The formation of peer networks, campus connections, and access to campus resources create an opportunity for students to develop access to a social infrastructure and resources, or social capital.

A logical critical period in the process of social attachment is in emerging adulthood. During this time, emerging adults balance both ties to their parents and hometown and the social capital available to them through those relationships, and begin to develop an individual identity $^{91,110}$ and a social and campus network within which they have direct access to resources unavailable to their parents and peers at home. Very little is known about the process of how college students maintain, develop, or utilize social capital. ${ }^{90}$ It is also unclear, theoretically, which paradigm of social capital is most salient to the college experience. Does Coleman's emphasis on family structure and intergenerational closure for childhood outcomes translate to emerging adults? Does Putnam's focus on community engagement emerge as an important component to the development of social capital among college students? How does the social context of hometown manifest in new and developing social support and engagement in college? How does social capital in the hometown and family converge or diverge from social capital on campus? In order to best understand how health and wellbeing are influenced by social capital and how to best measure social capital in the emerging adult population, it is critical to first understand how and when social capital emerges, and its qualitative meaning to emerging adults.

The purpose of this study is to qualitatively investigate the experience of social capital among college students to understand which social capital constructs are most salient in this stage of life and to advance our understanding of how they are operationalized in this population in order to create valid and reliable social capital measures. ${ }^{40,62}$ First, is there a qualitative 
difference in how students experience hometown (parental social capital) versus campus (personal) social capital? Second, what constructs across social capital paradigms are most central to college students' experiences? Finally, how do students begin to feel connected to the campus in order to develop social capital and adopt a "student identity?"

\subsection{Methods}

This qualitative study used focus groups in order to understand the mechanisms by which social capital are formed and maintained by emerging adults at one public, land grant midAtlantic University. Enrollment at the University in Fall 2009 was 21,720 undergraduates, 52\% male and $48 \%$ female, and $7 \%$ minority students. Fifty-four percent were residents of the state and $46 \%$ were non-state residents.

\subsubsection{Focus Group Procedures}

Ten focus groups $(\mathrm{N}=59)$ were conducted in February and March 2010. The focus groups were held in private, central locations on the University's central campus. The groups consisted of currently enrolled undergraduate students on the University's main campus (as opposed to extension campuses across the state). Groups averaged 5 participants per group (range 2-20) and lasted approximately 1.5 hours each. The groups followed a semi-structured focus group guide developed by the author to explore the central constructs of social capital found in both adult and adolescent social capital literature. We obtained permission to audiotape the focus group from all study participants, a notetaker was present at each session, and we read an informed consent script to all participants prior to the start of the focus group. We asked participants to complete a demographic information sheet with information about gender, age, class rank, year in school, and living situation. Demographic information was not linked to focus group responses, notes, or audiotapes. This study was approved by the University's Institutional Review Board. 


\subsubsection{Participants}

Participants were undergraduate students currently enrolled on the main campus of the University. They were recruited through flyers posted on public campus bulletin boards and in dining facilities, class announcements, and internet/campus television announcements and were asked to contact the research staff via email if they were interested in participating. Participants received a \$10 gift certificate to a local merchant for participating. Member checking for internal reliability was conducted using reflective listening during the focus groups.

\subsubsection{Data Analysis}

Each audio file was transcribed by a professional transcriptionist, the author, or a student assistant and any references to identifying information were removed. The transcripts were compared to the original audio files and notes for accuracy and reliability. NVIVO 8.0 student version software was used to code and categorize themes within the data. ${ }^{139}$ Directed content analysis was used to explore the themes of traditional social capital theory which allows for deeper exploration of an existing theory or phenomenon. ${ }^{140}$ Initial codes were developed based on the semi-structured focus group guide, followed by a thorough reading by the primary author in which each construct was thoroughly examined by consistency and divergence from its operational definition, and new codes developed for any categories or themes not supported by the initial coding scheme until no new variations in the dataset were identified in the transcripts. Coding rules based on the operational definitions for each category were developed, and chunks were independently coded based on those definitions by a primary and secondary coder to increase credibility. See Appendix B for the codebook. A comparison of the codes for each coder resulted in a Cohen's Kappa statistic for each construct. According to Cohen, a Kappa of 1.0 is perfect, .80 is very good, and .60 is good. ${ }^{141}$ If any Kappa was below .65 for a category, the 
coders met and consensus reached on coding chunks according to the operational definitions in the codebook until an acceptable Kappa statistic was obtained. The entire process was documented and an audit trail produced in order to increase transferability should anyone want to replicate the study in another setting with college students. The audit trail is a transparent process in which each step of the research project is recorded including instrument development, raw data, personal notes and observations, coding decisions, theme and category construction.

\section{$\underline{3.2 .4 \text { Themes and Categories }}$}

First, themes and categories were examined along traditional social capital constructs, including informal and formal participation (religiosity, volunteerism, civic engagement, club and student organization membership, etc), informal social control, intergenerational closure, norms and values, trust and reciprocity, and social support in order to understand how social capital functioned for the participants. Both hometown and campus related social capital were explored. Then, secondary themes and categories, such as using social networking sites and development and maintenance of personal relationships were examined as they emerged from the data. Finally, endogeneity was explored as a possible limitation to the study. Quotes were selected to illustrate consistency in themes presented by the students or specific deviations from themes found to be common among groups. Any mention of specific towns, people, or colleges were removed from the quotes to protect anonymity.

\subsection{Results}

Participants ranged in age from $18-43$ years $($ mean $=19.8$ years and mode $=18$ years $)$ and $66 \%$ reported that they were in their first year at the University. Seventy-one percent of student participants reported living in an on-campus residence hall with one or more roommates, and 
$18 \%$ reported living off-campus in an apartment with one or more roommates. Twenty-eight participants reported being female and 10 did not respond to the gender question. See Table 3.1 for full demographic details. Inter-coder Kappa's are reported for each section.

\section{$\underline{\text { 3.3.1Multiple Contexts }}$}

The descriptions of the student experience reflect differences in how social capital is developed (college) and maintained (home) during this critical time period. Mobility and breaking ties often seen as a detriment to social capital, and many studies on social capital among children include measures of family mobility. ${ }^{4,13,24,142,143}$ However, in most cases, college campuses are a unique context within which emerging adults expect to develop new social support systems. Dufur found evidence for studying multiple contexts of social capital, school and family, for children related to achievement scores in school. ${ }^{69}$ The findings suggest that even children utilize and develop social capital in differing contexts and it is important to understand how emerging adults may do the same. A series of working papers produced by The World Bank's Social Capital Initiative stressed the importance of understanding social capital within the context of the population and unit of analysis (individual, community, or nation) of interest. $^{3,62,68}$

The constructs of social capital for college students are not easily encapsulated into neat and defined categories. Often in the focus groups, a discussion centered on a single construct merged and blurred with other constructs, as well as incorporating both cognitive and structural elements. They are not easily separated into concise themes and are often bridged by categories not initially explored as part of the directed content semi-structured script. In order to fully explore each construct, first, we present findings within constructs in detail, and then fully discuss the bridging themes in the discussion section. 


\subsubsection{Formal Participation (Kappa .74)}

Formal participation is the active participation in organized activities. In most studies of social capital, engagement in these formal activities is measured by membership in groups and leadership roles assumed therein. These formal groups can encapsulate both cognitive and structural elements and allow access to and mobilization of various informational, educational, and financial resources. Cognitive aspects of participation in formally organized activities at the University is used by emerging adults as a tool to make social connections when they first arrive at school, and over time, reinforces these social connections, increases opportunities for informal socialization, and creates a social network that can be utilized for support. On-campus formal participation addressed by students included participation in social, service or volunteer, political, religious, and academic organizations, institutions and clubs. Structurally, participants saw participation in these formal activities as a way to meet new people with similar interests. The University actively encouraged students to become involved in formal organizations, and often sanctioned student organizations through events during new student orientation and allowing groups to actively advertise on campus.

Formal participation in organized groups from students' hometowns was rarely continued as a way to stay connected to the hometown community once emerging adults arrived on campus. Generally, students discontinued formal participation in activities at home with two exceptions. Three participants indicated that they would occasionally go home and participate in training or recreational activities as high school alums with sports teams. Second, students who were reluctant or unable to participate in religious activities on campus, often continued to participate in religious or spiritual activities at home.

Religious Participation (Kappa .98) 
Religious participation was not perceived to be formally sanctioned by the University, but participants stated that there were opportunities for students to get involved in almost any form of religious activity that they might want to join in the surrounding community. Most indicated that although they might have an interest in religious or spiritual activities, or they knew someone personally who participated in activities local to the University, that they did not choose to participate themselves. Reasons such as they liked to sleep in on Sunday after a night out (structural element related to time), or that they did not feel comfortable walking in to a religious facility to which they did not already belong or know anyone (cognitive feelings of belonging and trust) were cited for non-participation. However, when discussing religion and spirituality at home, participants were much more likely to say that they would attend religious services with family.

"I just like spending time with them and like sharing I don't know like spirituality and stuff that you have and you have to commit like I don't say prayers and stuff to myself at all but when I'm at church and just like your with them and you are kind of like more nicely dressed and it's just like nice family environment I guess"- Participant 3, Group 6

"I feel like when we all go it makes my parents feel happy you know where all here and it just makes everybody seem happier so..."--Participant 4, Group 6

"When college students go back home I think they may be more motivated to go with their family and people who they grew up with and love so I feel like when they are home that's where the better opportunity is. "'- Participant 12, Group 8

"Agree with \#12. I go to church all summer and came here and kind of looked around for a church. I was baptized greek orthodox but later I would rather go to an Assemblies of God church. I liked that better. My mom was in that kind of church when she was younger. I went here a couple times but it didn't feel like my home church. Everything was the same, but it still wasn't my church. Home you know everyone."'-Participant 11, Group 8 


\section{Volunteerism and Philanthropy (Kappa .97)}

The emerging adults in this study expressed three different viewpoints on volunteerism and philanthropy while at college. First, some students expressed cognitive reasons to volunteer and used volunteerism as a means to connect to the University and the surrounding community and as a path to personal growth. The second set of students expressed general apathy toward volunteering and would only do so when forced to either through sanctions imposed by the University for policy violations (the issue of forced participation is discussed in greater detail below). The final group participated in formal volunteer activities as a requirement of their major course of study. Both force and required service learning represent structural aspects of volunteer participation.

"I think they only volunteer if it is a requirement. Extra credit. I work with the boys and girls clubs and the only reason they volunteer is if they are with a fraternity or sorority."- Participant 3, Group 3

"I've seen a big influx of student volunteers, talking about student volunteer work. I believe if there were more opportunities, you would see more volunteering and stuff. But that's just from the new student's point of view."- Participant 4, Group 9

As with participation in other formal activities, this group of participants most often did not continue volunteer activities in their hometowns after leaving to attend college. The importance of volunteerism at home was mixed. Several participants indicated that they participated in volunteer activities at home (when in high school) as a means to improve their chances of college admission. Others talked about the relationship between volunteerism and religious participation. Finally, some saw volunteering as a more informal event involving helping out neighbors when needed, but not as a formal activity of collective action. 
"I think it meant more to me in high school, I did a lot of volunteer stuff in high school, I enjoyed

it. I don't have motivation now. I volunteered at the humane society. Transportation here, unless I can get my sister to take me and she's to difficult to. "- Participant 1, Group 3

"I joined a catholic church here, and go to one at home, and to go through confirmation you have to have a bunch of community service hours. Obviously the idea is to get you hooked on it, and so after that. I love volunteering, in my hometown in general. If there was a needy family someone who went to our high school went to Afghanistan and got shot and was paralyzed and so the entire community came together for that."- Participant 3, Group 4

"[At home it is] just a smaller neighborhood and I'm trying to think of what I'm trying to say... I'd say people back home are kind of ... there not really going and looking for people that need help and there not required to do it like some people are up here. Random acts of kindness week, supposed to be kind this week."- Participant 4, Group 5

\section{Civic Engagement (Kappa .97)}

Civic engagement includes the participation in formalized political activities such as voting, participating in rallies, writing editorials and civic officials, and campaigning. In this group of participants, most were interested in participating in national elections, such as the general election for president, and thought their vote was important, but were unable to vote in the 2008 election because they were too young. One group indicated that they did not feel that national elections were geared toward college-aged individuals and that most of the issues being debated were pertinent to older adults. They indicated that if they were to vote, they were more likely to do so at home because they felt more empowered and informed (cognitive). They often knew local candidates personally (if from a small community) or felt more informed about issues relevant to their hometown communities.

"I would be more apt to vote in my hometown than here because I know more of what is going on and what vote is going to effect something."- Focus Group 4, Participant 4

"I don't really know anything about politics. If I was old enough I would have voted for the president, I don't even know who I would have voted for but I would have voted."- Focus Group 4, Participant 8 
Several students indicated that they were members of student political groups such as the Young Democrats. The focus groups happened to coincide with campus student government elections and students were aware of active campaigning at the institution. They indicated that they were more likely to vote if someone they knew personally was running for student government office, but were willing to sign a petition to get someone on the student government election ballot regardless of whether or not they knew them personally. However, when asked if they knew what the student government of the college did, almost unanimously, students did not know. Generally, they did not feel empowered to write or approach elected campus officers with their concerns or feel empowered through them to make changes at the University level. On yet a more localized level at the campus, those who lived in residence halls did feel empowered to approach their hall council should an issue arise (structural). Finally, of note, none of the students who participated in the focus groups who lived off campus participated in neighborhood associations or political action groups in the local community within which the University is located.

\subsubsection{Informal Participation (Kappa .79)}

Informal participation is the time spent in informal social situations with peers, neighbors, and family. Generally, there was little difference between the time participants spent with others in informal social situations at home and on campus. They spent more time with family at home, but time with peer groups at home and on campus were very similar. Participants spent time going out to eat, shopping, playing video or board games, watching television shows or sporting events (including televised University sports), doing recreational or outdoor activities, and "partying" with friends. 
Informal socializing in which alcohol or other drugs ("partying") played a central role was employed to meet people and build social networks in a parallel manner to formal participation on campus. These cognitive outcomes of participating in alcohol related activties is highlighted by participant 5 from focus group 8.

"My biggest mistake was to not join anything. I should have joined a fraternity or something. The only way I met people was through parties which I don't really like going to. When I met them at a party they were the type of people who just wanted to go out to other parties. Keg parties, clubs, bars, whatever. I didn't want to do that I at least want to go to a restaurant or Starbucks, whatever."

Participant 10, from the same focus group concurred.

"People don't feel comfortable around me if you are there and not drinking. I was like if they aren't comfortable with me sober then what's the point of being friends with this person. I just want to make friends that didn't want to just go out all the time. If I meet people there that's all they will want to do and it wouldn't be a good relationship for me."

A participant from focus group 7 suggested that using partying as a means to meet people is a

transitional pattern of behavior that is outgrown as students mature. Instead, informal socializing is a way to structurally maintain social networks of already established peer groups.

"Granted there are people underage, go to clubs or house parties and go to socialize and drink, whereas upper classman can have a set group of friends vs going out to meet new people. Like, might get together with a smaller group and hang out, watch football or basketball and just drink, not get obliterated for the night."

Therefore, the cognitive rewards from alcohol and drug use experienced as new students, feeling like they are part of a shared experience, may transition to structural rewards as the students age, a way of maintaining relationships.

\subsubsection{Norms and Values (Kappa .94)}

Shared norms and values of a community is one of the central tenets of social capital, and is primarily cognitive. College students come from diverse backgrounds and experiences, but 
most expressed that they hold on to the values of their hometowns and families. Hometown values focused on working hard, valuing an education, future employment opportunities, and family. However, some talked about a dual set of values- one at home and one at school.

"I don't know it would be close for my hometown but its totally different types of values, basically. Honestly, like two completely different types of values like how I would act like in school... and how [in] my home town." - Participant 3, Group 6

"I don't think it is so much that your values are changing but when you come to college you are out from under your parents roof and you are moving into your own beliefs and everything rather than what they have pushed on you your whole life. My parents were fairly free with me, let me do whatever I wanted, let me make my mistakes. I don't think I have changed that much between high school and college."- Participant 16, Group 8

"Um, I'm basically like I've had other qualities from home and here and it's pretty equal. I did bring a lot of what I learned at home on how to be respectful. In my household you learn to be respectful. You don't judge someone for what they look like or how they act. I brought that up here with me and that's probably why I have so many friends."- Participant 4, Group 9

"Most of us realize that you are in college once and most people think it's the best time of your life so.... make the most of it while you're here. Make a lot of friends. Socialize and go out, have fun. Whatever their definition of having fun is." -Participant 6, Group 7

For students from small towns, they consistently talked about the size of the school feeding into the collective norms and values of the University community. At the University, they felt the size of the school allowed for a certain anonymity in which values from home may be overlooked and reflected in behaviors such as partying or drinking that would not be appropriate in the hometown. Perceptions of increased informal social control in hometowns, as residents and neighbors that were more likely to gossip or share information with parents tended to keep behavior in check. We explore this more in the discussion section on personal relationships.

We also wanted to explore if there was a shared set of community values for the University that are integral to the development of social capital at the institution. Here, 
participants talked about the need for "stories" to create a collective identity and shared

experience. Sporting events, drinking and partying, and negative/odd experiences on the school's

transportation system were all events that students could talk about and identify with. For them,

this led to being able to meet and connect with people faster in order to build their social

networks. This exchange from Focus Group 3 illustrates the importance of "stories:"

"I feel like most of them, I don't like saying most of them because I know a lot of people who care about school, most that I have interacted with, really don't care about class so much. I have a lot of my own friends skipping class... They just don't care so much about school and it's more about partying....I just don't think people care about coursework and it's all about partying.

Who is best at beer pong."- Participant 1

"In the two years I was in a dorm I noticed people just carrying on, going out, partying. One of my suitemates was on a full ride, she got money from the state, over twelve grand to pay for her schooling and she finished the semester with a .04 GPA. It's just aggravating."- Participant 3

"You said something that intrigues me, they want to impress?? Tell me more about this."Moderator

"My roommate has this one friend who will see things or act a certain way to impress him to show that he is of his same stature. Same level of intelligence. Money, or something like that. He completely changes with this one person. My roommates will do the same thing with certain people. Talk differently, say different things. I guess they were trying to have them like them more, faster, so they can have a relationship with them but it is based on fake versions of themselves. I hate it." - Participant 3

"So do you think that's important? Especially as a student. Everybody is new, so do you think that being able to develop those friendships and ties really fast is important?"- Moderator

"I think if you develop them fast it should be because you are real. If you are not real it's not going to be a lasting friendship. I had a friend my freshman year and we were really close but she would flip personalities. She would be your best friend and then be talking behind your back. I just couldn't take it anymore. I don't think there is pressure to make the friendship fast, the desire to constantly do something and be on the go and have that story."- Participant 3

"Why are the stories important?"- Moderator

"So you can share with people, so they don't think you are loser that sits at home. I don't know. No one wants to sit home on Friday night."- Participant 3 
Finally, although drinking and partying came up frequently across the focus groups, it is important to note that not all students shared this as a community value. Instead, they talked about the diversity that attending a large institution affords and the value of a good education.

"Well, in my classes I do have a lot of diversity. People are all over the place. I am just more like not really open but it helps me to get to know other people a lot better." Participant 4,

\section{Group 9}

In the same way participants talked about a maturing effect with drinking in the informal participation section of the focus group, in talking about values, they also expressed decreased lack of interest in alcohol and more focus on education as they became upperclassman.

"It depends on the year you are in college. As a freshman it seemed like everyone was going crazy with their freedom and partying was the only thing they could think about... Now that I am a grad student and have a lot of classes with people who are masters or even PhD students, I realize the value of the academics is still there, it's just kind of lost."-, Participant 8, Group 8

"I do agree with her. Nobody takes it seriously when I say I go to [the University]. Do you like to party, is that why? Or sports? Never for academic reasons. I hate that. I hate the fact that we are the top ten party schools, known as a party school. I am really glad that we are becoming more academically known... We should continue to just go down [as a party school] and academics should go up."- Participant 5, Group 8

"I say this because I'm a senior and I feel like I am in this all the time I guess it's a sense of like excellence and greatness in everything you do. It's not just going to class and studying hard but it's in the classroom and what's outside of the classroom, like looking out for people and making the most of the complete college experience. Becoming, maturing and learning about yourself and other people. Diversity, getting to know a bunch of different things not just being inside one little bubble. "- Participant 10, Group 10

\subsubsection{Informal Social Control (Kappa .84)}

Informal social control is often interpreted in relation to social capital constructs as applied to children and is primarily a meso-level structural element. It was explored in the focus groups to see if it was salient to emerging adults as well. Informal social control is the extent to which neighbors work collectively to maintain social order, such as delinquency of children in 
the neighborhood. It included the extent to which neighbors disciplined children, called parents when children misbehaved, and reported delinquent behaviors. Almost uniformly, participants in the focus groups expressed that they would not report residence hall policy violations or report neighborhood disturbances to local or campus police at the University. When probed to try to ascertain if there was any circumstance in which they would directly or if they perceived that their neighbors would intervene in such situations, students replied that the violation would need to be serious, but would not provide an example of a serious enough offense to condone reporting. They expressed that acting out, through noise late at night was considered normal college student behavior, that they could just as easily be the violator, were afraid that they might damage delicate relationships with new roommates and friends, and students who did report violations were often seen as "rats." The one exception seemed to be a participant who had a personal relationship with her resident assistant. When asked if the same applied if they lived in off-campus neighborhoods, most participants indicated that they lived in a college town and neighbors should accept late night parties as par for the course or live in non-student neighborhoods of town. In their hometown, however, participants gave mixed reactions when asked if they or their neighbors would intervene in situations in which someone was breaking a law, or being generally delinquent. While none indicated that they personally would intervene, many indicated that their parents would. Others reflected the idea of damaging relationships should they or parents intervene in unruly situations or creating a situation in which disagreement or violence might escalate. Finally, several participants agreed that neighbors would alert their parents or talk with others about their behavior if they were perceived to be doing something of which their parents would not approve. 
Although informal social control seemed to have little importance to these college students, several of the groups talked about a non-traditional mode of informal social control, using social networking sites on the Internet to monitor others behavior. They also indicated that parents and older adult relatives and friends monitor their behavior online. Conversely, they talked about how they in turn monitor the behavior of friends and younger relatives.

\subsubsection{Intergenerational Closure (Kappa .84)}

Intergenerational closure refers to connectedness to adults other than one's parents.

Coleman introduced the concept in his research on educational outcomes in children. ${ }^{24}$ Although not traditionally measured in adult studies of social capital, because the development and maintenance of social capital in emerging adults is not well understood, we examined intergenerational closure within the context of college students' lives. Participants expressed maintaining close relationships with older adults and mentors from their hometowns, but very few indicated relationships with adults on campus. There is a fine line between "other adults" and "peer group" as these emerging adults transition into full-fledged adulthood.

\subsubsection{Trust and Reciprocity (Kappa .91)}

Trust and reciprocity refers to the belief that neighbors can be trusted and relied upon to provide instrumental resources if needed, it includes both cognitive and structural elements. Trust was described by students (independent of context- home or campus) as being related to the familiarity with neighbors and friends. If they "knew" them, they were more likely to trust them. This is described in further detail in the discussion section, personal relationships below.

Reciprocity is a structural element and refers to the willingness of neighbors to share resources and goods with one another. Participants expressed a willingness to share items with 
neighbors on campus in fairly specific situations. They would loan items to neighbors that valued under $\$ 10-\$ 25$, but did not generally trust neighbors with items worth more either monetarily or personally. The one exception seems to be vehicles. Participants expressed willingness to loan and borrow cars when transportation was challenging. Participants also said that they were more likely to share with on-campus residence hall, house, or suitemates than those who lived in off-campus neighborhoods. They were willing to share class notes and books, but only with those that they knew well. They said that they would make copies of class notes, but would not be likely to share originals. This exchange from Focus Group 3 illustrates a common theme:

"I agree. The people that I live with and the people at the international house I trust them, but in terms of being in a classroom and someone wanting to borrow my notes. I tell them I will make a copy but they aren't taking my notebook. I guess it's just in cases where I'm not good friends with someone." - Participant 1

"I agree. They forget to return your books. A week later I'm asking for them back."Participant 3

"So with course stuff you are more protective?"- Moderator

"Yes."- Participant 1

\section{"Because it affects you more."- Participant 3}

Some of the participants indicated that they would be more likely to ask for help or borrow items from people in their hometowns, particularly family members. This was expressed most among students who were from small towns. In addition to tangible items, they were likely to seek emotional support from people in their hometown communities.

\subsubsection{Social Support Networks(Kappa .68)}

Social support generally refers to the ability of individuals to utilize connections in their social networks for help when needed. Social support is a structural construct that is often 
challenging to operationalize, yet is often linked to improved health outcomes and general wellbeing. ${ }^{144-146}$ In 1981, House introduced four primary types of social support including appraisal, emotional, instrumental, and informational. ${ }^{146}$ Appraisal support refers to the feedback individuals received from others in order to self-evaluate and as social comparison. Emotional support is often the type of support that students considered first when asked about social support. It includes the concern and caring among individuals. Instrumental support is salient and tangible support in the form of money, items borrowed, or time exchanged among individuals. This type of support is described above as reciprocity and will not be discussed further in this section. Finally, informational support includes advice or recommendations specific to a situation.

Participants in this study were asked to describe who they rely on for support and what types of support they receive in order to explore the facets of social support, however, in almost every other discussion point explored, social support or the development and maintenance of social networks came up. This is discussed further in the personal relationships section below. For the purposes of this section, we will limit the description to who provides support and the types of support that are provided by others. We believe that the Kappa score is less for social support than the other constructs of social capital (although still acceptable) because it is so diffuse and discussed in multiple categories.

When asked who they rely on for support, many of the participants said that they were most likely to rely on people from home. This included parents, siblings, other family members, peers, high school teachers, coaches, clergy, and occasionally neighbors. Parents and other family members were relied on to provide emotional support. 
"... I would go to my father... Just to talk. Even if it's just to complain. My dad would complain back to me. I just got called out again, he complains too!"- Participant 3, Group 3

"I guess mostly family members. Always count on, don't know if I have any friends that are that close, yeah I guess I would like to say that maybe I know they may not always be there, but family will always be there."- Participant 6, Group 7

Peers, high school teachers, coaches, and clergy were more likely to mentioned as a source of informational and appraisal support. The following excerpt is from Group 6.

"There are a few neighbors down the street I became friends with their son when I was like 2 years old. Our parents became really close friends so I feel like they are pretty much a second family to me. I have another neighbor that is the same way. I have three families I can come to if

I need help or am struggling with something they would be there for me."- Participant 12

"Probably my coaches back home"- Participant 1

"Some of my teachers from back home I'm so close with like I visit on breaks and I would go to them - Participant 2

Few participants offered people on campus as people they rely on for support until prompted to think about it. Peer groups, on-campus staff (such as resident assistants or advisors), and professors were mentioned as sources of support. Peers were cited as providing all four types of support. Professors and campus staff were most often mentioned as providing appraisal support (academic), and informational (offering advice on classes), although this was expressed most often among upperclassman. Participants also utilized online resources, campus calendar, and social networking groups (specifically Facebook) to find information on formal and informal events. However, repeatedly, participants indicated that who they would go to for support really depended on the problem they were facing as illustrated in Focus Group 1:

"It all depends on what kind of problem it is"- Participant 8

"Tell me more about that"- Moderator 
"I don't know, it like depends on how personal it is or I don't even know how to explain it"Participant 8

"Like if it is something pretty superficial, like especially if it is something about the University, I will ask one of my friends here that is in a grade above me or something, but personal problems I always go to my friends at home"- Participant 3

"I feel like if it's a problem that one of my friend's has experienced before, I would go to that person"- Participant 8

"I agree"- Participant 5

"It's not a matter of (location), because they are just a phone call away, it's a matter of what they can help me with"- Participant 2

Although participants did not cite on-campus social support until prompted, as mentioned above, the idea of social support was interspersed throughout the entire discussion. Participants used formal and informal participation when they arrive on campus specifically to build social networks and presumably to be able to rely on those networks for support. Trust and reciprocity, norms and values, informal social control, and civic participation in turn were reliant on the social networks that students formed after arriving. This is explored in further detail in the discussion section on personal relationships.

\subsubsection{Endogeneity (Kappa $=.94)$}

One of the primary limitations of trying to understand the mechanisms by which social capital emerges and is sustained in a community is endogeneity. Endogeneity refers to the potential for individuals to choose the community to which they want to belong and relocate to be a part of that community. This is a particular concern when trying to apply social capital theory to the experience of college students. College students and their families "shop" for colleges in order to find the financial, cultural, and educational experience that best suits their needs and desires. In order to explore endogeneity in this population, we asked why students chose this University and who helped them to make that decision. 
Reasons for college selection included proximity to home, family traditions, cost, school atmosphere, sports tradition, and academic opportunities. The most frequently cited reason for attending this University was that it was close to home and family, but far enough away that it seemed like a new experience.

"My parents don't like the idea of me going far away. I am the first person in the family to go out of state college. I have a huge family. A lot of my aunts and uncles want their children to go to closer colleges, like ANOTHER UNIVERSITY is only 20 minutes. My parents wanted me to go there because they wanted me to be home. I've been living with them my whole life, for once I just wanted to be by myself, learn to live alone and not depend on your parents."- Participant 5 , Group 8

There was also a strong support for attending the University because a family member was alumni. As one participant said, "I've always wanted to come here since I was little...more of a family thing because my mom and a lot of my cousins came here." The relatively low cost, school atmosphere, well-known sports teams, and academic reputation of the school were also mentioned as reasons to attend.

"Honestly, the party reputation probably had a little something to do with it, I'm not gonna lie. Basically, [it was] in-state and I wanted to go to a big school"- Participant 6, Group 7.

"The atmosphere, it feels like home" - Participant 1, Group 7.

\subsection{Discussion}

While there were differences in how participants in this study accessed social capital depending on if they were in their hometown or campus context, the underlying reasons why and how they accessed social capital channels and mechanisms had similarities. In the exploration of each social capital construct, the emergence and maintenance of social networks was a central theme regardless of context, and all of the social capital constructs explored were integrated into 
cultivating or maintaining social networks and support. This supports Carpiano's distinction between social capital and social cohesion. ${ }^{39}$ Students used participation in activities (formal and informal) to develop social networks on campus. They simultaneously maintained social ties between individuals at home through frequent communication through multiple channels, specifically technology such as cell phones and the Internet. The data supports that the social networks are not necessarily viewed by students as a mechanism to create "collective action" or greater good for the community, but they primarily use those ties to facilitate their own growth and development. Social capital ultimately moves beyond the individual to a community infrastructure that supports collective action and identity.

In relation to Putnam's concept of social capital, the University affords students an opportunity to join and actively engage in hundreds of established social organizations and clubs, or create one based on interests if it does not already exist. However, the findings of this study more rigorously support the theoretical construct of social cohesion as introduced by Carpiano. Social cohesion as defined by Carpiano stress the development of individual connectedness to community, familiarity, and shared norms and values as the "foundation for establishing social capital within neighborhoods" (p.168) ${ }^{39}$ How social cohesion is developed within the context of personal relationships and the connections to the University are discussed at length below.

Participants continued to maintain ties not just with family members, but extended social networks at home and relied on them for support. This is an indication that Coleman's conceptualization of intergenerational closure extends beyond childhood into the experience of emerging adults. ${ }^{24}$ Figure 3.1 illustrates the complexity of how participants developed new social networks on campus while maintaining ties at home. As described in the personal relationships section, developing and maintaining these social networks were critical to the development of 
social capital infrastructure. Two types of student emerged, those who fully embraced the college experience and those who were attending school with the intention of going "home" when their educational goals were attained. Participants who were able to develop personal relationships either with people on campus, or cultivate a University identity (shared norms and values), expressed a greater likelihood to embrace the college experience. Personal relationships increased trust and reciprocity, informal social control, and participation in informal and formal activities at home and on campus. Conversely, students who expressed a desire to "go home" when they completed college expressed strong ties to home that were maintained throughout their educational experience. They used a variety of avenues including continued participation in formal and informal activities in their hometowns, frequent contact with members of their social support system in their hometown, and frequent visits home to maintain ties.

\subsubsection{Personal Relationships}

Personal relationships were a key theme throughout the focus group discussions, and represents the essence of cognitive rewards related to social capital. How student participants described their experiences of many of the social capital constructs, whether at home or at the University, were framed through personal relationships and social networks. This indicates a strong influence of the cognitive elements of social capital for this population. Students indicated that when they initially came to the University, they sought out others from their hometowns, students with a shared history and understanding of home. These relationships tended to be maintained throughout the course of the academic career and often lead to broadening social support networks, opportunities for engagement in formal and informal activities based on shared interests, shared norms and values, and a way to maintain a tie to home. This exchange from Focus Group 2 illustrates the hometown connection. 
"I'm from CITY, and it's like far, but there's actually a lot of people from like my area. Like XXX's from my hometown sort of, but we didn't know each other before we came. So, I feel like connected to people from home here." - Participant 7

"Same here." - Participant 8

"I meet a lot of people who are like...oh, I am from this part of STATE. You just feel closer to them because you know, like, where they are from."'- Participant unknown number

"I'm from a smaller town so like you try to grab that quirky thing. You may not have been in the same clubs and stuff in high school or activities but you can talk about how the band played at

Wal-Mart when Wal-Mart opened. Laughter. Just like silly things you can relate to"Participant 3, Group 4

Not all connections made to hometown peers lead to increased connections within the University. They can prohibit making external connections that could create bridges with new and unique social groups and experiences.

"From where we are from, a lot of people from my hometown and the area are down here, so we haven't really met that many new people or joined any clubs. Our close group of friends from back home are pretty much all together and live in the same dormitories." -

Participant 5, Group 10

“Do you feel like you're a part of WVU's community?- Moderator

"Nah, probably not I kind of just stayed in my own little group with my friends [from home]and I don't really go out or anything so I stay probably in my own little group."-

Participant 5, Group 5

Although most of the participants said they would vote in national elections (if old enough), generally they indicated that they were more likely to engage in civil activities such as voting in local (home) or school-based elections if they had a personal relationship with the candidates. If they planned to vote, they planned to go back to their hometown to do so as opposed to registering to vote in the county within which the University is located. Consistently, they felt more familiar with the issues and candidates in their hometown communities. Also, they did not necessarily feel empowered to manifest change through elected officials, regardless 
of hometown or campus context. Most did not understand University or local officials' roles or how to contact them. At a local level, they did not feel empowered to facilitate change in their residence hall unless they had a personal relationship with a representative on the Residence Hall Council. They did, however, speak to a willingness to sign petitions regardless of the manner of the relationship with candidates or causes.

"Being a freshman, I don't know that many people or anything. My high school was such a smaller amount of people by far, so I knew everyone that was running. I would definitely be more involved in my old high school setting than this. I actually plan to vote because I do know one person!'- Focus Group 4, Participant 4 on the upcoming Student Government Elections at University.

"If somebody needs help, I'll sign the petition"--Participant 8, Group 2

Almost unanimously, they expressed a reluctance to intervene (informal social control) with neighbors in on campus residence halls or off campus housing. Because of the nature of college, issues like partying in neighborhoods and noise late at night are generally considered par for the course and even when students wanted to say something, there was unspoken social pressure not to intervene.

"Roommates that you don't know, the first time, you are extra courteous. I don't know this person, I've never lived with them, and you don't want to invade their space. I don't want to get involved. I'd rather have them not hate me than 15 minutes of peace before they start up again."'- Participant 10, Group 8

Also, within the on-campus University housing system, as with most colleges, resident advisors (RA) act as a formalized system of social control. This highly controlled environment includes rules and regulations meant to enhance and control shared community space. Participants shared mixed reactions about going to RA's if they had problems with neighbors. Some expressed having good relationships with RA's, others saw them as semi-parental. 
"And they [RA's] are seen as disciplinary, and also as, like a nanny because they are there for comfort, discipline and questions."- Participant 4, Group 9.

"I think most people in the dorms pretty much have each other's back. I don't necessarily think it is a good system, but if anything happens, they are usually not going to report it to an RA." Participant 12, Group 8

However, at home, where they have known neighbors for a long time, they expressed an increase of informal social control, either through rumors, direct intervention, or calling parents to report behavior.

"I had someone call my house last year. I am on the track team so I like to run.... I had a lady call my house asking for my parents with this severe urgency. Like something horrible had happened, but they wanted to tell them I was running in the dark and it was not safe."Participant 10, Group 9

“Would your neighbors intervene at home?”- Moderator

"I think definitely yes, because they have been there for like 30 years, so they know the area and they know who they don't recognize. Here [the University] everyone is new, so they don't know what is going on." Focus Group 4-Participant 3

Intertwined with informal social control, the perceptions of shared norms and values differ between hometown and campus. Shared norms and values of a community is one of the central tenets of social capital. College students come from diverse backgrounds and experiences and have varied norms and values that they bring with them from home. Several groups in which the participants were from small communities expressed that the anonymity that a large University affords tests the values that students shared with family and neighbors at home. This exchange from Focus Group 5 highlights the differences:

"[Our hometown values are] to help each other out. I don't know always help your neighbor out, or I usually do.... There's a lot more older people home I guess. The values would be a little bit different because the age difference. Up here there's a lot of younger kids and drinking isn't really considered bad but back home if you just stay drunk, then, well, people are gonna get mad."- Participant 5 
"Yeah, definitely. Also up here, people kind of seem like they don't care too much what they do, but back at home, people actually care about what you do and what you say."- Participant 4

"Here you have kind of like a hidden identity where it's like 30,000 kids. You can do something and they will be like, they might not remember you. Back home, if you do something, they're going to know."- Participant 5

"Because where we live, if you do something, then everybody's going to start talking about it and everyone will find out."'- Participant 4

Finally, the level of trust and reciprocity for and between neighbors at home and at school was expressed in terms of the nature of personal relationships. Most participants expressed that they were more likely to trust neighbors, borrow things from them, or lend them items from home than their neighbors in their University community. They were also more likely to trust them with personal issues and solicit advice for anything other than University issues. Repeatedly, students said of their University neighbors, that they would only trust the ones that they knew well and would not loan to or borrow from someone that they did not know well. Most said that they knew their most proximal neighbors the best and those who did not live in adjoining rooms or apartments were virtually unknown to them.

\section{$\underline{3.4 .2 \text { Force }}$}

Although Putnam described engagement in community activities as a primary focus of social capital, and hundreds of opportunities to become involved in clubs and activities with shared interests on college campuses, in describing aspects of formal participation at the University, the issue of "force" was a consistent theme. This was especially true of the participants who lived in on-campus residence halls. Colleges often mandate that students live in on campus residence halls the first year in school, participate in orientation activities or "first year experience" activities, and take courses such as University 101 (a mandatory freshman class meant to introduce freshman students to University life). These mandated activities are meant to 
integrate students into the University community, contribute to a shared experience, facilitate the development of social networks, and foster academic excellence. Students in the focus groups, however, often described being forced to participate in hall meetings, social events, and to get credit for University 101. About half of the participants described their volunteer activities as either a requirement for a major or due to a disciplinary sanction. Social capital, by definition is a function of voluntary (as opposed to hierarchically imposed) associations, therefore, "force" in this context is an interesting finding that may impede development of structural relationships in this population. ${ }^{38,47,48}$

"You don't really go to community service by choice, you normally are forced to do it."Participant 6, Group 1

Although these forced situations were generally described as unpleasant, the participants did occasionally state that participation in the forced activities increased connections to others in their communities.

"Um, we have the honors 199, which is equivalent to the University 101, but lots of people complained but I liked it. Go over adjusting to college. It was really beneficial I thought."Participant 4, Group 4

\section{$\underline{3.4 .3 \text { Sports }}$}

Much University identity development revolved around participation in events for sporting activities. The University has an intergenerational sports tradition. When students initially arrive at University in the fall semester, football was a way for students to connect to the greater University community. It was a common interest that celebrated the connection to the University and instilled a sense of community and school pride. Often in-state students grew up rooting for University sports teams and watching football or basketball games were a family tradition. 
It wasn't really my parents influences, it was more my uncle telling me about it and just decided to come.- Participant 4, Group 10

"What did he tell you about it?"- Moderator

"[Football] games and everything in coming here and visiting the games and all that stuff.", Participant 4, Group 10

Outings to sporting events were often community events and it helped new students to transition into new social networks with peers. Also, when students are away from the University, school recognition and pride helps students to feel connected.

"Depends on the person and own circumstances and actually getting involved with the campus once you start going here. It took a while, you start to get involved in clubs, activities and sports. After going to like football games and stuff like that you actually take on the persona of being a University Mascot! It grows on you."- Participant 10, Group 10

"Going to the football games in the beginning kind of got us a lot close and like who your going to hang out with and that was like the good experience everyone got everyone got dressed up and went and had fun together."- Participant 2, Group 6,

"I feel like the University community is pretty awesome. Anywhere you go there are people from $W V$, all around the country and even the world. Well, I don't know about the world but the country. Like when you are riding on buses there are chants against other teams and for your own team. Even if you don't even care about the game, they are still chanting-laughter." -

Participant 8, Group 4,

Sometimes, when students did not embrace the sports culture, they often found it difficult to connect or become involved in University culture. This excerpt from Focus Group 9 illustrates the conflict:

"I haven't really done a whole lot yet." Participant 3

"Are you interested in doing stuff but haven't found anything to do?"- Moderator

"Yeah, just haven't found anything to do yet. I mean I didn't really want to go to any of the games, not a big sports fan. It's still fun to go to but either didn't know there was a game, missed the ticket or whatever." - Participant 3

3.4.4 Social Networking on the Internet-The Paradox of Facebook 
Any discussion of social capital in the $21^{\text {st }}$ century cannot overlook the growing importance of online social networking. In nearly every focus group, students became more engaged and animated during the focus groups when questions centered on how they used online social networking sites such as Facebook, MySpace (to a much less extent), Skype, and Oovoo, to connect or stay connected to others in their daily lives. Social networking websites did not just reflect traditional ideas of bridging and bonding social capital through social support, they also provided mechanisms by which students became actively involved in the political process, found out about organized activities at home and on campus, practiced informal social control, built trust and reciprocity, and developed a shared sense of community norms and values. This is consistent with findings by Kerr that showed Internet usage generated new structures through which individuals could connect and engage in civic activities ${ }^{84}$. Social networking sites made it possible to share multiple contexts, to live and experience college and hometown simultaneously, even when not proximally viable. Although the purpose of this paper is not online social networking, it is impossible to talk about social capital in this modern age, without interweaving it throughout the conversation. The importance of social networking sites to this generation was summed up in a conversation that occurred in Focus Group 8:

“I mean, facebook is just like everybody's life. It's a problem when the first thing you do is get on facebook. If you are doing anything like homework, open the laptop and then go to facebook.- Participcant 14

\section{I do email, facebook and then homework.- Participant 7}

Facebook is pretty much the ultimate way to procrastinate. I also like was talking with some of my friend. A couple years ago facebook didn't exist and people were like setting their own way of experiencing college. People had to go through different ways, not always being connected to back home. They had themselves out there meeting new people and not always be associated with the drama that goes on back home. Sometimes I feel like it takes away from the experience and you should try and stray away from it. That's really tough, because I can't. I don't know.Participant 12 
I guess I talk to my high school teacher, he brought it up how networking has ruined the college experience. When you go to college you should stray away and make your own path and leave the past behind. - Participant 14

I actually think the networking is a positive thing. Facebook got really big, probably my junior or senior year of high school. Originally it was just college kids. When I started out in Kentucky the first guy I dated we were part of a mutual group on facebook. I never would have talked to him because he was in a different building."'- Participant 16

Swenson and colleagues found support that for the hypothesis that college students who maintained attachments to friends from home had a harder time adjusting to their college environment than those who made new college friends that they judged to be trustworthy and loyal. ${ }^{81}$ As described in the Internet social networking section above, modes of communication such as Facebook and MySpace make it easier for students to continue ties to home in ways that were not possible ten years ago. In another study by Stevens Aubrey and colleagues, Internet social networking sites (specifically Facebook) was found to be associated with greater capacity for online social capital, but this did not translate to offline bonding or social network capital. ${ }^{85}$ In fact, continued connections to home and lack of offline social capital may impede the development of social capital beyond social networks and social cohesion.

Interestingly, although informal social control was not particularly relevant to these groups in "real life," it was mentioned frequently when Internet social networking was the primary topic. Participants talked about "cyber-stalking" friends and family from home to see how their lives changed. They also talked about how older family members (parents, aunts, uncles) used social networking sites such as Facebook to monitor what they were doing at college, and that they in turn would often monitor younger family members (siblings, cousins) behavior through posts and photos. 
Participants also used Internet social networking sites to find out information about events around campus such as locations bar specials, parties and informal events hosted by friends, events hosted by the University, and study groups. They talked about getting social support from their Facebook network in all four forms. Finally, they would use Facebook to arrange borrowing or loaning class notes and sharing information about assignments.

Internet Social networking sites provide students with an easy and efficient way to stay in touch with their social networks both at school and at home. They are able to maintain relationships from home, even some that would be nearly impossible without the mechanism of access and ease of use, with immediate and extended family members while cultivating new networks with "friends" on campus. It is often seen as a double-edged sword and students feel more connected and less connected at the same time. Focus Group 10:

"When I had it I liked it because my mom has like ten brothers and sisters, so I have lots of aunts, uncles, and cousins. Most of them live like out of state. A lot are in STATE, STATE, STATE. I feel like I can get on and talk. We see them once a year for a reunion, but I can send a message on the chat and talk for a little bit. I feel like I got to know some of my cousins more through that. I never talked to them before till then."- Participant 5

"Agrees, but at the same time I feel like it disconnects you from people that you are close to. I know there have been times when it's like the weekend and people that I know that live around here, and aren't doing anything, you get on facebook and they are on. Instead of going out you just talk on facebook. Makes you lazy and stay in front of your laptop instead of going to see the person. Impersonal relationships."- Participant 10

\section{$\underline{3.4 .5 \text { Connections }}$}

Within the groups there was a strong sense of campus identity and nearly uniformly, students expressed a connection to the University both on campus, at home, and even when traveling. The connection to the University was felt almost immediately by participants and often developed long before they arrived on campus. However, participants often made a distinct 
separation of the University and the town within which it is located. Although they felt strong connections to the University, they did not necessarily feel the same way about the surrounding community. They also expressed that as their time at the University grew, so did their feelings of connectedness to it. The bonds to the University were lifelong, while their ties to the community surrounding the University was transitory. See the exchange from Focus Group 10 below as an illustration:

"Here. Like, I guess because I have been away for so long. I do go back and forth during breaks it seems like every time I go back there is something different, and when I come back here it just feels more like home."- Participant 10

"Thinking back, did you always feel that way, or did it happen over time?"- Moderator

"I think it's something that happened over time. I know over my freshman year, that first Thanksgiving break and winter break after everyone went away and came back, we felt like we were still in high school and it was just another day and we went on vacation and were excited to tell everyone where we had been. And then another year, and year after that, it got to the point that everyone was so focused on doing their own thing like internships or getting ready for grad school, where when we came home the classes below us would take our place. All of the other classes would take our places. Even things in the community like new buildings or housing developments. It didn't even look the same. Every time you would go back it would feel different even though we call it home. I know some of my friends how we would say that we are going home but we meant our universities. I know when I am down in HOMETOWN I say I'm going back home but I'm talking about THE UNIVERSITY. Happens over time, when you close a chapter and open a new one. It's a process that happens. "- Participant 10

"[I] feel more connected here now but like she said over time I think I will be more connected here. In the dorms it is not the best place to live. You are there with all your friends. After I have an apartment it will become more of my home."- Participant 5

\subsection{Conclusions}

These results are not generalizable beyond the participants, however, they provide useful insights to help understand social capital in a college population. Traditional measures of social capital for adults and children may not translate to emerging adults in a college setting. A new set of valid and reliable measures needs to be explored. The development and maintenance of 
social capital among the participants had both similarities (modes of communication, participation) and differences (intergenerational closure, informal social control, norms, and trust) depending on the context (home or campus). Although this study is not generalizable beyond the study population, it does provide unique insights into the experience of college students and how the theoretical constructs of social capital are or are not relevant to that experience. It also allowed for the exploration of hometown versus campus social capital. The primary limitation of social capital theory in a college population is endogeneity, or the fact that students actively participate in the selection of the kind of campus community in which they want to be a part. In order to account for this limitation, endogeneity was explored with the participants of the study in order to better understand its role. Three points, key to developing accurate measures for social capital research among emerging adults, emerged from the study.

First, measures must account for dual contexts and differential access to social capital at home and on campus. Hometown social capital, although similar to campus social capital is still primarily filtered through parents and family in this group of participants. Although participants were able to maintain social support and ties to family and friends in their hometowns, when asked about social capital constructs such as neighborhood trust, informal social control, and shared values and norms, family was referenced by participants above community or neighborhood. It is only when asked about these constructs as they relate to campus that personal experiences were discussed. Therefore, separate measures for hometown and campus contexts are necessary, including questions about familiar ties.

Formal and informal activities were important to emerging adults to develop social networks on campus, and religious participation was cited as a way of maintaining key relationships with family and hometowns. Norms and values were applied differentially 
depending on context. Trust and reciprocity and informal social control were dependent upon the personal relationships and social networks of participants. Longevity of the relationships with hometown connections made trust and informal social control more likely in the hometown context. Intergenerational closure was a key feature in maintaining social capital and ties to the hometown and familiar communities and was facilitated by the ease and accessibility of social media.

Absent from the focus group discussions, until probed by the moderator, were themes associated with relationships with faculty and staff at the university. Again, although we cannot generalize beyond the study sample, this has significant implications for the university. Universities often make substantial efforts to encourage academic and mentoring relationships between students and faculty/staff. This university is no exception. The university's efforts include Resident Faculty Leaders whose goal is to "provide... support, guidance, and out-ofclass interaction with a faculty member," first-year seminar classes (the opportunity to work more closely with instructors and connect them earlier to their academic department or residence hall and the University at large), and academic advisors. Close evaluation of the success of these programs to integrate first year students, and to create connections with the university may enhance our understanding of this aspect of social capital development within the university itself.

Among the college student participants in this study, although there was a strong collective identity associated with the University, its traditions and history, primarily, participants used the infrastructure of formal activities (even those that were "forced"), clubs, sports, and resources in order to develop personal social networks, support and ties for individual over collective growth. Perhaps the social cohesion students were able to develop on campus 
was unable to continue to advance to social capital as an artifact of the limited time that students stay at the University. Academic institutions are typically four to five years for the undergraduate experience and may be too limited to progress to the next level. Upperclassmen in the focus groups were more likely than second semester freshman to express their role within the community as a means of collective action for the campus.

Second, theoretically, this study supports Carpiano's conceptualization of social capital theory in which social cohesion is a separate but necessary element in the development of social capital. ${ }^{39}$ It highlights the importance of the cognitive aspects of social support networks as across contexts. Participants repeatedly talked about building and maintaining personal relationships/social support which must be a key component to the operationalization and measurement of any study of social capital among this population. According to the responses from the participants, the structural function of delineated construct of social capital in Carpiano's conceptualization are not as salient in this population as the cognitive elements (social cohesion). In addition, Coleman's conceptualization of intergenerational closure does play an important role in maintenance of social capital and ties to the hometown social network, but it needs to be reworked for this population to account for the personal relationships that exist between emerging adults and other adult family members or trusted community members from their own ties as opposed to parental ties. ${ }^{24}$

Finally, the continuing importance of technology, including cell phones, texting, Internet messaging, and social networking sites cannot be overemphasized in this population in regards to the formation and maintenance of social networks and social ties. It is primarily through these channels that students gained and maintained access to resources and information that are the hallmark of social capital theory and should be accounted for in any study measuring social 
capital in this population. This supports findings by Ellison and others that social networking sites can function as an important channel through which social capital is maintained and developed, both among college students, and the general United States population. ${ }^{83-86}$ However, because the progression to social capital in this population was limited, it remains unclear if these channels continue to be important beyond the scope of the undergraduate experience and needs to be studied further. It is also unclear as to whether there are difference in race, gender, or socioeconomic status related to social capital formation and maintenance. The findings of this study can be used to facilitate valid and reliable measures of social capital in the emerging adult population in order to enhance studies in sociology, education, political science, economics, and public health. 
Table 3.1: Demographic Characteristics of Focus Group Participants

\begin{tabular}{|c|c|}
\hline Demographic Characteristic & n (\%) \\
\hline $\begin{array}{l}\text { Gender } \\
\text { Male } \\
\text { Female } \\
\text { Unknown }\end{array}$ & $\begin{array}{l}22(36.7 \%) \\
28(46.7 \%) \\
10(16.7 \%)\end{array}$ \\
\hline $\begin{array}{l}\text { Year in School } \\
1^{\text {st }} \text { Year Undergrad } \\
2^{\text {nd }} \text { Year Undergrad } \\
3^{\text {rd }} \text { Year Undergrad } \\
4^{\text {th }} \text { Year Undergrad } \\
5^{\text {th }} \text { Year Undergrad } \\
\text { Graduate or Professional Student } \\
\text { Adult Special }\end{array}$ & $\begin{array}{l}36(65.5 \%) \\
7(12.7 \%) \\
2(3.6 \%) \\
5(8.3 \%) \\
2(3.3 \%) \\
2(3.3 \%) \\
1(1.7 \%)\end{array}$ \\
\hline $\begin{array}{l}\text { Class Rank } \\
\text { Freshman } \\
\text { Sophomore } \\
\text { Junior } \\
\text { Senior } \\
\text { Graduate or Professional Student }\end{array}$ & $\begin{array}{c}35(63.6 \%) \\
8(14.5 \%) \\
2(3.6 \%) \\
7(12.7 \%) \\
2(1.8 \%)\end{array}$ \\
\hline $\begin{array}{l}\text { Living Situation } \\
\text { On Campus Residence Hall with One or More Roommates } \\
\text { On Campus Residence Hall Single Room } \\
\text { On Campus Family Housing or Apartment } \\
\text { Other On Campus Housing } \\
\text { Fraternity or Sorority House } \\
\text { Off Campus Housing with One or More Roommates } \\
\text { Off Campus Housing Living Alone } \\
\text { Living with Parent or Other Family Member } \\
\text { Other }\end{array}$ & $\begin{aligned} 39 & (70.9 \%) \\
3 & (5.5 \%) \\
0 & (0.0 \%) \\
0 & (0.0 \%) \\
1 & (1.8 \%) \\
10 & (18.2 \%) \\
1 & (1.8 \%) \\
0 & (0.0 \%) \\
1 & (1.8 \%)\end{aligned}$ \\
\hline
\end{tabular}


Figure 3.1: Social Network Development and Maintenance

$\begin{array}{ll}\text { Structural Cognitive } & \end{array}$

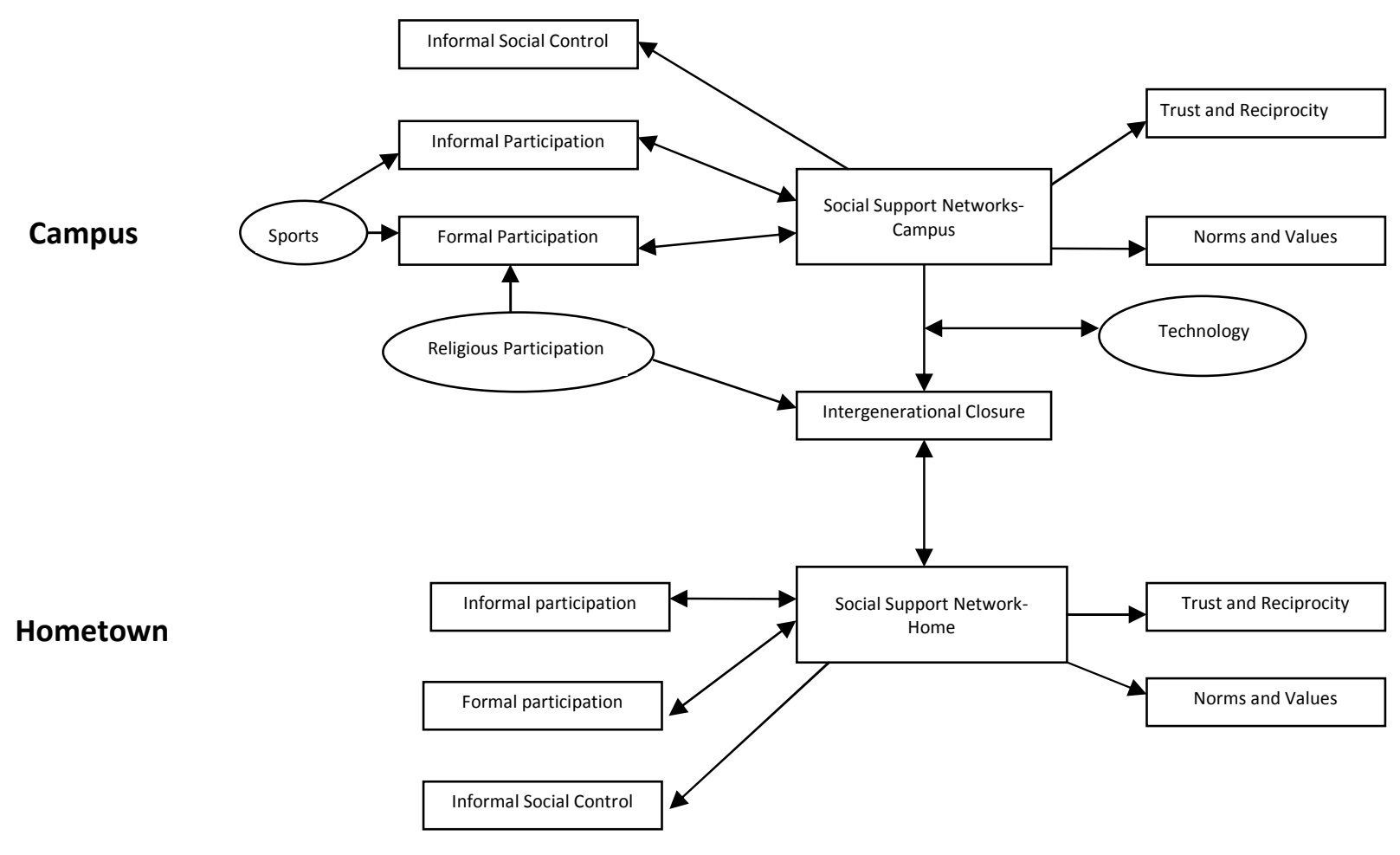




\section{Chapter 4}




\section{Chapter 4}

Measuring Social Capital among College Students: An Exploratory and Confirmatory Factor Analysis

\subsection{Introduction}

Social capital is a theoretical approach that is employed in a wide range of social science research including sociology, political science, economics, and public health. However, methodological inconsistencies regarding the operationalization and measurement of social capital make its "real world" application challenging and sometimes questionable. ${ }^{38,40,46,47,64,65 \text {, }}$ 142, 147, 148 Theoretical and methodological disagreements regarding the dimensions that define social capital and the unit of measurement (individual, community, or both) ${ }^{39,58,65}$ which best captures social capital continue over 100 years after sociologist Emile Durkheim introduced the concept in The Division of Labor in Society and Suicide. ${ }^{34,149}$ Although the concept of social capital was modernized in relation to economics, human capital, and education over two decades by James Coleman and Pierre Bourdieu, disagreements within and between scientific paradigms limit the application of social capital to policy reforms, social empowerment, and individual change. ${ }^{24,34,38,40,46,138,147}$

In addition to variable conceptualization and operationalization, dimensions of social capital are not consistent across contexts, such as studies using schools, families, communities, and nations as units of analysis. Researchers in Australia tasked with examining the role of social capital in families and communities identified four key areas in which social capital measurement falls short. Social capital research and measurement needs to be theoretically informed, understood as a resource for collective action, should be treated as a multidimensional 
concept, and dimensions will vary according to social network type and scale. ${ }^{68}$ In a study of school age children, two distinct dimensions of social capital emerged in relation to academic achievement, family social capital and school social capital, ${ }^{69}$ indicating that in addition to accounting for social capital across contexts, research must also consider the multiple contexts in which social capital may operate for individuals.

However, less is known about social capital among emerging adults. In particular, college students, or emerging adults (18-24 year olds), present a unique challenge to social capital research. First, college students are in the process of transitioning from childhood (in which parental measures of social capital may be appropriate) to adulthood in which the structural social relationships on which social capital research is grounded begin to develop and grow independent of parents. ${ }^{81,108}$ Therefore, it is unclear if measures of social capital among college students should focus on relationships in students' hometowns, on the college campus, or both. ${ }^{79}$, 150 Second, few studies directly measure social capital among college students. Instead, they assess social capital among parents and apply those results to college student outcomes. ${ }^{26,28-31,151}$ One of the few researchers to focus on social capital among college students using measures in a college student sample, Martin, focused on students' social network ties and occupational attainment from an elite university sample and found social capital to be a predictor of desire to attain professional level occupations. ${ }^{90}$

Although theoretical conceptualizations of social capital differ, they rely on social networks and relationships as the infrastructure by which social capital develops. A critical literature review reveals a consistent set of social capital indicators across scientific paradigms and studies in a variety of social contexts. These indicators include trust and reciprocity and membership in formal and informal social organizations. ${ }^{41,64}$ Specifically, trust and reciprocity 
represent cognitive aspects of social capital and are central to its development and collective action across paradigms, although the exact mechanisms by which it is developed and maintained differ. ${ }^{24,36,38,56}$ In addition, although findings vary, shared norms and values, informal social control, and intergenerational closure, are often included as indicators of social capital. $^{3,14,24,25,148}$

James Coleman, an American sociologist and educational theorist, conceptualized social capital based on the structure of social relationships that facilitate mutual obligation and trust through the creation and maintenance of social norms and sanctions. ${ }^{24}$ Family structure and stability, extra-familiar relationships (intergenerational closure), and religious participation serve as the infrastructure through which norms and values are learned and enforced (informal social control) and trust developed and practiced. ${ }^{24,25}$ Pierre Bourdieu, a contemporary French sociologist, conceived social capital emerging from institutionalized social relationships through which collective "goods" or resources are available to members and obligations are either subjectively implied or institutionally guaranteed. ${ }^{138}$ Robert Putman, a political scientist, defined social capital as both a "private" and "public good." Social relationships benefit both the individual by allowing access to resources via voluntary associations in community groups and communities by fostering active and engaged citizens allowing for easier mobilization of resources. ${ }^{36}$ Putnam primarily defines social capital through social connections, and subsequent trust and reciprocity, garnered as a result of membership in formal civic, political, religious, philanthropic, and workplace organizations as well as informal connections to friends and neighbors.

Four studies specifically to generate and/or validate social capital instruments provide a framework for the current study: 
The Social Capital Community Benchmark Survey (SCCBS) was developed in partnership with the John F. Kennedy School of Government at Harvard University, Saguaro Seminar and three dozen community centers based on Robert Putnam's book, Bowling Alone ${ }^{152}$ Conducted in 2000 , the survey included a national sample of 3000 participants and 26,200 participants geographically tied to the contributing community centers. The survey was developed with the assistance of a scientific review panel and was administered via telephone (approximately 25 minutes to complete). It tested eleven dimensions of social capital including: trust, political engagement, giving and volunteering, faith-based engagement, informal socializing, involvement in associations, civic leadership, diversity of friendships, and equality of civic participation. Two separate studies assessed the survey items. First, the primary researchers conducted a factor analysis and created a SCCBS short form for easy administration. ${ }^{153}$ All eleven dimensions were retained and several underlying sub-factors emerged in the analysis. The second study conducted a confirmatory factor using Nan Lin's framework of social capital which includes three underlying dimensions which were allowed to covary: voluntary association, network diversity, and social trust. ${ }^{148}$ The model was found to be a statistically significant representation of social capital.

In 1995, researchers Onyx and Bullen conducted a study to test an instrument to measure social capital in five communities in New South Wales, Australia. ${ }^{47}$ The instrument was developed based on a literature review, current instruments in the field, a discussion panel of content experts, and a pilot test among students and community workers. A total of 1,211 participants completed the survey. Thirty-six items (of 68) were retained following a principal components analysis. Discarded questions focused on the role of government, contractual versus voluntary reciprocity, and social isolation. Eight factors (or dimensions) of social capital were 
identified: participation in the local community, social agency, feelings of trust and safety, workplace connections, neighborhood connections, tolerance of diversity, family and friends connections, and value of life. A hierarchical factor analysis of with the eight individual factors produced a single general factor solution, social capital. ${ }^{40,47}$

The Global Social Capital Survey was developed in order to test social capital constructs at a national level. ${ }^{40}$ A questionnaire was developed using existing questionnaires, qualitative data, and a workshop of leading experts at the World Bank in 1998. Seven dimensions of social capital were measured and analyzed including: group characteristics (participation, membership and funding), generalized norms, togetherness, everyday sociability, neighborhood connections, volunteerism, and trust. The questionnaire was pilot tested in Ghana and the Republic of Uganda. Analysis included an exploratory factor analysis of the seven proposed dimensions followed by a confirmatory factor analysis. The dimensions were relatively stable, valid and reliable across countries.

Using methodology employed in previous studies addressed above, the purpose of this study is to twofold: (1) to create a valid and reliable survey instrument to test social capital in a college student population, (2) to conduct a confirmatory hierarchical factor analysis tested four models for best fit. The four models included a single social capital factor model; a model delineating hometown and campus social capital indicators; a hierarchical model using the dimensions and factors identified in the exploratory factor analysis loaded onto a single second order factor of social capital; and an empirically re-specified model in which only those factors and dimensions of social capital with a sufficient factor loading identified in model 3 with a single second order social capital factor are included in the final model. 


\subsection{Methods}

\subsubsection{Survey Development}

Potential items for the College Student Social Capital Survey (CSSCS) were developed using a multi-prong approach to maximize validity and reliability of the measures. First, an extensive literature review of social capital theory as well as studies that used surveys to operationalize social capital constructs were reviewed. Then, constructs central to social capital across studies were explored in a qualitative study using focus groups among 18-24 year old college students. Results from the focus groups are discussed in Chapter 3. Focus group and literature review data were compiled and used to develop a broad initial set of items crosscutting each of the central theories of social capital for the CSSCS.

The initial survey items were reviewed for content validity by eleven content matter experts including experts in social capital, social epidemiology/public health, and political science. Each content matter expert ranked each question as "essential," "useful," and "not necessary." Each content matter expert was also encouraged to provide feedback on item wording, content, and survey flow. Items were retained if there was at least $60 \%$ agreement that

the item was "essential" or "useful." ${ }^{154}$ Additional feedback from the content matter experts was incorporated into the final survey items.

\subsubsection{Survey Instrument}

There were 92 items included in the final survey. Survey items addressed demographic information and community of origin, the six dimensions of social capital (trust and reciprocity, formal participation, informal participation, norms and values, informal social control, and 
intergenerational closure), social networking and communication via computers and cell phones, tobacco use behaviors, and the Community Self-Esteem scale (to test divergent validity). ${ }^{155}$ Endogeneity was also assessed as a potential bias. Any items that were reverse coded in the survey were re-coded to be consistent in directionality. The full questionnaire is available in Appendix C. Specific descriptions of the items by dimension are included in the results section. Only questions related to social capital were included in this study. All items were in English.

The survey was adapted for the Internet using Qualtrics survey software and took approximately 30 minutes to complete. ${ }^{156}$ Qualtrics survey software offers security enabled, firewall protected confidential survey hosting. Finally, the survey was pilot tested among college students for wording, flow, ease of use, and computer interface ease. The final survey included ninety-two items including demographic questions. The West Virginia University Institutional Review Board approved the survey questions and administration protocol.

\subsubsection{Survey Recruitment}

Participants for the CSSCS were recruited from a list of currently enrolled students in the Spring term of 2011 on the main campus of West Virginia University provided by the Office of the Registrar. Inclusion criteria included current enrollment at the main Morgantown campus and being aged 18-24 years for a total of 18,961 eligible students. Factor analysis relies on correlation matrices to reliably estimate the relationships among variables and factors. Comfrey and Lee (1992) suggest a sample size of 100=poor, 300=good, and 500= very good for reliable estimates. ${ }^{157,158}$ Therefore, a random sample of 5000 potential participants was selected using

SPSS $19.0^{159}$ based on an anticipated response rate of $10-25 \%$. Potential respondents were sent an email to their student email account inviting them to participate in the survey (each West 
Virginia University student is assigned a college email account upon enrollment). The email included a brief description of the survey purpose and a link to the survey specific to the invited participant. The first page of the survey was informed consent and participants had to click on "I agree" at the bottom of the page to continue to the full survey. Non-respondents were sent up to two reminder emails inviting them to complete the survey. Students who completed the survey were emailed a gift code worth $\$ 10$ at an online retailer.

A sub-sample of participants was invited to take the survey a second time two-four weeks after they initially completed the survey in order to assess test-retest reliability. One hundred nine original participants were invited to participate in the survey a second time, and 57 completed it. The sub-sample was randomly drawn from participants who originally completed the survey using SPSS 19.0. ${ }^{159}$ We sent the sub-sample an email invitation asking them to complete the survey a second time and non-respondents were sent up to two reminder emails. Students who completed the survey a second time were emailed a gift code worth $\$ 10$ at an online retailer. The responses to items from time 2 were compared to responses to items at time 1 and a reliability coefficient (item to item correlation) determined. Item and scale stability is outlined in Tables 4.2-4.6.

\subsubsection{Analysis}

The purpose of this study is to develop a parsimonious, valid and reliable survey to measure social capital among college students. In order to accomplish this goal, the analysis is two-fold. First, an exploratory factor analysis was used for data reduction, to identify those items that best measure each underlying dimension of social capital. Based on the work of Narayan and Cassidy, we chose to analyze each of the six hypothesized dimensions (trust and reciprocity, 
formal and informal participation, norms and values, informal social control, and intergenerational closure) separately. ${ }^{40}$ The primary dimensions of social capital are generally consistent across multiple paradigms, although the operationalization and measurement of the dimensions varies. Analyzing each dimension separately allows for parsimonious selection of items that best captures the underlying dimension.

Exploratory factor analysis was conducted using SPSS 19.0 using principal axis factoring, and varimax rotation which maximizes the variance explained by each factor. ${ }^{159}$ The Bartlett test of sphericity and Keiser-Meyer-Olkin test statistics were assessed for suitability of factor analysis for each dimension. Factors on which more than one item loaded and with eigenvalues greater than 1.0 were retained. Items with a factor loading of $>.55$ (considered good by Comfrey and Lee) were retained. ${ }^{157}$ Bivariate correlations and item-to-scale correlations were analyzed. Retained items were combined to form a scale score for the underlying factor and Cronbach's alpha determined for each scale. ${ }^{160}$ Because of the exploratory nature of the study, scales with an alpha of over .65 were retained for the secondary analysis (.70 is considered moderate reliability, but satisfactory alpha reliability is dependent on the nature of the study). ${ }^{160}$ Retained items loaded squarely on a single factor (>.50), had adequate test-retest reliability, and item-to-scale correlations. ${ }^{158}$ Items that did not meet the inclusion criteria for a factor solution were discarded from the hierarchical analysis.

A hierarchical factor analysis (HFA), a type of confirmatory factor analysis (CFA) was used to confirm that each identified dimension of social capital loaded onto a second order factor using AMOS 19.0. ${ }^{159} \mathrm{CFA} / \mathrm{HFA}$ allows for the factors/dimensions identified in part one of the analysis to covary and to confirm the factor structure loads onto a single second order factor of social capital. Four models were tested for best fit. Maximum likelihood estimation was utilized. 
The final model was identified according to standard CFA/HFA rules (i.e. greater than three factors and greater than two indicators per factor). ${ }^{161}$ No single fit statistic is adequate to assess model fit. Multiple criteria provide a picture of adequate fit. Fit statistics analyzed included chi square, the Steiger-Lind root mean square error approximation (RMSEA), the Normative Fit Index (NFI) and the Bentler Compartive Fit Index (CFI) ${ }^{161}$ In the unstandardized models, one parameter for each dimension (latent construct) of social capital is fixed or constrained to 1 , in order to correctly scale the variable.

\subsubsection{Missing data}

Due to the structure of the survey software, some questions that allowed for multiple selections (check all that apply) were presented as missing data even as other options were checked. In this case, we chose to recode missing data as "not checked," or "no" for inclusion in the analysis. If a participant did not select any of the "check all that apply" options for a particular item, each option was coded as missing data. Otherwise, items were deleted listwise in the exploratory factor analysis and no missing imputation was performed (missing data ranged from $0 \%$ to $13 \%$ for individual variables). Items with the most "missingness" were at the end of the survey, indicating that the length of the survey may have been a factor. However, because missing data are not permitted in the hierarchical factor analysis, means and intercepts were calculated for missing data during the analysis.

\subsection{Results}

\subsubsection{Sample}


Seven hundred two potential respondents clicked the link to the survey from the email invitation and 541 completed it, for an overall response rate of 10.8\%. Although the response rate is low overall, of the 702 people who viewed the link to the survey (it is unclear why others did not, potentially they thought it was spam), $77 \%$ completed the survey and the sample obtained is adequate to conduct the statistical analysis presented. The sample was primarily female (63.8\%) and white (83.9\%). The largest proportion of the sample was seniors (34\%), and the overall grade point average (GPA) was 2.95. The mean age of participants was 20.3 years. Most (98.7\%) were full-time students, and 63.9\% reported being single. Additional demographic information is presented in Table 4.1. Fifty-seven participants took the survey a second time (response rate 53\%).

A demographic comparison was conducted to assess response bias based on data received from West Virginia University's Office of the Registrar. Comparisons were available based on gender, age, race, class rank and grade point average. Compared to non-respondents who were invited to participate, there were significant differences based on gender $(43.8 \%$ of those invited to participate were female and $63.8 \%$ of the respondents were female, $\mathrm{X}^{2}=98.4, p<0.001$ ), age (mean age for non-respondents was 20.7 versus 20.6 years for respondents, $t=1.73, p=.042$ ), and overall GPA (mean GPA for non-respondents was 2.87 versus 3.07 for respondents, $t=-5.61$, $p<0.001)$. There were no significant differences between respondents and non-respondents based on race and class rank. Additionally, a comparison with the entire eligible population from which the random sample was drawn was conducted using the same available demographic variables. Again, there were significant differences based on gender ( $44.8 \%$ of eligible students were female versus $63.8 \%$ of respondents), and overall GPA (mean GPA was 2.9 for eligible students 
versus 3.07 for respondents, $t=-5.36, p<0.001$ ). There were no significant differences in mean age, race, and class rank of eligible students compared to participants.

\subsubsection{Exploratory Factor Analysis}

Trust and Reciprocity. Trust and reciprocity is the belief that neighbors can be trusted and relied upon to provide resources if needed. Trust and reciprocity often include feelings of safety and crime. Twenty items were assessed for factor structure. Thirteen items assessing cognitive feelings of trust and safety were measured on a Likert scale, where $1=$ Strongly Disagree and $5=$ Strongly Agree. Three items assessing reciprocity were measured on Likert scales, where $1=$ Never and 5= Always. Finally, four summary items to assess structural reciprocity including favors done for others at WVU or hometown, and favors that others have done for the participant at WVU or in their hometown were included in the hierarchical factor analysis. The CSSCS had a five factor solution for the trust and reciprocity dimension accounting for $57.1 \%$ of the variance. Four items loaded onto factor 1 , trust among the campus community $(\alpha=.84)$. Five items loaded onto a factor representing hometown trust and reciprocity $(\alpha=.68)$. Two items loaded onto factor three, daytime safety in the campus community $(\alpha=.83)$. Two items loaded onto factor four, reciprocity in the campus community $(\alpha=.87)$. Finally, two items loaded onto factor five, nighttime safety in the campus community $(\alpha=.91)$. Factor loadings and test-retest reliabilities are shown in Table 4.2.

Formal Participation. Formal participation includes civic (participation in organized clubs or groups), political (active engagement in local and national political processes like voting), and religious activities (active participation in spiritual activities). These formal groups allow access to and mobilization of various informational, educational, and financial resources. Fifteen items 
measuring volunteerism and religiosity were assessed in the initial exploratory factor analysis. Additional count measures of political participation and civic participation were included in the hierarchical analysis. Volunteerism and religiosity were measured on Likert scales, where 1=Strongly Disagree and 5=Strongly Agree. There was a two factor solution for the formal participation dimension, that accounted for $44.9 \%$ of the variance. Six items measuring religiosity loaded onto factor one $(\alpha=.92)$, and five items measuring volunteerism loaded onto factor two $(\alpha=.81)$. See Table 4.3 .

In the hierarchical analysis, five additional items were included as measures of formal participation. Political participation included a count of voting behavior (voting in school, local and national elections) and active political participation, such as signing a petition, writing a political figure, or writing an editorial. Participation in organized groups in the hometown, on campus, and in the surrounding off-campus community were coded as " 1 " if they indicated they were a member of a group, and "2" if they indicated they were a leader in the group. The codes were multiplied by the number of hours per month the participant spent on each activity in order to develop an organized group intensity measure. Results are detailed in the hierarchical analysis section below.

Informal Participation. Informal participation is the gathering of two or more individuals in an informal setting. Thirty items were assessed for factor structure related to the informal participation dimension. Items were drawn from activities identified as important to students during the focus groups. Eighteen focused on the frequency of activities that students may participate in on campus and twelve focused on the frequency informal activities that students may participate in with family and friends in their hometowns. All items were measured on Likert scales in which $1=$ "Never" and 7="Daily." There was a six factor solution for the 
informal participation that accounted for $45.5 \%$ of the variance. Four items measured alcohol related behaviors $(\alpha=.90)$, four items measured sports-related activities $(\alpha=.85)$, four items for gaming activities $(\alpha=.86)$, two items for informal communication including talking in person, on the phone/text/chat/email ( $\alpha=.72)$, drug use ( $\alpha=.92)$, and time spent with significant other $(\alpha=.70)$. Time bowling $(\alpha=.58)$ and time spent with a university mentor or teacher/professor $(\alpha=.55)$ were not retained for the hierarchical factor analysis due to insufficient alpha scores. See Table 4.4.

Norms and Values. Norms and values are a set of collective norms and values that reflect a shared understanding of behavior. Nine items were assessed in the exploratory factor analysis. The CSSCS had a two factor solution for norms and values as a social capital construct accounting for $59.4 \%$ of the variance. Five items were retained for the first factor, university norms and values $(\alpha=.83)$. Three items were retained for the second factor, described as hometown norms and values $(\alpha=.77)$. Factor loadings and test-retest reliabilities for items are shown in Table 4.5.

Informal social control. Informal social control is a hallmark of social capital as measured among children and adolescents. It refers to the extent to which neighbors work collectively to maintain social order, such as neighborhood delinquency of children, it included the extent to which neighbors disciplined children, called parents when children misbehaved, and reported delinquent behaviors. ${ }^{39,66,75}$ The relevance of informal social control to college students lives was explored in the qualitative study referenced above. In that study, college students were asked about situations in which they would intervene, and that they perceived others would intervene. Six situations were referenced and included in the survey. Participants were asked to select all that apply for a total informal social control activity score $(\alpha=.66)$, which was included in the 
hierarchical factor analysis. In addition, students in the focus groups consistently reported that they personally used social networking sites such as Facebook and MySpace to monitor friends and relatives activities and parents, peers, and other relatives utilize the same mechanisms to monitor their activities. Therefore, we included a series of eight questions about social networking sites to assess informal social control via the Internet. The social networking site questions were measured on a Likert scale from 1="Strongly Disagree" to 5="Strongly Agree." The social networking questions were factor analyzed and had a two factor solution accounting for $33.8 \%$ of the variance. Factor one was related to worry about what employers or relatives may view on their profiles and had a two item solution $(\alpha=.68)$ and factor two was related to relatives monitoring their posts on social networking sites and had a two item solution ( $\alpha=.77)$. See Table 4.6 for details.

Intergenerational Closure- Intergenerational closure was introduced in education literature by James Coleman. It refers to relationships of children outside of the family. The nature of intergenerational closure past childhood was explored in the focus groups referenced above and included questions about adults from their family and hometown environments as well as engagement with professionals at the university ${ }^{80}$ According to the results, emerging adults do rely on adults outside of their immediate family for advice, feedback about behavior, emotional support, and information. Intergenerational closure was measured using two scales, one for connections with people in students' hometown communities and one for campus connections. It was not included in the exploratory factor analysis but was part of the HFA. Participants were asked to select up to sixteen people in their lives that they turn to for ten types of support identified by students during the focus groups (emotional, roommate issues, career advice, financial issues, romantic relationships, academics, general advice, feedback about behavior, 
general advice, and serious issues). The total selected for seven people from the students' hometown (grandparent, cousin, aunt/uncle, friend from home, coach/teacher/youth group leader, religious/spiritual advisor, family friend, other adult from hometown neighborhood) were summed for a hometown intergenerational closure score $(\alpha=.80)$. The total selected for seven people from the campus (friend from WVU, resident assistant, academic advisor, faculty, other staff, religious/spiritual advisor, and student organization leader) were summed for a campus intergenerational closure score $(\alpha=.73)$.

\subsubsection{Convergent and Divergent Validity}

In order to assess the degree to which the new survey items captured the underlying constructs of social capital among college students, they were compared two studies that measured theoretically similar (convergent validity) and dissimilar constructs (divergent validity). First, scales developed based on the exploratory factor analysis were compared to similar measures of social capital measured using the Los Angeles Family and Neighborhood Survey (LA FANS).$^{92}$ The LA FANS was administered among Los Angeles families in 2003, and included 2522 participants. Seventeen items were analyzed to assess constructs of social capital including social cohesion, social support, social leverage, neighborhood organization participation, and individual neighborhood participation among adults. Variations of these seventeen items were included in the CSSCS. Although the LA FANS was administered in an adult population in an urban area compared to the college population in this study, the core concepts were similar enough to be used to assess convergent validity of the survey. Results indicate that several scales identified in the exploratory factor analysis were adequately correlated with scales of the LA FANS, including norms, trust, and intergenerational closure (see Table 4.7). Also, a combined social capital score (a summative score of the dimension scales) 
using the results from the HFA indicated adequate correlations with social cohesion and social support measures of the LA FANS. See Table 4.8.

A similar, yet theoretically different instrument that measured collective self-esteem was used to assess divergent validity. The Collective Self-Esteem (CSE) survey was developed in 1992 and was validated among a college sample. ${ }^{155}$ The CSE includes sixteen items that measure private, public, membership, and personal identity benefits of social group membership (reflecting concepts similar to the cognitive elements of social capital). For both the scales and total social capital scores for the EFA and HFA, small correlations are reported (see Tables 4.7 and 4.8), indicating theoretically distinct constructs.

\subsubsection{Confirmatory and Hierarchical Factor Analysis}

Confirmatory and hierarchical factor analysis using a structural equation models (SEM) were performed in order to test the model fit of theoretically-based model structures. Four models were tested. First, underlying factors were loaded onto a single social capital factor with no intermediate dimensions included. This model was poorly fitted and rejected as a solution $\left(\mathrm{X}^{2}=1630.6 \mathrm{df}=275 p<0.001, \mathrm{RMSEA}=.10, \mathrm{NFI}=.38, \mathrm{CFI}=.40\right)$. Model 2 assessed the relationship between identified factors (in the EFA) and two second order factors that differentiated based hometown and campus social capital. It also indicated poor model fit $\left(\mathrm{X}^{2}=1146.3 \mathrm{df}=183 p<0.001, \mathrm{RMSEA}=.10, \mathrm{NFI}=.49, \mathrm{CFI}=.53\right)$. Model 3 (Figure 4.1) included a single second order factor with all dimensions empirically identified in the exploratory factor analysis. Model 3 also performed poorly $\left(\mathrm{X}^{2}=1131.4 \mathrm{df}=269 p<0.001\right.$, RMSEA=.08, NFI $=.57$, $\mathrm{CFI}=.62)$. The final model was modified based on the standardized factor loadings in Model 3 (Figure 4.2). Scales with standardized factor loadings of $<.50$ in Model 3 were deleted from the 
re-specified model (4) because they did not sufficiently explain the variance of each indicator. ${ }^{161}$ The final model performed well $\left(\mathrm{X}^{2}=46.7 \mathrm{df}=11 p<0.001, \mathrm{RMSEA}=.08, \mathrm{NFI}=.93, \mathrm{CFI}=.94\right)$. Significant chi-square goodness of fit statistics in CFA/HFA does not automatically indicate overall poor model fit and must be assessed collectively with other fit statistics. Model 4 included three primary factors: trust, values, and informal participation that loaded onto a single second order factor. The standardized estimates of the re-specified model are presented in Figure 4.3 .

\subsection{Discussion}

The exploratory factor analysis greatly reduced the number of items required to estimate the underlying factors associated with social capital. The exploratory factor analysis identified multiple underlying factors associated each hypothesized dimension of social capital. The results of the exploratory factor analysis did not indicate two distinct types of social capital derived by students from their hometowns versus their campus for each dimension of social capital. Specifically, formal participation did not yield separate factors related to hometown and campus volunteer activities or religiosity. Informal participation factors loaded according to activity as opposed to context. Informal social control did not have a clear distinction between hometown and campus monitoring behavior even among those who used social networking sites. However, there were clear delineations of social capital in the dimensions of norms and values and trust and reciprocity between hometown and campus contexts.

The results of the hierarchical confirmatory factor analysis indicates that three traditional dimensions of social capital best represent the experience of college students in this sample, informal participation, norms and values, and trust and reciprocity. The confirmatory results are 
consistent with relatively low scores of internal reliability, item-to-total correlations, and measures of test-retest reliability, indicating that the simpler re-specified model is the most parsimonious. Also, factors representing hometown social capital identified in the exploratory factor analysis were not retained as part of the HFA (Model 2), indicating that separate contexts for hometown and campus social capital are not supported in this study The three dimensions of social capital retained in the re-specified model align with a conceptual model of social capital presented by Carpiano. ${ }^{39}$ Carpiano utilized Bourdieu's conceptualization of social capital in order to address health outcomes and status. He deconstructs social capital from a general umbrella theory in which a variety of social processes and networks are generated and maintained through civic engagement into specific focus on resources "rooted in neighborhood social networks (p.168)."39 This distinction allows for delineation between social cohesion (cognitive elements of social capital), which focuses on "patterns of social interaction and values...[which] are necessary for the foundations of establishing social capital within neighborhoods ( $p$ 168)" and social capital itself (the mobilization of resources within networks or the structural aspects of social capital). Social cohesion in Carpiano's theoretical model includes measures of connectedness through trust and informal interactions, and collective values and norms. Again, this aligns with the dimensions of social capital assessed and retained in the HFA. Because college students are in a transition period in their lives, in which they are developing a unique identity from their parents and beginning to develop their own social networks, ${ }^{81}$ this finding indicates that they are in the process of laying the foundations of social capital (i.e. social cohesion) based on Carpiano's theory, but have not yet advanced to actively mobilizing the resources available to them via their social groups. Social cohesion may be a 
precursor to the development of social capital among emerging adults as opposed to a measure of social capital itself. ${ }^{58}$

Based on the combined results of the study a revised CSSCS would include a total of 21 items and include three dimensions of social capital that are salient in adult social capital literature. However, it must be noted that this study was conducted among students at a single institution. The fact that the types of activities that were retained as factors representing the latent construct of informal participation included sporting and alcohol related activities (both prominent features of the institution in question- West Virginia University is a National Collegiate Athletic Association Division 1 university with nationally ranked football, basketball, and soccer programs and is often ranked as a top twenty party school by the Princeton Review), ${ }^{162}$ indicates that the results may not be generalizable to the greater college population. Future studies must also consider oversampling males and stratifying by class rank in order to achieve a representative sample of the general student population.

Endogeneity, a potential bias in any study of neighborhood effects or engagement, is a particular concern among college students. A number of factors influence an emerging adult's decision to attend a specific college or university. In order to understand and account for these underlying influences, we included a question of possible reasons students chose to attend WVU (based on results from the focus groups). Although the majority of participants indicated financial reasons (48.6\%), a quality education (53.4\%), and school pride (43.4\%), a total of $33.6 \%$ selected sports tradition and $13.9 \%$ selected party school. This indicates that the type of student who chooses to attend WVU may do so for reasons that factored into the resultsspecifically the significance of drinking alcohol and attending sporting events in the dimension of informal participation. For full results see Table 4.1 . 
Finally, distinctions between the adult and adolescent population and the college student emerging adult population are evident in this study. Informal social control and intergenerational closure, key constructs in adolescent outcomes research were not significant as a feature of social capital in this population. Also, political participation, volunteer activities, religious participation, and participation in formal clubs or groups were not significant. These findings call into question the relevance of social capital as conceptualized by Coleman and Putnam among these students. Again, a broader cross-section of college students on a variety of campuses would illuminate these findings.

\subsubsection{Limitations}

A primary limitation of this study is the low response rate (10.8\% overall). Although $77 \%$ of students who actually viewed the survey link completed it, a response rate of $10.8 \%$ is low among a college population (where responses for Web-based surveys range from 21-60\%). ${ }^{163-165}$ However, patterns of responses are similar to other studies. Women, white students, and those with higher grade point averages completed the survey more than men, minorities, and those with lower academic achievement. ${ }^{165,166}$ A number of factors may have contributed to low response including, "survey fatigue" (college students may be overburdened with survey research due to the nature of the academic environment- i.e. researchers are the primary employees of universities), failure to see implications of the survey results to their own lives, ${ }^{167}$ failing to check their school-based email in the timeframe the survey was open, forgetting to return to the email after initially opening it, intentionally or unintentionally deleting it, and assuming it was spam mail. ${ }^{164}$ In addition, the timing of the survey and retest (just prior to spring break and finals) did not allow for the three reminder emails recommended by the literature to maximize response rates in a college population. ${ }^{166}$ 
Further research is needed with samples from a diverse cross-section of universities in order to assess the scientific generalizability of the survey. We recommend repeated studies using the results of the exploratory factor analysis followed by identical HFA models in order to confirm the results. We also recommend oversampling males and racial minority students in order to close the gap in non-response. The full revised survey based on this recommendation would include 66 items. In addition, the larger sample could be stratified by class rank in order to see if older students who spent more time as a part of the university community were more likely to move beyond developing social cohesion to the mobilization of resources that is the hallmark of social capital in Bourdieu and Carpiano's framework. ${ }^{108,138}$ This study included measures at the individual level. Although research suggests that trust and participation measured at the micro or individual level (as opposed to the meso or community level) is associated with outcomes such as self-rated health, ${ }^{60}$ the complexity of social capital and its unit of measurement (individual versus community) are still hotly debated after more than a century since its intellectual inception by Durkheim. ${ }^{8,14,24,34,36,38,39,58,59,68,136,138,142,149}$ Future research should also include measures of social capital at the meso/community/campus level in order to develop a more complete understanding of social capital as a multidimensional theory encompassing the subjective experience of the student and the broader utilization of resources via social groups on and among campuses.

\subsection{Conclusions}

Many universities employ a variety of formal methods to engage students in the academic and social environment. These methods include freshman orientation/freshman experience, mandatory University 101 or first year classes, ${ }^{80}$ career fairs, faculty mentoring and advising, centers for engagement (volunteer opportunities), seminars and special guests to enhance 
university experiences, student governance, and free or reduced admission to athletic and cultural events. Activities (a result of university policy and priorities) such as these act to develop social capital even if they do not explicitly state it as a goal of the university. ${ }^{168}$ In addition, most colleges and universities offer health, psychological, academic, and social services to students as a part of their tuition and fees. Resources such as these can provide health information, access to physical and mental health care, tutoring, social support and enforcement of community norms from residence hall assistants, services for students with disabilities, cultural activities, and opportunities for informal interactions (e.g. residence hall living situations, athletic events, etc.) that encourage social capital to develop among students. These resources (or the structural aspects of social capital) are often not as easily accessed by emerging adults who do not attend college. Again, these activities and services are a direct result of university policy decisions and a budgetary commitment from the institution to enhance students' experience and engagement with the campus community. This study highlights the importance of encouraging informal interactions and opportunities to develop community trust and norms that support healthful behaviors and educational advancement.

Understanding the development and function of social capital in this population can help universities to plan for public health interventions and may broaden the range of public health policy options available to them. ${ }^{168}$ As mentioned above, college is a time of increased autonomy, identity development, and often, risky health behaviors. ${ }^{91}$ Informal social networks can enhance or deter unhealthy behaviors such as physical activity, proper nutrition, cigarette and alcohol use among college students. ${ }^{120}$ Supportive relationships built on trust (a hallmark of social capital supported by this study), and particularly the social networks in which individuals are embedded are a key element to intentional change (as it relates to personal identity) if an 
unhealthy behavior already exists. ${ }^{169}$ Enhancing norms around healthy behaviors, such as abstaining from or moderating alcohol and cigarette consumption, increased physical activity, well-balanced nutrition, healthy sleep and study habits, and even recycling in a college setting may lessen the burden on the institution to provide services to students around these issues. This study provides a validated instrument with which to measure the association between social capital and health behaviors in a college student population.

In conclusion, the body of literature on social capital measurement and practice continues to manifest, and remains controversial. ${ }^{68}$ The results of this study develop a baseline survey specifically to measure social capital among college students, a current gap in research. The validation of a survey among this population will help refine our understanding of how social capital functions and emerges in a college population. It is an empirically validated survey that has the can be used to assess social capital's relation to student health outcomes (public health), engagement (which is often actively sanctioned and cultivated by universities), ${ }^{80}$ retention, and academic outcomes. The survey has the potential to be used as a tool to assess college student social capital along with a variety of outcomes that have implications for college and university policies and planning, as well as for individual behavior change. 
Table 4.1: Sample Demographic Characteristics

\begin{tabular}{|c|c|}
\hline Demographic Characteristic & $n(\%)$ \\
\hline \multicolumn{2}{|l|}{ Gender } \\
\hline Male & $196(36.2 \%)$ \\
\hline Female & $344(63.8 \%)$ \\
\hline Transgender & $1(0.2 \%)$ \\
\hline \multicolumn{2}{|l|}{ Race } \\
\hline White (including Middle Eastern) & $497(92.2 \%)$ \\
\hline Black & $11(2.0 \%)$ \\
\hline Hispanic or Latino & $5(0.9 \%)$ \\
\hline Asian or Pacific Islander & $6(1.1 \%)$ \\
\hline Other race & $6(1.1 \%)$ \\
\hline Multiracial & $14(2.6 \%)$ \\
\hline \multicolumn{2}{|l|}{ Sexual Orientation } \\
\hline Heterosexual & $508(94.1 \%)$ \\
\hline Gay/Lesbian & $12(2.2 \%)$ \\
\hline Bisexual & $16(3.0 \%)$ \\
\hline Unsure/Questioning & $4(0.7 \%)$ \\
\hline \multicolumn{2}{|l|}{ Relationship status } \\
\hline Single & $230(42.8 \%)$ \\
\hline Single, but in a dating relationship & $114(21.2 \%)$ \\
\hline Engaged or in a committed dating relationship & $183(34.0 \%)$ \\
\hline Married/domestic partnership & $8(1.5 \%)$ \\
\hline Separated/widowed/divorced & $3(0.6 \%)$ \\
\hline Full-time student status & $530(98.7 \%)$ \\
\hline \multicolumn{2}{|l|}{ Highest Education Completed by Mother } \\
\hline Less than high school/GED & $8(1.5 \%)$ \\
\hline High school diploma & $114(21.1 \%)$ \\
\hline Some college or Associate's Degree & $161(29.9 \%)$ \\
\hline 4 year college (Bachelor's Degree) & $157(29.1 \%)$ \\
\hline Master's Degree & $92(17.0 \%)$ \\
\hline Doctoral or professional degree & $8(1.5 \%)$ \\
\hline \multicolumn{2}{|l|}{ Hometown Classification } \\
\hline Very large city (population over 500,000 ) & $36(6.7 \%)$ \\
\hline Large city (population $250,000-499,999$ ) & $32(5.9 \%)$ \\
\hline Small city or suburb (population $50,000-250,000$ ) & $113(21.0 \%)$ \\
\hline Large town (population 10,000-49,999) & $118(21.9 \%)$ \\
\hline Small town (population 2500-9999) & $149(27.7 \%)$ \\
\hline Rural community (population 2500) & $90(16.7 \%)$ \\
\hline Student currently employed & $253(46.9 \%)$ \\
\hline \multicolumn{2}{|l|}{ What community do you feel most connected to? (check all that apply)* } \\
\hline People in my hometown & $361(66.7 \%)$ \\
\hline People at WVU & $299(55.3 \%)$ \\
\hline People in Morgantown or the off-campus community in which I live & $74(13.7 \%)$ \\
\hline People in formal social community (club, sports team, organization or group) & $122(22.6 \%)$ \\
\hline People in informal social community based on common interests & $40(7.4 \%)$ \\
\hline People in my work environment & $104(19.2 \%)$ \\
\hline \multicolumn{2}{|l|}{ Why did you choose to attend West Virginia University? (check all that apply)* } \\
\hline Parents decided & $19(3.5 \%)$ \\
\hline Financial reasons & $263(48.6 \%)$ \\
\hline Quality education & $289(53.4 \%)$ \\
\hline Close to my hometown & $213(39.4 \%)$ \\
\hline Reputation as a "party school" & $75(13.9 \%)$ \\
\hline Sports tradition & $182(33.6 \%)$ \\
\hline School pride & $235(43.4 \%)$ \\
\hline Friends were coming to WVU & $170(31.4 \%)$ \\
\hline Family tradition & $74(13.7 \%)$ \\
\hline Sense of community or belonging & $124(22.9 \%)$ \\
\hline
\end{tabular}


Table 4.2: Trust and Reciprocity placement of scale items by factor analysis

\begin{tabular}{|c|c|c|c|c|c|c|c|c|c|}
\hline Item & $\begin{array}{l}\text { Factor } \\
\text { One }\end{array}$ & $\begin{array}{l}\text { Factor } \\
\text { Two }\end{array}$ & $\begin{array}{l}\text { Factor } \\
\text { Three }\end{array}$ & $\begin{array}{l}\text { Factor } \\
\text { Four }\end{array}$ & $\begin{array}{l}\text { Factor } \\
\text { Five }\end{array}$ & $M(S D)$ & $h^{2}$ & $\begin{array}{l}\text { Test-Retest } \\
\text { Reliability }\end{array}$ & $\begin{array}{l}\text { Item-to-Scale } \\
\text { Correlations }\end{array}$ \\
\hline $\begin{array}{l}\text { My WVU neighbors are willing to help } \\
\text { each other out. }\end{array}$ & .82 & & & & & $3.5(1.0)$ & .69 & 0.729 & 0.870 \\
\hline I trust the people in my hometown. & & .59 & & & & $3.9(0.9)$ & .45 & 0.473 & 0.454 \\
\hline $\begin{array}{l}\text { My hometown neighbors are willing to } \\
\text { help each other out. }\end{array}$ & & .69 & & & & $4.0(0.9)$ & .61 & 0.667 & 0.490 \\
\hline $\begin{array}{l}\text { How often do people in your hometown } \\
\text { (not your family) do favors for each } \\
\text { other? }\end{array}$ & & .99 & & & & $4.4(0.8)$ & .44 & 0.646 & 0.580 \\
\hline $\begin{array}{l}\text { Count of favors respondent did for } \\
\text { hometown neighbors }\end{array}$ & & .65 & & & & $5.6(3.5)$ & .63 & 0.519 & 0.899 \\
\hline $\begin{array}{l}\text { I feel safe on-campus at WVU during the } \\
\text { day. }\end{array}$ & & & .81 & & & $4.3(0.6)$ & .74 & 0.662 & 0.920 \\
\hline I feel safe in Morgantown during the day. & & & .70 & & & $4.2(0.7)$ & .60 & 0.531 & 0.926 \\
\hline $\begin{array}{l}\text { Count of favors neighbors from WVU did } \\
\text { for respondent. }\end{array}$ & & & & .86 & & $5.9(2.5)$ & .81 & 0.479 & 0.941 \\
\hline $\begin{array}{l}\text { Count of favors respondent did for WVU } \\
\text { neighbors. }\end{array}$ & & & & .76 & & $6.2(2.4)$ & .64 & 0.364 & 0.936 \\
\hline I feel safe at WVU on-campus at night. & & & & & .83 & $3.5(1.0)$ & .83 & 0.779 & 0.953 \\
\hline I feel safe in Morgantown at night. & & & & & .80 & $3.2(1.1)$ & .76 & 0.803 & 0.959 \\
\hline $\begin{array}{l}\text { Scale Internal Reliability } \\
\text { Test-Retest Scale Reliability }\end{array}$ & $\begin{array}{l}\alpha=.84 \\
r=0.704\end{array}$ & $\begin{array}{l}\alpha=.68 \\
r=0.562\end{array}$ & $\begin{array}{l}\alpha=.83 \\
r=0.597\end{array}$ & $\begin{array}{l}\alpha=.87 \\
r=0.421\end{array}$ & $\begin{array}{l}\alpha=.91 \\
r=0.791\end{array}$ & & & & \\
\hline
\end{tabular}


Table 4.3: Formal Participation placement of scale items by factor analysis

\begin{tabular}{|c|c|c|c|c|c|c|}
\hline Item & Factor One & Factor Two & $M(S D)$ & $h^{2}$ & $\begin{array}{l}\text { Test-Retest } \\
\text { Reliability }\end{array}$ & $\begin{array}{l}\text { Item-to-Scale } \\
\text { Correlation }\end{array}$ \\
\hline I consider myself to be religious or spiritual. & .75 & & $3.4(1.3)$ & .61 & 0.931 & 0.843 \\
\hline $\begin{array}{l}\text { Before I came to WVU, I attended religious } \\
\text { services regularly. }\end{array}$ & .73 & & $3.1(1.5)$ & .66 & 0.924 & 0.867 \\
\hline $\begin{array}{l}\text { Attending religious or spiritual services while at } \\
\text { WVU is important to me. }\end{array}$ & .90 & & $2.6(1.2)$ & .89 & 0.881 & 0864 \\
\hline $\begin{array}{l}\text { Belonging to a religious/spiritual organization } \\
\text { at WVU provides a sense of community. }\end{array}$ & .80 & & $2.8(1.2)$ & .71 & 0.734 & 0.835 \\
\hline $\begin{array}{l}\text { Belonging to a religious/spiritual organization } \\
\text { in my hometown provides a sense of } \\
\text { community. }\end{array}$ & .78 & & $3.1(1.3)$ & .74 & 0.648 & 0.878 \\
\hline $\begin{array}{l}\text { Going to religious services in my hometown is a } \\
\text { time to be with my family. }\end{array}$ & .66 & & $3.2(1.4)$ & .68 & 0.688 & 0.815 \\
\hline $\begin{array}{l}\text { Volunteering was important to me in high } \\
\text { school. }\end{array}$ & & .71 & $3.6(1.2)$ & .51 & 0.585 & 0.792 \\
\hline I enjoy volunteering. & & .71 & $4.1(0.9)$ & .54 & 0.527 & 0.772 \\
\hline Volunteering is important in my hometown. & & .66 & $3.5(1.1)$ & .48 & 0.557 & 0.812 \\
\hline $\begin{array}{l}\text { Volunteering is a great way to help the } \\
\text { community. }\end{array}$ & & .55 & $4.5(0.7)$ & .32 & 0.518 & 0.611 \\
\hline Volunteering is important to my family. & & .66 & $3.4(1.1)$ & .49 & 0.763 & 0.790 \\
\hline $\begin{array}{l}\text { Scale Internal Reliability } \\
\text { Test-Retest Reliability Scale }\end{array}$ & $\begin{array}{l}\alpha=.92 \\
r=0.801\end{array}$ & $\begin{array}{l}\alpha=.81 \\
r=0.584\end{array}$ & & & & \\
\hline
\end{tabular}


Table 4.4: Informal Participation placement of scale items by factor analysis

\begin{tabular}{|c|c|c|c|c|c|c|c|c|c|c|}
\hline Item & $\begin{array}{l}\text { Factor } \\
\text { One }\end{array}$ & $\begin{array}{l}\text { Factor } \\
\text { Two }\end{array}$ & $\begin{array}{l}\text { Factor } \\
\text { Three }\end{array}$ & $\begin{array}{l}\text { Factor } \\
\text { Four }\end{array}$ & $\begin{array}{l}\text { Factor } \\
\text { Five }\end{array}$ & $\begin{array}{l}\text { Factor } \\
\text { Six }\end{array}$ & $M(S D)$ & $h^{2}$ & $\begin{array}{l}\text { Test-Retest } \\
\text { Reliability }\end{array}$ & $\begin{array}{l}\text { Item-to-Scale } \\
\text { Correlations }\end{array}$ \\
\hline $\begin{array}{l}\text { When you are at WVU, how often do you go to a club/bar } \\
\text { with friends? }\end{array}$ & .79 & & & & & & $3.2(1.7)$ & .70 & 0.926 & 0.849 \\
\hline $\begin{array}{l}\text { When you are at WVU, how often do you pre-party or pre- } \\
\text { game with friends? }\end{array}$ & .82 & & & & & & $3.4(1.9)$ & .79 & 0.958 & 0.915 \\
\hline $\begin{array}{l}\text { When you at WVU, how often do you drink alcohol with } \\
\text { friends? }\end{array}$ & .85 & & & & & & $3.8(1.9)$ & .84 & 0.961 & 0.928 \\
\hline $\begin{array}{l}\text { When you are in your hometown, how often do you drink } \\
\text { alcohol with friends? }\end{array}$ & .71 & & & & & & $3.1(1.9)$ & .71 & 0.851 & 0.809 \\
\hline $\begin{array}{l}\text { When you are at WVU, how often do you attend a WVU } \\
\text { sporting event? }\end{array}$ & & .64 & & & & & $3.2(1.3)$ & .49 & 0.833 & 0.728 \\
\hline $\begin{array}{l}\text { When you are at WVU, how often do you watch WVU } \\
\text { sporting events with friends? }\end{array}$ & & .83 & & & & & $3.7(1.6)$ & .77 & 0.859 & 0.874 \\
\hline $\begin{array}{l}\text { When you at WVU, how often do you watch other (than } \\
\text { WVU) sporting events with friends? }\end{array}$ & & .81 & & & & & $3.9(2.1)$ & .76 & 0.870 & 0.903 \\
\hline $\begin{array}{l}\text { When you are in your hometown, how often do you watch } \\
\text { sporting events on television with family or friends? }\end{array}$ & & .74 & & & & & $4.0(2.1)$ & .71 & 0.783 & 0.851 \\
\hline $\begin{array}{l}\text { When you at WVU, how often do you play video games (in } \\
\text { person) with friends? }\end{array}$ & & & .80 & & & & $2.7(2.2)$ & .69 & 0.920 & 0.858 \\
\hline $\begin{array}{l}\text { When you at WVU, how often do you play video games } \\
\text { (online) with friends? }\end{array}$ & & & .76 & & & & $2.3(2.0)$ & .63 & 0.718 & 0.834 \\
\hline $\begin{array}{l}\text { When you are in your hometown how often do you play video } \\
\text { games (in person) with friends? }\end{array}$ & & & .75 & & & & $2.8(2.1)$ & .63 & 0.756 & 0.827 \\
\hline $\begin{array}{l}\text { When you are in your hometown, how often do you play } \\
\text { video games (online) with friends? }\end{array}$ & & & .79 & & & & $2.2(2.0)$ & .65 & 0.715 & 0.855 \\
\hline $\begin{array}{l}\text { When you are at WVU, how often do you talk in person with } \\
\text { friends? }\end{array}$ & & & & .87 & & & $6.5(1.0)$ & .79 & 0.513 & 0.941 \\
\hline $\begin{array}{l}\text { When you are at WVU, how often do you talk on the } \\
\text { phone/email/chat or text with friends? }\end{array}$ & & & & .82 & & & $6.6(1.0)$ & .71 & 0.440 & 0.940 \\
\hline $\begin{array}{l}\text { When you are at WVU, how often do you use drugs with } \\
\text { friends? }\end{array}$ & & & & & .84 & & $1.7(1.6)$ & .79 & 0.854 & 0.962 \\
\hline $\begin{array}{l}\text { When you are in your hometown, how often do you use drugs } \\
\text { with family and friends? }\end{array}$ & & & & & .95 & & $1.6(1.5)$ & .95 & 0.927 & 0.958 \\
\hline $\begin{array}{l}\text { When you are at WVU, how often do you spend time with a } \\
\text { significant other? }\end{array}$ & & & & & & .90 & $4.3(2.6)$ & .87 & 0.831 & 0.874 \\
\hline $\begin{array}{l}\text { When you in your hometown, how often do you spend time } \\
\text { with a significant other? }\end{array}$ & & & & & & .61 & $4.1(2.5)$ & .40 & 0.804 & 0.880 \\
\hline $\begin{array}{l}\text { Scale Internal Reliability } \\
\text { Test-Retest Reliability }\end{array}$ & $\begin{array}{l}\alpha=.90 \\
r=0.924\end{array}$ & $\begin{array}{l}\alpha=.85 \\
r=0.836\end{array}$ & $\begin{array}{l}\alpha=.86 \\
r=0.777\end{array}$ & $\begin{array}{l}\alpha=.72 \\
r=0.477\end{array}$ & $\begin{array}{l}\alpha=.92 \\
r=0.891\end{array}$ & $\begin{array}{l}\alpha=.70 \\
r=0.818\end{array}$ & & & & \\
\hline
\end{tabular}


Table 4.5: Norms and Values placement of scale items by factor analysis

\begin{tabular}{|c|c|c|c|c|c|c|}
\hline Item & Factor One & Factor Two & $M(S D)$ & $h^{2}$ & $\begin{array}{l}\text { Test-Retest } \\
\text { Reliability }\end{array}$ & $\begin{array}{l}\text { Item-to-Scale } \\
\text { Correlations }\end{array}$ \\
\hline $\begin{array}{l}\text { WVU students have a shared sense of pride } \\
\text { about being Mountaineers. }\end{array}$ & .81 & & $4.3(0.8)$ & .65 & 0.657 & 0.783 \\
\hline $\begin{array}{l}\text { Sports and athletics bring us closer together } \\
\text { as a WVU community. }\end{array}$ & .73 & & $4.3(0.9)$ & .55 & 0.695 & 0.753 \\
\hline $\begin{array}{l}\text { Academics and a good education are } \\
\text { important parts of WVU's values. }\end{array}$ & .74 & & $4.0(0.8)$ & .58 & 0.654 & 0.769 \\
\hline I share WVU's values. & .82 & & $4.0(0.8)$ & .71 & 0.699 & 0.835 \\
\hline $\begin{array}{l}\text { Being a Mountaineer means giving back to } \\
\text { the Morgantown community. }\end{array}$ & .66 & & $3.8(0.9)$ & .50 & 0.465 & 0.739 \\
\hline $\begin{array}{l}\text { People in my neighborhood share similar } \\
\text { values. }\end{array}$ & & .77 & $3.7(0.9)$ & .63 & 0.559 & 0.805 \\
\hline I share my parents' values. & & .74 & $4.0(0.9)$ & .60 & 0.680 & 0.786 \\
\hline I share my hometown's values. & & .91 & $3.6(0.9)$ & .83 & 0.808 & 0.898 \\
\hline $\begin{array}{l}\text { Scale Internal Reliability } \\
\text { Test-Retest Reliability }\end{array}$ & $\begin{array}{l}\alpha=.83 \\
r=0.634\end{array}$ & $\begin{array}{l}\alpha=.77 \\
r=0.682\end{array}$ & & & & \\
\hline
\end{tabular}


Table 4.6: Informal Social Control placement of scale items by factor analysis

\begin{tabular}{|c|c|c|c|c|c|c|}
\hline Item & Factor One & Factor Two & $M(S D)$ & $h^{2}$ & $\begin{array}{l}\text { Test-Retest } \\
\text { Reliability }\end{array}$ & $\begin{array}{l}\text { Item-to-Scale } \\
\text { Correlations }\end{array}$ \\
\hline My relatives view my profile to see what I am up to. & .56 & & $3.6(1.1)$ & .32 & 0.769 & 0.880 \\
\hline $\begin{array}{l}\text { If a relative found something on my profile } \\
\text { questionable, they would say something to me. }\end{array}$ & .80 & & $3.8(1.0)$ & .38 & 0.495 & 0.862 \\
\hline $\begin{array}{l}\text { I worry about what future employers might see on my } \\
\text { profile. }\end{array}$ & & .94 & $3.6(1.3)$ & .46 & 0.501 & 0.903 \\
\hline I worry about what relatives might see on my profile. & & .66 & $3.4(1.3)$ & .44 & 0.360 & 0.906 \\
\hline $\begin{array}{l}\text { Scale Internal Reliability } \\
\text { Test-Retest Scale Reliability }\end{array}$ & $\begin{array}{l}\alpha=.68 \\
r=.632\end{array}$ & $\begin{array}{l}\alpha=.77 \\
r=0.431\end{array}$ & & & & \\
\hline
\end{tabular}


Table 4.7: Correlations between the College Student Social Capital Survey Exploratory Factor Analysis Dimensions and Other Measures

\begin{tabular}{|c|c|c|c|c|c|c|c|}
\hline Measure & Norms & Trust & $\begin{array}{c}\text { Formal } \\
\text { Participation }\end{array}$ & $\begin{array}{c}\text { Informal } \\
\text { Participation }\end{array}$ & $\begin{array}{c}\text { Informal Social } \\
\text { Control }\end{array}$ & $\begin{array}{c}\text { Intergenerational } \\
\text { Closure }\end{array}$ & $\begin{array}{c}\text { Social Capita } \\
\text { Total }\end{array}$ \\
\hline Collective Self-Esteem Scale Total & $.326^{*}$ & $.279 *$ & $.236^{*}$ & $.103^{*}$ & .070 & $.153^{*}$ & $.209^{*}$ \\
\hline Membership Self-Esteem & -.007 & .057 & $-.127^{*}$ & $.161^{*}$ & -.052 & -.067 & -.022 \\
\hline Private Collective Self-Esteem & $.212^{*}$ & $.159 *$ & $.157^{*}$ & .033 & .024 & $.114^{*}$ & $.119 *$ \\
\hline Public Self-Esteem & $.169 *$ & $.130^{*}$ & $.133^{*}$ & -.023 & .076 & .017 & -.015 \\
\hline Importance to Identity & $.294^{*}$ & $.246^{*}$ & $.238^{*}$ & $.096 *$ & .086 & $.215^{*}$ & $.281^{*}$ \\
\hline \multicolumn{8}{|l|}{ Los Angeles Family and Neighborhood Survey } \\
\hline Social Cohesion & $.776^{*}$ & $.533^{*}$ & $.294^{*}$ & $.223^{*}$ & $.340^{*}$ & $.157^{*}$ & $.509 *$ \\
\hline Social Support & $.543^{*}$ & $.675^{*}$ & $.351^{*}$ & $.207^{*}$ & $.283^{*}$ & $.255^{*}$ & $.535^{*}$ \\
\hline Social Leverage & $.229 *$ & $.221^{*}$ & $.315^{*}$ & $.093 *$ & $.213^{*}$ & $.843 *$ & $.652 *$ \\
\hline Neighborhood Organization Participation & .201 & $.402 *$ & $.325^{*}$ & .135 & -.188 & .201 & .269 \\
\hline Individual Neighborhood Attachment & -.083 & -.046 & -.032 & .060 & -.067 & -.052 & $.125^{*}$ \\
\hline
\end{tabular}

Table 4.8: Correlations between the College Student Social Capital Survey Re-specified Hierarchical Factor Analysis Dimensions and Other Measures

\begin{tabular}{lcccc}
\hline Measure & Norms & Trust & $\begin{array}{c}\text { Informal } \\
\text { Participation }\end{array}$ & $\begin{array}{c}\text { Social Capital } \\
\text { Total }\end{array}$ \\
\hline Collective Self-Esteem Scale Total & & & $.304^{*}$ \\
$\quad$ Membership Self-Esteem & $.326^{*}$ & $.344^{*}$ & $.147^{*}$ & $.120^{*}$ \\
Private Collective Self-Esteem & -.007 & .002 & $.189^{*}$ & $.143^{*}$ \\
Public Self-Esteem & $.212^{*}$ & $.193^{*}$ & .040 & $.122^{*}$ \\
Importance to Identity & $.169^{*}$ & $.214^{*}$ & -.011 & $.263^{*}$ \\
& $.294^{*}$ & $.286^{*}$ & $.143^{*}$ & \\
Los Angeles Family and Neighborhood Survey & & & & \\
Social Cohesion & & & & $.666^{*}$ \\
Social Support & $.776^{*}$ & $.720^{*}$ & $.291^{*}$ & $.527^{*}$ \\
Social Leverage & $.543^{*}$ & $.620^{*}$ & $.224^{*}$ & $.120^{*}$ \\
Neighborhood Organization Participation & $.229^{*}$ & .039 & .084 & .157 \\
Individual Neighborhood Attachment & .201 & .126 & .088 & .064 \\
\hline
\end{tabular}




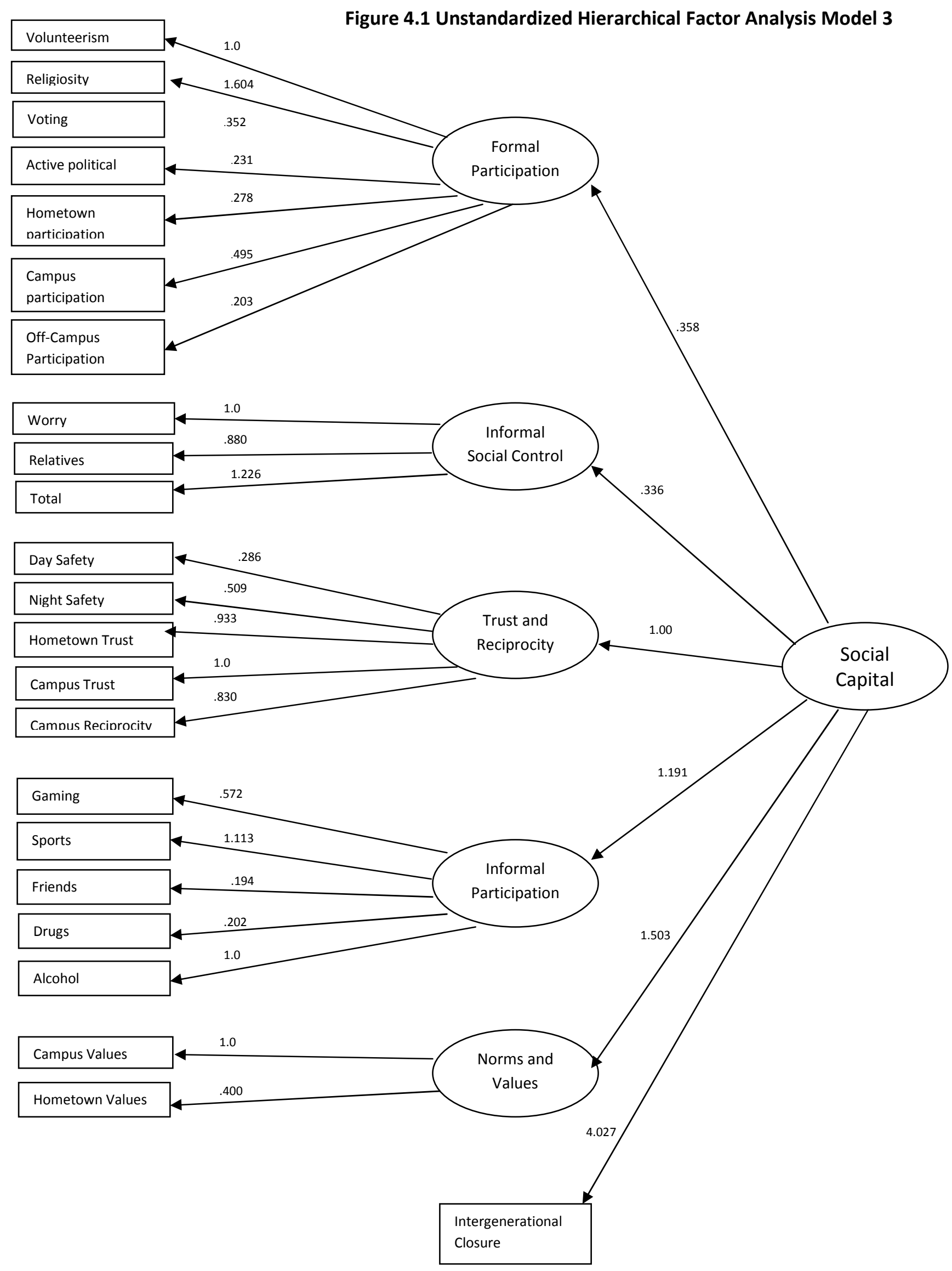



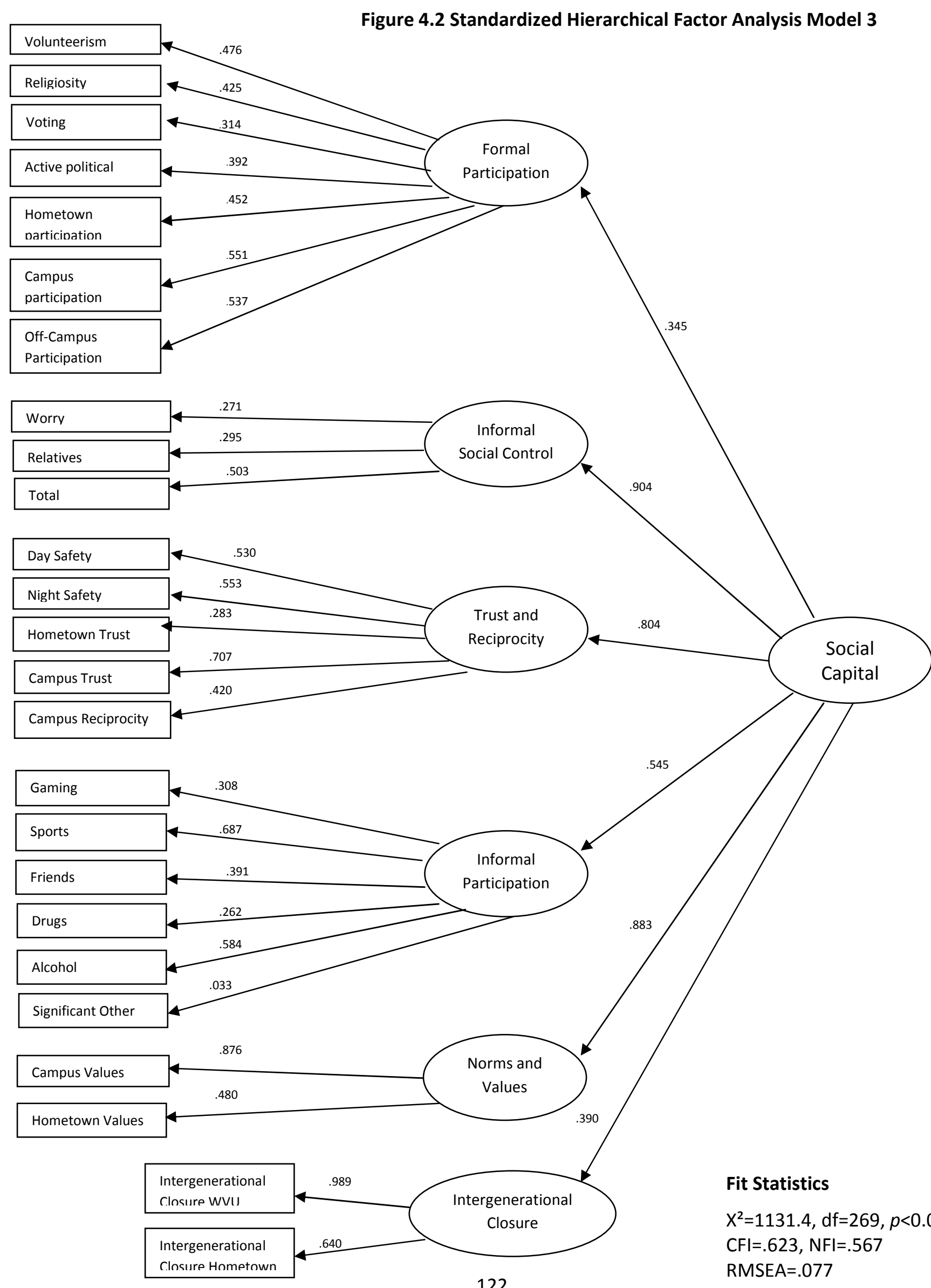

Fit Statistics

$X^{2}=1131.4, d f=269, p<0.001$

$\mathrm{CFI}=.623, \mathrm{NFI}=.567$

RMSEA $=.077$ 
Figure 4.3 Standardized Hierarchical Factor Analysis Respecified Model 4

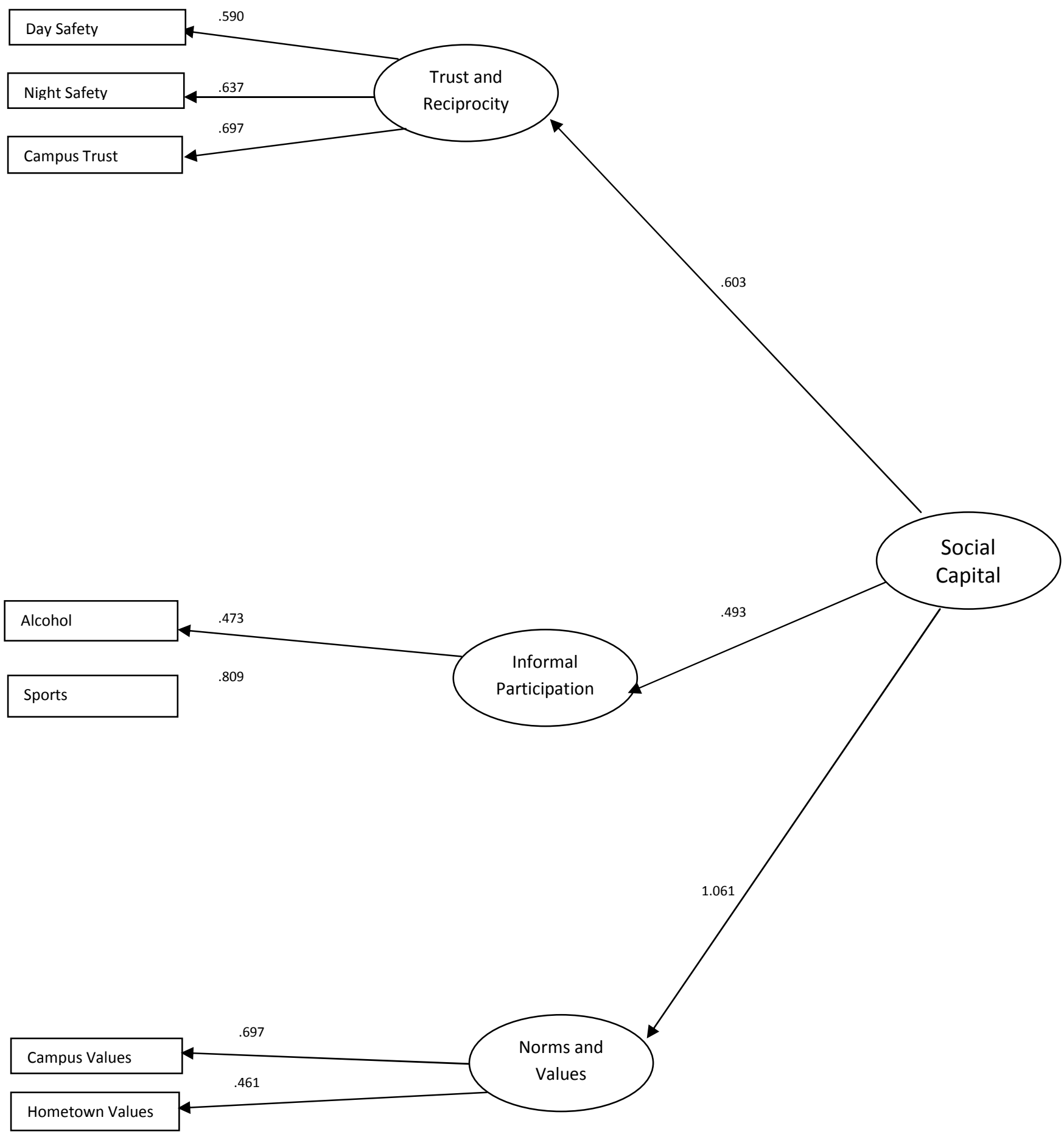

Fit Statistics

$\mathrm{X}^{2}=46.7, \mathrm{df}=11, p<0.001$

$\mathrm{CFI}=.941, \mathrm{NFI}=.926$

RMSEA $=.077$ 


\section{Chapter 5}




\section{Chapter 5}

\subsection{Summary}

The goal of this dissertation project was to understand the role of social capital among college students. Specifically, we utilized three interconnected studies to 1) explore the magnitude and direction of the relationship between cigarette use and social capital using a large national survey of college students; 2) qualitatively understand social capital and related constructs in a sample of college students; and 3) develop a reliable and valid instrument to measure social capital among college students. To date, although a large body of literature exists on the relationship between social capital and educational outcomes, studies on social capital among post-secondary students is lacking. ${ }^{25,90}$ Of the few studies that do investigate social capital among college students, most focus on parental measures as opposed to the experience of the emerging adult. ${ }^{28-30}$ College is a critical time of transition when parental bonds are renegotiated and students' identities and self-concepts are reforming, as are their social relationships, which are the defining characteristic of social capital. ${ }^{79,81,82,91,170}$

It is also a time of risk taking. Emerging adults often engage in health risk behaviors such as substance abuse, violence, and risky sexual relationships, that can influence lifelong health

outcomes. $^{77,91}$ Given the interest in the public health field to understand the social determinants of health and to identify potentially modifiable community-level variables that contribute to risk behaviors and poor health outcomes in order to inform community interventions, emerging adulthood, and particularly college students, is a prime opportunity to understand how social capital is developed and utilized.

Social capital refers to the ability of individuals and groups to access resources through their social connections (community organizations, formal and informal groups, and family) 
based on norms of trust and reciprocity. Although social capital is employed in a variety of social science fields, its' practical application as a theoretical framework is limited by methodological issues (operationalization and measurement). Disagreement abounds regarding the appropriate set of indicators to fully capture the multiple dimensions of social capital, as well as the appropriate level of measurement (individual/micro, community/group/meso, or nation/macro). However, regardless of flaws, each scientific inquiry using a social capital framework contributes to our understanding of how to best measure, and ultimately modify, social capital variables within specific contexts and communities. ${ }^{3,68}$ The studies presented here contribute to our understanding of social capital within an emerging adult, college population.

The secondary data analysis using a large national sample of college students described in Chapter 2 provided evidence that elements of social capital were associated with increased cigarette use among college students. Specifically, increased campus level volunteerism was associated with lower reported cigarette use among a sample of 18-24 year old students $(\mathrm{N}=85,475)$ from 144 individual colleges and universities in the United States. We employed a multilevel analysis (hierarchical linear modeling) in order to account for both individual and campus level variance in the model.

Building on the findings of Chapter 2, the qualitative study presented in Chapter 3 focuses on social capital in a college context at a large mid-Atlantic university. Ten focus groups $(\mathrm{N}=59)$ were conducted with undergraduate students to broaden our depth of understanding of how social capital is developed and maintained at this critical life juncture. We also explored social capital within the possible dual context of home and campus. Findings revealed that trust/reciprocity and norms/values indeed reflected dual contexts in which students clearly delineated home from campus. Student participants also maintained relationships with family, 
mentors and leaders from their hometown communities (both in person and via social networking sites) and cultivated relationships with faculty, staff, and peer groups on campus (intergenerational closure). Participation in both formal and informal groups, community and student organizations provided a means for students to develop social networks. Informal social control was not meaningful to the participants unless a situation escalated to violence or criminal behavior. Discussions about each construct frequently overlapped and all pointed to developing cognitive bonds of trust associated with personal relationships. The results of this study highlighted the importance of including both cognitive and structural measures of social capital in investigations using an emerging adult population. It also illustrated the growing reliance on social networking sites to maintain and develop social capital among this technologically savvy generation.

In the final study presented in Chapter 4, we utilized the results of the qualitative study to develop a survey (the College Student Social Capital Survey) in order to test the cognitive and structural elements identified as valid and reliable indicators of social capital in a general student population. Combined with an extensive literature review, feedback from multidisciplinary content experts, and qualitative responses from the population of interest, a 92 item survey was assessed in a random sample of West Virginia University students using exploratory and confirmatory/hierarchical factor analysis. Results indicate that three dimensions of social capital, campus-based trust and reciprocity, shared norms and values, and informal participation should be retained as indicators for this population. (Hometown factors were not supported by the results). These factors align with Carpiano's conceptual model in which social cohesion (cognitive elements) is differentiated from social capital (structural elements). 
Jointly, the results of the current project indicate that social capital, as a structural element, is not yet fully formed in this population to be exchanged as "currency" for social leverage and position. Instead, the studies suggest that social cohesion, or cognitive elements (in the form of individual trust/reciprocity, shared norms and values, and informal associations), is a precursor to its development. The results highlight the importance of examining social capital with respect to context and in a manner meaningful to participants (regardless of unit of analysis).

\subsection{Significance}

The goal of this study was two-fold. First, we sought to broaden our understanding of the magnitude and direction of the relationship between social capital and cigarette use in a college population, using individual and campus level measures. Second, we sought to develop a valid and reliable survey to measure social capital among college students. In order to accomplish this goal, we employed a mixed methods approach to investigate the development of social capital in a college population.

The conclusions from the three studies contribute to social capital and public health literature as they relate to college student emerging adults, and may help to inform translation from individual experiences of social capital to campus level strategies to support positive social capital development and health. The combined results point to social capital as an emerging, yet not fully developed, resource for students. In the first study, we identified elements of social capital that operate at a campus level related to smoking behaviors. Specifically, volunteerism at a campus level is negatively associated with cigarette use at an individual level. The second and third studies indicate that social capital operates primarily as a cognitive construct related to trust and reciprocity, community norms, and informal socializing in this population. This is consistent 
with Carpiano's conceptualization of Bourdieu's work that separates the concepts of social cohesion (cognitive elements) from social capital proper (structural resources). ${ }^{37,39}$ However, the results of the studies did not bear out two distinct forms of social capital for students related to hometown and campus. Although there are elements of both at work, they are not statistically significant for this population of West Virginia University students.

Based on the results, there are potential implications for community interventions and institutional policies at the campus level. Universities may act to strengthen existing campus activities that directly or indirectly build social capital in a college population. However, care must be taken to create situations to develop social capital that reflect campus norms around healthy behaviors, educational achievement, fan behavior at sporting events, volunteerism and giving back to the community, etc. As evidenced by the qualitative discussion in study 2 , forcing students to volunteer may backfire and create resentment toward the institution, therefore, policy and intervention strategies must reflect "natural" situations in which these norms can be strengthened (for example, making community service a core component of admissions decisions).

Although more research is needed with a variety of campuses to fully validate the results of this dissertation, the results help provide administrators, faculty, parents, and students with insights into opportunities to capitalize on social capital (particularly schools with a similar institutional and student demographic profile to West Virginia University). Institutions may seek to support policies making an economic commitment to strengthen campus norms around healthy behaviors using campus level interventions and existing informal social networks within residence halls, academic programs, and off-campus housing facilities, which may embolden students to access campus resources. Campuses may seek to expand opportunities to foster 
relationships between students and faculty/staff to create structural social capital for students and allow faculty/staff to develop informal relationships with students beyond their job descriptions. Campus resources may work to address public health issues such as smoking cessation programs, mental health assistance, tutoring services, alcohol moderation or abstinence, nutrition, and physical activity. Campus policies such as smoking and tobacco bans, forbidding the sale and possession of alcohol at sporting events (including tailgating by students and alumni), and actively advocating similar policies in the community indicate an institutional support for normative behaviors that enhance health. ${ }^{171-173}$ Tobacco control policies such as campus smokefree policies ( $>75 \%$ in favor in campus buildings, residence halls, and dining areas), marketing restrictions ( $71 \%$ in favor), and restrictions on on-campus tobacco access (59\% in favor) are supported by a college students. ${ }^{174}$ In addition, excise taxes/higher prices and state-level clean indoor air policies are associated with lower levels of cigarette use and smoking bans on campus are associated with lower levels of smoking among current users. ${ }^{173,175}$ Reducing risk behaviors in college may prevent long-term health consequences for emerging adults and significant economic savings in health care costs, quality of life, and days of work lost over a lifetime.

The distinction between social cohesion (already at work in this population) and social capital- as defined by Carpiano- also points to policy interventions. Specifically, universities may utilize informal social networks to create formal channels to develop the structural aspects of social capital. Structural elements include access to resources and may involve a lifelong commitment to helping current students and alumni advance career opportunities, educational support, financial support for low income students, and formalized support to enhance individual behavior change (smoking cessation programs, alcohol reduction programs, physical activity requirements, etc). Also, campuses may encourage and empower students to participate in the 
governing responsibilities and policy decisions of the university in order to enhance cognitive feelings and structural determinants of engagement and investment in the university. College is a transitory time in an emerging adult's life. They are students for a limited time, and they move on to other aspects of their lives. Creating a sense of collective university identity and opportunities to engage meaningful ways in the university across a lifetime may allow for a structural mechanism to facilitate social capital in ways not currently utilized by campuses. One way to enhance this may be to build bridges with parents and alumni to create community support and reinforcement of campus norms and policies.

Finally, based on the sample of students in studies 2 and 3, connections to the greater community in which the campus resides are weak. Policies and sanctioned activities that focus on strengthening the bonds to the greater community may contribute to more active engagement in city and county political matters, volunteerism, informal social control in off campus neighborhoods, and a greater respect for the year round residents of the city. The survey instrument developed as a goal of this project provides a starting place to analyze and measure social capital in this population that may unlock the best ways to quantify the relationship between policy decisions to strengthen social capital among students, the campus, the community and ultimately, health outcomes.

\subsection{Strengths and Weaknesses}

These studies highlight the importance of a mixed methods approach to understanding social capital in specific populations. The multi-level study in study 1 is among the first to investigate social capital at a campus level as it relates to individual smoking behaviors among college students. We utilized a large national dataset of college students, the National College Health Assessment, that allows for generalizability (with caveats of selection bias), to the greater 
population of college students. It also is among the first studies to indicate that health behaviors of college students may be associated with a combination of individual and campus level factors. However, there are limitations related to the nature of secondary data analysis. Campuses must pay to conduct the research, and more importantly, key measures of social capital may be omitted as it was not the focus of the study.

Study 2 was a qualitative study that allowed for in depth focus on the constructs of social capital in a college population. We were able to investigate the both multiple conceptualizations and dimensions of social capital as related to the specific context of the college experience. In addition, we were able to delineate between students' experiences of social capital within their families and hometowns versus campus. As with any qualitative study, there are limits to the generalizability of the study results to a broader college population.

The results of study 3 offer a third arm to triangulate the findings in studies 1 and 2 . Based on the results of those studies, we were able to create a survey instrument to measure multiple dimensions of social capital within a college population. A primary strength of study 3 includes the scientific diligence involved in creating the study, and analyzing the instrument for validity and reliability. Multiple steps including an extensive literature review, review by experts, pre-testing with the population of interest, and comparison to similar (and divergent) instruments strengthen the validity of the study. However, the instrument was validated among a college student population at a single university. Although the sample was randomly selected from the entire eligible population, there were significant differences between the study population and the sample, highlighting the importance of survey delivery and sampling methods. In addition, the response rate for the survey was low at $10.8 \%$. Although there may be 
valid reasons for low response rate, we were unable to ascertain as a part of this study, the underlying contributing factors.

Finally, in each study, there is the potential for endogeneity, or self-selection to the campus community. This is a potential bias for any study that focuses on community. However, we were careful to include in depth questions (study 2) and measures (study 3) about how the college was selected in order to account for this potential bias. Future studies should also include these measures in order to compare and contrast reasons for attendance.

\subsection{Future Research}

Results from this study highlight the importance of investigating social capital in a context specific and multidimensional manner. However, it is only a first step to fully understanding social capital in a student population. Future research priorities should include replicating the full survey developed in study 3 in multiple college populations in order to validate the results of the confirmatory/hierarchical factor results, and to allow for stratification by age/year in school, race, gender, and socio-economic status. Following a broad validation, studies should focus on the public health outcomes associated with social capital (and specific dimensions of social capital) in a college population. Of critical importance is a focus on cigarette and other tobacco use in this population, due to the high prevalence among emerging adults and lifelong health and economic consequences. In addition, because smoking initiation is

often a "social" behavior, ${ }^{113,176}$ it is important to ascertain the relationship between structural social networks as defined by social capital and smoking uptake in a young adult population.

\subsection{Conclusion}


The findings of this study expand our understanding of how to operationalize and measure social capital among a college population. It also highlights the relationship between campus level factors and individual behaviors, specifically, cigarette use. The results support the conclusions of The World Bank's Social Capital Initiative that social capital needs to be measured according to context (here, college), and is a multidimensional theoretical framework. ${ }^{3,}$ $41,43,45,48,64,68$ Specifically, the results support Carpiano's conceptualization of social capital that includes separate cognitive (social cohesion) and structural (resources) elements for emerging adults. This study provides strong preliminary evidence as to the appropriate social capital framework and measures to include for studies among college students. It provides a baseline by which future researchers, institutional administrators, and students themselves can address policy and public health issues within the microcosm of a campus community. 


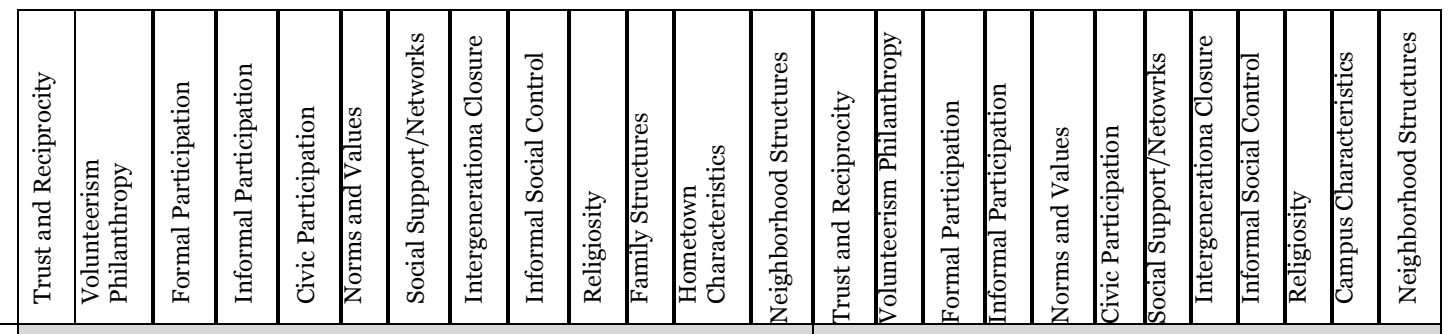

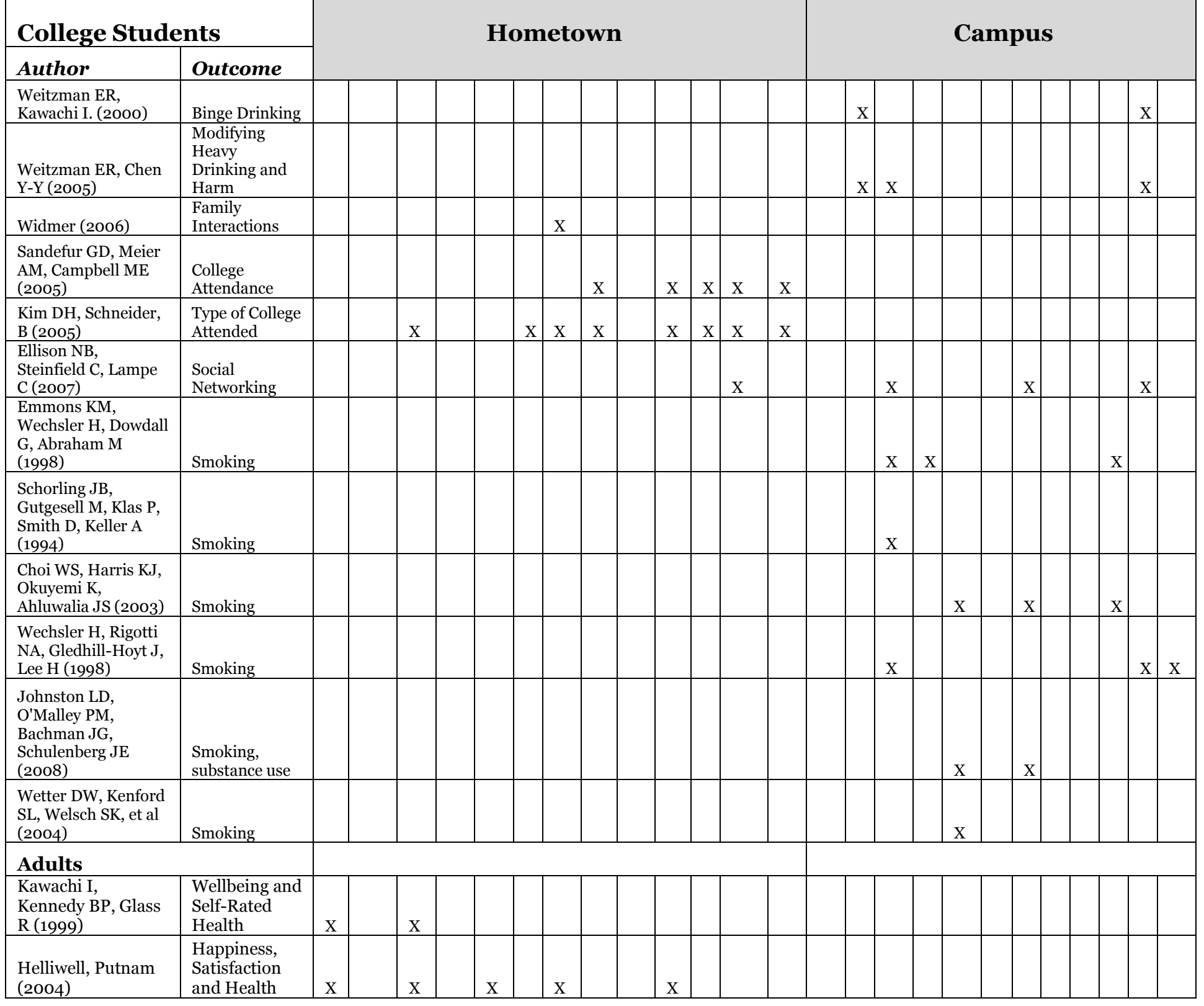




\begin{tabular}{|c|c|c|c|c|c|c|c|c|c|c|c|c|c|c|c|c|c|c|c|c|c|c|c|c|}
\hline 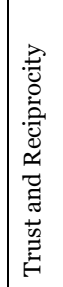 & 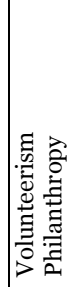 & 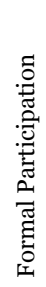 & 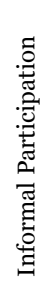 & 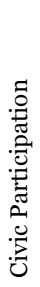 & 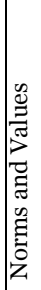 & 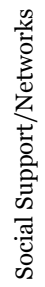 & 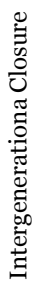 & 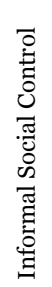 & 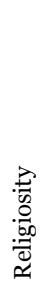 & 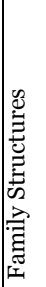 & r & 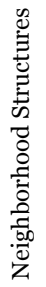 & 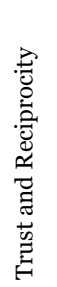 & 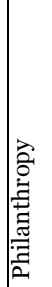 & 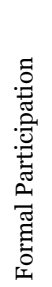 & 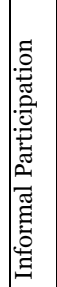 & 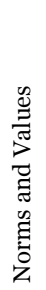 & 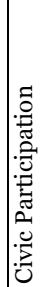 & 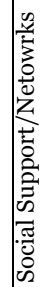 & 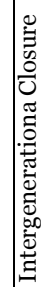 & 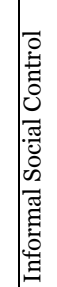 & $\mid$ & 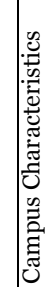 & 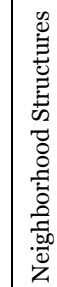 \\
\hline
\end{tabular}

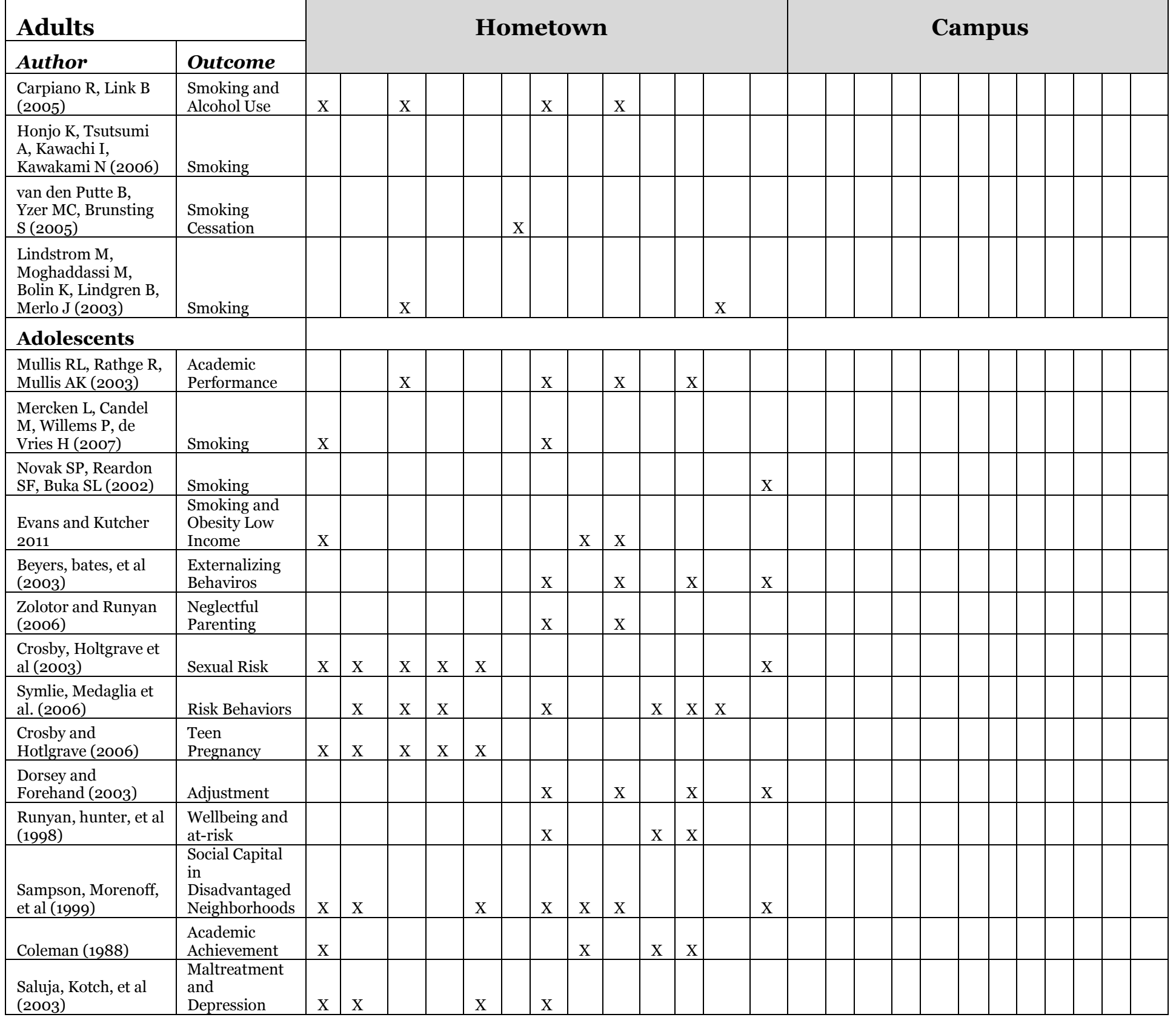




\begin{tabular}{|c|c|c|c|}
\hline Social Capital Construct & Subcategories & Coding Description & Example \\
\hline \multirow[t]{3}{*}{$\begin{array}{l}\text { Formal Participation- refers to } \\
\text { participation in formally sponsored } \\
\text { activities including clubs and } \\
\text { social organizations (participation } \\
\text { in organized clubs or groups), } \\
\text { volunteer activities, and religious } \\
\text { (active participation in spiritual } \\
\text { activities). These formal groups } \\
\text { allow access to and mobilization } \\
\text { of various informational, } \\
\text { educational, and financial } \\
\text { resources }\end{array}$} & $\begin{array}{l}\text { Campus- Clubs and social } \\
\text { organizations }\end{array}$ & $\begin{array}{l}\text { This node includes all references } \\
\text { to participation in clubs and social } \\
\text { organizations. This may include } \\
\text { both participation and non- } \\
\text { participation. Clubs (other than } \\
\text { religious or volunteer) include } \\
\text { intramural or club sports, } \\
\text { fraternity or sororities, and any } \\
\text { other club or organization. }\end{array}$ & $\begin{array}{l}\text { Focus Group 7: } \\
\text { " I don't really know how to get } \\
\text { involved in club sports, not sure } \\
\text { what route to go to get involved. } \\
\text { Maybe they could try to advertise } \\
\text { it more, intramural sports. They } \\
\text { do a relatively good job } \\
\text { advertising other clubs. Often } \\
\text { times there are only a few people } \\
\text { involved with those. Student } \\
\text { body is real apathetic and doesn't } \\
\text { like to get involved. They are out } \\
\text { there, but not everyone involved." }\end{array}$ \\
\hline & $\begin{array}{l}\text { Home- Clubs and social } \\
\text { organizations }\end{array}$ & $\begin{array}{l}\text { This node includes all references } \\
\text { to participation in clubs or social } \\
\text { organizations at home. This may } \\
\text { include both participation and } \\
\text { non-participation. }\end{array}$ & $\begin{array}{l}\text { Focus Group 8: } \\
\text { " I used to wrestle in high school } \\
\text { so that distracted me from doing } \\
\text { homework. Sometimes we would } \\
\text { have practice before and after } \\
\text { school and when I came home I } \\
\text { was to tired to do anything. One } \\
\text { year I played football and } \\
\text { wrestling and that whole year I } \\
\text { had bad grades because I was so } \\
\text { lazy. " }\end{array}$ \\
\hline & Campus- Volunteerism & $\begin{array}{l}\text { This node includes all references } \\
\text { to participation in volunteer } \\
\text { activities on campus. This may } \\
\text { include both participation and } \\
\text { non-participation. }\end{array}$ & $\begin{array}{l}\text { Focus Group 10: } \\
\text { " I'm sure there are but I haven't } \\
\text { really looked for any ways to } \\
\text { volunteer. I have heard of people } \\
\text { volunteering. I don't think it's out } \\
\text { for people to know about. They } \\
\text { don't advertise the groups that } \\
\text { you can volunteer with as much as } \\
\text { they should." }\end{array}$ \\
\hline
\end{tabular}




\begin{tabular}{|c|c|c|c|}
\hline & Home- Volunteerism & $\begin{array}{l}\text { This node includes all references } \\
\text { to participation in volunteer } \\
\text { activities at home. This may } \\
\text { include both participation and } \\
\text { non-participation. }\end{array}$ & $\begin{array}{l}\text { Focus Group 7: } \\
\text { teered for awhile, usually with } \\
\text { disability kids so I have no } \\
\text { problem doing it, just haven't } \\
\text { really gotten around to picking a } \\
\text { place and sticking with it. At this } \\
\text { point in time my education is } \\
\text { more important than volunteering, } \\
\text { as selfish as that might sound." }\end{array}$ \\
\hline & Campus- Religious Participation & $\begin{array}{l}\text { This node includes all references } \\
\text { to participation in religious } \\
\text { activities on campus. This may } \\
\text { include both participation and } \\
\text { non-participation. }\end{array}$ & $\begin{array}{l}\text { Focus Group 5: } \\
\text { " yeah id say there's a lot of } \\
\text { opportunities. I heard about a lot } \\
\text { of bible studies from student } \\
\text { organizations and stuff." }\end{array}$ \\
\hline & Home- Religious Participation & $\begin{array}{l}\text { This node includes all references } \\
\text { to participation in religious } \\
\text { activities at home. This may } \\
\text { include both participation and } \\
\text { non-participation. }\end{array}$ & $\begin{array}{l}\text { Focus Group 4: } \\
\text { "Yes, because my parents go. I } \\
\text { don't think I would have gone on } \\
\text { my own. They are like 8:00 let's } \\
\text { go to church. Yes, you do get } \\
\text { back into it. I wouldn't without } \\
\text { my parents." }\end{array}$ \\
\hline & Home- Other participation & $\begin{array}{l}\text { Any other reference to } \\
\text { participation at home. }\end{array}$ & \\
\hline & Campus- Other WVU & $\begin{array}{l}\text { Any other reference to } \\
\text { participation at home. }\end{array}$ & \\
\hline $\begin{array}{l}\text { Informal Participation- refers to } \\
\text { both planned and unplanned } \\
\text { activities that have no formal } \\
\text { protocol such as parties, family } \\
\text { get-togethers, talking with friends } \\
\text { and neighbors, peer study groups, } \\
\text { etc. Such activities strengthen } \\
\text { social bonds, reinforce norms, and }\end{array}$ & General & $\begin{array}{l}\text { This node includes codes for all } \\
\text { references to unplanned activities } \\
\text { and informal socializing both at } \\
\text { home and on campus. Examples } \\
\text { include spending time at a friend's } \\
\text { house playing video games, } \\
\text { talking, internet gaming, internet } \\
\text { chatting, going to restaurants, }\end{array}$ & $\begin{array}{l}\text { Focus Group 3: } \\
\text { " Hang out at the international } \\
\text { house, I practically live there } \\
\text { now! My sister is an RA there so } \\
\text { that's why I was originally there. } \\
\text { I have made good friends there. } \\
\text { Dinners for holidays, they } \\
\text { celebrate everybody's birthday. }\end{array}$ \\
\hline
\end{tabular}




\begin{tabular}{|c|c|c|c|}
\hline \multirow[t]{6}{*}{ create social cohesion } & & $\begin{array}{l}\text { clubs, or bars, attending sporting } \\
\text { events, etc. }\end{array}$ & $\begin{array}{l}\text { Just the kids are a lot of fun. At } \\
\text { this point there are only } 5 \text { foreign } \\
\text { kids. Last semester there a lot of } \\
\text { them. Fun to learn about their } \\
\text { cultures." }\end{array}$ \\
\hline & Campus- Alone Time & $\begin{array}{l}\text { This node includes all references } \\
\text { to informal time spent alone } \\
\text { including studying, using the } \\
\text { internet. playing video games, } \\
\text { sleeping, outdoor activities, } \\
\text { exercising or going to the rec } \\
\text { center while on campus. }\end{array}$ & $\begin{array}{l}\text { Focus Group 4: } \\
\text { " I just sleep longer and take more } \\
\text { naps." }\end{array}$ \\
\hline & Home- Alone Time & $\begin{array}{l}\text { This node includes all references } \\
\text { to informal time spent alone } \\
\text { including studying, using the } \\
\text { internet. playing video games, } \\
\text { sleeping, outdoor activities, } \\
\text { exercising while at home. }\end{array}$ & $\begin{array}{l}\text { Focus Group 1: } \\
\text { "go run or workout because that } \\
\text { is the only thing you can do." }\end{array}$ \\
\hline & $\begin{array}{l}\text { Campus- Friends in private } \\
\text { residence }\end{array}$ & $\begin{array}{l}\text { This node includes any reference } \\
\text { to hanging out with friends } \\
\text { including video gaming, talking, } \\
\text { partying or pre-gaming or other } \\
\text { activity in private residence or } \\
\text { dorm room on campus. }\end{array}$ & $\begin{array}{l}\text { Focus Group 10: } \\
\text { " My brother is a junior here so } \\
\text { usually if we are bored me and my } \\
\text { friends will go to his place and } \\
\text { watch tv or something" }\end{array}$ \\
\hline & $\begin{array}{l}\text { Home- Friends in private } \\
\text { residence }\end{array}$ & $\begin{array}{l}\text { This node includes any reference } \\
\text { to hanging out with friends } \\
\text { including video gaming, talking, } \\
\text { partying or pre-gaming or other } \\
\text { activity in private residence in } \\
\text { hometown. }\end{array}$ & $\begin{array}{l}\text { Focus Group 1: } \\
\text { "I see all of my friends...other } \\
\text { friends" }\end{array}$ \\
\hline & $\begin{array}{l}\text { Campus- Outings with friends and } \\
\text { family }\end{array}$ & $\begin{array}{l}\text { This node includes any references } \\
\text { to going out with friends or family } \\
\text { to restaurants, bars, sporting } \\
\text { events, outdoor activities on } \\
\text { campus. }\end{array}$ & $\begin{array}{l}\text { Focus Group 4: } \\
\text { " I always plan on the fly. } \\
\text { Nothing is ever, I mean ok for } \\
\text { school and major and work and } \\
\text { stuff, social stuff is like I have an } \\
\text { extra half hour, wanna go do this? }\end{array}$ \\
\hline
\end{tabular}




\begin{tabular}{|c|c|c|c|}
\hline & & & $\begin{array}{l}\text { My friends and I have been going } \\
\text { to different restaurants or cafes } \\
\text { downtown and there are so many } \\
\text { little boutiques and we just } \\
\text { window shop and find little } \\
\text { adventures that we didn't think of. } \\
\text { It's usually not planned though." }\end{array}$ \\
\hline & $\begin{array}{l}\text { Home- Outings with friends and } \\
\text { family }\end{array}$ & $\begin{array}{l}\text { This node includes any references } \\
\text { to going out with friends or family } \\
\text { to restaurants, bars, sporting } \\
\text { events, outdoor activities at home. }\end{array}$ & $\begin{array}{l}\text { Focus Group 5: } \\
\text { " We still go to basketball games, } \\
\text { our high school games and we } \\
\text { can't sit in the student section } \\
\text { anymore because that just } \\
\text { creepy." }\end{array}$ \\
\hline & Campus- Significant Other & $\begin{array}{l}\text { This node includes all references } \\
\text { to time spent with significant other } \\
\text { on campus. }\end{array}$ & \\
\hline & Home- Significant Other & $\begin{array}{l}\text { This node includes all references } \\
\text { to time spent with significant other } \\
\text { at home. }\end{array}$ & $\begin{array}{l}\text { Focus Group 1: } \\
\text { "4: drink, see my boyfriend } \\
\text { 2: yeah, spend as much time as } \\
\text { humanly possible with my } \\
\text { boyfriend } \\
\text { 5: with my girlfriend, but she's } \\
\text { always busy" }\end{array}$ \\
\hline & Home- Time with Family & $\begin{array}{l}\text { This node includes all references } \\
\text { to time spent with family while at } \\
\text { home. }\end{array}$ & $\begin{array}{l}\text { Focus Group 6: } \\
\text { " I only went home really twice } \\
\text { because one was my sisters } \\
\text { birthday so I had to go home for } \\
\text { that and the other one I had a lot } \\
\text { of laundry so I decided to go } \\
\text { home and have my mom do it." }\end{array}$ \\
\hline $\begin{array}{l}\text { Informal Social Control- refers to } \\
\text { the extent to which neighbors } \\
\text { work collectively to maintain } \\
\text { social order, such as neighborhood } \\
\text { delinquency of children, it } \\
\text { included the extent to which }\end{array}$ & General & $\begin{array}{l}\text { Informal social control includes } \\
\text { any reference to self or others } \\
\text { intervening if a fellow student or } \\
\text { neighbor were violating policy or } \\
\text { law, disturbing the peace, or other } \\
\text { situation that is considered }\end{array}$ & $\begin{array}{l}\text { Focus Group 6: } \\
\text { " my dads on it and I wont accept } \\
\text { him and my brother too so he's } \\
\text { not he happiest with me but my } \\
\text { little cousins have facebook so } \\
\text { I'm friends with them and there }\end{array}$ \\
\hline
\end{tabular}




\begin{tabular}{|c|c|c|c|}
\hline \multirow[t]{3}{*}{$\begin{array}{l}\text { neighbors disciplined children, } \\
\text { called parents when children } \\
\text { misbehaved, and reported } \\
\text { delinquent behaviors. }\end{array}$} & & $\begin{array}{l}\text { socially unacceptable behavior. } \\
\text { This includes ISC in hometown } \\
\text { neighborhoods and at WVU both } \\
\text { in person and via internet social } \\
\text { networking sites. }\end{array}$ & $\begin{array}{l}\text { cute but they're in like } 8^{\text {th }} \text { grade } \\
\text { and ones in } 5^{\text {th }} \text { grads that just } \\
\text { funny to see what there doing on } \\
\text { it" }\end{array}$ \\
\hline & Campus- ISC & $\begin{array}{l}\text { This node includes all references } \\
\text { to informal social control or } \\
\text { absence of on campus. }\end{array}$ & $\begin{array}{l}\text { Focus Group 9: } \\
\text { " If someone was upset about a } \\
\text { certain situation in the dorm or } \\
\text { with a roommate or suitemate we } \\
\text { normally go to the RA, but most } \\
\text { of the time, the residents don't } \\
\text { because they are fearful of the } \\
\text { other residents. I am one who is } \\
\text { slightly fearful of the residents } \\
\text { that live with us which I shouldn't } \\
\text { be but I am. They have attitudes." }\end{array}$ \\
\hline & Home- ISC & $\begin{array}{l}\text { This node includes all references } \\
\text { to informal social control or } \\
\text { absence of at home. }\end{array}$ & $\begin{array}{l}\text { Focus Group 8: } \\
\text { "I feel like my neighbors are the } \\
\text { weirdest mix of people in the } \\
\text { entire world. I had someone call } \\
\text { my house last year. I was on the } \\
\text { track team so I like to run. When } \\
\text { we didn't have practice, I would } \\
\text { run around the neighborhood. } \\
\text { When I would finish my } \\
\text { homework I would get up and go } \\
\text { out and run. I had a lady call my } \\
\text { house asking for my parents with } \\
\text { this severe urgency. Like } \\
\text { something horrible had happened, } \\
\text { but they wanted to tell them I was } \\
\text { running in the dark and it was not } \\
\text { safe. I am } 18 \text {, I wear white and no } \\
\text { cars drive through our } \\
\text { neighborhood, I just thought it } \\
\text { was crazy. We have had people }\end{array}$ \\
\hline
\end{tabular}




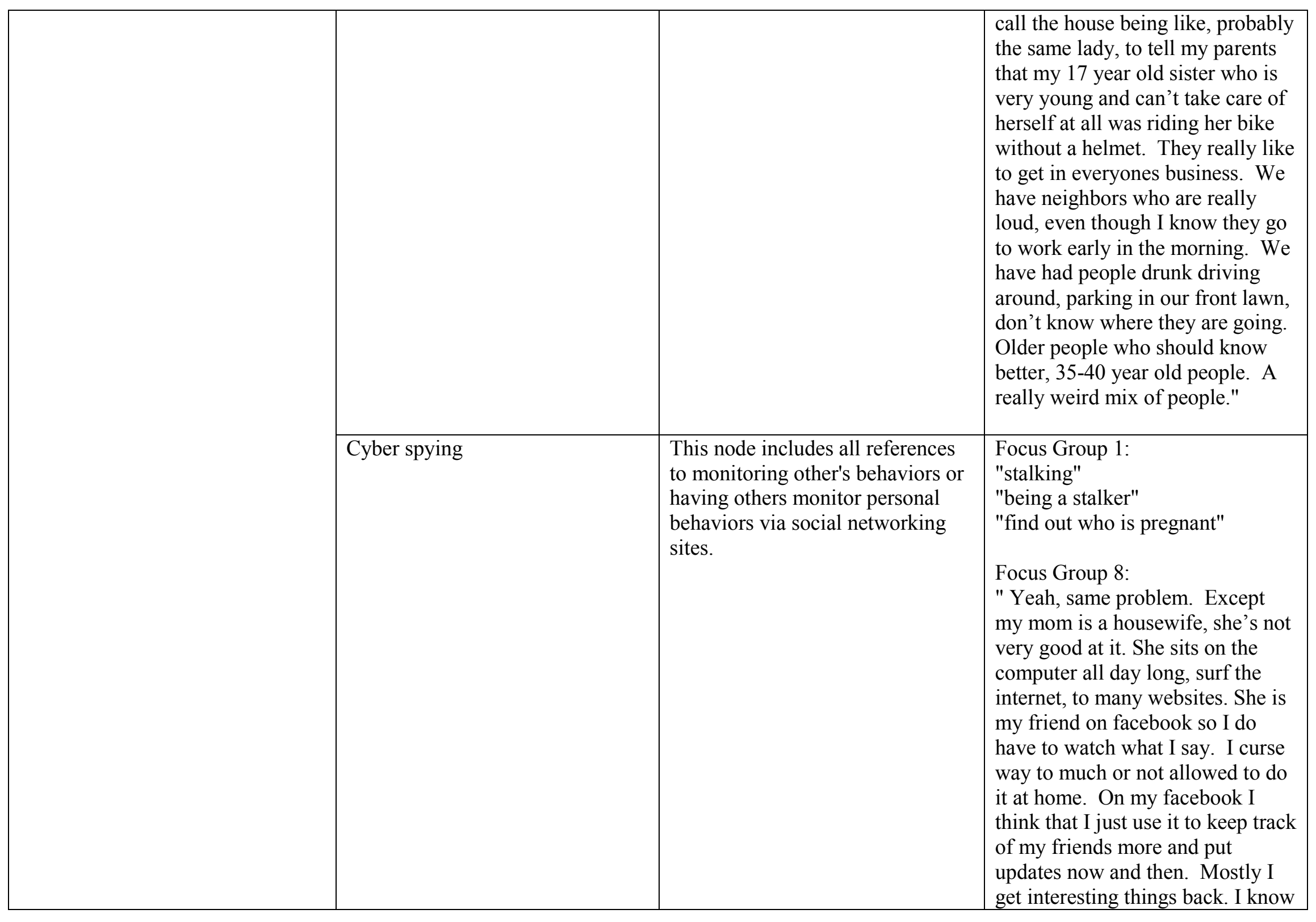




\begin{tabular}{|c|c|c|c|}
\hline & & & $\begin{array}{l}\text { she stalks me because she'll ask } \\
\text { about it. " }\end{array}$ \\
\hline \multirow[t]{6}{*}{$\begin{array}{l}\text { Intergenerational } \\
\text { Connectedness- refers to how } \\
\text { connected individuals feel with } \\
\text { adults and mentors who are not } \\
\text { their parents }\end{array}$} & General & $\begin{array}{l}\text { Intergenerational connectedness } \\
\text { refers to any reference to adults } \\
\text { other than parents that students } \\
\text { reported feeling connected to } \\
\text { either at home or on campus. } \\
\text { Examples include other family } \\
\text { members, coaches, WVU staff, } \\
\text { older students, significant others, } \\
\text { or other adults. }\end{array}$ & $\begin{array}{l}\text { Focus Group 6: } \\
\text { "My coaches back home" }\end{array}$ \\
\hline & Activity leaders & $\begin{array}{l}\text { This node refers to persons in } \\
\text { students' lives that they rely on for } \\
\text { support who were activity leaders } \\
\text { (such as coaches, youth group } \\
\text { leaders). }\end{array}$ & $\begin{array}{l}\text { Focus Group 3: } \\
\text { " My friends parents. I could go } \\
\text { to some of my professors for } \\
\text { school related stuff. Advisors for } \\
\text { the club I belong to." }\end{array}$ \\
\hline & Older peers & $\begin{array}{l}\text { This node refers to persons in } \\
\text { students' lives that they rely on for } \\
\text { support who are older non-related } \\
\text { peers. }\end{array}$ & $\begin{array}{l}\text { Focus Group 1: } \\
\text { "my roommate" }\end{array}$ \\
\hline & On Campus Staff & $\begin{array}{l}\text { This node refers to persons in } \\
\text { students' lives that they rely on for } \\
\text { support who are professors, } \\
\text { instructors, staff, or RAs. }\end{array}$ & $\begin{array}{l}\text { Focus Group 3: } \\
\text { " My friends parents. I could go } \\
\text { to some of my professors for } \\
\text { school related stuff. Advisors for } \\
\text { the club I belong to." }\end{array}$ \\
\hline & Other adults & $\begin{array}{l}\text { This node refers to persons in } \\
\text { students' lives that they rely on for } \\
\text { support who are other non-related } \\
\text { adults (neighbors, family friends, } \\
\text { etc). }\end{array}$ & $\begin{array}{l}\text { Focus Group 3: } \\
\text { " My friends parents. I could go } \\
\text { to some of my professors for } \\
\text { school related stuff. Advisors for } \\
\text { the club I belong to." }\end{array}$ \\
\hline & Other family & $\begin{array}{l}\text { This node includes all references } \\
\text { to family members other than } \\
\text { parents who students count on for } \\
\text { support. }\end{array}$ & $\begin{array}{l}\text { Focus Group 10: } \\
\text { " when I had it I liked it because } \\
\text { my mom has like ten brothers and } \\
\text { sisters, so I have lots of aunts, } \\
\text { uncles, and cousins. Most of them } \\
\text { live like out of state. A lot are in }\end{array}$ \\
\hline
\end{tabular}




\begin{tabular}{|c|c|c|c|}
\hline & & & $\begin{array}{l}\text { Columbus, California, Georgia. I } \\
\text { feel like I can get on [facebook] } \\
\text { and talk. We see them once a } \\
\text { year for a reunion, but I can send } \\
\text { a message on the chat and talk for } \\
\text { a little bit. I feel like I got to } \\
\text { know some of my cousins more } \\
\text { through that. I never talked to } \\
\text { them before until then" }\end{array}$ \\
\hline & Religious leaders & $\begin{array}{l}\text { This node refers to persons in } \\
\text { students' lives that they rely on for } \\
\text { support who were religious leaders } \\
\text { such as pastors, youth pastors, and } \\
\text { others }\end{array}$ & $\begin{array}{l}\text { Focus Group 1: } \\
\text { "also, youth pastors" }\end{array}$ \\
\hline \multirow[t]{2}{*}{$\begin{array}{l}\text { Norms \& Values- refers to a set } \\
\text { of community norms that reflect a } \\
\text { shared meaning of behaviors }\end{array}$} & General & $\begin{array}{l}\text { This node includes codes that } \\
\text { reference the norms and values } \\
\text { that are important to students at } \\
\text { home and on campus as a } \\
\text { Mountaineer. These may include } \\
\text { examples of behavior related } \\
\text { norms, religious norms, social } \\
\text { responsibility norms, academic } \\
\text { norms, or emotional norms. }\end{array}$ & $\begin{array}{l}\text { Focus Group 7: } \\
\text { " I guess it's different between my } \\
\text { parents and my siblings. One of } \\
\text { them is graduated and has a job } \\
\text { now. Um, another one is in third } \\
\text { year of med school. She wants to } \\
\text { graduate and become a doctor. } \\
\text { Hard to tell my parents values? } \\
\text { sigh I guess it's still to make sure, } \\
\text { I don't know, they are kind of } \\
\text { done with raising us because we } \\
\text { are older. I don't know, just enjoy } \\
\text { the rest of their lives I guess. } \\
\text { Make sure they are a good } \\
\text { member of society. They have } \\
\text { certain friends, make sure they } \\
\text { keep their social lives active." }\end{array}$ \\
\hline & Campus-Values and Norms & $\begin{array}{l}\text { This node includes references to } \\
\text { values held by family or perceived } \\
\text { to be campus or Mountaineer } \\
\text { values. }\end{array}$ & $\begin{array}{l}\text { Focus Group 9: } \\
\text { " WVU is solely concerned about } \\
\text { accruing more money and less } \\
\text { concerned about the students } \\
\text { themselves. And, that's based on }\end{array}$ \\
\hline
\end{tabular}




\begin{tabular}{|c|c|c|c|}
\hline & & & $\begin{array}{l}\text { more stories. Um. The students, } \\
\text { although I said I like going here, I } \\
\text { do not have need to drink every } \\
\text { day or every weekend but when I } \\
\text { do I have a tendency to make up } \\
\text { for lost time. Most of the students } \\
\text { I feel are kind of just here because } \\
\text { their parents told them that they } \\
\text { should be. That's why we have } \\
\text { such a high turnover rate. I heard } \\
\text { that } 2 \text { out of } 3 \text { people don't } \\
\text { actually manage to graduate. } \\
\text { Example of why, when I was out } \\
\text { on the green a few minutes ago all } \\
\text { there is on frat row is blaring } \\
\text { music and people drunk while the } \\
\text { sun is still up. I would imagine } \\
\text { that since they are drunk at } 5 \text { p.m. } \\
\text { they have been doing it for } \\
\text { awhile, which probably means } \\
\text { they didn't make it to class. I } \\
\text { think that is a huge proportion of } \\
\text { our students." }\end{array}$ \\
\hline & Home- Values and Norms & $\begin{array}{l}\text { This node includes references to } \\
\text { values held by family or perceived } \\
\text { to be hometown values. }\end{array}$ & $\begin{array}{l}\text { Focus Group 2: } \\
\text { "I mean like some people change } \\
\text { from like high school to college, } \\
\text { but I didn't feel like I did. Like, } \\
\text { my values are the same values." }\end{array}$ \\
\hline $\begin{array}{l}\text { Social Support- refers to the } \\
\text { informational, instrumental, } \\
\text { emotional, and appraisal support } \\
\text { provided within the neighborhood } \\
\text { and to individuals }\end{array}$ & General & $\begin{array}{l}\text { This node includes coded sections } \\
\text { that refer to social support } \\
\text { (informational, instrumental, } \\
\text { appraisal, emotional) that students } \\
\text { receive from both home and } \\
\text { campus sources either in person, } \\
\text { over the phone or via internet } \\
\text { social networking sites. Types of }\end{array}$ & $\begin{array}{l}\text { Focus Group 3: } \\
\text { " I think if you develop them fast } \\
\text { it should be because you are real. } \\
\text { If you are not real it's not going to } \\
\text { be a lasting friendship. I had a } \\
\text { friend my freshman year and we } \\
\text { were really close but she would } \\
\text { flip personalities. She would be }\end{array}$ \\
\hline
\end{tabular}




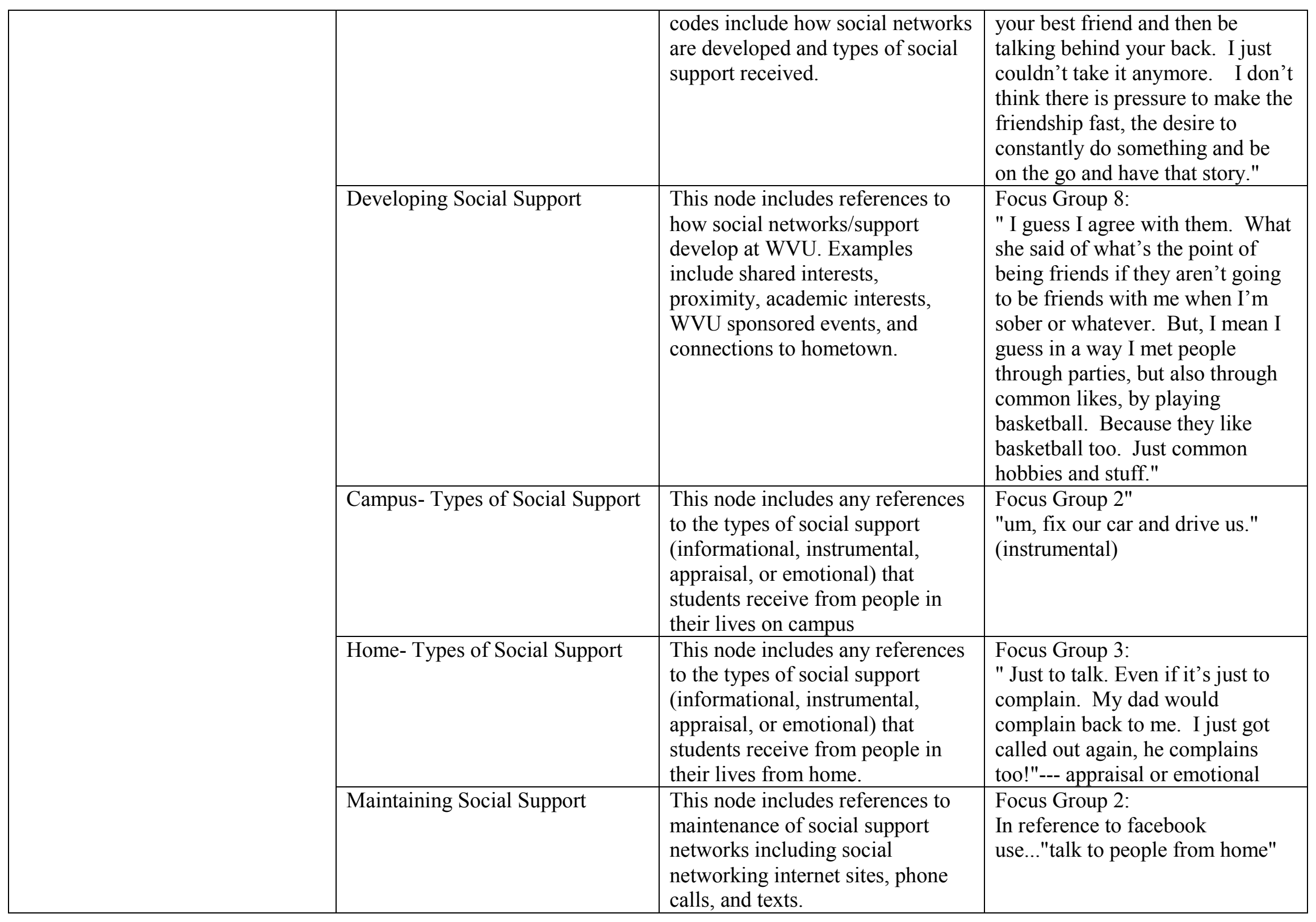




\begin{tabular}{|c|c|c|c|}
\hline & Who Provides Support & $\begin{array}{l}\text { This node includes references to } \\
\text { who provides social support in } \\
\text { students' lives. Examples include } \\
\text { friends, parents, etc. }\end{array}$ & $\begin{array}{l}\text { Focus Group 3: } \\
\text { "parents, siblings, friends." }\end{array}$ \\
\hline \multirow[t]{2}{*}{$\begin{array}{l}\text { Trust \& Reciprocity- refers to the } \\
\text { belief that neighbors can be trusted } \\
\text { and relied upon to provide } \\
\text { instrumental resources if needed. } \\
\text { Trust and reciprocity often include } \\
\text { feelings of safety and crime }\end{array}$} & General & $\begin{array}{l}\text { Trust and reciprocity includes } \\
\text { codes for any reference to feelings } \\
\text { of trust, reciprocity such as favors } \\
\text { for neighbors (or self from } \\
\text { neighbors), and feelings of safety } \\
\text { in both hometown and on campus. }\end{array}$ & $\begin{array}{l}\text { Focus Group 3: } \\
\text { "I never feel unsafe anywhere, I } \\
\text { think. In general. Any city. I grew } \\
\text { up in Baltimore and it was kind of } \\
\text { a bad city. If you mind your } \\
\text { business and act normal no one } \\
\text { really bothers you. I never } \\
\text { really..." }\end{array}$ \\
\hline & Campus- Safety & $\begin{array}{l}\text { This node includes any references } \\
\text { to feelings of safety on campus. }\end{array}$ & $\begin{array}{l}\text { Focus Group 1: } \\
\text { "9: no } \\
\text { 5: not past } 2 \text { in the morning } \\
\text { 2: I feel completely safe walking } \\
\text { around by myself for the most part } \\
\text { 3: I also feel safe walking around } \\
\text { by myself, even at night } \\
\text { 20: I don't feel safe walking } \\
\text { around by myself } \\
\text { 2: I feel capable of self defense, } \\
\text { plus I am a lot bigger than they } \\
\text { and also everywhere I go is } \\
\text { usually pretty well lit and pretty } \\
\text { well populated } \\
\text { 14: The only time I was kind of } \\
\text { (bitched?) out was when I was } \\
\text { like walking from Arnold to } \\
\text { Towers and took like University, } \\
\text { but that wasn't even that bad } \\
\text { 5: I had to go to the Dairy Mart in } \\
\text { the middle of the night because I } \\
\text { had a bad headache and I was } \\
\text { afraid I was going to get mugged } \\
\text { cause that is what happens at the }\end{array}$ \\
\hline
\end{tabular}




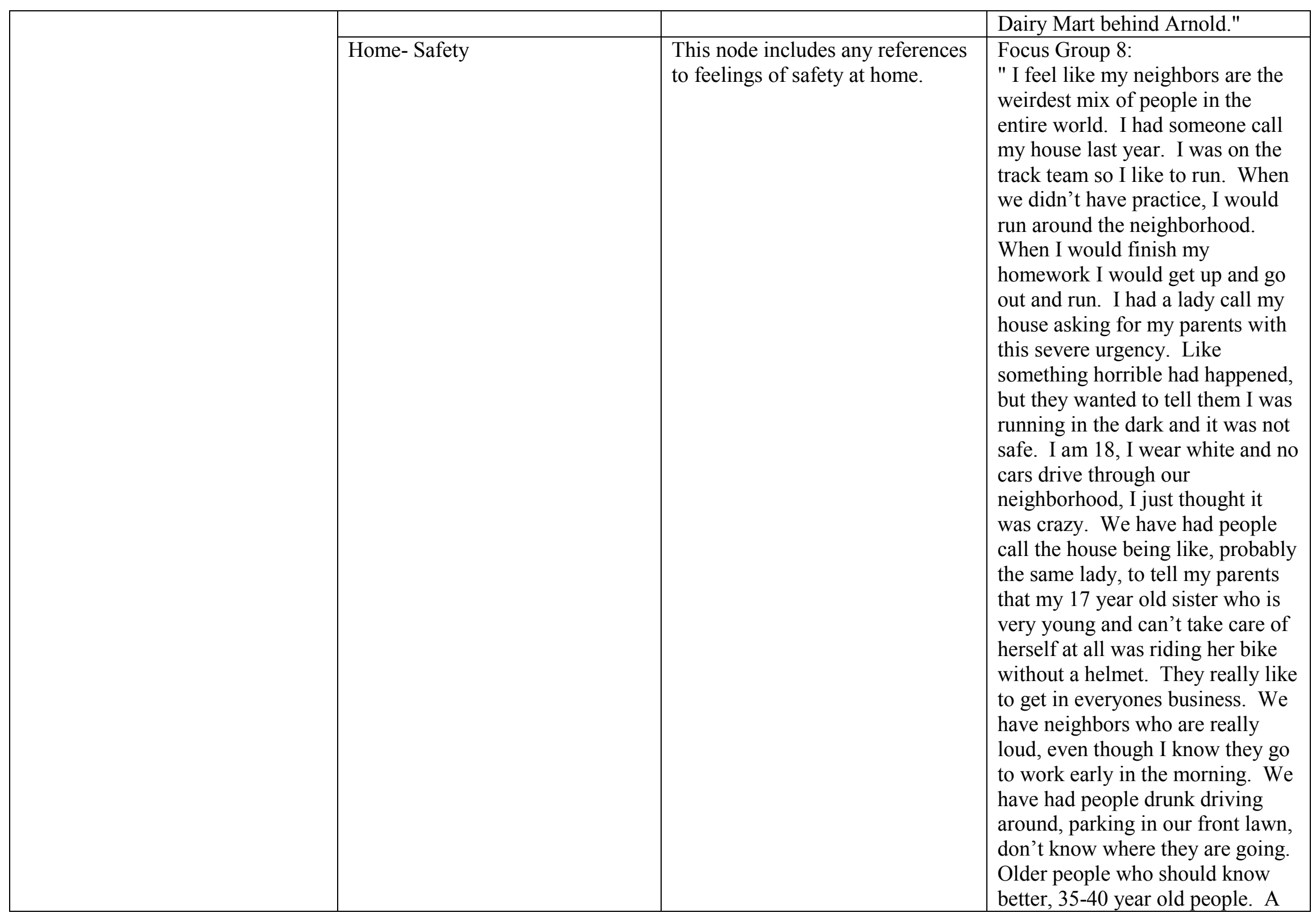




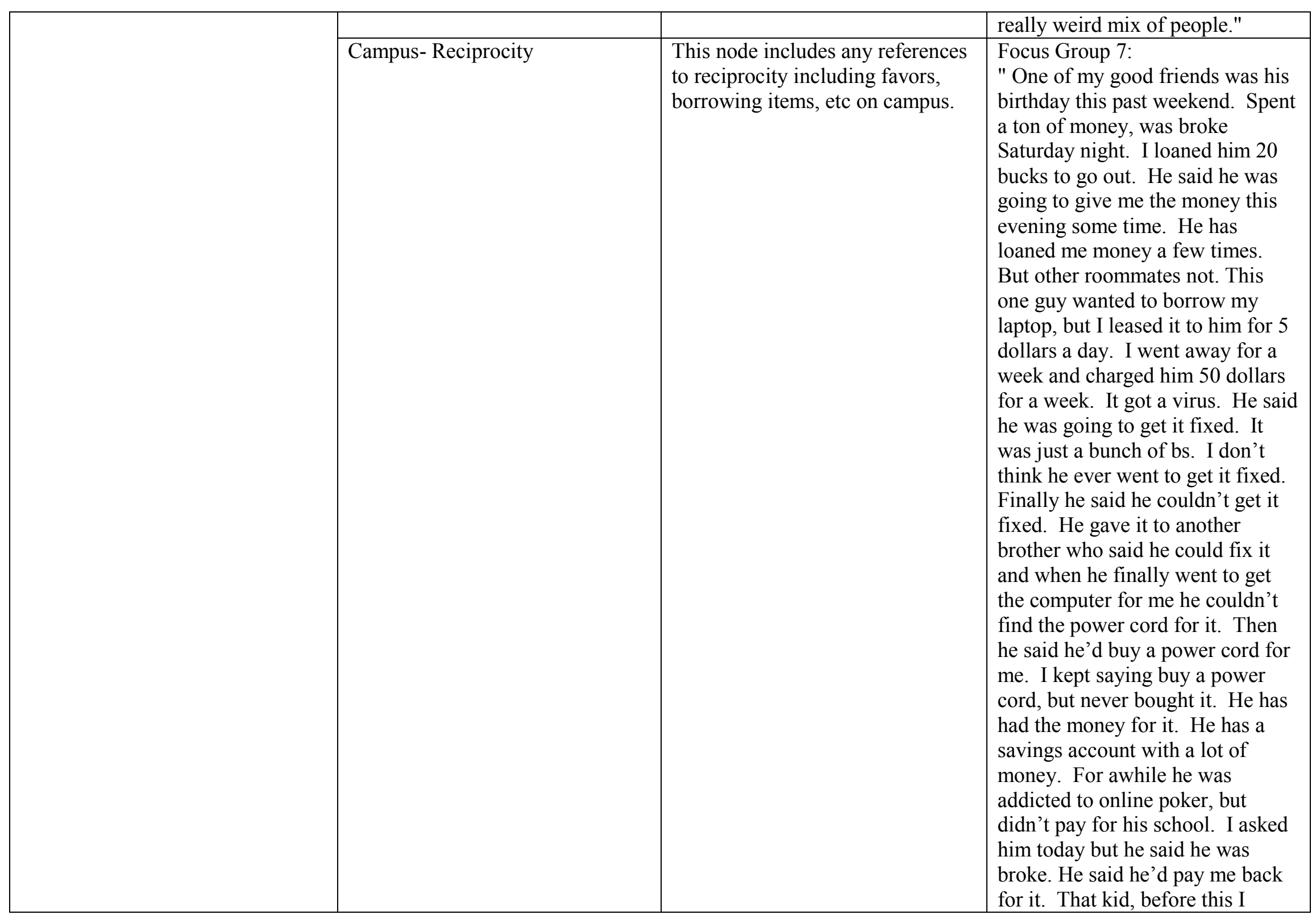




\begin{tabular}{|c|c|c|c|}
\hline & & & $\begin{array}{l}\text { would say, I would have his back } \\
\text { for anything really. Certain times } \\
\text { I don't know if I would have his } \\
\text { back because I lost trust in him." }\end{array}$ \\
\hline & Home- Reciprocity & $\begin{array}{l}\text { This node includes any references } \\
\text { to reciprocity including favors, } \\
\text { borrowing items, etc at home. }\end{array}$ & $\begin{array}{l}\text { Focus Group 5: } \\
\text { " yeah, everybody is kind of like } \\
\text { you just share each other, if you } \\
\text { need something you give it to } \\
\text { them and if they need something } \\
\text { they give it to you. } \\
4: \text { yeah that the way it's where I } \\
\text { live too, everybody pretty much } \\
\text { helps out everybody." }\end{array}$ \\
\hline & Campus- Trust & $\begin{array}{l}\text { This node includes any references } \\
\text { to trust on campus. This can } \\
\text { include feelings of trust and } \\
\text { feelings of distrust.--secondary } \\
\text { coding of relationship history-- } \\
\text { This node includes references to } \\
\text { relationship history with friends } \\
\text { and neighbors as a mechanism of } \\
\text { trust (good or bad). }\end{array}$ & $\begin{array}{l}\text { Focus Group 2: } \\
\text { "I trust people in my, like on my } \\
\text { floor, cause we're all like close, we } \\
\text { hang out. But I wouldn't trust them } \\
\text { just like walking downtown. I } \\
\text { wouldn't like leave my like } \\
\text { something laying in the } \\
\text { Mountainlair or something like } \\
\text { that. But like in my like hallway, I } \\
\text { would leave something." }\end{array}$ \\
\hline & Home- Trust & $\begin{array}{l}\text { This node includes any references } \\
\text { to trust at home. This can include } \\
\text { feelings of trust and feelings of } \\
\text { distrust.--secondary coding of } \\
\text { relationship history-- This node } \\
\text { includes references to relationship } \\
\text { history with friends and neighbors } \\
\text { as a mechanism of trust (good or } \\
\text { bad). }\end{array}$ & $\begin{array}{l}\text { Focus Group 1: } \\
\text { " I have a church right behind my } \\
\text { home so I should have to, I should } \\
\text { be able to trust a church" }\end{array}$ \\
\hline $\begin{array}{l}\text { Civic Engagement- refers to an } \\
\text { individual's willingness to } \\
\text { participate in the political process. }\end{array}$ & General & $\begin{array}{l}\text { This node includes codes that refer } \\
\text { to participation in political } \\
\text { activities including voting, signing } \\
\text { petitions, writing editorials, in }\end{array}$ & $\begin{array}{l}\text { Focus Group 9: } \\
\text { "When I'm home I vote. My } \\
\text { grandfather was on the house of } \\
\text { delegates and so I always heard }\end{array}$ \\
\hline
\end{tabular}




\begin{tabular}{|c|c|c|c|}
\hline & & $\begin{array}{l}\text { national, state, local home, local } \\
\text { Morgantown, or campus elections. }\end{array}$ & $\begin{array}{l}\text { politics, politics, politics all the } \\
\text { time. I got used to it. It can be } \\
\text { quite interesting sometimes." }\end{array}$ \\
\hline & Political Behaviors & $\begin{array}{l}\text { This node includes any references } \\
\text { to voting behaviors including } \\
\text { registering to vote, intentions to } \\
\text { vote, feelings about voting, voting } \\
\text { behaviors, participation in political } \\
\text { organizations, neighborhood } \\
\text { associations, or student residence } \\
\text { hall associations, and signing } \\
\text { petitions. }\end{array}$ & $\begin{array}{l}\text { Focus Group 4: } \\
\text { "I don't know much about the } \\
\text { government so I'm not going to } \\
\text { vote, but if I had to vote I would } \\
\text { probably vote for the most } \\
\text { popular because I've seen that } \\
\text { everywhere." }\end{array}$ \\
\hline & Empowerment & $\begin{array}{l}\text { This node includes references to } \\
\text { whether or not students feel } \\
\text { empowered through the political } \\
\text { process. }\end{array}$ & $\begin{array}{l}\text { Focus Group 8: } \\
\text { " Is there a level at the university } \\
\text { that you feel you do have } \\
\text { influence? } \\
\text { RHA meetings, we do affect more } \\
\text { stuff. It mostly only affects people } \\
\text { in the residence halls. We are } \\
\text { working on a big thing to do with } \\
\text { the visitation policy fixing the } \\
\text { wording so it will include } \\
\text { homosexuals. Need to rewrite the } \\
\text { rules to include this. Especially } \\
\text { for overnight guests of the same } \\
\text { sex. Important to talk to people, } \\
\text { going to Charleston and talking to } \\
\text { Senators about issues here. Even } \\
\text { though it is here, it is very } \\
\text { political. They do have a lot of } \\
\text { influence." }\end{array}$ \\
\hline Endogeneity-refers to a potential & General & Endogeneity includes codes for all & Focus Group 5: \\
\hline
\end{tabular}




\begin{tabular}{|c|c|c|c|}
\hline \multirow{6}{*}{$\begin{array}{l}\text { bias in social capital research } \\
\text { because it is possible that selection } \\
\text { of a neighborhood as a residence is } \\
\text { a choice and therefore the } \\
\text { participant has the potential to } \\
\text { affect their own level of social } \\
\text { capital. This is a particular concern } \\
\text { in the college population because } \\
\text { of the myriad of choices available } \\
\text { to them. }\end{array}$} & & $\begin{array}{l}\text { references to why students chose } \\
\text { to attend WVU as their } \\
\text { undergraduate institution. } \\
\text { Examples include family reasons, } \\
\text { school attributes, finances, peer } \\
\text { group attending, and no other } \\
\text { choice. }\end{array}$ & $\begin{array}{l}\text { "Because most of my friends } \\
\text { came up here, my real close } \\
\text { friends and it seems like a good } \\
\text { choice it's far enough away from } \\
\text { home that where mom couldn't } \\
\text { show up every day. That'd be } \\
\text { bad." }\end{array}$ \\
\hline & Family & $\begin{array}{l}\text { This node includes references to } \\
\text { the family that influenced the } \\
\text { student to come to WVU. This } \\
\text { may include WVU as a family } \\
\text { tradition, proximity to family, and } \\
\text { parental influences (or lack } \\
\text { thereof). }\end{array}$ & $\begin{array}{l}\text { Focus Group 1: } \\
\text { " Family tradition" }\end{array}$ \\
\hline & Peer Group Attendance & $\begin{array}{l}\text { This node includes all references } \\
\text { to students choosing to attend } \\
\text { WVU because peer groups were } \\
\text { also attending. This may include } \\
\text { friends from current hometown, } \\
\text { internet friends, friends from a } \\
\text { previous hometown, or family } \\
\text { friends. }\end{array}$ & $\begin{array}{l}\text { Focus Group 2: } \\
\text { "...I mean, I know a couple of } \\
\text { people who go here and they liked } \\
\text { it, so..." }\end{array}$ \\
\hline & Other- Proximity to hometown & $\begin{array}{l}\text { This node includes all reference to } \\
\text { other reasons that students chose } \\
\text { to attend WVU such as no other } \\
\text { option and proximity to } \\
\text { hometown. }\end{array}$ & $\begin{array}{l}\text { Focus Group 1: } \\
\text { " close to home" }\end{array}$ \\
\hline & Financial reasons & $\begin{array}{l}\text { This node includes all references } \\
\text { to financial reasons that students } \\
\text { chose to attend WVU. }\end{array}$ & $\begin{array}{l}\text { Focus Group 1: } \\
\text { " Money" }\end{array}$ \\
\hline & School attributes & $\begin{array}{l}\text { This node includes any references } \\
\text { to WVU as a school as a reason } \\
\text { for attendance. Examples include } \\
\text { facilities, academic and } \\
\text { educational reputation, party } \\
\text { school reputation, sports, and }\end{array}$ & $\begin{array}{l}\text { Focus Group 4: } \\
\text { " I originally came here for } \\
\text { athletic training and I always } \\
\text { thought I wanted to be a physical } \\
\text { therapist and still that is a huge } \\
\text { option, but its like, but I've come }\end{array}$ \\
\hline
\end{tabular}




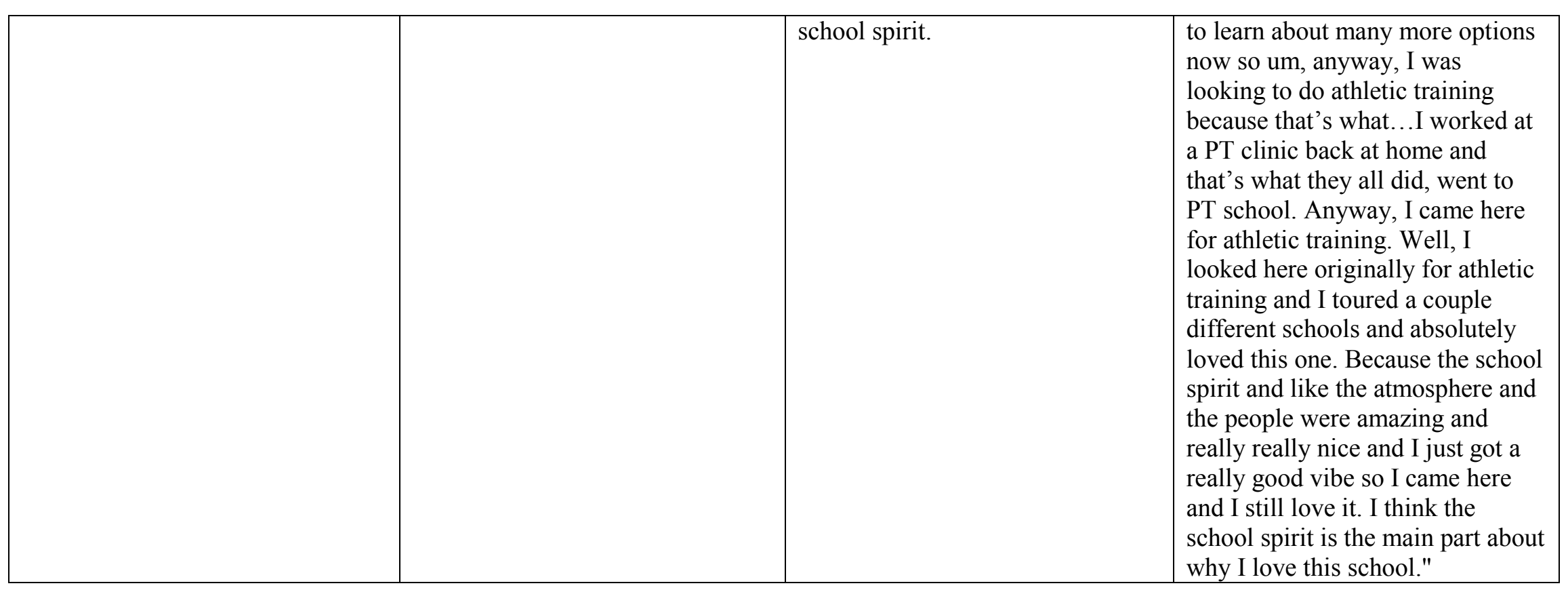

\section{Other Connections:}

\section{Focus Group 10:}

" Here. Like, I guess because I have been away for so long. I do go back and forth during breaks it seems like everytime I go back there is something different, and when I come back here it just feels more like home.

M: Thinking back, did you always feel that way, or did it happen over time?

I think it's something that happened over time. I know over my freshman year, that first Thanksgiving break and winter break after everyone went away and came back, we felt like we were still in high school and it was just another day and we went on vacation and were excited to tell everyone where we had been. And then another year, and year after that, it got to the point 
that everyone was so focused on doing their own thing like internships or getting ready for grad school, where when we came home the classes below us would take our place. All of the other classes would take our places. Even things in the community like new buildings or housing developments. It didn't even look the same. Every time you would go back it would feel different even though we call it home. I know some of my friends how we would say that we are going home but we meant our universities. I know when I am down in Rockville I say I'm going back home but I'm talking about Morgantown. Happens over time, when you close a chapter and open a new one. It's a process that happens.

Feel more connected here now but like she said over time I think I will be more connected here. In the dorms it is not the best place to live. You are there with all your friends. After I have an apartment it will become more of my home.

\section{Morgantown:}

Focus Group 8:

"In my opinion this is one of the best college towns. They have so much pride whether the townspeople have never been to the university or if they have been. During a football game it is the most amazing site I have ever seen. All of Patteson drive is filled with tailgate parties and so much traffic. Everyone has a WVU flag. A whole parking lot filled with trailers and tailgate parties. It was really a nice thing to watch. A lot of my friends and I used to walk to the games and like just seeing everyone excited and cheering. Everybody has pride in the university. University is also responsible for the economy here."

"Morgantown itself the city is really run down, but I also agree it's a great college town. People really do take pride in the university. I feel like people respect the college but I don't feel like the college respects the town back almost. It's trashy, dirty, people throw stuff everywhere. Even if we are students we are technically living here. We are here more than we are at home. Need to take more pride in the town. Clean it up a little better. They do fix the roads but do a temporary job. Spend a minimal amount of money and then do it again in a year." 


\section{Appendix C: College Student Social Capital Survey}

DO NOT FILL OUT THIS SURVEY IF YOU ARE UNDER THE AGE OF 18.

1. Purpose of the Study: The purpose of this research study is to measure social capital among college students at West Virginia University. We are interested in how students engage in the campus community and also stay connected to home. We are also interested in cigarette smoking behaviors among college students. Although the smoking questions are secondary to the primary purpose of the study, and whether or not you do or do not smoke, your answers are important to help us understand how connections at WVU happen.

2. Procedures to be followed: You are being asked to complete an online survey designed to examine social capital among college students. If you need to stop the survey before completing it, you will be able to resume where you left off when you log in again. We may ask you to complete the survey again 2-4 weeks after the initial invitation.

3. Discomforts and Risks: Some of the questions are personal and might cause minimal discomfort. In addition, some of the questions ask about potentially illegal behavior, such as drinking and drug use. This information could potentially be a risk to you if it became known and could be linked to your identity. At the end of the survey we will a list of resources available to WVU students if you become concerned about any of these issues.

4. Benefits: Your participation in this research will provide valuable insight into how students become engaged in their campus communities and how they stay connected to their hometowns. You will receive no extra credit for participation as well as if you do no participate, it will not impact your standing at the university or in your classes.

5. Duration: It will take about 25-30 minutes to complete the survey.

6. Statement of Confidentiality: This research is confidential. That means that with the exceptions noted below, no one outside the research team will know your identity, and we will not release your identity in any publications or reports about this research. We will not share your individual responses with your parents, faculty, or with the campus administration. We have taken the following steps to protect your identity as a research participant:

a) Your name will not be on your survey. Your questionnaire will be identified only by a unique Personal Identification Number (PIN), randomly generated for this research study.

b) We will keep a master list of names and PINs, for payment purposes. However, the master list will be stored separately from your questionnaire, in a locked file cabinet accessible only to the research team, and on a password-protected computer with restricted access.

c) Your consent form and other identifying information such as address update information will also be stored on a password-protected computer, accessible only to the research team.

d) We retain all data indefinitely; however, the master list linking your name and other identifying information with your PIN number will be destroyed at the end of the semester during which you completed the survey.

e) The survey will be completed online using a secure server supporting 128-bit encryption, which provides the highest available level of protection for your confidentiality. However, there are no guarantees that a third party could not intercept the data. These data will be retained indefinitely identified only by the PIN.

7. Right to Ask Questions: Please contact Dr. Kim Horn at (304) 293-0268 or Traci Jarrett, MPH at tjarrett@hsc.wvu.edu or (304) 293-0670 with questions, complaints, or concerns about this research. You can also call these numbers if you feel this study has harmed you. If you have any questions, concerns, or problems about your rights as a research participant or would like to offer input, please contact the WVU Office of Human Subjects Protection at (304) 293-1119. The Office of Human Subjects Protection cannot answer questions about research procedures. Questions about research procedures can be answered by the research team.

8. Payment for participation: The first 500 participants will receive a $\$ 10$ online gift card for your participation for completing the survey. We will email you a gift card code that you can access at the end of the survey which you can use at an online business.

9. Voluntary Participation: Your decision to be in this research is voluntary. You can stop at any time.

You do not have to answer any questions you do not want to answer. Refusal to take part in or 
withdrawing from the survey will involve no penalty or loss of benefits.

You must be 18 years of age or older to take part in this research study.

Respondent's Statement

This study has been explained to me. I volunteer to take part in this research and I am at least 18 years of age. If I have questions, concerns, or complaints, or feel that this study has harmed me, I can

contact Kimberly Horn 304-293-0268 (khorn@hsc.wvu.edu) or Traci Jarrett at 304-293-0670

(tjarrett@hsc.wvu.edu). If I have questions, concerns, or problems about my rights as a research participant or would like to offer input, I can contact the WVU Office of Human Subjects Protection, at (304) 293-1119.

By clicking the "I agree" button and completing this survey, I acknowledge that I have read the information in this form and consent to take part in the research.

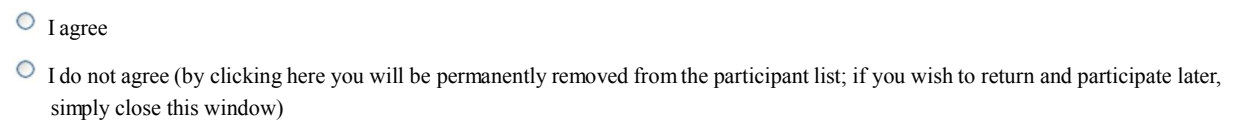

What is your gender?

Male

Female

Transgender

What is your age?

What race/ethnicity do you identify as (check all that apply)?

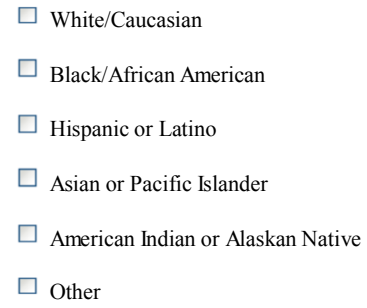

What is your current relationship status?

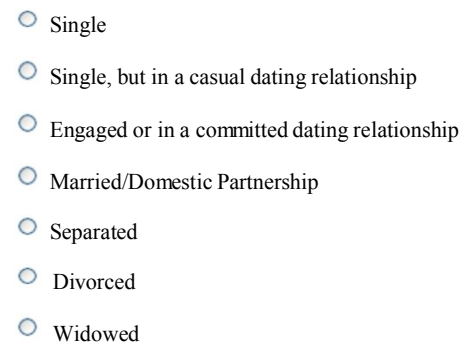

What is your sexual orientation?
Heterosexual
- Gay/Lesbian
Bisexual
Unsure/Questioning

Are you a full-time student? 
What is your current living situation?

Campus residence hall with roommates

Campus residence hall single

On-campus family housing or apartment

Other on-campus housing

Fraternity or sorority house

Off-campus housing with roommates

Off-campus housing living alone

Parent or other family member home

Other

My hometown could be classified as:

Very large city (population over 500,000 )

Large city (population 250,000-499,999)

Small city or suburb (population 50,000-250,0000)

Large town (population 10,000-49,999)

Small town (population 2500-9999)

Rural community (population under 2500)

Before coming to West Virginia University, how long did you live in your hometown?
less than 1 year
1-2 years
O $3-5$ years
O6-10 years
10-15 years
my whole life
$\bigcirc$ other

In the year before you came to college, did your parent or guardian (if your parents are divorced, think of your primary parent):
Own their home
$\bigcirc$ Own a second home
Rent a home or apartment
$\bigcirc$ Live with other family members
O Other 
What is the highest level of education completed by your mother?

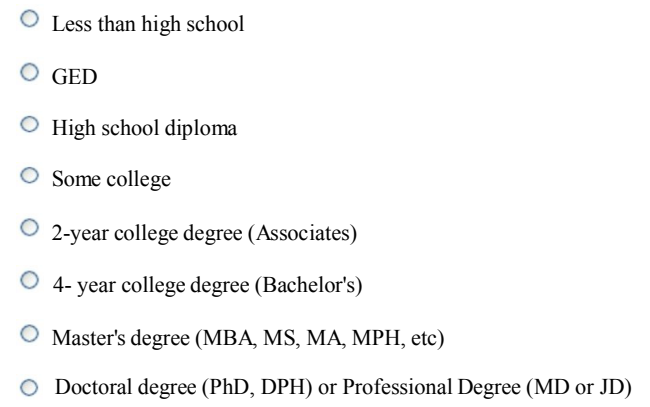

Please check the box corresponding to your parent or guardian's occupation.

\begin{tabular}{|c|c|c|c|}
\hline & Your mother's occupation & Your father's occupation & $\begin{array}{l}\text { Your primary guardian's } \\
\text { occupation (if not mother or } \\
\text { father) }\end{array}$ \\
\hline Accountant or actuary Actor & 0 & 0 & 0 \\
\hline or entertainer Architect or & 0 & 0 & 0 \\
\hline urban planner Artist & 0 & 0 & 0 \\
\hline Business (clerical) & 0 & 0 & 0 \\
\hline $\begin{array}{l}\text { Business executive } \\
\text { (management or }\end{array}$ & 0 & O & 0 \\
\hline $\begin{array}{l}\text { admınistrator) } \\
\text { Clergy (minister or priest) }\end{array}$ & 0 & 0 & 0 \\
\hline Clergy (other religious) & 0 & 0 & 0 \\
\hline Clinical psychologist & 0 & 0 & 0 \\
\hline Coal miner or coal industry & 0 & 0 & 0 \\
\hline College administrator/staff & 0 & 0 & 0 \\
\hline College professor or teacher & 0 & 0 & 0 \\
\hline $\begin{array}{l}\text { Computer programmer or } \\
\text { analyst }\end{array}$ & 0 & 0 & 0 \\
\hline Conservationist or forester & 0 & 0 & 0 \\
\hline Dentist & 0 & 0 & 0 \\
\hline Dietitian or nutritionist & 0 & 0 & 0 \\
\hline Engineer & 0 & 0 & 0 \\
\hline Farmer or rancher & 0 & 0 & 0 \\
\hline $\begin{array}{l}\text { Foreign service worker } \\
\text { (including diplomat) }\end{array}$ & o & 0 & 0 \\
\hline Homemaker (full time) & 0 & 0 & 0 \\
\hline Interior decorator & 0 & 0 & 0 \\
\hline Lab technician or hygienist & 0 & 0 & 0 \\
\hline Law enforcement officer & 0 & 0 & 0 \\
\hline Lawyer (attorney) or judge & 0 & 0 & 0 \\
\hline Military service (career) & 0 & 0 & 0 \\
\hline $\begin{array}{l}\text { Musician (performer or } \\
\text { composer) }\end{array}$ & 0 & 0 & 0 \\
\hline Nurse & 0 & 0 & 0 \\
\hline Optometrist & 0 & 0 & 0 \\
\hline Pharmacist & 0 & 0 & 0 \\
\hline Physician & O & 0 & 0 \\
\hline Policymaker/government & 0 & 0 & 0 \\
\hline School counselor & 0 & 0 & 0 \\
\hline $\begin{array}{l}\text { School principal or } \\
\text { superintendent }\end{array}$ & 0 & 0 & 0 \\
\hline Scientific researcher & O & 0 & 0 \\
\hline Self-employed & 0 & 0 & 0 \\
\hline \multirow{2}{*}{$\begin{array}{l}\text { Social, welfare, or recreation } \\
\text { worker }\end{array}$} & O & 0 & 0 \\
\hline & 0 & 0 & 0 \\
\hline
\end{tabular}




\begin{tabular}{l|ccc}
\cline { 2 - 3 } & Your father's occupation & $\begin{array}{c}\text { Your primary guardian's } \\
\text { occupation (if not mother or } \\
\text { father) }\end{array}$ \\
\hline $\begin{array}{l}\text { Therapist (physical, } \\
\text { occupational, speech) }\end{array}$ & 0 & 0 & 0 \\
$\begin{array}{l}\text { Teacher or administrator } \\
\text { (elementary) }\end{array}$ & 0 & 0 & 0 \\
$\begin{array}{l}\text { Teacher or administrator } \\
\text { (secondary) }\end{array}$ & 0 & 0 & 0 \\
$\begin{array}{l}\text { Veterinarian } \\
\text { Writer or journalist }\end{array}$ & 0 & 0 & 0 \\
Skilled trades Laborer & 0 & 0 & 0 \\
(unskilled) Semi- & 0 & 0 & 0 \\
skilled worker & 0 & 0 & 0 \\
Unemployed & 0 & 0 & 0 \\
Other & 0 & 0 & 0
\end{tabular}

What is your parents' or guardians' approximate combined annual income before taxes (if your parents are divorced, use the income of your primary guardian)? If you do not know, please indicate your best estimate.
$\bigcirc$ Less than $\$ 10,000$
○ $\$ 10,000-\$ 19,999$
○ $\$ 20,000-\$ 29,999$
○ $\$ 30,000-\$ 39,999$
○ $\$ 40,000-\$ 49,999$
○ $\$ 50,000-\$ 59,999$
○ $\$ 60,000-\$ 69,999$
○ $\$ 70,000-\$ 79,999$
○ $\$ 80,000-\$ 99,999$
- $\$ 100,000-\$ 124,999$
○ $\$ 125,000-\$ 149,999$
○ $\$ 150,000-\$ 174,999$
More than $\$ 175,000$
I don't know

What was your approximate personal annual income last year?
Less than $\$ 2000$
○ $\$ 2000-\$ 2999$
- $\$ 3000-\$ 3999$
○ $\$ 4000-\$ 4999$
○ $\$ 5000-\$ 5999$
○ $\$ 6000-\$ 7999$
○ $\$ 8000-\$ 9999$
Over $\$ 10,000$
Not employed last year

What percentage of your educational expenses are covered by each of the sources listed below? (Include tuition, room, board, books, etc). The total should equal 100\%.

Parents or guardians

Other family members

Educational grants (Pell, SEOG, Private, etc) 
Personal savings or other resources

Work-study positions

Other

Total

Are you currently employed?

$\bigcirc$ Yes

No

If yes, how many hours per week do you work?

Approximately how many HOURS do you spend studying each week in the ways described below? Studying alone

Studying with one other person

Studying in an informal study group

Studying in a formal study group (required by a course, fraternity/sorority, etc)

The next series of questions are about the communities of people that you feel connected to.

If you had to choose a community of people that you feel MOST connected to, which community would you choose? (check all that apply)

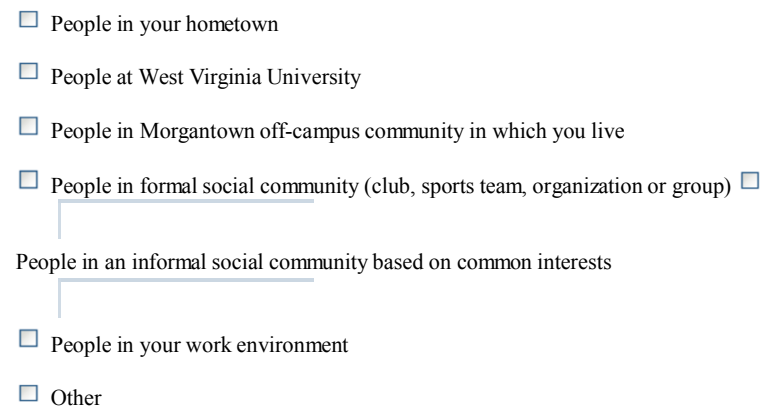

Why did you choose to attend WVU? (check all that apply)

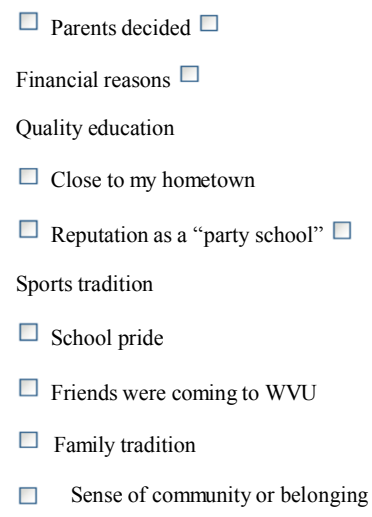


We are all members of different social groups or social categories. Some such social groups or categories pertain to gender, race, religion, nationality, ethnicity, socioeconomic class, or on college campuses, common interests. Social groups can be formal (regular meetings with goals an priorities) or informal (friends, classmates). Consider your memberships in those particular groups or categories,

and respond to the following statements based on how you feel about those groups and your

membership in them. Please read each statement carefully, and respond by using the following scale from 1 to 7 :

\begin{tabular}{|c|c|c|c|c|c|c|c|}
\hline & Strongly & Disagree & & & somewhe & & Strongly \\
\hline & Disagree & Somewhat & Disagree & Neutral & Agree & Agree & Agree \\
\hline I am a worthy member of the & & & & 0 & & & \\
\hline social groups I belong to. & 0 & 0 & 0 & 0 & 0 & 0 & 0 \\
\hline $\begin{array}{l}\text { I often regret that I belong to } \\
\text { some of the social groups I do. }\end{array}$ & 0 & 0 & 0 & 0 & 0 & 0 & 0 \\
\hline $\begin{array}{l}\text { Overall, my social groups are } \\
\text { considered good by others. }\end{array}$ & 0 & 0 & 0 & 0 & 0 & 0 & 0 \\
\hline $\begin{array}{l}\text { Overall, my group memberships } \\
\text { have very little to do with how I } \\
\text { feel about myself. }\end{array}$ & 0 & 0 & 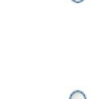 & 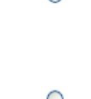 & 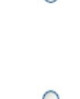 & 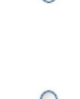 & ? \\
\hline $\begin{array}{l}\text { I feel like I don't have much to } \\
\text { offer the social groups I belong } \\
\text { to. }\end{array}$ & 0 & 0 & 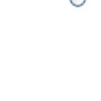 & 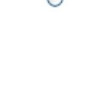 & 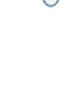 & 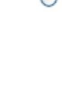 & 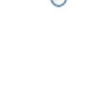 \\
\hline $\begin{array}{l}\text { In general, I'm glad to be a } \\
\text { member of the social groups I } \\
\text { belong to. }\end{array}$ & 0 & 0 & 0 & 0 & 0 & 0 & 0 \\
\hline $\begin{array}{l}\text { Most people consider my social } \\
\text { groups, on average, to be more } \\
\text { ineffective than other social } \\
\text { groups. }\end{array}$ & 0 & 0 & 0 & 0 & 0 & 0 & 0 \\
\hline $\begin{array}{l}\text { The social groups I belong to are } \\
\text { an important reflection of who I } \\
\text { am. }\end{array}$ & 0 & 0 & 0 & 0 & 0 & 0 & 0 \\
\hline $\begin{array}{l}\text { I am a cooperative participant in } \\
\text { the social groups I belong to. }\end{array}$ & 0 & 0 & 0 & 0 & 0 & 0 & 0 \\
\hline $\begin{array}{l}\text { Overall, I often feel that the } \\
\text { social groups of which I am } \\
\text { member are not worthwhile. }\end{array}$ & 0 & 0 & 0 & 0 & 0 & 0 & 0 \\
\hline $\begin{array}{l}\text { In general, others respect the } \\
\text { social groups I am a member of. }\end{array}$ & 0 & 0 & & & & & \\
\hline $\begin{array}{l}\text { The social groups I belong to are } \\
\text { unimportant to my sense of what } \\
\text { kind of person I am. }\end{array}$ & 0 & 0 & 0 & 0 & 0 & 0 & 0 \\
\hline $\begin{array}{l}\text { I often feel I'm a useless member } \\
\text { of my social groups. }\end{array}$ & 0 & 0 & 0 & 0 & 0 & 0 & 0 \\
\hline $\begin{array}{l}\text { I feel good about the social } \\
\text { groups I belong to. }\end{array}$ & 0 & 0 & ö & $\overline{0}$ & o & o & o \\
\hline $\begin{array}{l}\text { In general, others think that the } \\
\text { social groups I am a member } \\
\text { of are unworthy. }\end{array}$ & 0 & 0 & o & o & 0 & o & 0 \\
\hline $\begin{array}{l}\text { In general, belonging to social } \\
\text { groups is an important part of my } \\
\text { self-image. }\end{array}$ & 0 & 0 & 0 & 0 & 0 & 0 & 0 \\
\hline
\end{tabular}

if-imagertant part of my

This series of questions are about who you rely on for different types of support. For each type of support described, please select the people in your life you may turn to (check all that apply).

\begin{tabular}{|c|c|c|c|c|c|c|c|c|c|c|}
\hline & $\begin{array}{c}\text { Emotional } \\
\text { support }\end{array}$ & $\begin{array}{l}\text { Roommate } \\
\text { issues }\end{array}$ & $\begin{array}{r}\text { Career } 1 \\
\text { advice }\end{array}$ & $\begin{array}{l}\text { Financial } \\
\text { e issues }\end{array}$ & $\begin{array}{c}\text { Romantic } \\
\text { relationships }\end{array}$ & Academics & $\begin{array}{c}\text { General } \\
\text { advice }\end{array}$ & $\begin{array}{c}\text { Feedback } \\
\text { about } \\
\text { behavior }\end{array}$ & $\begin{array}{c}\text { General } \\
\text { information }\end{array}$ & $\begin{array}{l}\text { Serious } \\
\text { issues }\end{array}$ \\
\hline Parent & $\square$ & $\square$ & $\square$ & $\square$ & $\square$ & $\square$ & $\square$ & $\square$ & $\square$ & $\square$ \\
\hline Grandparent & $\square$ & $\square$ & $\square$ & $\square$ & $\square$ & $\square$ & $\square$ & $\square$ & $\square$ & $\square$ \\
\hline Sibling & $\square$ & $\square$ & $\square$ & $\square$ & $\square$ & $\square$ & $\square$ & $\square$ & $\square$ & $\square$ \\
\hline
\end{tabular}




\begin{tabular}{|c|c|c|c|c|c|c|c|c|c|c|}
\hline & $\begin{array}{c}\text { Emotional } \\
\text { support }\end{array}$ & $\begin{array}{c}\text { Roommate } \\
\text { issues }\end{array}$ & $\begin{array}{l}\text { Career } \\
\text { advic }\end{array}$ & $\begin{array}{l}\text { Financial } \\
\text { e issues }\end{array}$ & $\begin{array}{l}\text { Romantic } \\
\text { relationships }\end{array}$ & Academics & $\begin{array}{l}\text { General } \\
\text { advice }\end{array}$ & $\begin{array}{c}\text { Feedback } \\
\text { about } \\
\text { behavior }\end{array}$ & $\begin{array}{l}\text { General } \\
\text { information }\end{array}$ & $\begin{array}{c}\text { Serious } \\
\text { issues }\end{array}$ \\
\hline Cousin & $\square$ & $\square$ & $\square$ & $\square$ & $\square$ & $\square$ & $\square$ & $\square$ & $\square$ & $\square$ \\
\hline Aunt or Uncle & $\square$ & $\square$ & $\square$ & $\square$ & $\square$ & $\square$ & $\square$ & $\square$ & $\square$ & $\square$ \\
\hline $\begin{array}{l}\text { Significant } \\
\text { Other }\end{array}$ & $\square$ & $\square$ & $\square$ & $\square$ & $\square$ & $\square$ & $\square$ & $\square$ & $\square$ & $\square$ \\
\hline \multirow[t]{2}{*}{$\begin{array}{l}\text { Friend from } \\
\text { home }\end{array}$} & $\square$ & $\square$ & $\square$ & $\square$ & $\square$ & $\square$ & $\square$ & $\square$ & $\square$ & $\square$ \\
\hline & $\begin{array}{l}\text { Emotional } \\
\text { support }\end{array}$ & $\begin{array}{l}\text { Roommate } \\
\text { issues }\end{array}$ & $\begin{array}{c}\text { Career } \\
\text { advic }\end{array}$ & $\begin{array}{l}\text { Financial } \\
e \quad \text { issues }\end{array}$ & $\begin{array}{l}\text { Romantic } \\
\quad \text { relationships }\end{array}$ & Academics & $\begin{array}{l}\text { General } \\
\text { advice }\end{array}$ & $\begin{array}{l}\text { Feedback } \\
\text { about } \\
\text { behavior }\end{array}$ & $\begin{array}{l}\text { General } \\
\text { information }\end{array}$ & $\begin{array}{l}\text { Serious } \\
\text { issues }\end{array}$ \\
\hline $\begin{array}{l}\text { Coach, } \\
\text { teacher, or } \\
\text { youth group } \\
\text { leader from } \\
\text { hometown }\end{array}$ & $\square$ & $\square$ & $\square$ & $\square$ & $\square$ & $\square$ & $\square$ & $\square$ & $\square$ & $\square$ \\
\hline $\begin{array}{l}\text { Religious or } \\
\text { spiritual } \\
\text { advisor from } \\
\text { hometown }\end{array}$ & $\square$ & $\square$ & $\square$ & $\square$ & $\square$ & $\square$ & $\square$ & $\square$ & $\square$ & $\square$ \\
\hline Family friend & $\square$ & $\square$ & $\square$ & $\square$ & $\square$ & $\square$ & $\square$ & $\square$ & $\square$ & $\square$ \\
\hline $\begin{array}{l}\text { Other adult in } \\
\text { my } \\
\text { hometown } \\
\text { neighborhood }\end{array}$ & $\square$ & $\square$ & $\square$ & $\square$ & $\square$ & $\square$ & $\square$ & $\square$ & $\square$ & $\square$ \\
\hline $\begin{array}{l}\text { Friend at } \\
\text { WVU }\end{array}$ & $\square$ & $\square$ & $\square$ & $\square$ & $\square$ & $\square$ & $\square$ & $\square$ & $\square$ & $\square$ \\
\hline $\begin{array}{l}\text { Resident } \\
\text { Assistant }\end{array}$ & $\square$ & $\square$ & $\square$ & $\square$ & $\square$ & $\square$ & $\square$ & $\square$ & $\square$ & $\square$ \\
\hline \multirow{2}{*}{$\begin{array}{l}\text { WVU } \\
\text { academic } \\
\text { advisor }\end{array}$} & $\square$ & $\square$ & $\square$ & $\square$ & $\square$ & $\square$ & $\square$ & $\square$ & $\square$ & $\square$ \\
\hline & $\begin{array}{l}\text { Emotional } \\
\text { support }\end{array}$ & $\begin{array}{l}\text { Roommate } \\
\text { issues }\end{array}$ & $\begin{array}{l}\text { Career } \\
\text { advic }\end{array}$ & $\begin{array}{l}\text { Financial } \\
e \quad \text { issues }\end{array}$ & $\begin{array}{l}\text { Romantic } \\
\text { relationships }\end{array}$ & Academics & $\begin{array}{l}\text { General } \\
\text { advice }\end{array}$ & $\begin{array}{l}\text { Feedback } \\
\text { about } \\
\text { behavior }\end{array}$ & $\begin{array}{l}\text { General } \\
\text { information }\end{array}$ & $\begin{array}{l}\text { Serious } \\
\text { issues }\end{array}$ \\
\hline $\begin{array}{l}\text { Faculty at } \\
\text { WVU }\end{array}$ & $\square$ & $\square$ & $\square$ & $\square$ & $\square$ & $\square$ & $\square$ & $\square$ & $\square$ & $\square$ \\
\hline $\begin{array}{l}\text { Other WVU } \\
\text { staff }\end{array}$ & $\square$ & $\square$ & $\square$ & $\square$ & $\square$ & $\square$ & $\square$ & $\square$ & $\square$ & $\square$ \\
\hline $\begin{array}{l}\text { Religious or } \\
\text { spiritual } \\
\text { leader from } \\
\text { WVU }\end{array}$ & $\square$ & $\square$ & $\square$ & $\square$ & $\square$ & $\square$ & $\square$ & $\square$ & $\square$ & $\square$ \\
\hline $\begin{array}{l}\text { WVU student } \\
\text { organization } \\
\text { leader }\end{array}$ & $\square$ & $\square$ & $\square$ & $\square$ & $\square$ & $\square$ & $\square$ & $\square$ & $\square$ & $\square$ \\
\hline Other & $\square$ & $\square$ & $\square$ & $\square$ & $\square$ & $\square$ & $\square$ & $\square$ & $\square$ & $\square$ \\
\hline
\end{tabular}

For each of the following people, what is your most frequently used method to stay connected to them:

\begin{tabular}{|c|c|c|c|c|c|c|c|c|}
\hline & In person & Phone & Text & Email & Skype & $\begin{array}{c}\text { Social } \\
\text { networking } \\
\text { site } \\
\text { messaging } \\
\text { or chat }\end{array}$ & Other & $\begin{array}{c}\text { Not } \\
\text { applicable }\end{array}$ \\
\hline Parents/guardians & $\square$ & $\square$ & $\square$ & $\square$ & $\square$ & $\square$ & $\square$ & $\square$ \\
\hline Siblings & $\square$ & $\square$ & $\square$ & $\square$ & $\square$ & $\square$ & $\square$ & $\square$ \\
\hline Other relatives & $\square$ & $\square$ & $\square$ & $\square$ & $\square$ & $\square$ & $\square$ & $\square$ \\
\hline Friends from hometown Other & $\square$ & $\square$ & $\square$ & $\square$ & $\square$ & $\square$ & $\square$ & $\square$ \\
\hline adults from hometown & $\square$ & $\square$ & $\square$ & $\square$ & $\square$ & $\square$ & $\square$ & $\square$ \\
\hline Significant other & $\square$ & $\square$ & $\square$ & $\square$ & $\square$ & $\square$ & $\square$ & $\square$ \\
\hline Friends at WVU & $\square$ & $\square$ & $\square$ & $\square$ & $\square$ & $\square$ & $\square$ & $\square$ \\
\hline Professors at WVU & $\square$ & $\square$ & $\square$ & $\square$ & $\square$ & $\square$ & $\square$ & $\square$ \\
\hline Other & $\square$ & $\square$ & $\square$ & $\square$ & $\square$ & $\square$ & $\square$ & $\square$ \\
\hline
\end{tabular}


In the past 30 days, how many of your on campus neighbors (residence hall, fraternity/sorority house, apartment, or Morgantown community) did you talk to for more than 10 minutes in person?
$\bigcirc$ None
○ $1-2$
○ $3-4$
$5-6$
more than 6

How many of your close friends attend WVU?
$\bigcirc$ None
$\bigcirc$ A few
Some
$\circ$ Most
$\bigcirc$ All

How many times do you call or text your parents/guardians each week? Please enter a number.

How many times do you call, message, or text friends from your hometown each week? Please enter a number.

How many tiomes do you call, message, or text friends from WVU each week? Please enter a number.

The next series of questions are about participation in formal activities at WVU, Morgantown, and at home.

Think about the activities that you participate in at WVU. Please indicate if you are a member of or hold a leadership position (e.g., president, treasurer, social chairperson, etc.) in the following activities. In the second column, please indicate approximately how many hours per month you spend on each activity.

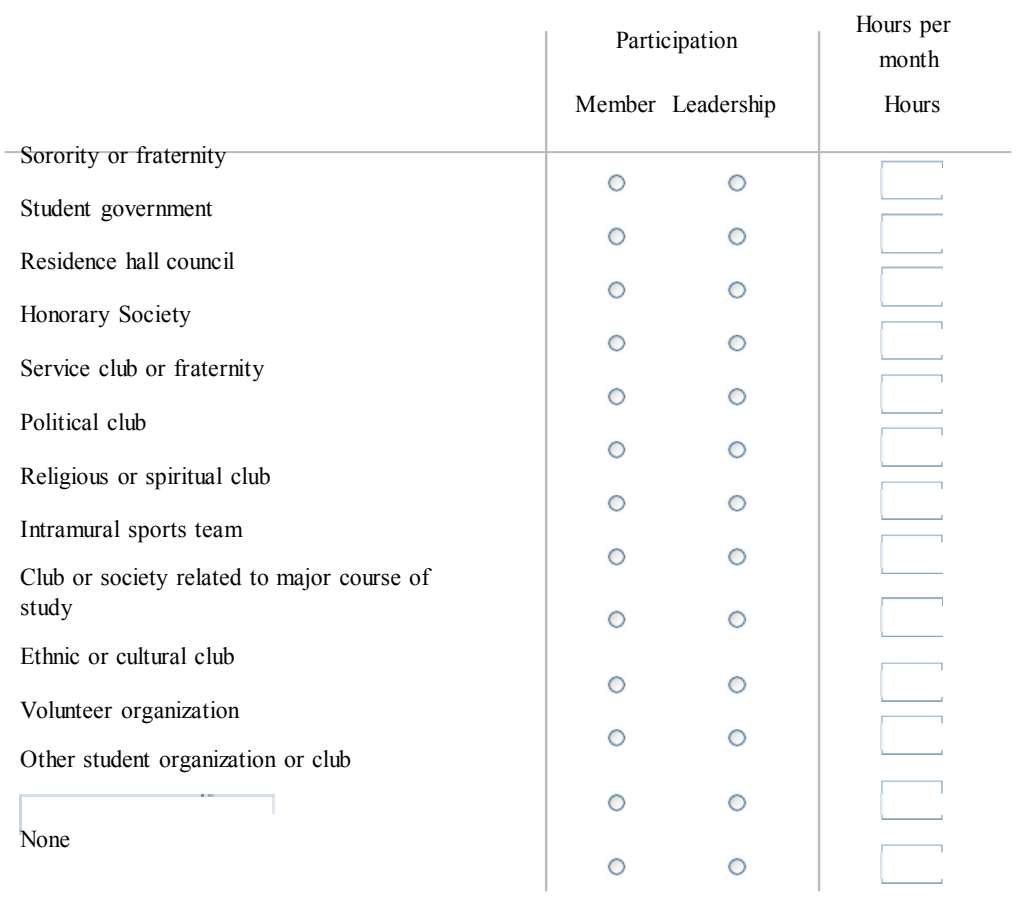


Think about the activities that you participate in Morgantown. Please indicate if you are a member of or hold a leadership position (e.g., president, treasurer, social chairperson, etc.) in the following activities. In the second column, please indicate approximately how many hours per month you spend on each activity.

\begin{tabular}{l|cc|} 
& \multicolumn{2}{|c|}{ Participation } \\
Service club (volunteer organization) & Member Leadership & Hours per month \\
Neighborhood association & 0 & 0 \\
Political party organization & 0 & 0 \\
Arts related organization & 0 & 0 \\
Other & 0 & 0 \\
Other & 0 & 0 \\
None & 0 & 0 \\
\end{tabular}

Think about the activities that you participate in your hometown. Please indicate if you are a member of or hold a leadership position (e.g., president, treasurer, social chairperson, etc.) in the following activities. In the second column, please indicate approximately how many hours per month you spend on each activity.

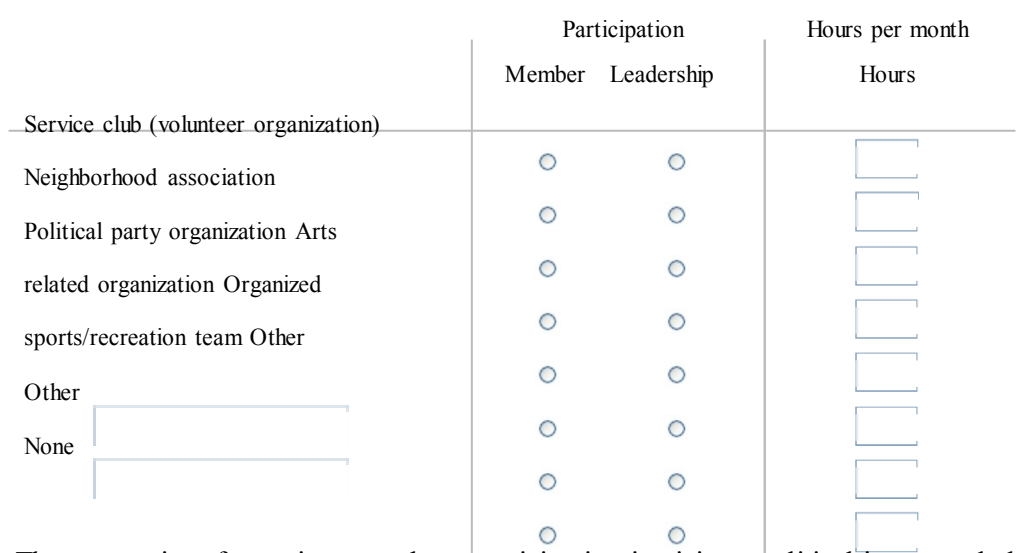

The next series of questions are about participation in civic or political issues and elections. Are you

registered to vote?

$\circ$ Yes

$\bigcirc$ No

$\circ \mathrm{N} / \mathrm{A}$

Have you ever voted in (check all that apply):

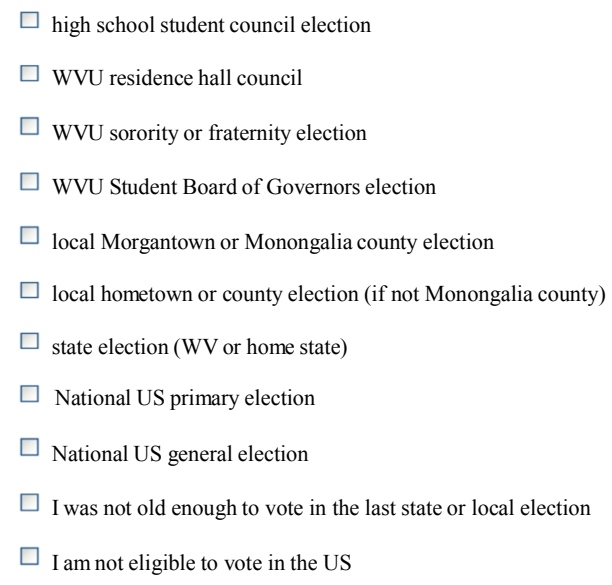

Thinking back over the last 12 months, did you do any of the following (check all that apply): 


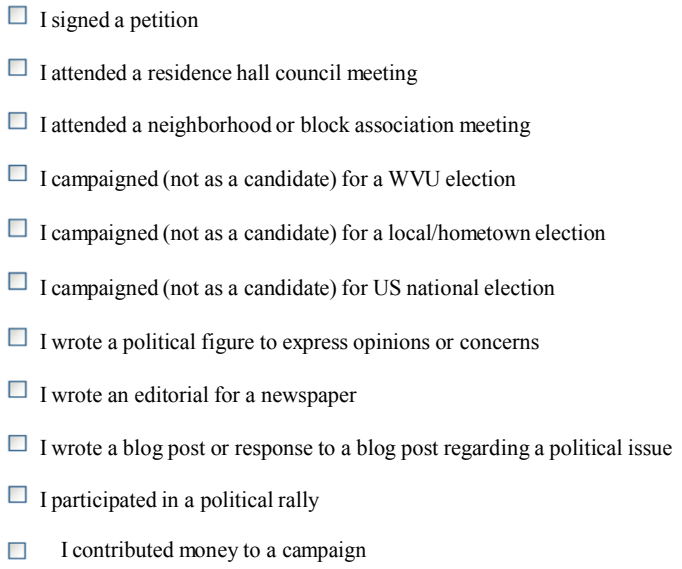

The next questions are about your experiences of volunteering and religious/spiritual participation. On average, how many hours per month do you volunteer (enter "0" if none).

If you do volunteer, in what situations do you volunteer (check all that apply):

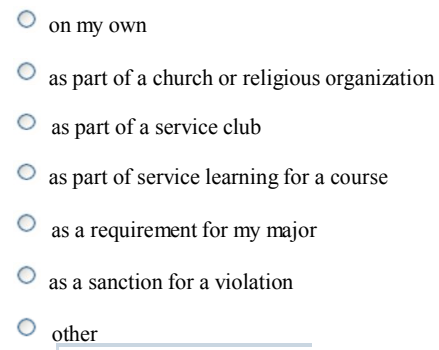

Please answer the following questions about volunteering on a scale from strongly disagree to strongly agree

\begin{tabular}{|c|c|c|c|c|c|c|}
\hline \multirow{3}{*}{$\begin{array}{l}\text { I only volunteered in high school } \\
\text { for college applications }\end{array}$} & \multirow{2}{*}{$\begin{array}{l}\text { Strongly } \\
\text { Disagree }\end{array}$} & \multicolumn{3}{|c|}{ Neither agree } & \multirow{2}{*}{$\begin{array}{l}\text { Strongly } \\
\text { Agree }\end{array}$} & \multirow{2}{*}{$\begin{array}{c}\text { Not } \\
\text { applicable }\end{array}$} \\
\hline & & Disagree & or disagree & Agree & & \\
\hline & $0^{-}$ & $0^{-}$ & $0^{-}$ & $0^{-}$ & & \\
\hline $\begin{array}{l}\text { Volunteering was important to } \\
\text { me in high school }\end{array}$ & 0 & 0 & 0 & 0 & 0 & 0 \\
\hline $\begin{array}{l}\text { Volunteering is an important } \\
\text { part of WVU culture }\end{array}$ & 0 & 0 & 0 & 0 & 0 & 0 \\
\hline $\begin{array}{l}\text { I only volunteer at WVU } \\
\text { because I am forced to }\end{array}$ & 0 & 0 & 0 & 0 & 0 & 0 \\
\hline I enjoy volunteering & 0 & 0 & 0 & 0 & 0 & 0 \\
\hline $\begin{array}{l}\text { Volunteering is important in my } \\
\text { hometown }\end{array}$ & 0 & 0 & 0 & 0 & 0 & 0 \\
\hline $\begin{array}{l}\text { Volunteering is a great way to } \\
\text { help the community }\end{array}$ & 0 & 0 & 0 & 0 & 0 & 0 \\
\hline $\begin{array}{l}\text { Volunteering is important to } \\
\text { my family }\end{array}$ & 0 & 0 & 0 & 0 & 0 & 0 \\
\hline
\end{tabular}

Please answer the following questions about religious or spiritual activities on a scale from strongly disagree to strongly agree

\begin{tabular}{l|cccccc}
\cline { 2 - 4 } & $\begin{array}{c}\text { Strongly } \\
\text { Disagree }\end{array}$ & Disagree & $\begin{array}{c}\text { Neither agree } \\
\text { of disagree }\end{array}$ & Agree & $\begin{array}{c}\text { Strongly } \\
\text { Agree }\end{array}$ & $\begin{array}{c}\text { Not } \\
\text { applicable }\end{array}$ \\
\hline $\begin{array}{l}\text { I consider myself to be } \\
\text { religious or spiritual }\end{array}$ & 0 & 0 & 0 & 0 & 0 & 0 \\
$\begin{array}{l}\text { Before I came to WVU, I } \\
\text { attended religious services } \\
\text { regularly }\end{array}$ & 0 & 0 & 0 & 0 & 0 & 0
\end{tabular}




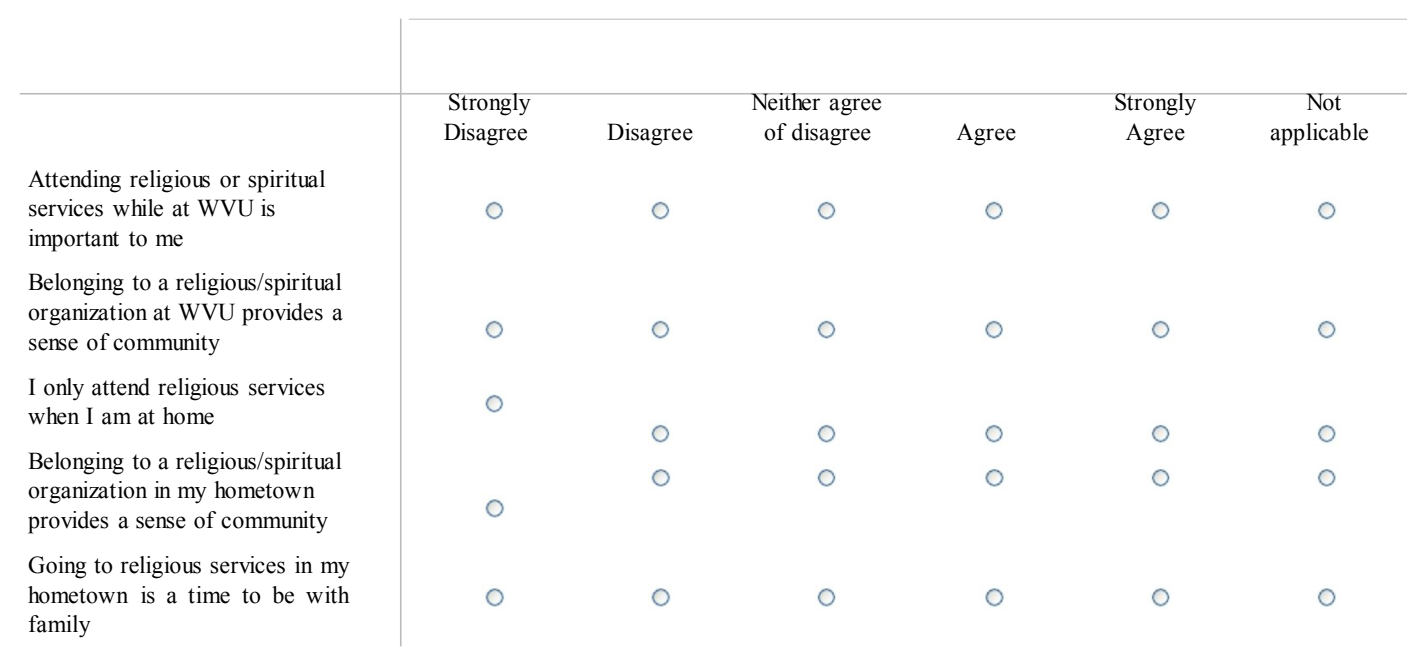

The next set of questions are about how neighbors look out for one another, please answer on a scale of strongly disagree to strongly agree.

I can count on neighbors to look out for one another:

\begin{tabular}{l|ccccc}
\cline { 2 - 4 } & $\begin{array}{c}\text { Strongly } \\
\text { Disagree }\end{array}$ & Disagree & $\begin{array}{c}\text { Neither agree } \\
\text { or disagree }\end{array}$ & $\begin{array}{c}\text { Strongly } \\
\text { Agree }\end{array}$ & $\begin{array}{c}\text { Not } \\
\text { Agree }\end{array}$ \\
\hline $\begin{array}{l}\text { in my residence hall } \\
\text { my fraternity/sorority }\end{array}$ & 0 & 0 & 0 & 0 & 0 \\
my apartment building & 0 & 0 & 0 & 0 & 0 \\
in & 0 & & 0 & 0 & 0 \\
$\begin{array}{l}\text { in my off-campus } \\
\text { neighborhood }\end{array}$ \\
$\begin{array}{l}\text { in my neighborhood in my } \\
\text { hometown }\end{array}$
\end{tabular}

My friends/neighbors at WVU look out for one another by (check all that apply):

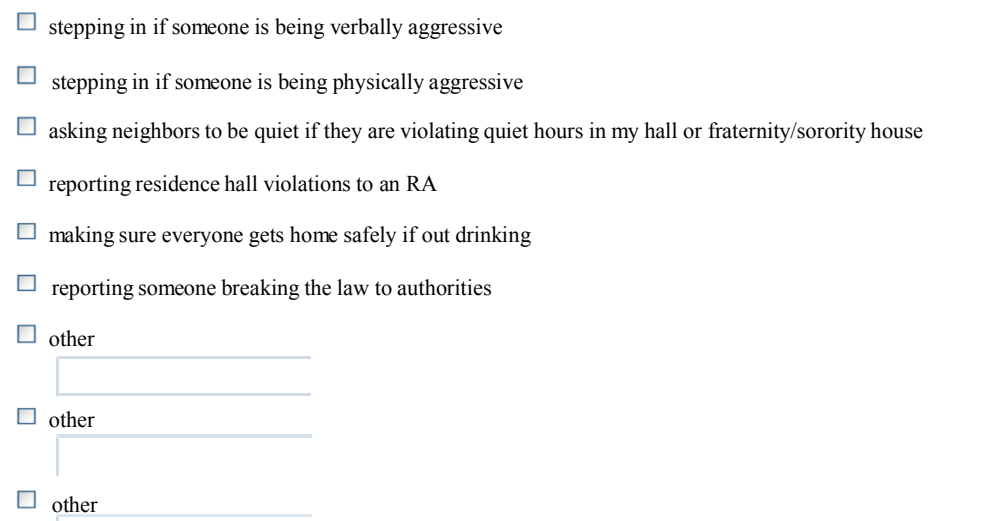

The following set of questions are about what you do in your spare time. When

you are at WVU, how often do you do the following with friends?

\begin{tabular}{l|cccccc} 
& \multicolumn{7}{c}{$\begin{array}{c}\text { Less than } \\
\text { Once a } \\
\text { Month }\end{array}$} & $\begin{array}{c}\text { Once a } \\
\text { Month }\end{array}$ & $\begin{array}{c}2-3 \text { Times a } \\
\text { Month }\end{array}$ & $\begin{array}{c}\text { Once a } \\
\text { Week }\end{array}$ & $\begin{array}{c}2-3 \text { Times } \\
\text { a Week }\end{array}$ \\
\hline Go to a restaurant & Never & 0 & 0 & 0 & 0 & 0 \\
Attend a WVU sporting event & 0 & 0 & 0 & 0 & 0 \\
Go to a bar/club & 0 & 0 & 0 & 0 & 0 \\
Go to a bowling alley & 0 & 0 & 0 & 0 & 0 \\
Go to the Mountainlair (play & & & 0 & 0 \\
pool, go to Up All Night, etc) & 0 & 0 & 0 & 0 & 0 \\
Go to a coffee shop & 0 & 0 & 0 & 0 & 0 \\
Talk in person & 0 & 0 & 0 & 0
\end{tabular}




\begin{tabular}{|c|c|c|c|c|c|c|c|}
\hline & Never & $\begin{array}{l}\text { Less than } \\
\text { Once a } \\
\text { Month }\end{array}$ & $\begin{array}{l}\text { Once a } \\
\text { Month }\end{array}$ & $\begin{array}{l}\text { 2-3 Times a } \\
\text { Month }\end{array}$ & $\begin{array}{c}\text { Once a } \\
\text { Week }\end{array}$ & $\begin{array}{l}\text { 2-3 Times } \\
\text { a Week }\end{array}$ & Daily \\
\hline $\begin{array}{l}\text { Talk on the phone/email/chat or } \\
\text { text }\end{array}$ & 0 & 0 & 0 & 0 & 0 & 0 & 0 \\
\hline Play video games (in person) & 0 & 0 & 0 & 0 & 0 & 0 & 0 \\
\hline Play video games (online) Watch & 0 & 0 & 0 & 0 & 0 & 0 & 0 \\
\hline $\begin{array}{l}\text { WVU sporting events } \\
\text { on television }\end{array}$ & 0 & 0 & 0 & 0 & 0 & 0 & 0 \\
\hline Watch other sporting events & 0 & 0 & 0 & o & 0 & 0 & 0 \\
\hline Pre-party or pre-game & 0 & 0 & 0 & 0 & 0 & 0 & 0 \\
\hline Drink alcohol & 0 & 0 & 0 & 0 & 0 & 0 & 0 \\
\hline Use drugs & 0 & 0 & 0 & 0 & 0 & o & o \\
\hline Spend time with a mentor & 0 & 0 & 0 & 0 & 0 & 0 & 0 \\
\hline $\begin{array}{l}\text { Spend time with a } \\
\text { teacher/professor }\end{array}$ & 0 & 0 & 0 & 0 & 0 & 0 & 0 \\
\hline $\begin{array}{l}\text { Spend time with a significant } \\
\text { other }\end{array}$ & 0 & 0 & 0 & 0 & 0 & 0 & 0 \\
\hline Other & 0 & 0 & 0 & 0 & 0 & 0 & 0 \\
\hline
\end{tabular}

When you are in your hometown, how often do you do the following with family or friends?

\begin{tabular}{|c|c|c|c|c|c|c|c|}
\hline & Never & $\begin{array}{l}\text { Less than } \\
\text { Once a } \\
\text { Month }\end{array}$ & $\begin{array}{l}\text { Once a } \\
\text { Month }\end{array}$ & $\begin{array}{l}\text { 2-3 Times a } \\
\text { Month }\end{array}$ & $\begin{array}{l}\text { Once a } \\
\text { Week }\end{array}$ & $\begin{array}{l}\text { 2-3 Times } \\
\text { a Week }\end{array}$ & Daily \\
\hline Go to a restaurant & 0 & 0 & 0 & 0 & 0 & 0 & 0 \\
\hline Go to a bar/club & 0 & 0 & 0 & 0 & 0 & 0 & 0 \\
\hline Attend a sporting event & 0 & 0 & 0 & 0 & 0 & 0 & 0 \\
\hline Go to a bowling alley Go & 0 & 0 & 0 & 0 & 0 & 0 & 0 \\
\hline to a coffee shop & 0 & 0 & 0 & 0 & 0 & 0 & 0 \\
\hline Play video games (in person) & 0 & 0 & 0 & 0 & 0 & 0 & 0 \\
\hline Play video games (online) & 0 & 0 & 0 & 0 & 0 & 0 & 0 \\
\hline $\begin{array}{l}\text { Watch sporting events on } \\
\text { television }\end{array}$ & 0 & 0 & 0 & 0 & 0 & 0 & 0 \\
\hline Drink alcohol & 0 & 0 & 0 & 0 & 0 & 0 & 0 \\
\hline Use drugs & 0 & 0 & 0 & 0 & 0 & 0 & 0 \\
\hline $\begin{array}{l}\text { Spend time with family } \\
\text { members }\end{array}$ & 0 & 0 & 0 & 0 & 0 & 0 & 0 \\
\hline $\begin{array}{l}\text { Spend time with a significant } \\
\text { other }\end{array}$ & 0 & 0 & 0 & 0 & 0 & 0 & 0 \\
\hline Other & 0 & 0 & 0 & 0 & 0 & 0 & 0 \\
\hline
\end{tabular}

The next series of questions are about trust.

Please indicate how much you agree or disagree with the following statements.

\begin{tabular}{|c|c|c|c|c|c|}
\hline & $\begin{array}{l}\text { Strongly } \\
\text { disagree }\end{array}$ & Disagree & $\begin{array}{l}\text { Neither Agree } \\
\text { nor Disagree }\end{array}$ & Agree & Strongly Agree \\
\hline $\begin{array}{l}\text { I trust the people in my } \\
\text { hometown }\end{array}$ & 0 & 0 & 0 & 0 & 0 \\
\hline I trust WVU, as an institution & 0 & 0 & 0 & 0 & 0 \\
\hline $\begin{array}{l}\text { I trust the people in the WVU } \\
\text { community }\end{array}$ & 0 & 0 & 0 & 0 & 0 \\
\hline $\begin{array}{l}\text { I trust my neighbors at WVU } \\
\text { (residence hall, } \\
\text { fraternity/sorority, or campus } \\
\text { neighborhood) }\end{array}$ & 0 & 0 & 0 & 0 & 0 \\
\hline $\begin{array}{l}\text { My hometown neighbors are } \\
\text { willing to help each other out }\end{array}$ & 0 & 0 & 0 & 0 & 0 \\
\hline $\begin{array}{l}\text { My WVU neighbors are willing } \\
\text { to help each other out }\end{array}$ & 0 & 0 & 0 & 0 & 0 \\
\hline $\begin{array}{l}\text { If I needed to borrow } \\
\text { something, I would not hesitate } \\
\text { to ask a neighbor or }\end{array}$ & 0 & 0 & 0 & 0 & 0 \\
\hline
\end{tabular}




\begin{tabular}{|c|c|c|c|c|c|}
\hline & $\begin{array}{l}\text { Strongly } \\
\text { disagree }\end{array}$ & Disagree & $\begin{array}{l}\text { Neither Agree } \\
\text { nor Disagree }\end{array}$ & Agree & Strongly Agree \\
\hline \multicolumn{6}{|l|}{ classmate at WVU } \\
\hline I feel safe in my hometown & 0 & 0 & 0 & 0 & 0 \\
\hline $\begin{array}{l}\text { I feel safe on-campus at } \\
\text { WVU during the day }\end{array}$ & 0 & 0 & 0 & 0 & 0 \\
\hline $\begin{array}{l}\text { I feel safe on-campus at } \\
\text { WVU at night }\end{array}$ & 0 & 0 & 0 & 0 & 0 \\
\hline $\begin{array}{l}\text { I feel safe in Morgantown } \\
\text { during the day }\end{array}$ & 0 & 0 & 0 & 0 & 0 \\
\hline $\begin{array}{l}\text { I feel safe in Morgantown at } \\
\text { night }\end{array}$ & 0 & o & 0 & 0 & 0 \\
\hline $\begin{array}{l}\text { I feel safe in my } \\
\text { neighborhood at WVU } \\
\text { (residence hall, } \\
\text { fraternity/sorority house, } \\
\text { campus neighborhood) }\end{array}$ & 0 & 0 & 0 & 0 & 0 \\
\hline
\end{tabular}

How often do people in your hometown (not family) do favors for each other?
Never
$\bigcirc$ Rarely
Sometimes
$\bigcirc$ Often
O Always

For each of the following, indicate if in the past year your hometown neighbors have done these things for you in column 1 or if you have done any of the following for your neighbors column 2

\begin{tabular}{l|c|c} 
& $\begin{array}{c}\text { Neighbors did for me } \\
\text { My hometown } \\
\text { neighbors did the } \\
\text { following for me }\end{array}$ & $\begin{array}{c}\text { I did for neighbors } \\
\text { I did the following for } \\
\text { my hometown } \\
\text { neighbors }\end{array}$ \\
\hline $\begin{array}{l}\text { Take care of house pet } \\
\text { Bring over food if someone in the } \\
\text { family is ill }\end{array}$ & 0 & 0 \\
$\begin{array}{l}\text { Look out for crime in the } \\
\text { neighborhood }\end{array}$ & 0 & 0 \\
$\begin{array}{l}\text { Provide advice } \\
\text { Loan a car or provide } \\
\text { transportation when needed }\end{array}$ & 0 & 0 \\
Fix a car or vehicle & 0 & 0 \\
Babysit children & 0 & 0 \\
Loan small items (tools, baking, & 0 & 0 \\
etc.) & 0 & 0 \\
Provide emotional support & 0 & 0 \\
Water plants & 0 & 0 \\
Watch the house when family is & 0 & 0 \\
away & & 0
\end{tabular}

How often do members of your family do favors for each other?
$\bigcirc$ Never
$\bigcirc$ Rarely
Sometimes
$\bigcirc$ Often
O Always 
How often do people at WVU do favors for each other?
Never
Rarely
Sometimes
Often
Always

For each of the following, indicate if in this school year someone at WVU has done these things for you in column 1 or if you have done any of the following for someone at WVU in column 2

\begin{tabular}{l|c|c} 
& $\begin{array}{c}\text { Someone at WVU } \\
\text { did for me }\end{array}$ & $\begin{array}{c}\text { I did for someone at } \\
\text { WVU }\end{array}$ \\
& $\begin{array}{c}\text { Someone at WVU did } \\
\text { the following for me } \\
\text { in this school year }\end{array}$ & $\begin{array}{c}\text { I did this for } \\
\text { someone at WVU in } \\
\text { this school year }\end{array}$ \\
\hline $\begin{array}{l}\text { Loaned class notes/assignments } \\
\text { Loaned small items (under \$20 in value) }\end{array}$ & 0 & 0 \\
$\begin{array}{l}\text { Loaned large items (computers, laptops, } \\
\text { game systems, etc) }\end{array}$ & 0 & 0 \\
$\begin{array}{l}\text { Loaned a car or provided transportation } \\
\text { Provided advice }\end{array}$ & 0 & 0 \\
$\begin{array}{l}\text { Provided emotional support } \\
\text { Provided information about resources on } \\
\text { campus (counseling, academic advising, } \\
\text { tutoring, clubs) }\end{array}$ & 0 & 0 \\
$\begin{array}{l}\text { Provided information about resources off- } \\
\text { campus (mechanic, restaurant, festival, } \\
\text { etc) }\end{array}$ & 0 & 0 \\
$\begin{array}{l}\text { Loaned medium items (clothing, } \\
\text { appliances, text books, etc) }\end{array}$ & 0 & 0 \\
$\begin{array}{l}\text { Other } \\
\text { Other }\end{array}$ & 0 & 0 \\
\hline
\end{tabular}

The following questions are about values that you share with your community. Please indicate if you disagree or agree with the following statements.

\begin{tabular}{|c|c|c|c|c|c|}
\hline & $\begin{array}{l}\text { Strongly } \\
\text { disagree }\end{array}$ & Disagree & Neutral & Agree & Strongly Agree \\
\hline $\begin{array}{l}\text { Students at WVU share } \\
\text { similar values }\end{array}$ & 0 & 0 & 0 & 0 & 0 \\
\hline $\begin{array}{l}\text { WVU students have a shared } \\
\text { sense of pride about being } \\
\text { Mountaineers }\end{array}$ & 0 & 0 & 0 & 0 & 0 \\
\hline $\begin{array}{l}\text { Sports and athletics bring us } \\
\text { closer together as a WVU } \\
\text { community }\end{array}$ & O & ○ & O & O & 0 \\
\hline $\begin{array}{l}\text { Academics and a good } \\
\text { education are important parts } \\
\text { of WVU's values }\end{array}$ & 0 & 0 & 0 & 0 & 0 \\
\hline I share WVU's values & O & 0 & 0 & 0 & 0 \\
\hline $\begin{array}{l}\text { Being a Mountaineer means } \\
\text { giving back to the } \\
\text { Morgantown community }\end{array}$ & 0 & 0 & 0 & 0 & 0 \\
\hline $\begin{array}{l}\text { People in my neighborhood at } \\
\text { home share similar values }\end{array}$ & 0 & 0 & 0 & 0 & 0 \\
\hline I share my parents' values & 0 & O & 0 & 0 & 0 \\
\hline $\begin{array}{l}\text { I share my hometown's } \\
\text { values }\end{array}$ & 0 & 0 & 0 & 0 & 0 \\
\hline
\end{tabular}

The next questions are about how you use social networking sites like Facebook, MySpace, Twitter, Oovoo and Skype. 
Do you use social networking sites?

$\bigcirc$ yes

○ No

When you spend time on social networking sites, how often do you:

\begin{tabular}{|c|c|c|c|c|c|c|c|}
\hline & Never & $\begin{array}{l}\text { Once a } \\
\text { month }\end{array}$ & $\begin{array}{l}\text { 2-3 Times a } \\
\text { Month }\end{array}$ & $\begin{array}{l}\text { Once a } \\
\text { Week }\end{array}$ & $\begin{array}{l}\text { 2-3 Times } \\
\text { a Week }\end{array}$ & Daily & $\begin{array}{c}\text { Multiple } \\
\text { times per } \\
\text { day }\end{array}$ \\
\hline Chat with friends & 0 & 0 & 0 & 0 & 0 & 0 & 0 \\
\hline Chat with family & 0 & 0 & 0 & 0 & 0 & 0 & 0 \\
\hline Post on friends' walls & 0 & 0 & 0 & o & 0 & 0 & 0 \\
\hline "Creep" on friends pages & 0 & 0 & 0 & 0 & 0 & 0 & 0 \\
\hline Look for parties & 0 & 0 & 0 & 0 & 0 & 0 & 0 \\
\hline Look for events/things to do & 0 & 0 & 0 & 0 & 0 & 0 & 0 \\
\hline $\begin{array}{l}\text { Look for WVU-related } \\
\text { organization events }\end{array}$ & 0 & 0 & 0 & 0 & o & 0 & 0 \\
\hline $\begin{array}{l}\text { Update your own } \\
\text { profile/pictures }\end{array}$ & 0 & 0 & 0 & 0 & 0 & 0 & 0 \\
\hline $\begin{array}{l}\text { Play games } \\
\text { (Bedazzle,Farmville,etc) }\end{array}$ & 0 & 0 & 0 & 0 & 0 & 0 & 0 \\
\hline Other & 0 & 0 & 0 & 0 & 0 & 0 & 0 \\
\hline
\end{tabular}

About how many hours per day do you spend on social networking sites?

Approximately how many "friends" do you have on social networking sites? Please enter a number.

Of your online friends, what percentage do you consider friends in "real life"?

Thinking about your use of social networking sites, indicate how much you agree or disagree with the following statements.

\begin{tabular}{|c|c|c|c|c|c|}
\hline & $\begin{array}{l}\text { Strongly } \\
\text { disagree }\end{array}$ & Disagree & $\begin{array}{l}\text { Neither Agree } \\
\text { nor Disagree }\end{array}$ & Agree & Strongly Agree \\
\hline $\begin{array}{l}\text { I use social networking sites } \\
\text { to stay in touch with friends at } \\
\text { home }\end{array}$ & 0 & 0 & 0 & 0 & 0 \\
\hline $\begin{array}{l}\text { I use social networking sites to } \\
\text { stay in touch with family }\end{array}$ & 0 & 0 & 0 & 0 & 0 \\
\hline $\begin{array}{l}\text { I use social networking sites } \\
\text { to check out younger relatives } \\
\text { profiles for questionable content }\end{array}$ & 0 & 0 & 0 & 0 & 0 \\
\hline $\begin{array}{l}\text { If a friend posted a photo or } \\
\text { status update that I found } \\
\text { objectionable on a their profile, I } \\
\text { would confront them }\end{array}$ & 0 & 0 & 0 & 0 & 0 \\
\hline $\begin{array}{l}\text { My relatives view my profile } \\
\text { to see what I am up to }\end{array}$ & 0 & 0 & 0 & 0 & 0 \\
\hline $\begin{array}{l}\text { If a relative found something on } \\
\text { my profile questionable, they } \\
\text { would say something to me }\end{array}$ & 0 & 0 & 0 & 0 & 0 \\
\hline $\begin{array}{l}\text { If a friend found something on } \\
\text { my profile questionable, they } \\
\text { would say something to me }\end{array}$ & 0 & 0 & & & \\
\hline \multirow[t]{2}{*}{$\begin{array}{l}\text { I am very careful about what I } \\
\text { post on my profile }\end{array}$} & 0 & 0 & 0 & 0 & 0 \\
\hline & & & 0 & 0 & 0 \\
\hline
\end{tabular}




\begin{tabular}{|c|c|c|c|c|c|}
\hline & $\begin{array}{l}\text { Strongly } \\
\text { disagree }\end{array}$ & Disagree & $\begin{array}{l}\text { Neither Agree } \\
\text { nor Disagree }\end{array}$ & Agree & Strongly Agree \\
\hline $\begin{array}{l}\text { I worry about what future } \\
\text { employers might see on my } \\
\text { profile }\end{array}$ & 0 & 0 & 0 & 0 & 0 \\
\hline $\begin{array}{l}\text { I worry about what relatives } \\
\text { might see on my profile }\end{array}$ & 0 & 0 & 0 & 0 & 0 \\
\hline $\begin{array}{l}\text { Social networking sites are a } \\
\text { huge part of my social life }\end{array}$ & 0 & O & 0 & 0 & 0 \\
\hline $\begin{array}{l}\text { I use social networking sites to } \\
\text { get feedback from friends about } \\
\text { things going on in my life }\end{array}$ & 0 & 0 & 0 & 0 & 0 \\
\hline $\begin{array}{l}\text { I use social networking sites to } \\
\text { find out information about job } \\
\text { opportunities }\end{array}$ & 0 & 0 & 0 & 0 & 0 \\
\hline $\begin{array}{l}\text { I use social networking sites to } \\
\text { get emotional support from } \\
\text { friends }\end{array}$ & 0 & 0 & 0 & 0 & 0 \\
\hline $\begin{array}{l}\text { I use social networking sites to } \\
\text { find out about class } \\
\text { assignments/notes }\end{array}$ & 0 & 0 & 0 & 0 & 0 \\
\hline $\begin{array}{l}\text { I use social networking sites to } \\
\text { ask for things I need to borrow }\end{array}$ & 0 & 0 & 0 & 0 & 0 \\
\hline $\begin{array}{l}\text { I use social networking sites to } \\
\text { get advice from friends }\end{array}$ & 0 & 0 & 0 & 0 & 0 \\
\hline
\end{tabular}

In the past week, how many of your online social networking friends or relatives from your hometown did you talk to for more than 5 minutes while online (using chat or messaging, etc)?
None
$1-2$
$3-4$
5-6
6 or more

In the past week, how many of your online social networking friends from WVU did you talk to for more than 5 minutes while online (using chat or messaging, etc)?
$\bigcirc$ None
$1-2$
3-4
- 5-6
6 or more

The final series of questions are about health behaviors, specifically use of tobacco products. For each product, please indicate if you have ever used the product, if you used the product in the last 30 days, and on how many days in the last 30 days you used the product. If you did not use the product, please enter " $0 . "$

\begin{tabular}{l|c|c|c} 
& $\begin{array}{c}\text { Lifetime Use } \\
\text { Have you EVER used the } \\
\text { tobacco product listed } \\
\text { below (check all that } \\
\text { apply)? }\end{array}$ & $\begin{array}{c}\text { Past 30 Days Use } \\
\text { Did you use the } \\
\text { product in the last } \\
30 \text { days (check all } \\
\text { that apply)? }\end{array}$ & $\begin{array}{c}\text { Past 30 Days Frequency } \\
\text { On how many days in the last 30 days } \\
\text { did you use the product } \\
\text { (approximately)? Enter "0" if none. }\end{array}$ \\
\hline $\begin{array}{l}\text { cigarettes (non-flavored) } \\
\text { cigarettes (flavored) cigars }\end{array}$ & $\square$ & $\square$ & \\
bidis & $\square$ & $\square$ & \\
smokeless tobacco & $\square$ & $\square$ & \\
snus & $\square$ & $\square$ &
\end{tabular}




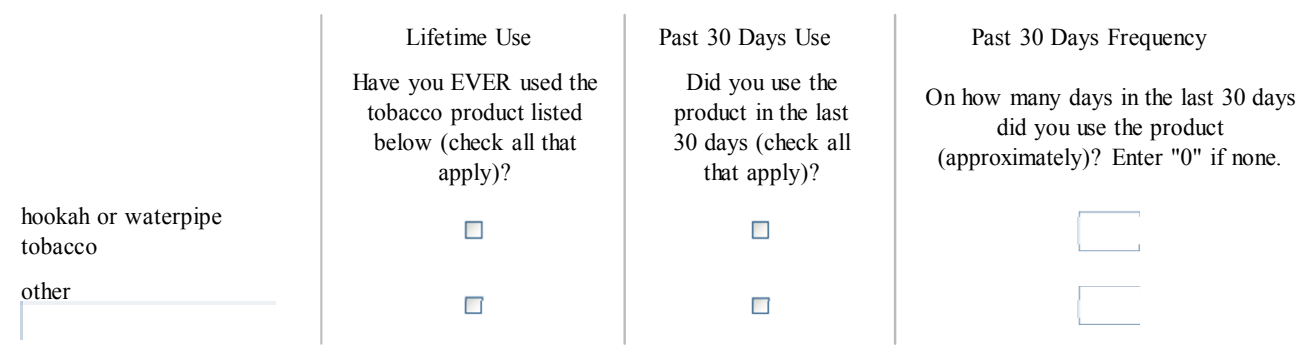

How old were you when you smoked a whole cigarette for the first time? Please type in the age you first tried a cigarette.

Have you ever smoked cigarettes daily, that is, at least one cigarette every day for 30 days?

$\bigcirc$ Yes

No

During the past 30 days, on the days you smoked, how many cigarettes did you smoke per day? Please enter a number.

If you smoke daily, about how many years have you been a daily smoker? Please enter a number.

Where do you smoke cigarettes? (Check all that apply)

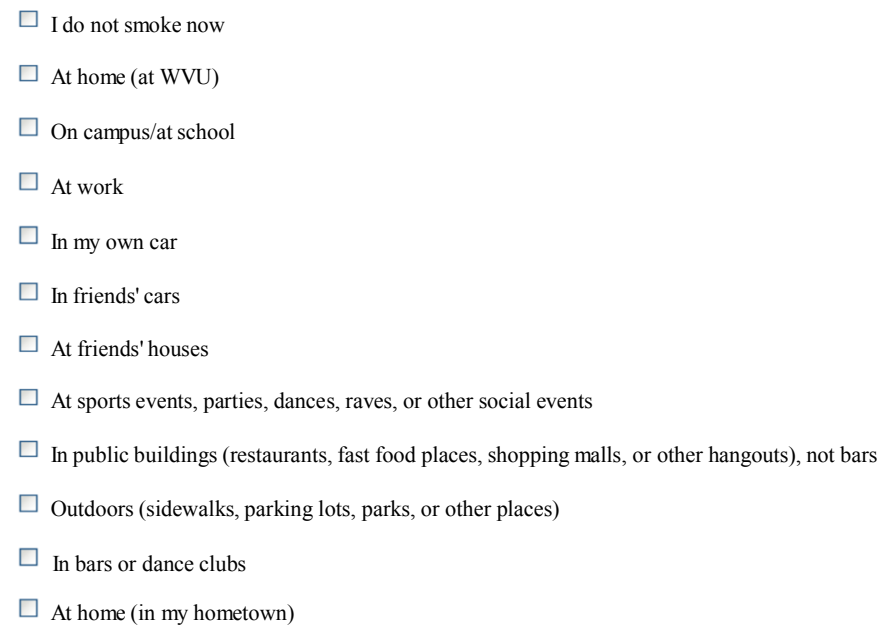

If you have EVER smoked cigarettes, do you consider yourself:
$O$ a daily smoker
$\bigcirc$ a former smoker
a social smoker, only with friends who also smoker
a social smoker, only when I am also drinking alcohol
$\checkmark$ an experimental smoker who only tried it a few times
something else 
How many of your four closest friends at WVU smoke cigarettes?
None
One
Two
Three
Four
Not Sure

How many of your four closest friends in your hometown smoke cigarettes?
$\bigcirc$ None
$\bigcirc$ One
$\circ$ Two
O Three
$\bigcirc$ Four
$\bigcirc$ Not Sure

Do any of the following people in your life smoke cigarettes? (check all that apply)
$\square$ parent or guardian
$\square$ sibling
$\square$ significant other (boyfriend/girlfriend/spouse)
$\square$ roommate(s)
$\square$ close friend(s)
$\square$ casual friends or acquaintances
$\square$ co-worker
$\square$ other:

If any of the questions from this survey caused you discomfort, there are resources on campus available to you. Please click this link to WELL WVU to see the resources. http://well.wvu.edu/

Thank you for taking the College Student Social Capital Survey. Your answers are important and will help us to better understand how students get connected to the WVU campus community and stay connected to home. The first 500 participants are eligible for a $\$ 10$ online gift card. The gift certificate will be emailed to you at the completion of the study (within 30 days). You may be contacted again in the next 2-4 weeks to take the survey a second time. Thank you again for your participation. 


\section{References}

1. Brown TT, Scheffler RM, Seo S, Reed M. The empirical relationship between community social capital and the demand for cigarettes. Health Econ. 11 2006;15(11):1159-1172.

2. Scheffler RM, Brown TT, Syme L, Kawachi I, Tolstykh I, Iribarren C. Community-level social capital and recurrence of acute coronary syndrome. Soc Sci Med. 04 2008;66(7):1603-1613.

3. Grootaert C, van Bastelaer T. Understanding and Measuring Social Capital: A Synthesis of Findings and Recommendations from the Social Capital Initiative. Washington, DC: The World Bank; 1998 2001.

4. Beyers JM, Bates JE, Pettit GS, Dodge KA. Neighborhood structure, parenting processes, and the development of youths' externalizing behaviors: a multilevel analysis. Am J Community Psychol. 2003;31(1-2):35-53.

5. Kawachi I, Kennedy BP, Glass R. Social Capital and Self-Rated Health: A Contextual Analysis. Am J Public Health.1999;89(8):1187-1193.

6. Kawachi I, Kennedy BP, Lochner K, Prothrow-Stith D. Social capital, income inequality, and mortality. Am J Public Health. 09 1997;87(9):1491.

7. Kennedy BP, Kawachi I, Prothrow-Stith D, Lochner K, Gupta V. Social capital, income inequality, and firearm violent crime. Soc Sci Med. 07 1998;47(1):7-17.

8. Kim D, Kawachi I. U.S. state-level social capital and health-related quality of life: multilevel evidence of main, mediating, and modifying effects. Ann Epidemiol. 04 2007;17(4):258-269.

9. Lindstrom M. Social capital, economic conditions, marital status and daily smoking: A populationbased study. Pub Health. 02;124(2):71-77.

10. Lindstrom M, Janzon E. Social capital, institutional (vertical) trust and smoking: a study of daily smoking and smoking cessation among ever smokers. Scand J Public Health. 2007;35(5):460-467.

11. Lindstrom M. Social capital and the miniaturization of community among daily and intermittent smokers: a population-based study. Prev Med. 2003;36(2):177.

12. Lindstrom $M$, Moghaddassi $M$, Bolin K, Lindgren B, Merlo J. Social participation, social capital and daily tobacco smoking: a population-based multilevel analysis in Malmo, Sweden. Scand J Public Health. 2003;31(6):444-450.

14. Sampson RJ, Morenoff JD, Gannon-Rowley T. Assessing 'neighborhood effects': Social processes and new directions in research. Annu Rev Sociol. 2002;28:443-478.

15. Kim D, Subramanian SV, Gortmaker SL, Kawachi I. US state- and county-level social capital in relation to obesity and physical inactivity: a multilevel, multivariable analysis. Soc Sci Med. 08/15/ 2006;63(4):1045-1059. 
16. Crosby RA, Holtgrave DR. The protective value of social capital against teen pregnancy: a statelevel analysis. J Adolesc Health. 2006;38(5):556-559.

17. Crosby RA, Holtgrave DR, DiClemente RJ, Wingood GM, Gayle JA. Social capital as a predictor of adolescents' sexual risk behavior: a state-level exploratory study. AIDS Behav. 2003;7(3):245-252.

18. Zolotor AJ, Runyan DK. Social capital, family violence, and neglect. Pediatrics. 2006;117(6):e11241131.

19. Saluja G, Kotch J, Lee L-C. Effects of child abuse and neglect: does social capital really matter? Arch PediatrAdolesc Med. 2003;157(7):681-686.

20. Centers for Disease Control and Prevention. Annual smoking-attributable mortality, years of potential life lost, and economic costs: United States, 1995-1999. MMWR. 2002;51(14):300-303.

21. Finkelstein EA, Trogdon JG, Cohen JW, Dietz W. Annual Medical Spending Attributable To Obesity: Payer- And Service-Specific Estimates. Health Affairs. 2009;28:w822-w831.

22. Wolf AM, Colditz GA. Current estimates of the economic cost of obesity in the United States. Obes Res. 1998;6(2):97-106.

23. Bronfenbrenner U. Ecology of the family as a context for human development: Research perspectives. Dev Psychol. 1986;22(6):723-742.

24. Coleman JS. Social capital and the creation of human capital. Am J Sociol. 1988;94:S95-S120.

25. Dika SL, Singh K. Applications of social capital in educational literature: A critical synthesis. Rev Educ Res. Spring2002 2002;72(1):31.

26. Vryonides M. Social and cultural capital in educational research: issues of operationalisation and measurement. Br Educ Res J. 12 2007;33(6):867-885.

27. Freudenberg N, Ruglis J, Centers for Disease C, Prevention AGA. Reframing School Dropout as a Public Health Issue. Prev Chron Dis. Volume 4, Number 4: Centers for Disease Control and Prevention;2007.

28. Doo Hwan K, Schneider B. Social Capital in Action: Alignment of Parental Support in Adolescents' Transition to Postsecondary Education. Social Forces. 12 2005;84(2):1181-1206.

29. Perna LW, Titus MA. The relationship between parental involvement as social capital and college enrollment: An examination of racial/ethnic group differences.J Higher Educ. 09 2005;76(5):485518.

30. Sandefur GD, Meier AM, Campbell ME. Family resources, social capital, and college attendance. SocSci Res. 06 2006;35(2):525-553.

31. Smith MH, Beaulieu LJ, Seraphine A. Social capital, place of residence, and college attendance. Rural Sociol. 1995;60(3):363-388. 
32. Durkheim E. The division of labor in society: Free Press; 1897/1984.

33. Jones RA. Émile Durkheim: An Introduction to Four Major Works. Beverly Hills: Sage Pubns; 1986.

34. Durkheim E. Suicide, a Study in Sociology: Free Press. 1897.

35. Olson M. The logic of collective action; public goods and the theory of groups. Harvard University. Dept. of Economics. Harvard economic studies, v. 124: Cambridge, Mass., Harvard University Press, 1965.

36. Putnam RD. Bowling Alone: The Collapse and Revival of American Community. New York: Simon \& Schuster; 2000.

37. Bourdieu P. The Forms of Capital. In: Granovetter M, Swedberg R, eds. The sociology of economic life: Second edition. Boulder and Oxford: Westview Press; 2001:96-111.

38. Portes A. SOCIAL CAPITAL: Its origins and applications in modern sociology. Annul Rev Sociol. 08 1998;24(1):1.

39. Carpiano RM. Toward a neighborhood resource-based theory of social capital for health: can Bourdieu and sociology help? Soc Sci Med. (1982). 2006;62(1):165-175.

40. Narayan D, Cassidy MF. A Dimensional Approach to Measuring Social Capital: Development and Validation of a Social Capital Inventory. Current Sociology. 2001;49(2):59-102.

41. Pope J. Social Capital and Social Capital Indicators: A Reading List. Adelaide, South Australia: The World Bank; 20032003.

42. Boix C, Posner DN. Making Social Capital Work: A Review of Robert Putnam's Making Democracy Work: Civic Traditions in Modern Italy. Cambridge, MA: Harvard University; June 19961996.

43. Grootaert C. Social Capital, The Missing Link? Washington, DC: The World Bank; 19981998.

44. Putnam RD, Leonardi R, Nanetti RY. Making Democracy Work: Civic Traditions in Modern Italy1993:1.

45. Paldam M. Social capital: One or many? Definition and measurement.J Econ Surv. 2002;14(5):629-653.

46. Lin N. A network theory of social capital. In: Castiglione D, van Deth JW, Wolleb G, eds. The Handbook of Social Capital. New York, NY US: Oxford University Press; 2008:50-69.

47. Onyx J, Bullen P. Measuring social capital in five communities. J App/Behav Sci. 2000;36(1):23.

48. Paldam M, Svendsen GT. Is Social Capital an Effective Smoke Condenser? An Essay on a Concept Linking the Social Sciences. Washington, DC: The World Bank; May 19991999.

49. Cutler DM, Lleras-Muney A. Education and Health: Evaluating Theories and Evidence. In: Schoeni RF, House JS, Kaplan GA, Pollack H, eds. Making Americans Healthier: Social and Economic Policy 
as Health Policy: National Poverty Center Series on Poverty and Public Policy. New York: Russell Sage Foundation; 2008:29-60.

50. Glanz K, Rimer BK, Viswanath K. Health behavior and health education: Theory, research, and practice (4th ed.). San Francisco, CA US: Jossey-Bass; 2008.

51. Lochner L, Moretti E. The Effect of Education on Crime: Evidence from Prison Inmates, Arrests, and Self-Reports [Article]. American Economic Association2004.

52. German D, Latkin C. Social Stability and Health: Exploring Multidimensional Social Disadvantage. J Urban Health. 2012;89(1):19-35.

53. Price JH, McKinney MA, Braun RE. Social Determinants of Racial/Ethnic Health Disparities in Children and Adolescents. Health Edu. 2011;43(1):2-12.

54. Webb BC, Simpson SL, Hairston KG. From politics to parity: using a health disparities index to guide legislative efforts for health equity. Am J Public Health. 2011;101(3):554-560.

55. Gilbert KL. A meta-analysis of social capital and health. US, ProQuest Information \& Learning; 2010.

56. Helliwell JF, Putnam RD. The social context of well-being. Philosophical Transactions of the Royal Society of London B Biological Sciences. 09/29/ 2004;359(1449):1435-1446.

57. Macinko J, Starfield B. The Utility of Social Capital in Research on Health Determinants. Milbank Quarterly. 2001;79(3).

58. Subramanian SV, Lochner KA, Kawachi I. Neighborhood differences in social capital: a compositional artifact or a contextual construct? Health \& Place. 03 2003;9(1):33.

59. Sampson RJ. Linking the Micro- and Macrolevel Dimensions of Community Social Organization. Soc Forces. 1991;70(1):43-65.

60. Poortinga W. Social capital: an individual or collective resource for health? Soc Sci \& Med. 2006;62(2):292-302.

61. Pearce N, Smith GD. Is Social Capital the Key to Inequalities in Health? Am J Public Health. 01 2003;93(1):122-129.

62. Dudwick N, Keuehnast K, Jones VN, Woolcock M. Analyzing Social Capital in Context: A Guide to Qualitative Methods and Data. Washington, DC: The World Bank Institute; 2006.

63. Martin ND. Social Class and Elite University Education: A Bourdieusian Analysis, ProQuest LLC; 2010.

64. Stone W. Measuring Social Capital: towards a theoretically informed measurement framework for researching socialc capital in family and community life. Melbourne, Australia: Australian Institute of Family Studies; Feb 2001. 
65. Lochner K, Kawachi I, Kennedy BP. Social capital: a guide to its measurement. Health \& Place. 12 1999;5(4):259-270.

66. Sampson RJ, Morenoff JD, Earls F. Beyond social capital: Spatial dynamics of collective efficacy for children. Am Sociol Rev. 1999;64(5):633-660.

67. Bank TW. Social Capital Initiative Working Paper Series 2010. Accessed February 2012.

68. Stone W, Hughes J. Social Capital: Empirical meaning and measurement validity. Melbourne, Australia: Australian Institute of Family Studies; June 2002.

69. Dufur MJ, Parcel TL, Troutman KP. Social Capital in Multiple Spheres: Measuring Social Capital at Home and at School. Annual meeting of the American Sociological Association. Philadelphia, PA2005.

70. Stone WJ. What role for social capital in family policy? Family Matters. Winter2000 2000(56):20.

71. Putnam RD. Bowling alone: America's declining social capital. Current. 06 1995(373):3.

72. Leventhal T, Brooks-Gunn J. The neighborhoods they live in: The effects of neighborhood residence on child and adolescent outcomes. Psychol Bull. 2000;126(2):309-337.

73. Coleman JS. Social Capital and the Development of Youth. Momentum. 1987;18(4ov):6.

74. Runyan DK, Hunter WM, Socolar RRS, et al. Children who prosper in unfavorable environments: The relationship to social capital. Pediatrics. 1998;101(1):12.

75. Dorsey S, Forehand R. The relation of social capital to child psychosocial adjustment difficulties: The role of positive parenting and neighborhood dangerousness. J Psychopathol Behav Assess. 2003;25(1):11-23.

76. Arnett JJ. Emerging adulthood(s): The cultural psychology of a new life stage. In: Jensen LA, ed. Bridging cultural and developmental approaches to psychology: New syntheses in theory, research, and policy. New York, NY US: Oxford University Press; 2011:255-275.

77. Park MJ, Mulye TP, Adams SH, Brindis CD, Irwin CE, Jr. The health status of emerging adults in the United States. J Adol Health. 2006;39(3):305-317.

78. Baxter Magolda MB. The activity of meaning making: A holistic perspective on college student development. J Coll Stud Dev. 11 2009;50(6):621-639.

79. Hiester M, Nordstrom A, Swenson LM. Stability and change in parental attachment and adjustment outcomes during the first semester transition to college life. J Coll Stud Dev. 09 2009;50(5):521-538.

80. Kuh GD. What student affairs professionals need to know about student engagement. J Coll Stud Dev. 11 2009;50(6):683-706. 
81. Swenson LM, Nordstrom A, Hiester M. The role of peer relationships in adjustment to college. $J$ Coll Stud Dev. 11 2008;49(6):551-567.

82. Yazedjian A, Toews ML, Navarro A. Exploring parental factors, adjustment, and academic achievement among white and hispanic college students. J Coll Stud Dev. 07 2009;50(4):458-467.

83. Ellison NB, Steinfield C, Lampe C. The benefits of Facebook "friends:" Social capital and college students' use of online social network sites. J Comput Mediat Commun. 07 2007;12(4):1143-1168.

84. Kerr J. Surfing Together: A Preliminary Inquiry into the Effects of Internet Use on Social Capital in American Communities. Conference Papers -- Midwestern Political Science Association. 2009 Annual Meeting 2009:1.

85. Stevens Aubrey J, Chattopadhyay S, Rill L. Are Facebook Friends Like Face-to-Face Friends: Investigating Relations Between the Use of Social Networking Websites and Social Capital. Conference Papers -- International Communication Association. 2008 Annual Meeting 2008:1-33.

86. Tufekci Z. Gender, Social Capital And Social Network(ing) Sites: Women Bonding, Men Searching. Annual meeting of the American Sociological Association Boston, MA2008.

87. Mullis RL, Rathge R, Mullis AK. Predictors of academic performance during early adolescence: A contextual view. Int J Behav Dev. 11 2003;27(6):541-548.

88. Weitzman ER, Chen Y-Y. Risk modifying effect of social capital on measures of heavy alcohol consumption, alcohol abuse, harms, and secondhand effects: national survey findings. $J$ Epidemiol Community Health. 04 2005;59(4):303-309.

89. Weitzman ER, Kawachi I. Giving means receiving: The protective effect of social capital on binge drinking on college campuses. Am J Public Health. 12 2000;90(12):1936-1939.

90. Martin ND. Social capital, academic achievement, and [prtgraduation plans at an elite, private university. Sociol Perspect. Summer 2009;52(2):185-210.

91. Arnett JJ. Emerging adulthood: A theory of development from the late teens through the twenties. Am Psychol. 2000;55(5):469-480.

92. Carpiano RM, and Link, Bruce G. Neighborhood Social Capital as a Health Determinant: An Empirical Test of a Bourdieu-based Framework and Model. Annual Meeting of the American Sociological Association. Lowes Hotel, Philadelphia, PA:

http://www.allacademic.com/meta/p19646_index.html; 2005.

93. U.S. Department of Health and Human Services. The Health Consequences of Smoking: A Report of the Surgeon General. Atlanta, GA: U.S. Department of Health and Human Services, Centers for Disease Control and Prevention, Coordinating Center for Health Promotion, National Center for Chronic Disease Prevention and Health Promotion, Office on Smoking and Health; 2004.

94. U.S. Department of Health and Human Services WDC. Healthy People 2010: Conference Edition, Volume I [and] Volume I/2000. 
95. American Cancer Society. American Cancer Society: Facts About Kids And Tobacco. URL: http://www.cancer.org/docroot/PED/content/PED_10_2X_Child_and_Teen_Tobacco_Use.asp. 2007

96. Zickler P. NIDA NOTES: Early Nicotine Initiation Increases Severity of Addiction, Vulnerability to Some Effects of Cocaine Research Findings. http://www.drugabuse.gov/NIDA_notes/NNvol19N2/Early.html. July 2004 Vol. 19(No. 2 ).

97. Baker TB, Brandon TH, Chassin L. Motivational influences on cigarette smoking. Annu Rev Psychol. 2004;55:463-491.

98. Youth Risk Behavior Surveillance: National College Health Risk Behavior Survey--United States, 1995. MMWR. CDC Surveillance Summaries: Morbidity And Mortality Weekly Report. CDC Surveillance Summaries / Centers For Disease Control. 1997;46(6):1-56.

99. Wechsler H, Rigotti NA, Gledhill-Hoyt J, Lee H. Increased levels of cigarette use among college students: a cause for national concern. JAMA. 1998;280(19):1673-1678.

100. Lantz PM. Smoking on the rise among emerging adults: implications for research and policy. Tob Control. 06/02/ 2003;12:i60-70.

101. American College Health Association. American College Health Association- National College Health Assessment: Reference Group Executive Summary Fall 2007. Baltimore: American College Health Assocation; 2008.

102. Johnston LD, O'Malley, P. M., Bachman, J. G., \& Schulenberg, J. E. . Monitoring the Future national survey results on drug use, 1975-2007. Volume II: College students and adults ages 19-45 Bethesda, MD: : (NIH Publication No. 08-6418B); 2008.

103. Patterson F, Lerman C, Kaufmann VG, Neuner GA, Audrain-McGovern J. Cigarette smoking practices among american college students: review and future directions. J Am Coll Health. 2004;52(5):203-210.

104. Costa FM, Jessor R, Turbin MS. College student involvement in cigarette smoking: the role of psychosocial and behavioral protection and risk. NicotineTob Res. 2007;9(2):213-224.

105. Prokhorov AV, Warneke C, de Moor C, et al. Self-reported health status, health vulnerability, and smoking behavior in college students: Implications for intervention. Nicotine \& Tobacco Research. 2003;5(4):545-552.

106. Stockdale MS, Dawson-Owens HL, Sagrestano LM. Social, attitudinal, and demographic correlates of adolescent vs college-age tobacco use initiation. Am J Health Behav. 07 2005;29(4):311-323.

107. Thompson B, Thompson LA, Hymer J, Zbikowsi S, Halperin A, Jaffe R. A qualitative study of attitudes, beliefs, and practices among 40 undergraduate smokers. J Am Coll Health. 2007;56(1):23-28.

108. Lefkowitz ES. "Things have gotten better": Developmental changes among emerging adults after the transition to university. J Adolesc Res. 01 2005;20(1):40-63. 
109. Demo DH. The self-concept over time: research issues and directions. Annu Rev Sociol. 1992;18(1):303-326.

110. Tanner JL, Arnett JJ, Leis JA. Emerging adulthood: Learning and development during the first stage of adulthood. In: Smith MC, DeFrates-Densch N, eds. Handbook of research on adult learning and development. New York, NY US: Routledge/Taylor \& Francis Group; 2009:34-67.

111. Murphy-Hoefer R, Alder S, Higbee $C$. Perceptions about cigarette smoking and risks among college students. Nicotine Tob Res. 2004;6 Suppl 3:S371-374.

112. Emmons KM, Wechsler $\mathrm{H}$, Dowdall G, Abraham M. Predictors of smoking among US college students. Am J Public Health. 1998;88(1):104-107.

113. Moran S, Wechsler H, Rigotti NA. Social smoking among US college students. Pediatrics. 2004;114(4):1028-1034.

114. Evans GW, Kutcher R. Loosening the link between childhood poverty and adolescent smoking and obesity: the protective effects of social capital. Psychol Sci. 01/01/;22(1):3-7.

115. Schorling JB, Gutgesell $M$, Klas $P$, Smith D, Keller A. Tobacco, alcohol and other drug use among college students. J Subst Abuse. 1994;6(1):105-115.

116. Choi WS, Harris KJ, Okuyemi K, Ahluwalia JS. Predictors of smoking initiation among collegebound high school students. Ann Behav Med. 2003;26(1):69-74.

117. Wetter DW, Kenford SL, Welsch SK, et al. Prevalence and predictors of transitions in smoking behavior among college students. Health Psychol. 2004;23(2):168-177.

118. Honjo K, Tsutsumi A, Kawachi I, Kawakami N. What accounts for the relationship between social class and smoking cessation? Results of a path analysis. Soc Sci Med. 2006;62(2):317-328.

119. van den Putte B, Yzer MC, Brunsting S. Social influences on smoking cessation: a comparison of the effect of six social influence variables. Prev Med. 2005;41(1):186-193.

120. Christakis NA, Fowler JH. The collective dynamics of smoking in a large social network. N Engl J Med. 2008;358(21):2249-2258.

121. Wilcox P. An ecological approach to understanding youth smoking trajectories: problems and prospects. Addiction. 05/02/May2003 Supplement 1 2003;98:57-77.

122. Cook TD. The case for studying multiple contexts simultaneously. Addiction. 05/02/May2003 Supplement 1 2003;98:151-155.

123. Substance Abuse Mental Health Services Administration. Results from the 2006 National Survey on Drug Use and Health: National Findings. 2007; http://www.oas.samhsa.gov/nsduh/2k6nsduh/2k6results.pdf.

124. Kenford SL, Wetter DW, Welsch SK, Smith SS, Fiore MC, Baker TB. Progression of college-age cigarette samplers: What influences outcome. Addict Behav. 02 2005;30(2):285-294. 
125. Ling PM, Neilands TB, Glantz SA. Young adult smoking behavior. Am J Prev Med. 05 2009;36(5):389-394.e382.

126. Nichter M. Smoking: what does culture have to do with it? Addiction. 05/02/May2003 Supplement 1 2003;98:139-145.

127. American College Health Association. American College Health Association - National College Health Assessment (ACHA-NCHA) Web Summary. Updated August 2007. Available at http://www.acha-ncha.org/data_highlights.html. 2007. 2007. Accessed March 2008.

128. American Collge Health Association. About ACHA-NCHA: Generalizability, reliability, and validity analysis. . 2009. http://www.acha-ncha.org/grvanalysis.html.

129. Giordano GN, Lindstrom M. The impact of social capital on changes in smoking behaviour: a longitudinal cohort study. Eur J Public Health. 06;21(3):347-354.

130. Scientific Software International, Inc. HLM 6.06 [computer program]. Version 6.06. Lincolnwood, IL2004.

131. Bryk AS, Raudenbush SW. Hierarchical linear models: Applications and data analysis methods. 2nd edition ed. Thousand Oaks, CA, US: Sage Publications, Inc; 2002.

132. Prokhorov AV, Fouladi RT, de Moor C, et al. Computer-assisted, counselor-delivered smoking cessation counseling for community college students: Intervention approach and sample characteristics. J Child Adolesc Subst Abuse. 2007;16(3):35-62.

133. Bryk AS, Raudenbush SW. Hierarchical Linear Models: Applications and Data Analysis Methods. Thousand Oaks, CA US: Sage Publications, Inc; 1992.

134. Dube SR, McClave A, Caraballo R, Kaufmann R, Pechacek T. Vital signs: current cigarette smoking among adults aged $=18$ years --- United States, 2009. MMWR. 2010;59(35):1135-1140.

135. Centers for Disease Control and Prevention, Office on Smoking and Health. Tobacco Control State Highlights, 2010. In: Promotion National Center for Chronic Disease Prevention and Health Promotion, ed: United States Department of Health and Human Services; 2010.

136. Kim D, Baum CF, Ganz ML, Subramanian SV, Kawachi I. The contextual effects of social capital on health: A cross-national instrumental variable analysis. Soc Sci Med. 2011;73(12):1689-1697.

137. Krueger J, Cody S, Peckham M. Bridging and Bonding in Cyberspace? The Impact of Online Communities on Social Capital and Political Participation. Conference Papers -- American Political Science Association. 2006 Annual Meeting 2006:1-33.

138. Bourdieu P, Granovetter M, Swedberg R. The Forms of Capital. The sociology of economic life: Second edition.Boulder and Oxford:Westview Press; 2001:96-111.

139. QSR International Pty Ltd. NVivo Qualitative Data Analysis Software [computer program]2008. 
140. Hsieh H, Shannon SE. Three approaches to qualitative content analysis. Qualitative Health Research. 11 2005;15(9):1277-1288.

141. Cohen J. Statistical Power Analysis for the Behavioral Sciences 2nd edition ed. New York: Academic Press; 1998.

142. Hawe P, Shiell A. Social capital and health promotion: a review. Soc Sci Med. 09 2000;51(6):871885.

143. Sampson RJ. How Do Communities Undergrid or Undermine Human Development? What are the Relevant Contexts and What are the Relevant Mechanisms? In: Crouter Ba, ed. Does it Take a Village? Community Effects on Children, Adolescents, and Families. Mahwah, NJ: Lawrence Erlbaum Associates; 2001:1-30.

144. Israel BA. Social networks and health status: linking theory, research, and practice. Patient Couns Health Educ. 07 1982;4(2):65-79.

145. Heaney CA, Israel BA, Glanz K, Rimer BK, Viswanath K. Social networks and social support. Health behavior and health education: Theory, research, and practice (4th ed.). San Francisco, CA US: Jossey-Bass; 2008:189-210.

146. House JS.Work stress and social support.Addison-Wesley series on occupational stress ; 4: Reading, Mass. : Addison-Wesley Pub. Co., c1981.; 1981.

147. Kikuchi M, Coleman C-L. Explicating and measuring social relationships in social capital research: A working paper. Annual meeting of the Association for Education in Journalism and Mass Communication. Chicago, IL2008:28.

148. Stout M. Measuring social capital: Results of a confirmatory factor analysis using the Social Capital Community Benchmark Survey. American Sociological Association Annual Meeting. Boston, MA2008:21.

149. Durkheim E. The division of labor in society: being a tr of his De la division du travail social, with an estimate of his work: Macmillan; 1934.

150. Mattanah JF, Brooks LJ, Ayers JF, Quimby JL, Brand BL, McNary SW. A social support intervention to ease the college transition: Exploring main effects and moderators. $J$ Coll Stud Dev. 01;51(1):93-108.

151. Martin N, Spenner K. Capital conversion and accumulation: a social portrait of legacies at an elite university. Res High Educ. 2009;50(7):623-648.

152. America SSCEi, Government JFKSo. The Social Capital Community Benchmark Survey. 2002; http://www.hks.harvard.edu/saguaro/communitysurvey/index.html. Accessed June 2009.

153. Saguaro Seminar, John F. Kennedy School of Government at Harvard University. Social Capital Community Benchmark Survey short form. 2002; http://www.hks.harvard.edu/saguaro/pdfs/socialcapitalshortform.pdf. Accessed March 2010. 
154. Lawshe CH. A quantitative approach to content validity. Pers Psychol. Winter75 1975;28(4):563575.

155. Luhtanen R, Crocker J, Luhtanen R, Crocker J. Collective Self-Esteem Scale. A Collective SelfEsteem Scale: Self-evaluation of one's social identity. 1992;18(3):302-318.

156. Qualtrics Survey Software [computer program]. Provo, UT: Qualtrics Labs, Inc. ; 2009.

157. Comfrey A, Lee H. A First Course in Factor Analysis. Hillsdale, NJ: Lawrence Erlbaum Associates; 1992.

158. Tabachnick BG, Fidell LS. Using multivariate statistics (5th ed.). Boston, MA: Allyn \& Bacon/Pearson Education; 2007.

159. SPSS Statistics 19 [computer program]. Chicago, IL: IBM SPSS, Inc. ; 2012.

160. Nunnally JC. Psychometric theory. New York, NY US: McGraw-Hill; 1967.

161. Kline RB. Principles and Practice of Structural Equation Modeling, Second Edition. New York: The Guilford Press, Inc; 2005.

162. The Princeton Review I. West Virginia University: Rankings and Lists. 2012; www.princetonreview.com/schools/college/CollegeBasics.aspx?search=site\&keyword=WestVirgi nia University.

163. Laguilles JS, Williams EA, Saunders DB. Can Lottery Incentives Boost Web Survey Response Rates? Findings from Four Experiments. Research in Higher Education. 2011;52(5):537-553.

164. Pealer LN, Weiler RM, Pigg RM, Jr., Miller D, Dorman SM. The feasibility of a web-based surveillance system to collect health risk behavior data from college students. Health Educ Behav. 10 2001;29(5):547-559.

165. Porter SR, Whitcomb ME. Non-response in student surveys: The Role of Demographics, Engagement and Personality. Res High Educ. 03 2005;46(2):127-152.

166. Mitra A, Jain-Shukla P, Robbins A, Champion H, Durant R. Differences in Rate of Response to Web-Based Surveys among College Students. International Journal on E-Learning. 2008;7(2):265281.

167. Bennett L, Nair CS. A Recipe for Effective Participation Rates for Web-Based Surveys. Assess Eval High Educ. 2010;35(4):357-365.

168. Productivity Commission 2003. Social Capital: Reviewing the Concept and its Policy Implications. Research Paper, AusInfo, Canberra, Australia2003.

169. Smith ML. Social capital and intentional change: Exploring the role of social networks on individual change efforts. J Manage Dev. 08 2006;25(7):718-731. 
170. Torres V, Jones SR, Renn KA. Identity development theories in Student Affairs: origins, current status, and new approaches. J Coll Student Dev. 11 2009;50(6):577-596.

171. Alesci NL, Forster JL, Blaine T. Smoking visibility, perceived acceptability, and frequency in various locations among youth and adults. Prev Med. 03 2003;36(3):272.

172. Chambliss $C$, Shull $M$, Baker $K$, et al. The social hazards of smoking in academic contexts: students' and teachers' attitudes about student smokers. J Alc Drug Educ. 2006;50(3):41-47.

173. Chaloupka FJ, Wechsler H. Price, tobacco control policies and smoking among emerging adults. J Health Econ. 06 1997;16(3):359-373.

174. Rigotti NA, Regan S, Moran SE, Wechsler H. Students' opinion of tobacco control policies recommended for US colleges: a national survey. Tob Control. 09 2003;12(3):251.

175. Czart C, Liccardo Pacula R, Chaloupka FJ, Wechsler H. THE IMPACT OF PRICES AND CONTROL POLICIES ON CIGARETTE SMOKING AMONG COLLEGE STUDENTS. Cont Econ Pol. 04 2001;19(2):135-149.

176. Levinson AH, Campo S, Gascoigne J, Jolly O, Zakharyan A, Tran ZV. Smoking, but not smokers: identity among college students who smoke cigarettes. Nicotine Tob Res. 2007;9(8):845-852. 